
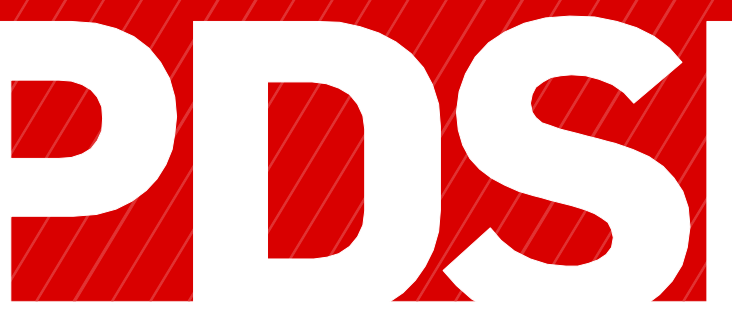

PROGRAMA DOUTORAL EM SAUDE PÚBLICA

UNIVERSIDADE DO PORTO FACULDADE DE MEDICINA

Bárbara Neves Peleteiro

The role of Helicobacter pylori infection in the web of gastric cancer causation 

Bárbara Neves Peleteiro

\section{The role of Helicobacter pylori infection in the web of gastric cancer causation}

Porto | 2011

Dissertação de candidatura ao grau de Doutor apresentada à Faculdade de Medicina da Universidade do Porto 


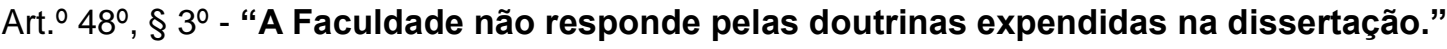

(Regulamento da Faculdade de Medicina da Universidade do Porto - Decreto-Lei no 19337 de 29 de Janeiro de 1931) 


\section{Corpo Catedrático da Faculdade de Medicina do Porto}

\section{Professores Catedráticos Efectivos}

Doutor Manuel Alberto Coimbra Sobrinho Simões

Doutor Jorge Manuel Mergulhão Castro Tavares

Doutora Maria Amélia Duarte Ferreira

Doutor José Agostinho Marques Lopes

Doutor Patrício Manuel Vieira Araújo Soares Silva

Doutor Daniel Filipe Lima Moura

Doutor Alberto Manuel Barros da Silva

Doutor José Manuel Lopes Teixeira Amarante

Doutor José Henrique Dias Pinto de Barros

Doutora Maria Fátima Machado Henriques Carneiro

Doutora Isabel Maria Amorim Pereira Ramos

Doutora Deolinda Maria Valente Alves Lima Teixeira

Doutora Maria Dulce Cordeiro Madeira

Doutor Altamiro Manuel Rodrigues Costa Pereira

Doutor Rui Manuel Almeida Mota Cardoso

Doutor António Carlos Freitas Ribeiro Saraiva

Doutor Álvaro Jerónimo Leal Machado de Aguiar

Doutor José Carlos Neves da Cunha Areias

Doutor Manuel Jesus Falcão Pestana Vasconcelos

Doutor João Francisco Montenegro Andrade Lima Bernardes

Doutora Maria Leonor Martins Soares David

Doutor Rui Manuel Lopes Nunes

Doutor José Eduardo Torres Eckenroth Guimarães

Doutor Francisco Fernando Rocha Gonçalves

Doutor José Manuel Pereira Dias de Castro Lopes

Doutor Manuel António Caldeira Pais Clemente 


\section{Professores Jubilados ou Aposentados}

Doutor Abel José Sampaio da Costa Tavares

Doutor Abel Vitorino Trigo Cabral

Doutor Alexandre Alberto Guerra Sousa Pinto

Doutor Amândio Gomes Sampaio Tavares

Doutor António Augusto Lopes Vaz

Doutor António Carvalho Almeida Coimbra

Doutor António Fernandes da Fonseca

Doutor António Fernandes Oliveira Barbosa Ribeiro Braga

Doutor António Germano Pina Silva Leal

Doutor António José Pacheco Palha

Doutor António Luís Tomé da Rocha Ribeiro

Doutor António Manuel Sampaio de Araújo Teixeira

Doutor Belmiro dos Santos Patrício

Doutor Cândido Alves Hipólito Reis

Doutor Carlos Rodrigo Magalhães Ramalhão

Doutor Cassiano Pena de Abreu e Lima

Doutor Daniel Santos Pinto Serrão

Doutor Eduardo Jorge Cunha Rodrigues Pereira

Doutor Fernando de Carvalho Cerqueira Magro Ferreira

Doutor Fernando Tavarela Veloso

Doutor Francisco de Sousa Lé

Doutor Henrique José Ferreira Gonçalves Lecour de Menezes

Doutor José Augusto Fleming Torrinha

Doutor José Carvalho de Oliveira

Doutor José Fernando Barros Castro Correia

Doutor José Luís Medina Vieira

Doutor José Manuel Costa Mesquita Guimarães

Doutor Levi Eugénio Ribeiro Guerra

Doutor Luís Alberto Martins Gomes de Almeida

Doutor Manuel Augusto Cardoso de Oliveira

Doutor Manuel Machado Rodrigues Gomes

Doutor Manuel Maria Paula Barbosa

Doutora Maria da Conceição Fernandes Marques Magalhães

Doutora Maria Isabel Amorim de Azevedo

Doutor Mário José Cerqueira Gomes Braga

Doutor Serafim Correia Pinto Guimarães

Doutor Valdemar Miguel Botelho dos Santos Cardoso

Doutor Walter Friedrich Alfred Osswald 
Ao abrigo do Art. ${ }^{\circ} 8^{\circ}$ do Decreto-Lei n.ำ 388/70, fazem parte desta dissertação as seguintes publicações:

I. Peleteiro B, Lunet N, Barros R, La Vecchia C, Barros H. Factors contributing to the underestimation of Helicobacter pylori-associated gastric cancer risk in a highprevalence population. Cancer Causes Control. 2010;21(8):1257-64.

II. Peleteiro B, Cavaleiro-Pinto $M$, Barros $R$, Barros $H$, Lunet $N$. Is cardia cancer aetiologically different from distal stomach cancer? Eur J Cancer Prev. 2011;20(2):96101.

III. Peleteiro B, Lopes C, Figueiredo C, Lunet N. Salt intake and gastric cancer risk according to Helicobacter pylori infection, smoking, tumour site and histological type. $\mathrm{Br}$ J Cancer. 2011;104(1):198-207.

IV. Peleteiro B, Carrilho C, Modcoicar P, Cunha L, Ismail M, Guisseve A, Lorenzoni C, Fernandes F, Almeida R, Figueiredo C, David L, Lunet N. Chronic atrophic gastritis, intestinal metaplasia, Helicobacter pylori virulence, IL1RN polymorphisms and smoking in dyspeptic patients from Mozambique and Portugal. Helicobacter. 2009;14(4):306-8.

V. Peleteiro B, Lunet N, Carrilho C, Durães C, Machado JC, La Vecchia C, Barros H. Association between cytokine gene polymorphisms and gastric precancerous lesions: systematic review and meta-analysis. Cancer Epidemiol Biomarkers Prev. 2010;19(3):762-76.

VI. Peleteiro B, Barros R, Carrilho C, Artiaga J, Cunha L, Modcoicar P, Ferreira R, Figueiredo C, Almeida R, La Vecchia C, David L, Barros H, Lunet N. Determinants of gastric CDX2 expression: a study in Mozambique. [submetido]

Em todos os artigos colaborei activamente na definição e operacionalização das hipóteses, tendo sido responsável pela análise e interpretação dos dados que reportam. Participei na recolha dos dados dos artigos I a III, assim como no armazenamento da informação em todos. Fui responsável pela redacção da versão inicial dos manuscritos e colaborei activamente na preparação das versões finais de todos os artigos. 
Esta investigação foi realizada no Serviço de Higiene e Epidemiologia da Faculdade de Medicina da Universidade do Porto e no Instituto de Saúde Pública da Universidade do Porto, sob orientação do Professor Doutor Nuno Lunet (Faculdade de Medicina e Instituto de Saúde Pública da Universidade do Porto) e co-orientação do Professor Doutor Carlo La Vecchia (Istituto di Ricerche Farmacologiche "Mario Negri" e Istituto di Statistica Medica e Biometria, Università di Milano).

Esta investigação foi financiada pela Fundação Calouste Gulbenkian e pela Fundação para a Ciência e a Tecnologia, através de projectos institucionais [FC-54918; FC-68697; POCTI/SAUESP/56126/2004; POCTI/SAU-ESP/61685/2004; PTDC/SAU-ESA/71517/2006] e da atribuição de uma bolsa de doutoramento individual [SFRH/BD/36818/2007], co-financiada pelo Programa Operacional Potencial Humano (POPH).

FCT Fundação para a Ciência e a Tecnologia
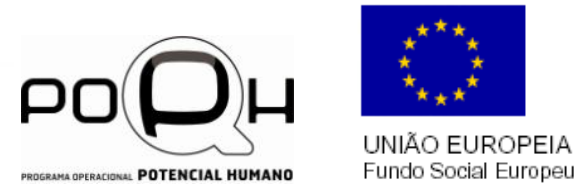


\section{Júri da Prova de Doutoramento}

Doutor José Agostinho Marques Lopes (Presidente)

Faculdade de Medicina, Universidade do Porto

Doutor José Henrique Dias Pinto de Barros

Faculdade de Medicina, Universidade do Porto

Doutora Maria Leonor Martins Soares David

Faculdade de Medicina, Universidade do Porto

Doutor António José Murinello Sousa Guerreiro

Faculdade de Ciências Médicas, Universidade Nova de Lisboa

Doutor José Joaquim Costa Cabrita da Silva

Faculdade de Farmácia, Universidade de Lisboa

Doutor Carlo La Vecchia

Istituto di Ricerche Farmacologiche "Mario Negri", Milão, Itália

Doutora Catherine Hill

Institut de Cancérologie Gustave-Roussy, Paris, França 
All scientific work is incomplete - whether it be observational or experimental. All scientific work is liable to be upset or modified by advancing knowledge. That does not confer upon us a freedom to ignore the knowledge we already have, or to postpone the action that it appears to demand at a given time.

Sir Austin Bradford Hill, 1965 


\section{Os meus agradecimentos...}

Ao Professor Nuno Lunet, pela determinação e persistência com que me orientou. Agradeço todo o apoio que me foi dado e a confiança depositada em mim.

To Professor Carlo La Vecchia, for his commitment in supervising this scientific work, and for allowing me to integrate his research team.

Ao Professor Henrique Barros, por ter criado as condições necessárias ao desenvolvimento desta investigação. Agradeço a oportunidade que me deu de fazer parte desta equipa.

A todos os co-autores dos artigos incluídos nesta tese, pelo seu contributo.

A todos os colegas do Serviço de Higiene e Epidemiologia, por terem tornado possível o meu percurso, em especial à Andreia, à Elisabete e à Sofia.

À Raquel, à Joana, à Marta e à Elisabete, que sempre me incentivaram mesmo nos momentos de desespero.

Aos meus Pais, por sempre terem acreditado em mim.

Ao Bruno, por me ensinar um novo caminho de felicidade.

Por último, ao Helder, porque sem ele nada disto teria sido possível. 

Abstract 3

Resumo

$\begin{array}{ll}\text { Background } & 19\end{array}$

Introduction $\quad 21$

Helicobacter pylori 22

Historical overview of $H$. pylori discovery 22

The outcomes of $H$. pylori infection $\quad 24$

A model of causation applied to the association between $H$. pylori infection $\begin{array}{ll}\text { and gastric cancer } & 27\end{array}$

$\begin{array}{ll}\text { Scope of the model } & 27\end{array}$

$\begin{array}{ll}\text { Induction period } & 28\end{array}$

Empirical evidence supporting the role of $H$. pylori infection in the causal mechanisms leading to gastric cancer 30

The other component causes $\quad 32$

$\begin{array}{ll}\text { Aims } & 37\end{array}$

$\begin{array}{ll}\text { Research Methods } & 43\end{array}$

Papers $\quad 49$

I. Factors contributing to the underestimation of Helicobacter pyloriassociated gastric cancer risk in a high-prevalence population $\quad 51$

II. Is cardia cancer aetiologically different from distal stomach cancer? 61

III. Salt intake and gastric cancer risk according to Helicobacter pylori infection, smoking, tumour site and histological type

IV. Chronic atrophic gastritis, intestinal metaplasia, Helicobacter pylori virulence, IL1RN polymorphisms and smoking in dyspeptic patients from Mozambique and Portugal

V. Association between cytokine gene polymorphisms and gastric precancerous lesions: systematic review and meta-analysis 87

VI. Determinants of gastric CDX2 expression: a study in Mozambique 105

General discussion

References 

Abstract 

This thesis aims to clarify the role of Helicobacter pylori infection in the web of gastric cancer causation as a potential necessary causal component and to identify factors that modulate the progression towards cancer among the $H$. pylori-infected subjects. To accomplish these objectives, six studies were performed using data obtained in two diverse settings, Portugal and Mozambique, and following different designs.

I. Peleteiro B, Lunet N, Barros R, La Vecchia C, Barros H. Factors contributing to the underestimation of Helicobacter pylori-associated gastric cancer risk in a high-prevalence population. Cancer Causes Control. 2010;21(8):1257-64.

A case-control study was conducted in Portugal aiming to explain the underestimation of the association between $H$. pylori infection and noncardia gastric cancer, in a high-risk European population.

It included 420 noncardia gastric cancer patients recruited in two major hospitals in north of Portugal and 1389 population controls. Whole-cell immunoglobulin G (IgG) antibodies against $H$. pylori were quantified by enzyme-linked immunosorbent assay (ELISA) and western blot testing was conducted in a subsample (272 cases and 186 controls) allowing for the detection of cytotoxin associated-gene $A(\mathrm{Cag} A)$.

When assessing infection status by ELISA, the odds ratio (OR) for the association with gastric cancer decreased as IgG titers increased. The same pattern was observed across strata of age and blood collection timing with stronger associations among younger subjects and in those providing blood samples earlier after diagnosis. The presence of CagA detected by western blot was associated with an increased risk of gastric cancer (sex- and age-adjusted $\mathrm{OR}=11.32,95 \%$ confidence interval [95\%Cl]: 5.64-22.73).

II. Peleteiro B, Cavaleiro-Pinto M, Barros R, Barros H, Lunet N. Is cardia cancer aetiologically different from distal stomach cancer? Eur J Cancer Prev. 2011;20(2):96-101.

This study aimed to provide evidence on the frequency of aetiologically distinct types of cardia cancer, either resembling distal stomach cancer or oesophageal adenocarcinoma. 
We evaluated 41 cardia and 339 noncardia cancer cases undergoing gastrectomy, and 380 community controls matched by age ( \pm 5 years) and sex (1:1). Gastric cardia and noncardia cancers were compared with regard to the frequency of $H$. pylori infection (assessed by ELISA and western blot), the histological characteristics of the nonneoplastic gastric mucosa and the tumour histological type, obtained from pathology reports.

No positive relation was found with $H$. pylori infection, but CagA-positive strains were associated with an increased risk of noncardia cancer (age- and sex-adjusted $\mathrm{OR}=1.60,95 \% \mathrm{Cl}: 1.17-2.18)$. Among $H$. pylori-infected cases, a $1: 1$ ratio of intestinal to diffuse/mixed histological subtypes was observed for both cardia and noncardia cancers. However, unlike noncardia cancers, all cardia cancer cases occurring in noninfected patients belonged to the intestinal histological subtype.

III. Peleteiro B, Lopes C, Figueiredo C, Lunet N. Salt intake and gastric cancer risk according to Helicobacter pylori infection, smoking, tumour site and histological type. Br J Cancer. 2011;104(1):198-207.

We conducted a case-control analysis aiming to quantify gastric cancer risk in relation to dietary salt exposure according to $H$. pylori infection status and virulence, smoking, tumour site and histological type.

It included 422 gastric cancer cases and 649 community controls. Salt exposure in the previous year, or the year before onset of symptoms for cases, was estimated through: sodium intake using a food frequency questionnaire; main food items/groups contributing to dietary sodium intake; visual analogical scale for salt intake preference; use of table salt; duration of refrigerator ownership. The association between salt consumption and gastric cancer was quantified through ORs adjusted for gender, age, education, smoking, $H$. pylori infection and total energy intake.

Comparing subjects with the highest with those with the lowest salt exposure, sodium intake $(\mathrm{OR}=2.01,95 \% \mathrm{Cl}: 1.16-3.46)$, consumption of food items with high contribution to sodium intake $(\mathrm{OR}=2.54,95 \% \mathrm{Cl}: 1.56-4.14)$ and salt intake evaluated using the visual analogical scale $(\mathrm{OR}=1.83,95 \% \mathrm{Cl}: 1.28-2.63)$ were associated with an increased risk of gastric cancer; subjects owning a refrigerator for more than 50 years had a lower risk $(\mathrm{OR}=0.28,95 \% \mathrm{Cl}$ : 0.14-0.57). These associations were observed regardless of $H$. pylori infection status and virulence, smoking, tumour site or histological type. 
IV. Peleteiro B, Carrilho C, Modcoicar P, Cunha L, Ismail M, Guisseve A, Lorenzoni C, Fernandes F, Almeida R, Figueiredo C, David L, Lunet N. Chronic atrophic gastritis, intestinal metaplasia, Helicobacter pylori virulence, IL1RN polymorphisms and smoking in dyspeptic patients from Mozambique and Portugal. Helicobacter. 2009;14(4):306-8.

Portuguese and Mozambican dyspeptic patients were compared to identify differences in the prevalence of gastric precancerous lesions, and genetic susceptibility, $H$. pylori virulence and lifestyles between these two populations.

Participants reporting dyspeptic symptoms underwent upper digestive endoscopy and gastric biopsy samples were collected following the same standardized protocol. The same experienced pathologists evaluated the Mozambican and Portuguese biopsy specimens.

The prevalence of chronic atrophic gastritis and intestinal metaplasia was lower in Mozambican subjects when compared to the Portuguese (8.3 vs. 36.3\%, $p<0.001$ and 8.3 vs. $37.1 \%, \mathrm{p}<0.001$, respectively), across age and education strata. $\mathrm{A}$ divergent distribution of $I L 1 R N$ variable number tandem repeat (VNTR) polymorphisms (proportion of carriers of the allele 2: 7.8 vs. $41.2 \%, p<0.001$ ) and smoking in men (proportion of ever smokers: 29.4 vs. 67.5\%, p<0.001) was observed.

V. Peleteiro B, Lunet N, Carrilho C, Durães C, Machado JC, La Vecchia C, Barros $\mathrm{H}$. Association between cytokine gene polymorphisms and gastric precancerous lesions: systematic review and meta-analysis. Cancer Epidemiol Biomarkers Prev. 2010;19(3):762-76.

This study aimed to quantify the association between IL1B-511, IL1RN VNTR and TNFA-308 gene polymorphisms, and intestinal metaplasia, using original data in two diverse populations from Portugal and Mozambique, and systematically reviewing the literature on the association between these polymorphisms and gastric precancerous lesions, placing our results into context.

Published studies were identified through PubMed search, and OR estimates were combined using random-effects meta-analysis, also taking into account individual data obtained from 215 Portuguese volunteer shipyard workers and 96 Mozambican dyspeptic patients who underwent endoscopic and pathologic evaluation following the same protocol. 
The OR estimates for intestinal metaplasia were $2.83(95 \% \mathrm{Cl}: 1.15-6.96)$ for the IL1RN²2 genotype, 1.86 (95\%Cl: $1.03-3.36)$ for IL1B-511 T carriers, and 0.59 (95\%Cl: 0.12-3.04) for the TNFA-308^AA genotype in the Portuguese sample. All Mozambican subjects with intestinal metaplasia were $T$ carriers for $I L 1 B-511$ and none had the 2 allele for IL1RN. In meta-analysis, IL1RN*22 genotype was associated with an increased risk of gastric precancerous lesions (22 vs. LL: summary $\mathrm{OR}=2.27,95 \% \mathrm{Cl}$ : 1.40-3.70, $I^{2}=26.4 \%, 12$ studies). No such association was found for the IL1B-511 (TT vs. CC: summary $\mathrm{OR}=1.34,95 \% \mathrm{Cl}: 0.87-2.07, l^{2}=65.7 \%, 13$ studies) or TNFA-308 genotypes (AA vs. GG: summary $\mathrm{OR}=0.93,95 \% \mathrm{Cl}: 0.35-2.43, P^{2}=0.0 \%, 7$ studies).

VI. Peleteiro B, Barros R, Carrilho C, Artiaga J, Cunha L, Modcoicar P, Ferreira R, Figueiredo C, Almeida R, La Vecchia C, David L, Barros H, Lunet N. Determinants of gastric CDX2 expression: a study in Mozambique. [submitted]

This study aimed to quantify the association between $H$. pylori infection and other environmental risk factors and the expression of caudal-type homeobox 2 protein (CDX2), according to the presence of gastric precancerous lesions.

It is a cross-sectional analysis of dyspeptic subjects undergoing upper digestive endoscopy conducted in Mozambique. All subjects with chronic atrophic gastritis or intestinal metaplasia were gender- and age-matched (1:2) with those classified as having normal stomach or chronic non-atrophic gastritis. $H$. pylori infection was assessed by histology and polymerase chain reaction (PCR), and CDX2 expression by immunohistochemistry. ORs for the association between gastric cancer risk factors and CDX2 expression were computed, adjusting for age, gender, education and $H$. pylori infection.

CDX2 expression was more frequent among the $H$. pylori-infected $(\mathrm{OR}=2.26$, 95\% Cl: 1.00-5.15). Infection with high-virulence strains was associated with CDX2 expression in subjects with chronic atrophic gastritis $\left(\mathrm{cagA}^{+}\right.$: OR=3.20, 95\% $\mathrm{Cl}: 1.35$ 7.52) and intestinal metaplasia (vacuolating cytotoxin $\mathrm{A}[\mathrm{vacA}] m_{1}$ : $\mathrm{OR}=5.86,95 \% \mathrm{Cl}$ : 1.08-31.62). A lower frequency of vegetables consumption was associated with a higher risk of marked CDX2 expression (OR=3.64, 95\%Cl: 1.02-12.95). 
The main conclusions of the present investigation are the following:

- $\quad$ The use of methods with low sensitivity to detect past infection, including study design, selection of the participants and assessment of infection status, leads to a substantial underestimation of gastric cancer risk in high-prevalence settings. Stronger associations were observed when these methodological limitations are overcome, which is more compatible with the hypothesis of $H$. pylori being a necessary cause for gastric cancer.

- In this Portuguese setting, the cardia cancer cases were similar to noncardia cancers with regard to the relation with infection, histological type and condition of the nonneoplastic mucosa, supporting the predominance of this cardia cancer subtype in high-risk settings. This suggests that only specific types of gastric cancer, more frequent in lowrisk settings, are not related to infection, reinforcing the evidence supporting the role of $H$. pylori as a necessary cause for gastric cancer.

- $\quad$ Salt intake was confirmed as an important dietary risk factor for gastric cancer, with no differences in risk according to the characteristics of the $H$. pylori infection, smoking and tumour location and histological type.

- $\quad$ The divergent distribution of IL1RN polymorphisms and smoking between dyspeptic subjects from Portugal and Mozambique may contribute to explain the observed differences in the frequency of gastric precancerous lesions between these settings with similar prevalence of H. pylori infection.

- $\quad$ The virulence of the infecting strains and vegetables consumption were associated with CDX2 expression and may play a role in the progression to more advanced lesions as co-factors interacting with $H$. pylori infection to produce gastric cancer. 

Resumo 

Com esta tese pretende-se clarificar o papel da infecção por Helicobacter pylori enquanto possível causa necessária para a ocorrência de cancro gástrico e identificar factores responsáveis pelo desenvolvimento deste cancro em indivíduos infectados. Para tal, foram desenvolvidos seis estudos com os objectivos descritos abaixo, usando dados obtidos em Portugal e Moçambique.

I. Peleteiro B, Lunet N, Barros R, La Vecchia C, Barros H. Factors contributing to the underestimation of Helicobacter pylori-associated gastric cancer risk in a high-prevalence population. Cancer Causes Control. 2010;21(8):1257-64.

Foi realizado um estudo caso-controlo em Portugal com o objectivo de explicar a subestimação da associação entre a infecção por $H$. pylori e o cancro gástrico não cardia, numa população Europeia com elevado risco de cancro do estômago.

Neste estudo foram incluídos 420 casos de cancro gástrico não cardia recrutados nos dois maiores hospitais da região norte de Portugal e 1389 controlos comunitários. Utilizou-se o método de ELISA (enzyme-linked immunosorbent assay) para quantificar a concentração de imunoglobulina $\mathrm{G}(\mathrm{lg} G)$ anti-H. pylori. A detecção de anticorpos anti-CagA (cytotoxin associated-gene A) foi efectuada por western blot numa sub-amostra de 272 casos e 186 controlos.

Relativamente ao estado de infecção avaliado por ELISA, observou-se uma diminuição do odds ratio (OR) para a associação com o cancro do estômago com o aumento dos níveis séricos de lgG. Este mesmo padrão verificou-se quando os participantes foram estratificados por classe etária e por tempo entre o diagnóstico do cancro e a colheita de sangue, sendo observadas associações mais fortes nos indivíduos mais jovens e nos casos em que o tempo entre o diagnóstico do cancro e a colheita de sangue foi menor. A presença de CagA, detectada por western blot, associou-se a um aumento do risco de cancro gástrico (OR ajustado para sexo e idade=11,32; intervalo de confiança a 95\% [IC95\%]: 5,64-22,73). 
II. Peleteiro B, Cavaleiro-Pinto M, Barros R, Barros H, Lunet N. Is cardia cancer aetiologically different from distal stomach cancer? Eur J Cancer Prev. 2011;20(2):96-101.

Com este estudo pretendeu-se determinar a frequência de cada um dos tipos de cancro do cardia, com etiologia potencialmente diferente, um semelhante ao cancro do estômago distal e o outro ao adenocarcinoma do esófago.

Foram avaliados 41 casos de cancro do cardia e 339 de cancro não cardia que tinham sido submetidos a gastrectomia e 380 controlos comunitários, emparelhados por idade ( \pm 5 anos) e sexo (1:1). O estado de infecção por $H$. pylori foi avaliado por ELISA e western blot. Os dados acerca das características histológicas da mucosa gástrica não-neoplásica assim como o tipo histológico do tumor foram obtidos através dos relatórios de anatomia patológica.

Não foi encontrada associação com a infecção, mas as estirpes CagA positivas associaram-se a um aumento do risco de cancro não cardia (OR ajustado para idade e sexo=1,60; IC95\%: 1,17-2,18). Entre os casos infectados, observou-se uma razão de 1:1 entre os tipos histológicos intestinal e difuso/misto em ambos os tipos de cancro. Em indivíduos não infectados, todos os casos de tumores localizados na região do cardia eram do tipo histológico intestinal, ao contrário do observado para casos de cancro não cardia.

III. Peleteiro B, Lopes C, Figueiredo C, Lunet N. Salt intake and gastric cancer risk according to Helicobacter pylori infection, smoking, tumour site and histological type. Br J Cancer. 2011;104(1):198-207.

Foi realizado um estudo caso-controlo de modo a quantificar o risco de cancro do estômago associado à ingestão de sal, de acordo com a infecção por $H$. pylori e a virulência das estirpes, o consumo de tabaco e a localização e tipo histológico do tumor.

Foram avaliados 422 casos de cancro do estômago e 649 controlos comunitários. A ingestão de sal durante o ano anterior ou, nos casos, no ano anterior ao aparecimento dos sintomas, foi estimada considerando as seguintes medidas de exposição ao consumo de sal: quantidade de sódio consumida avaliada por questionário de frequência alimentar; consumo de grupos alimentares que mais contribuem para a ingestão de sódio; aplicação de uma escala visual analógica indicativa da preferência do consumo de sal; frequência do uso de sal na mesa; tempo 
desde a existência de frigorífico em casa dos participantes. A associação entre o consumo de sal e o cancro do estômago foi quantificada através do cálculo de ORs ajustados para sexo, idade, escolaridade, consumo de tabaco, infecção por $H$. pylori e valor energético total.

Observou-se um aumento do risco de cancro do estômago associado ao elevado consumo de sal (3.v vs. 1.ำ terço), estimado através da ingestão de sódio (OR=2,01; IC95\%: 1,16-3,46), do consumo de grupos alimentares que mais contribuem para a ingestão de sódio (OR=2,54; IC95\%: 1,56-4,14) e da ingestão de sal avaliada pela escala visual analógica $(\mathrm{OR}=1,83$; IC95\%: 1,28-2,63). Os indivíduos que possuíam frigorífico em casa há mais de 50 anos tinham um risco diminuído de cancro gástrico (OR=0,28; IC95\%: 0,14-0,57). Estas associações foram observadas independentemente da presença de infecção por H. pylori e da virulência das estirpes, do consumo de tabaco e da localização ou tipo histológico do tumor.

IV. Peleteiro B, Carrilho C, Modcoicar P, Cunha L, Ismail M, Guisseve A, Lorenzoni C, Fernandes F, Almeida R, Figueiredo C, David L, Lunet N. Chronic atrophic gastritis, intestinal metaplasia, Helicobacter pylori virulence, ILIRN polymorphisms and smoking in dyspeptic patients from Mozambique and Portugal. Helicobacter. 2009;14(4):306-8.

Foram comparados indivíduos dispépticos Portugueses e Moçambicanos de modo a identificar diferenças na prevalência de lesões gástricas precursoras de cancro e na susceptibilidade genética, virulência da infecção por $H$. pylori e estilos de vida entre estas duas populações.

Todos os participantes seleccionados para esta análise reportavam sintomas dispépticos e foram sujeitos a endoscopia digestiva alta, segundo o mesmo protocolo. As biópsias recolhidas foram avaliadas pela mesma equipa de patologistas.

As prevalências de gastrite crónica atrófica e de metaplasia intestinal em Moçambique foram inferiores às observadas em Portugal ( 8,3 vs. $36,3 \% ; p<0,001$ e 8,3 vs. $37,1 \% ; \mathrm{p}<0,001$, respectivamente), nos mesmos estratos etários e de escolaridade. Observou-se que a proporção de portadores do alelo 2 no gene IL1RN VNTR (variable number tandem repeat) era inferior em Moçambique relativamente a Portugal ( 7,8 vs. $41,2 \% ; p<0,001)$, assim como a proporção de homens que alguma vez fumaram (29,4 vs. $67,5 \% ; p<0,001)$. 
V. Peleteiro B, Lunet N, Carrilho C, Durães C, Machado JC, La Vecchia C, Barros $\mathrm{H}$. Association between cytokine gene polymorphisms and gastric precancerous lesions: systematic review and meta-analysis. Cancer Epidemiol Biomarkers Prev. 2010;19(3):762-76.

Este estudo tinha como objectivo quantificar a associação entre polimorfismos dos genes que regulam a produção das citocinas pró-inflamatórias, tais como o factor de necrose tumoral- $\alpha$ (TNFA-308) e a interleucina-1 $\beta$ (IL1B-511), ou modulam a sua acção (IL1RN VNTR) e a metaplasia intestinal. Foram utilizados dados originais de Portugal e Moçambique e procedeu-se à revisão sistemática da literatura acerca da associação entre estes polimorfismos e as lesões pré-cancerosas.

Os estudos publicados foram identificados por pesquisa efectuada na PubMed. As estimativas da força da associação obtidas de cada estudo foram combinadas por meta-análise usando um modelo de efeitos aleatórios, tendo em conta os dados obtidos nas amostras de indivíduos Portugueses ( $n=215)$ e Moçambicanos $(n=96)$ submetidos a endoscopia digestiva alta, avaliados segundo o mesmo protocolo.

$\mathrm{Na}$ amostra Portuguesa, as estimativas de OR observadas para a metaplasia intestinal foram 2,83 (IC95\%: 1,15-6,96) para o genótipo IL1RN²2, 1,86 (IC95\%Cl: 1,03-3,36) para os portadores do alelo T do polimorfismo IL1B-511 e 0,59 (IC95\%: $0,12-3,04)$ para o genótipo TNFA-308*AA. Todos os participantes Moçambicanos diagnosticados com metaplasia intestinal eram portadores do alelo $\mathrm{T}$ do polimorfismo IL1B-511 e nenhum possuía o alelo 2 do polimorfismo IL1RN VNTR. Na meta-análise, verificou-se que o genótipo $I L 1 R N^{*} 22$ estava associado com um aumento do risco de lesões pré-cancerosas (22 vs. LL: estimativa sumária de OR=2,27; IC95\%: 1,40-3,70; $I^{2}=26,4 \% ; 12$ estudos). Não foi observada associação estatisticamente significativa para os polimorfismos $I L 1 B-511$ (TT vs. CC: estimativa sumária de OR=1,34; IC95\%: 0,87-2,07; $I^{2}=65,7 \% ; 13$ estudos) e TNFA-308 (AA vs. GG: estimativa sumária de OR $=0,93 ;$ IC95\%: 0,35-2,43; $I^{2}=0,0 \% ; 7$ estudos).

VI. Peleteiro B, Barros R, Carrilho C, Artiaga J, Cunha L, Modcoicar P, Ferreira R, Figueiredo C, Almeida R, La Vecchia C, David L, Barros H, Lunet N. Determinants of gastric CDX2 expression: a study in Mozambique. [submitted]

Com este estudo pretendeu-se quantificar a associação entre a infecção por $H$. pylori e outros factores ambientais e a expressão de CDX2 (caudal-type homeobox protein 2), de acordo com a presença de lesões pré-cancerosas. 
Neste estudo realizado em Moçambique, foi efectuada uma análise transversal de indivíduos dispépticos submetidos a endoscopia digestiva alta. Todos os participantes que apresentavam gastrite crónica atrófica ou metaplasia intestinal foram emparelhados por sexo e idade com indivíduos sem lesões na mucosa gástrica ou com gastrite crónica não atrófica (1:2). O estado de infecção por $H$. pylori foi avaliado por histologia e por PCR (polymerase chain reaction) e a expressão de CDX2 por imunohistoquímica. Foram calculados os ORs para a associação entre os factores de risco para cancro gástrico e a expressão de CDX2, ajustados para idade, sexo, escolaridade e infecção por H. pylori.

Verificou-se que a expressão de CDX2 era mais frequente entre os indivíduos infectados com $H$. pylori (OR=2,26; IC95\%: 1,00-5,15). A infecção por estirpes mais virulentas estava associada com a expressão de CDX2 em indivíduos com gastrite crónica atrófica (cagA $A^{+}$OR=3,20; IC95\%: 1,35-7,52) e com metaplasia intestinal (vacA [vacuolating cytotoxin $A$ ] $m_{1}$ : OR=5,86; IC95\%: 1,08-31,62). O baixo consumo de vegetais associou-se a um maior risco de expressão acentuada de CDX2 (OR=3,64; IC95\%: 1,02-12,95).

As principais conclusões desta investigação são as seguintes:

- $\quad$ O uso de métodos com baixa sensibilidade para detectar o estado de infecção, onde se incluem o desenho do estudo, a selecção dos participantes e o método de avaliação da infecção, levam à subestimação do risco de cancro do estômago em populações com uma elevada prevalência de $H$. pylori. Quando estas limitações são superadas, são observadas associações mais fortes, mais compatíveis com a hipótese da infecção por $H$. pylori ser uma causa necessária à ocorrência do cancro gástrico.

- Em Portugal, os cancros do cardia apresentavam características semelhantes aos casos de cancro do estômago não cardia relativamente à associação com a infecção, ao tipo histológico e às características da mucosa não-neoplásica, apoiando a hipótese de um predomínio deste subtipo de cancro do cardia nas populações com elevado risco de cancro gástrico. Estes resultados sugerem que apenas subtipos específicos de cancro do estômago não estão relacionados com a infecção por $H$. pylori, nomeadamente os tumores do cardia que 
se assemelham ao cancro do esófago, reforçando a hipótese desta infecção constituir uma causa necessária para o cancro do estômago.

- $\quad$ Confirma-se a importância do elevado consumo de sal como factor de risco para o cancro do estômago. Não se observaram diferenças na magnitude da associação de acordo com as características da infecção por $H$. pylori, consumo de tabaco e localização e tipo histológico dos tumores.

- As diferenças observadas na distribuição de polimorfismos no gene IL1RN e na proporção de fumadores entre indivíduos dispépticos de Portugal e Moçambique podem contribuir para explicar a divergência na frequência de lesões precursoras de cancro gástrico nestes contextos com uma prevalência de infecção por $H$. pylori semelhante.

- A elevada virulência das estirpes infectantes e o baixo consumo de vegetais associaram-se à expressão de CDX2 e estes factores poderão desempenhar um papel importante na progressão para lesões mais avançadas, interagindo com a infecção por $H$. pylori no desenvolvimento do cancro gástrico. 
BACKGROUND 



\section{INTRODUCTION}

A continued decline in gastric cancer incidence and mortality has been observed internationally for several decades $(1,2)$, but trends are unequal across distinct histological and topographical types. While the decrease was mainly attributed to the variation in the frequency of the tumours of the intestinal histological type, the incidence of those classified as diffuse seems to have remained stable or even increased over time (3-5). Similarly, the decline has been more pronounced for tumours located in the lower thirds of the stomach, while the frequency of tumours in the cardia region has been increasing, depicting a pattern of change that resembles more closely that observed for oesophageal adenocarcinoma (5-7). Thus, it remains the sixth most common cancer and the third leading cause of cancer-related deaths; the worldwide estimates for incidence and mortality rates in 2008 were 14.6/100,000 and 10.9/100,000, respectively, with a wide variation across geographical areas (8).

The decrease in gastric cancer rates was primarily attributed to a set of factors related to the improvement of the populations' living conditions, namely the increase in fruits and vegetables consumption and the decrease in salt intake (9). The discovery of Helicobacter pylori (10), and its classification as a human carcinogen within ten years (11), brought a new paradigm to interpret gastric carcinogenesis and temporal/geographical variation in gastric cancer frequency. $H$. pylori infection affects more than half of the world adult population and is responsible for approximately twothirds of all gastric cancer cases occurring worldwide (12). It is, therefore, a potentially important target of the gastric cancer control measures, through primary prevention and eradication of infection. 


\section{HISTORICAL OVERVIEW OF $\boldsymbol{H}$. PYLORI DISCOVERY}

$H$. pylori is a spiral, flagellated, Gram-negative bacterium (13). The first wellknown report of this organism was attributed to Bizzozero, an Italian anatomist, that, in 1893, observed these "spirochetes" inhabiting the gastric mucosa of dogs (14). His work was extended by Salomon (15), who transmitted the bacteria to mice from gastric scrapings from dogs. These pioneer experiments provided the basis for the mouse models currently used to investigate Helicobacter eradication therapeutics and vaccines (16). Nevertheless, it was Jaworski the first to suggest a possible role of this organism in the pathogenesis of gastric diseases, in 1899, when investigating sediments of gastric washings obtained from humans. His work was published in the Handbook of Gastric Diseases but it was written in Polish and had little impact (17).

During the following century, both anatomists and pathologists continued to observe these spiral organisms in the human gastric mucosa and, in 1940, Freedberg and Baron reported the presence of these bacteria in about $40 \%$ of resected human gastric specimens (18). These findings were challenged by Palmer (19), in 1954, who found no evidence of spirochetes in more than 1,000 gastric biopsies. He claimed that these spiral bacteria could not survive in the acidic gastric environment and would colonize the human stomach only post-mortem. Nonetheless, in 1967, Ito published an electron micrograph of one of these organisms from a sample of his own stomach obtained by blind suction biopsy (20). In the following years, Lockard and Boler published electron micrographs of these organisms in the stomach of cats and dogs (21). At this time, it was assumed that this organism was a commensal with no pathogenic function.

In 1975, Steer and Colin-Jones conducted a clinical trial on new therapies for peptic ulcer disease and reported its healing after treatment with carbenoxolone sodium. However, there was no effect on the degree of severity of gastric inflammation (22) and numerous spiral bacteria were observed in $80 \%$ of their gastric ulcer specimens.

Warren and Marshall established the pathogenicity of $H$. pylori, by connecting the evidence generated over the previous 100 years to their own clinical observations and experiments (23). In 1981, the two researchers started a pilot study analysing the clinical data of patients with upper gastrointestinal symptoms undergoing endoscopy. Instead of biopsy specimens from the ulcer borders, they collected tissue from the stomach wall, which would be representative of the antral mucosa in general. The 
histological scoring showed chronic gastritis in the mucosa that could not be attributed to the ulcer and the presence of the bacteria was detected through Gram-stain. Based on these preliminary results, Warren and Marshall initiated a prospective study of 100 consecutive patients, in 1982; more than $65 \%$ of the participants were infected and almost all of them had gastritis; patients without infection and with normal histology were taking nonsteroidal anti-inflammatory drugs (NSAIDs). During this study they were able to culture the bacteria (10), and the modern discovery of the initially named Campylobacter pylori bacteria was attributed to them.

The steps from the earlier observations of "spirochetes" in the gastric mucosa of dogs by Bizzozero to the rediscovery of "unidentified curved bacilli" by Warren and Marshal and its recognition as a pathogen are depicted in figure 1.

In 1989, after DNA sequencing, it was shown that the bacterium did not belong to the Campylobacter genus and it was placed on its own genus - Helicobacter (24). The International Agency for Research on Cancer (IARC) classified H. pylori as a class I definite carcinogen in 1994. In 2005, two decades after their discovery, Warren and Marshall were awarded the Nobel Prize in Medicine (23).

Figure 1. Timeline of $H$. pylori discovery.

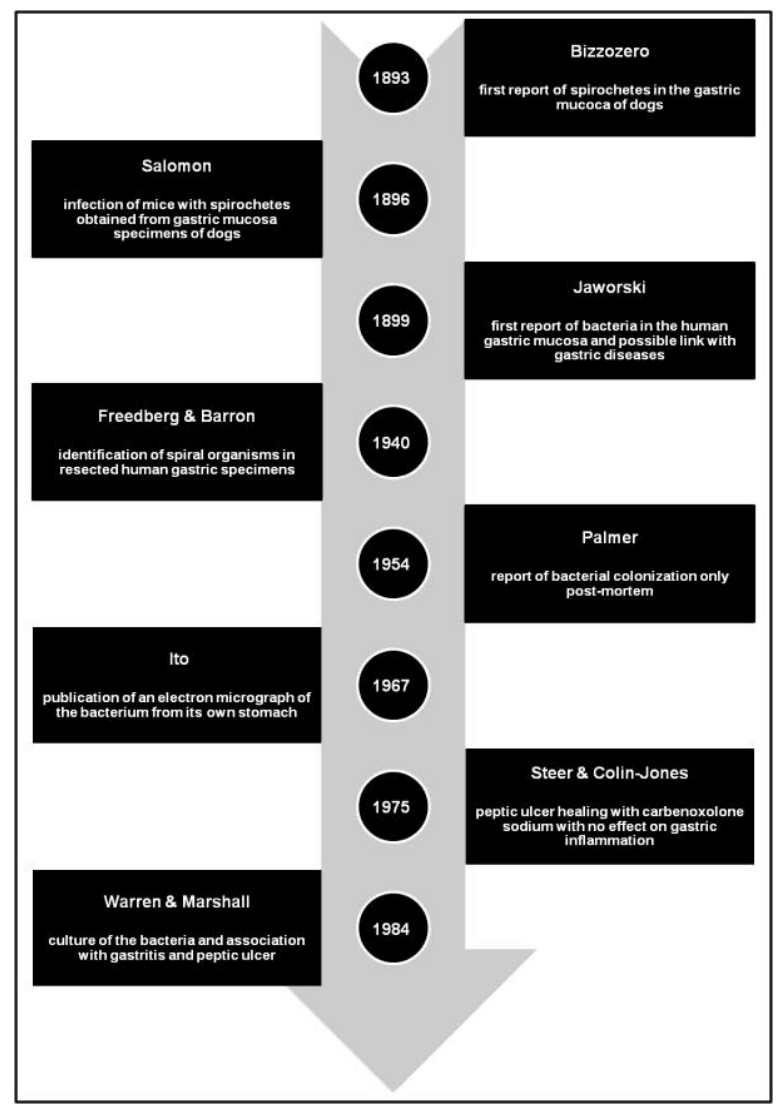

THE OUTCOMES OF H. PYLORI INFECTION 
H. pylori infection may result in different outcomes, that are associated with distinct patterns of acid secretion by parietal cells, depending on the extent and severity of gastric inflammation induced in the host (25). In most cases, however, infection will remain asymptomatic (figure 2).

The bacterium has developed a set of defence mechanisms that allow it to survive in the gastric acidic medium. On the other hand, when $H$. pylori colonises the gastric mucosa, the acute immunological response induced in the host is generally not sufficient to clear infection, leading to a state of chronic infection.

Figure 2. Natural history of $H$. pylori infection.

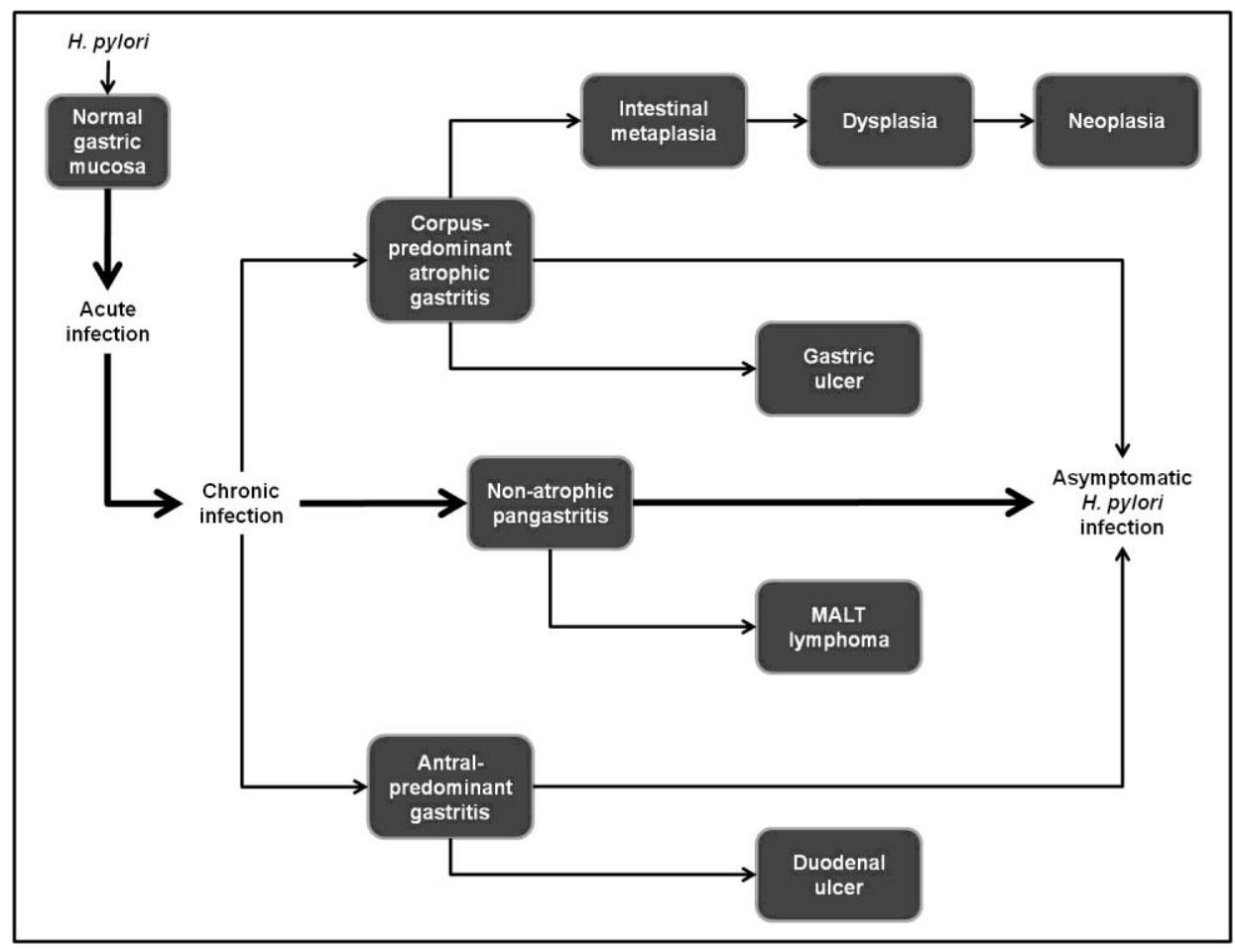

Adapted from (25). The predominant pathway is represented in bold.

Although most subjects presenting a non-atrophic pangastritis will remain asymptomatic, a few may develop mucosa-associated lymphoid-tissue (MALT) lymphoma $(26,27)$. The predominantly antral gastritis in duodenal ulcer disease leads to acid hypersecretion by suppressing somatostatin cells and increasing gastrin release from the $G$ cells in the gastric antrum. Acid hypersecretion in duodenal ulcer disease is almost always due to $H$. pylori infection because secretion returns to normal after the infection is eradicated $(28,29)$. Corpus gastritis, on the other hand, leads to low acid secretion, which predisposes to gastric ulcer $(30,31)$, and in turn increases corpus gastritis, further decreasing acid secretion. H. pylori gastritis affecting the gastric 
corpus leads to the suppression of parietal cells, potentially causing gastric cancer. The latter is the outcome with the poorest prognosis, and only moderate improvements have been achieved in the last decades, with an increase from 22 to $24 \%$ in the 5-year relative survival rates for European cancer patients diagnosed between 1988 and 1999 (32).

Over $95 \%$ of gastric malignancies are adenocarcinomas, among which a spectrum of different conditions may be defined according to the site of tumour origin and the histological features of the lesion.

In epidemiological studies, gastric adenocarcinomas are usually classified according to topography into cardia and noncardia or proximal (comprising cardia, fundus and the proximal third of the corpus) and distal (including antrum and the lower two thirds of the corpus). The cardia is the most proximal part of the stomach, adjacent to the oesophagus, involving the gastroesophageal junction. Tumours described as cardia include a mixture of neoplasms arising from the lower oesophagus and the gastric cardia, to a higher or lesser extent depending on the frequency of oesophageal and gastric adenocarcinomas in the populations under study $(33,34)$. The lack of a consensus definition of the cardia region accounts for some of the heterogeneity in studies reporting cancer trends by subsite $(35,36)$ or studying the determinants of gastric cancers with specific topographies (37).

From a histological standpoint, Laurén's classification system has been widely applied in epidemiological research (38), subdividing tumours into two main histological types - diffuse and intestinal. Still, the histological classification of an individual gastric adenocarcinoma is sometimes complex because a tumour often comprises a mixture of intestinal and diffuse tissue types in different extents. Diverse criteria may be used to fit these tumours within the main types; alternatively, they may be classified in a separate group (38-40). Nevertheless, most gastric cancers belong to the intestinal type, representing 52 to $82 \%$ of all tumours, and it was observed that this histological type is more common in males, blacks and older subjects. The diffuse type has a similar incidence in both genders and is more frequent in younger individuals (41). Also, there is a wide geographical variation in the frequency of intestinal type tumours, whereas the occurrence of diffuse adenocarcinomas is more uniform across regions (42). In addition, the decrease in cancer incidence among migrants from high- to low-risk areas has been observed predominantly for tumours of the intestinal type (41). These findings were taken as evidence of a relatively greater impact of environmental factors in the aetiology of intestinal type carcinomas, while the diffuse type was considered more dependent on the individuals' genetic profile (43). Pelayo Correa (44) proposed a model for the development of the intestinal type tumours, according to which a cascade 
of precancerous lesions from chronic atrophic gastritis to intestinal metaplasia and dysplasia may lead to cancer, as depicted in figure 2 .

Ecological studies were the first to quantify the association between infection and cancer (45-49). The EUROGAST Study Group evaluated 17 populations from 13 countries, chosen to reflect the global range of gastric cancer incidence, and they found an ecological relative risk of approximately six (comparing the predicted gastric cancer incidences for populations with a prevalence of $H$. pylori infection of $100 \%$ with predictions for populations that had no infection) (48).

In 1994, a combined analysis of the three pioneer prospective studies on this issue showed a nine-fold higher risk among infected subjects, after a follow-up of at least fifteen years (50); the IARC classified $H$. pylori as a class I definite carcinogen in the same year (11). According to this report, there was sufficient evidence from research conducted over human subjects, largely based on epidemiological studies. The association between infection with $H$. pylori and gastric cancer was stronger in younger patients and for cancers at sites other than the cardia, and similar for the intestinal and diffuse histological types.

This was the first time that a bacterium was recognized as a carcinogen and several authors considered premature to draw such bold conclusions. No experimental studies had been conducted $(51,52)$ and the results from epidemiological research were heterogeneous (52), especially those from case-control studies and across regions with different gastric cancer risk.

At the present time, the existence of an association between $H$. pylori and gastric cancer is no longer questioned, and research has been focused on a more indepth understanding of the role of infection in the causal mechanisms leading to cancer, and the implications of this knowledge for prevention and control. 


\section{A MODEL OF CAUSATION APPLIED TO THE ASSOCIATION BETWEEN $\boldsymbol{H}$. PYLORI INFECTION} AND GASTRIC CANCER

\section{SCOPE OF THE MODEL}

Cancer is currently interpreted as a multifactorial complex disease. According to the causality model proposed by Rothman (53), individual risk factors alone cannot be ascribed as causes, and only a set of risk factors, or component causes, may be sufficient for the outcome to occur. Removing any of these components will prevent the outcome. However, for a single disease multiple causal mechanisms leading to its occurrence may coexist, corresponding to different sufficient causes composed by different sets of component causes. Again, to prevent disease, it is not necessary to identify all these components; removing one, the component that appears in every sufficient cause, therefore defined as a necessary component cause, may be enough. The human papillomavirus (HPV) was the first factor to be recognized as necessary for the occurrence of a specific cancer (54), and the causal relation between $H$. pylori and gastric cancer may find some analogy with the observed for HPV and cervical cancer.

Figure 3 illustrates the concepts of necessary and sufficient cause applied to the causal relation between $H$. pylori infection and gastric cancer. A and B represent two different sets of causal mechanisms leading to gastric cancer, each one composed by three sufficient causes (I, II, III and IV, V, VI, respectively). In each of them, different environmental exposures (including $\mathrm{E}$ and $H$. pylori infection) and characteristics of the genetic background of the individuals $(\mathrm{G})$ interact to produce disease.

Figure 3. Possible causal mechanisms for gastric cancer, according to the causality model proposed by Rothman (53).

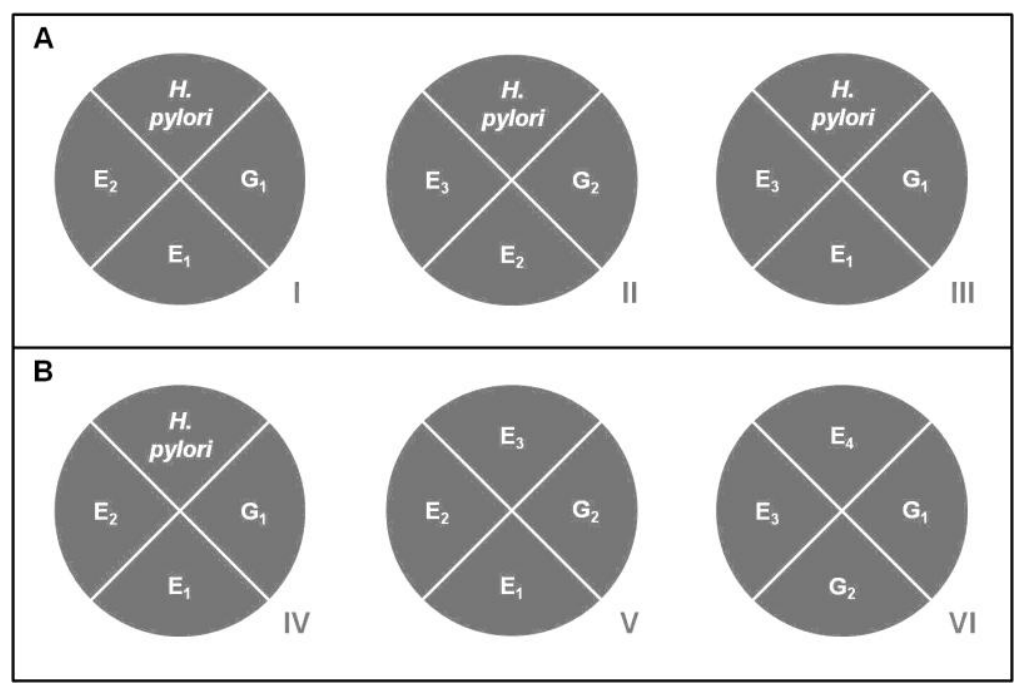


In model A, H. pylori is found in all sufficient causes (I, II and III), being defined as a necessary cause for gastric cancer, which, under this model, would be completely preventable by removing infection. On the contrary, in model $B$, none of the factors is recognized as a necessary causal component for gastric cancer, although each of the causal mechanisms will suffice for the production of gastric cancer. Under this model, removing infection would only lead to the blocking of sufficient cause IV.

To complete this reasoning a temporal dimension needs to be included in the model, as different factors may exert their effects in different phases of the mechanism or some of them may act to produce others that ultimately lead to disease.

\section{INDUCTION PERIOD}

The contribution of a given factor to disease occurrence as well as its interaction with other factors may vary over time due to changes in the prevalence of that causal component and how each of them groups with the remaining to form the various causal mechanisms. The period of time from causal action until disease initiation is defined as the induction period, which depends on the time that each causal component takes to group with others within the same sufficient cause. The early action of some factors may shorten the induction time of others.

In carcinogenesis, the terms initiator and promoter are used to identify component causes that act early and late in the causal mechanism, respectively. This is compatible with the intermediate steps (corresponding to intermediate outcomes) in a causal mechanism and we may postulate the action of the potential causal factors in specific stages of carcinogenesis. Under such hypothesis, the presence of a sufficient cause for an early outcome is also necessary for other sufficient causes to exert their actions in later outcomes.

The production of empirical evidence to support such a causal model requires the identification of different steps in carcinogenesis, corresponding to intermediate outcomes that precede cancer. A model for the progression of the gastric cancers of the intestinal type has been proposed by Correa et al., according to which precancerous lesions occur in sequential steps (44): atrophy, intestinal metaplasia, and dysplasia (figure 4). Atrophy is a result of chronic active inflammation that may ultimately lead to the destruction of gastric glands and the loss of normal mucosa architecture. Intestinal metaplasia consists of the replacement of the gastric mucosa by an epithelium that histologically resembles the intestinal mucosa. Dysplasia is regarded as an early step towards transformation into neoplasia. This model allowed the identification of intermediate stages in the causal mechanism leading to cancer and 
has provided a framework for understanding the role of different risk factors in different steps of the gastric carcinogenesis (55).

Figure 4. Gastric carcinogenesis model for the carcinomas of Laurén's intestinal type, according to Pelayo Correa (55).

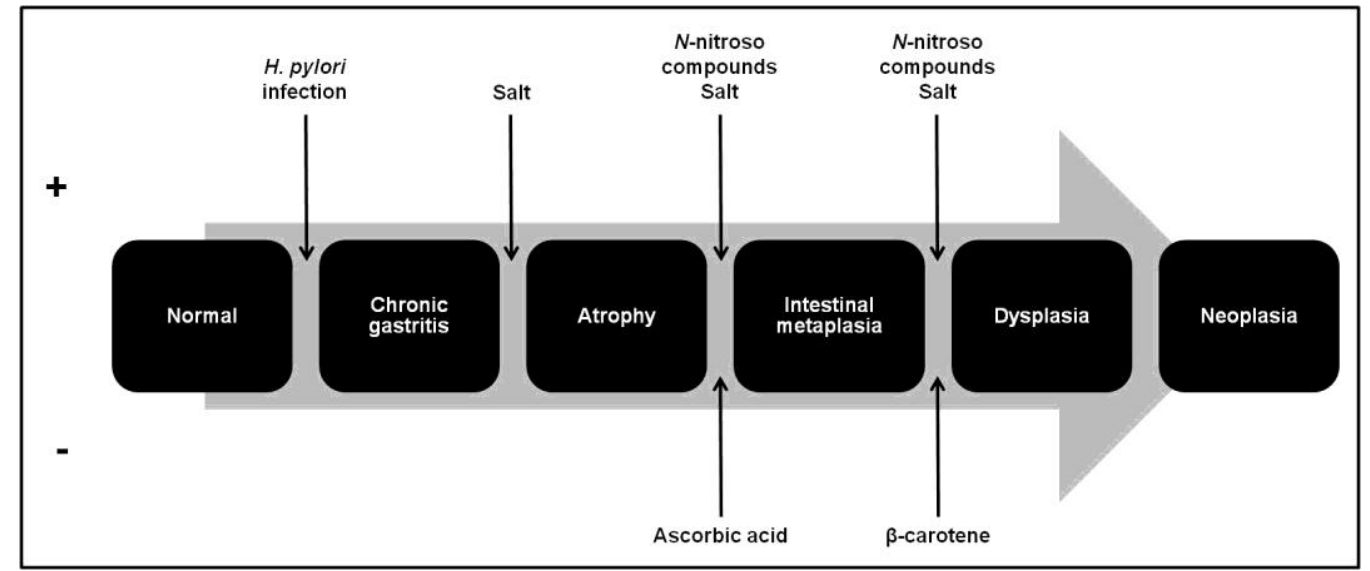

+ positive associations (increase the risk of gastric cancer); - negative associations (decrease the risk of gastric cancer).

Correa's model for gastric carcinogenesis was initially proposed for tumours of the intestinal type $(44,55)$, based on the aetiological hypothesis of a greater impact of environmental factors. However, recent epidemiological studies suggest that the two main gastric cancer types are similarly associated with infection $(11,56)$ and lifestyle exposures (57). Furthermore, markers of the cascade of events that involves intestinal differentiation, essential for the development of intestinal type gastric carcinomas, are also found in the diffuse type (58). This pathway is mediated by the $c d x 1$ and/or $c d x 2$ (caudal-type homeobox) genes (59), whose expression may be induced by $H$. pylori (60). CDX2 expression may be seen as an early marker of intestinal differentiation, occurring in the gastric carcinogenesis pathway even earlier than chronic atrophic gastritis or intestinal metaplasia $(61,62)$. In addition, molecular data show that CDX2 transactivates its own promoter, suggesting an auto-regulatory mechanism $(63,64)$, thus supporting the stability of intestinal metaplasia and the inevitable progression of the gastric carcinogenesis pathway once this step is reached. Epidemiological research relying on these tools to define the outcomes is still scarce $(65,66)$, but may be important to understand the aetiological heterogeneity of gastric cancer, by providing an additional early endpoint in the pathway towards gastric cancer. This may be particularly useful in settings where the frequency of gastric cancer and its precursor lesions are low. 
EMPIRICAL EVIDENCE SUPPORTING THE ROLE OF H. PYLORI INFECTION IN THE CAUSAL MECHANISMS LEADING TO GASTRIC CANCER

The above described models provide a conceptual framework for the interpretation of available evidence, to establish the probability of a causal relation and to frame its attributes.

The eight meta-analyses addressing the association between $H$. pylori infection and gastric cancer $(50,56,67-72)$ show summary odds ratios of approximately 2 . The magnitude of this association, however, varies according to different methodological and tumour characteristics, as illustrated in figure 5.

Figure 5. Meta-analyses on the association between $\mathrm{H}$. pylori infection and gastric cancer, according to different methodological and tumour characteristics.

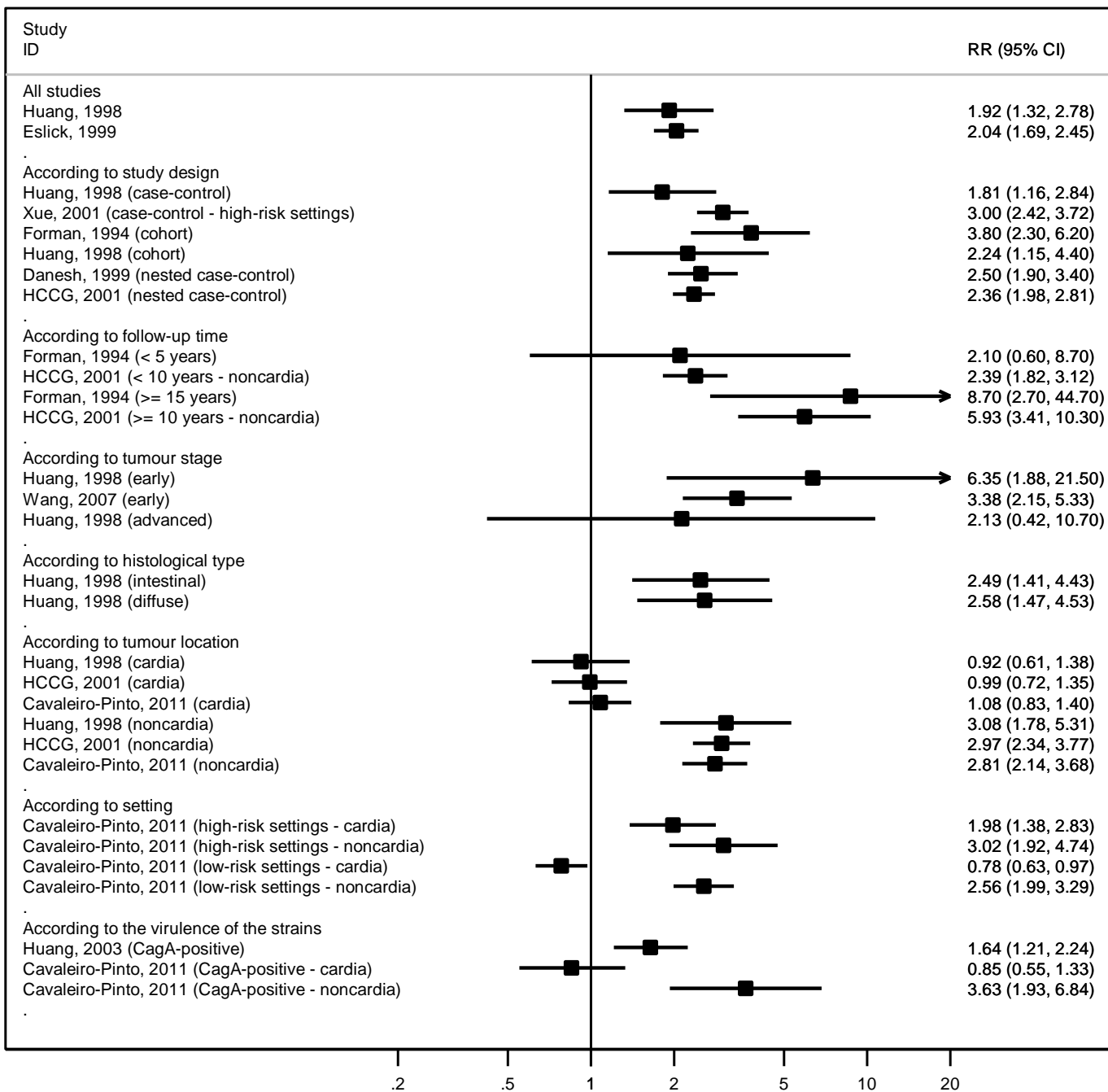

Data sources: Forman, 1994 (50); Huang, 1998 (56); Danesh, 1999 (67); Eslick, 1999 (68); HCCG, 2001 (69); Xue, 2001 (70); Huang, 2003 (73); Wang, 2007 (71); Cavaleiro-Pinto, 2011 (72). 
In general, studies with a prospective design show higher relative risk estimates than retrospective investigations $(50,56,67,69)$, and the longer the lag between the assessment of $H$. pylori infection status and the diagnosis of gastric cancer, the stronger is the association between infection and cancer $(50,69) . H$. pylori clearance tends to occur with the progression to cancer and infection may not always be present when cancer is diagnosed, which contributes to underestimate the association between infection and cancer in case-control studies $(74,75)$. Prospective studies provide a more accurate assessment of infection and more valid estimates for the risk of gastric cancer among the infected.

Studies restricting the analysis to early gastric cancer cases also show an increased gastric cancer risk in $H$. pylori-infected subjects $(56,71)$, mainly due to the fact that this is considered an early stage in the development of gastric cancer, closer to the precancerous lesions, and therefore less prone to differential misclassification. This is also in accordance with the stronger associations observed between $H$. pylori and precancerous lesions than with gastric cancer, as infection increases the risk of chronic atrophic gastritis by a factor of approximately five $(76,77)$.

Until recently, it was widely accepted that the association between $H$. pylori infection and gastric cancer was restricted to noncardia cancer $(56,69)$, which was taken as evidence of different aetiologies according to topography. However, in highrisk settings the magnitude of the association is similar for both cardia and noncardia cancers (72), supporting the hypothesis that two aetiologically distinct types of cardia cancer could coexist: one similar to the noncardia cancer and highly associated with $H$. pylori infection, and the other more similar to oesophageal cancer not related with infection (78-80). Therefore, $H$. pylori infection may be present in causal mechanisms for the occurrence of both cardia and noncardia stomach cancers.

Considering the virulence of the infecting strains as a marker of the exposure dose, we observe that, among $H$. pylori-infected populations, infection with cytotoxin associated-gene A (CagA)-positive strains further increases the risk of gastric cancer $(72,73)$. When more sensitive methods, based on the detection of antibodies against CagA, are used to determine infection status, the proportion of $H$. pylori-infected cases approaches $100 \%(81,82)$, leading to the hypothesis that $H$. pylori infection is present in all cases of gastric cancer.

Several studies assessed the impact of $H$. pylori eradication on the risk of gastric cancer. The clinical trials, not always randomized, provided evidence that supports the potential for prevention of stomach cancer through eradication of the infection (83-85). However, one of the trials (86) analysed separately the subjects with and without precancerous lesions, and eradication of $H$. pylori infection was 
significantly associated with a decreased risk of developing gastric cancer only among the latter. Also, in a trial conducted in Colombia, which only included subjects with gastric precancerous lesions at baseline evaluation, there was no association between eradication and cancer $(87,88)$. This supports the hypothesis that the effects of infection are exerted at the early stages of gastric carcinogenesis. Two recent metaanalyses estimated the impact of $H$. pylori eradication on the incidence of gastric precancerous lesions, with significant reduction in chronic atrophic gastritis risk but not of intestinal metaplasia $(89,90)$. Furthermore, intestinal metaplasia regression is even less frequent in subjects previously infected with high-virulence strains (91), probably because DNA alterations such as mutations or altered methylation profiles may have already occurred $(92,93)$. Taken together, these results support the irreversibility of intestinal metaplasia, since $H$. pylori eradication must occur before a point of no return in order to be effective for prevention of the outcomes corresponding to more advanced lesions.

In spite of previous observations suggesting $H$. pylori infection as a necessary cause for gastric cancer, acting at the early stages of the carcinogenesis pathway, a direct correlation between $H$. pylori prevalence and gastric cancer rates is not always observed at an ecological level. In fact, some countries present a low gastric cancer incidence despite the high frequency of infection, the so-called Asian and African enigmas $(94,95)$. In the latter settings, the cancer precursor lesions, especially intestinal metaplasia, are also less frequent than expected given the high prevalence of infection (96-100). This supports the hypothesis of $H$. pylori acting at earlier steps of the carcinogenesis and that other genetic and/or environmental exposures are needed for the progression towards cancer. Differences in the host response to infection (101$104)$, his/her genetic profile (105-107), environmental hazards and lifestyles $(108,109)$, H. pylori virulence $(98,110)$, or combined bacterial/host genotypic features have been proposed as possible co-factors for gastric cancer occurrence.

\section{THE OTHER COMPONENT CAUSES}

Although $H$. pylori infection is the most important gastric cancer determinant, only a small proportion of infected subjects will reach this endpoint $(111,112)$, and several other potential causal components have to be considered (figure 6).

The role of environmental factors in the gastric carcinogenesis has been studied and mechanisms by which they can lead to cancer have been proposed (55). Although salt, fruits and vegetables consumption were the first to be associated with gastric cancer (113), the evidence currently available shows a lack of consistent results and 
these exposures may have a weaker effect than initially thought (114). Evidence is also not so robust for other lifestyles, such as meat intake (114). On the contrary, the association with smoking, not previously accounted for, is now well-established (115).

The individuals' genetic profile was not included in the first versions of the model proposed by Correa $(44,55)$ but, along with the advent of new technologies and their use in epidemiological research, several studies addressing the association between genetic polymorphisms and gastric cancer have been conducted. In the aetiological model of gastric cancer, individual genetic susceptibility may be critical in a variety of processes relevant to gastric carcinogenesis (116), namely mucosal protection, inflammatory response, carcinogen detoxification, antioxidant protection, DNA repair and oncogenes and tumour suppressor genes expression. The most widely studied polymorphisms, and for which more promising results have been achieved, are those related to proinflammatory cytokines.

Figure 6. Meta-analyses on the association between lifestyle and genetic factors and gastric cancer.

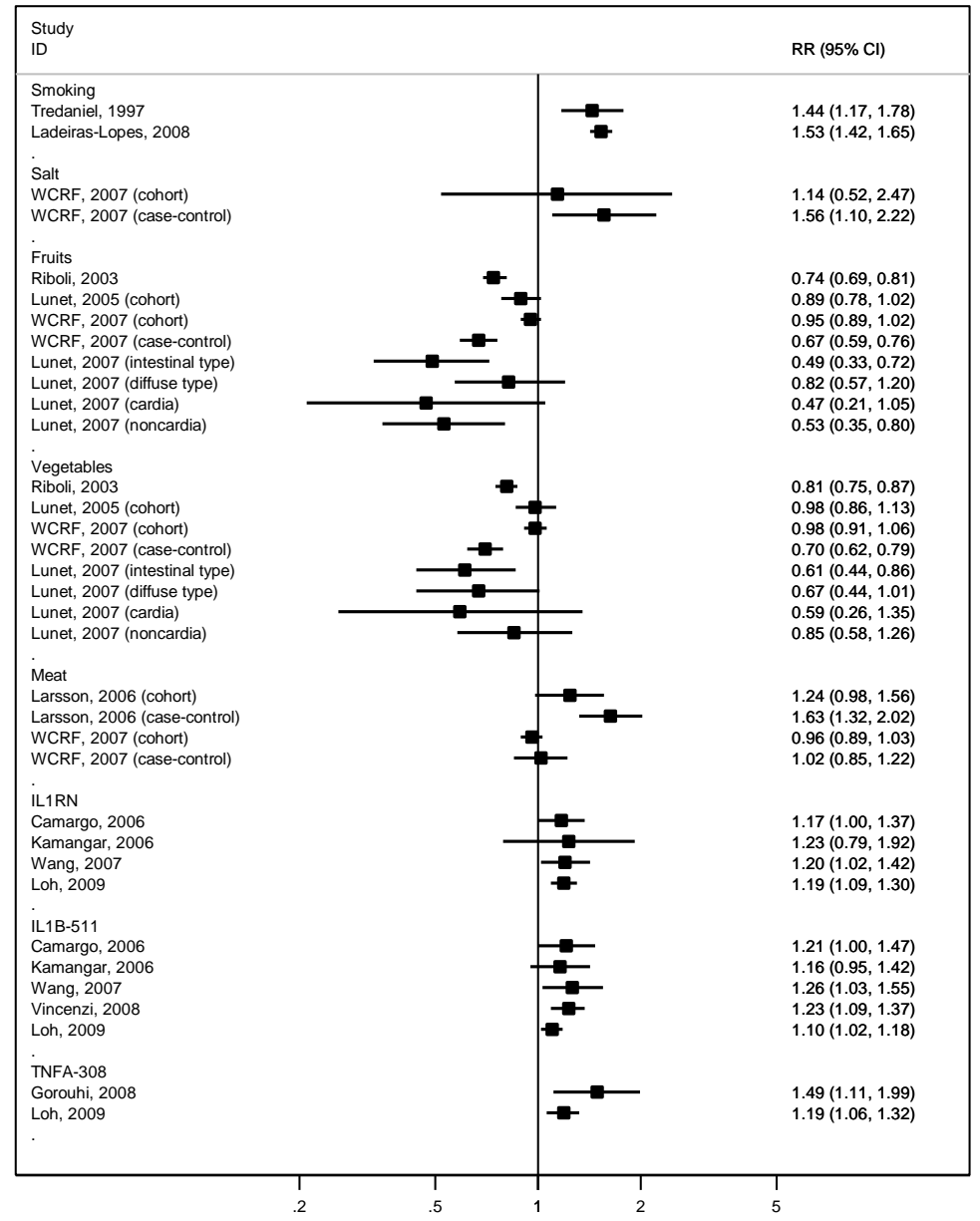

Data sources: Tredaniel, 1997 (117); Riboli, 2003 (118); Lunet, 2005 (119); Camargo, 2006 (120); Kamangar, 2006 (121); Larsson, 2006 (122); Lunet, 2007 (57); Wang, 2007 (123); WCRF, 2007 (114); Gorouhi, 2008 (124); LadeirasLopes, 2008 (125); Vincenzi, 2008 (126); Loh, 2009 (127). 


\section{SMOKING}

Stomach cancer is now considered a tobacco-related cancer (115). Current smokers have a $20 \%$ (among women) to $62 \%$ (among men) higher risk of gastric cancer when compared to never-smokers $(117,125)$. The risk, however, is lower in former smokers than in those that continue smoking (125); this suggests that smoking cessation contributes to a reduction in gastric cancer risk.

The relation between smoking and precancerous lesions, especially intestinal metaplasia, has been the more extensively studied lifestyle exposure, with individual reports yielding relative risk estimates ranging from 1.42 to $4.91(128,129)$.

An ecological analysis showed a strong correlation between apparent tobacco consumption and the frequency of intestinal metaplasia among $H$. pylori-infected subjects (109), suggesting that the low cigarette consumption observed in developing countries may be a contributory factor for the disruption of the carcinogenesis pathway, precluding the progression to the more advanced lesions. This was also supported by another ecological analysis that showed lower gastric cancer incidence rates in settings with high prevalence of infection and low apparent tobacco consumption than in those where smoking was more frequent (108).

Taken together, these results are indicative of a role for smoking in the stages closer to cancer. In addition, the risk of $H$. pylori-associated gastric cancer is higher in smokers compared to non-smokers (130-132), suggesting an interaction between these two risk factors.

\section{SALT INTAKE}

The global decline in gastric cancer rates was primarily attributed to a more frequent consumption of fresh products, together with a decrease of food preservation in salt (9). The proposed mechanisms by which salt can cause gastric cancer are either the direct damage to the gastric mucosa causing excessive cell replication or an indirect effect by increasing the mutagenic potential of $N$-nitroso compounds (55). More recently, it was shown that the damage caused by salt may also increase gastric $H$. pylori colonization $(133,134)$.

Previous meta-analyses on the association between salt intake and gastric precancerous lesions (135) or gastric cancer (114) concluded that the large methodological heterogeneity and in the presentation of the results did not allow for a comprehensive quantitative synthesis of the findings $(114,135)$. Many methodological limitations preclude valid measurements of salt consumption (136), and the excretion of sodium in urine over a 24-h period is the method that most accurately reflects the sodium ingested from different sources (114). The latter, however, was used only in an 
ecological study assessing the association between salt and intestinal metaplasia (137).

The currently available evidence on this topic does not allow definite conclusions on the magnitude of the effects of salt consumption, overall and in different steps of carcinogenesis.

\section{FRUITS AND VEGETABLES INTAKE}

The increase in fruits and vegetables consumption was considered a major contributor to the reduction of gastric cancer burden. Based on the inverse association between ingestion of fresh fruits and vegetables and gastric cancer observed in epidemiological studies, antioxidants such as ascorbic acid and beta-carotene were postulated to play a protective role in the stages closer to cancer by acting as freeradical scavengers (55). However, chemoprevention trials found no evidence of a beneficial effect for antioxidant supplementation on gastric cancer prevention (138, 139). Also, the summary estimates from several meta-analyses on the association with fruits and vegetables intake are closer to 1 when derived from cohort studies $(114,118$, 119). Although it is plausible that naturally occurring antioxidants may inhibit the carcinogenesis progression, the evidence on the specific steps where these factors may act is limited.

\section{MEAT INTAKE}

$\mathrm{N}$-nitroso compounds were hypothesized to act in gastric carcinogenesis by promoting the synthesis of carcinogens via nitrosation reactions (55). Processed meat is often an important source of exposure to carcinogenic $N$-nitroso compounds, and a meta-analysis of studies that quantified the association between processed meat consumption and stomach cancer found stronger associations in case-control studies (122). The relation between these exposures and cancer precursor lesions has seldom been addressed $(140,141)$ and the effect of these compounds in the gastric carcinogenesis pathway remains to be fully understood.

\section{CYTOKINE GENE POLYMORPHISMS}

Individual differences in the intensity of the inflammatory response affecting the maintenance, severity and outcome of $H$. pylori infection may contribute to gastric carcinogenesis. $H$. pylori infection induces both interleukin-1 $\beta$ (IL-1 $\beta$ ) and tumour necrosis factor- $\alpha$ (TNF- $\alpha$ ) production, and these cytokines inhibit gastric acid secretion, leading to the development of gastric precancerous lesions and cancer $(142,143)$. The IL1B gene codes for IL-1 $\beta$ and the IL1RN gene for an anti-inflammatory cytokine, 
interleukin-1 receptor antagonist (IL-1ra). Polymorphisms within the IL $1 B$ gene increase $\mathrm{IL}-1 \beta$ expression and IL-1ra binds to the IL-1 receptors, modulating the proinflammatory effects of IL-1 $\beta$. Regarding the IL1RN gene, a variable number tandem repeat (VNTR) polymorphism has been detected within intron 2 , and five allelic variants have been identified with the number of repeats varying from 2 to $6(116,144)$. The ability of $H$. pylori to infect and remain in the human stomach induces a chronic inflammatory response, which may be of variable magnitude depending on the host's genetic make-up. Most of the single nucleotide polymorphisms (SNPs) studied are situated in the gene promoter region and play important roles in modulating gene expression and thus the inflammatory response. Previous meta-analyses have shown an increased gastric cancer risk associated with polymorphisms in IL1RN, IL1B-511 and TNFA-308 (120, 121, 123, 124, 126, 127), although results differed when stratifying the data by race/ethnicity, study quality, tumour histological type and anatomical site. No systematic reviews of studies quantifying this association in gastric precancerous lesions are available. 
Aims 

This research aims to clarify the role of Helicobacter pylori infection in the web of gastric cancer causation, namely by providing evidence to answer the following research questions:

A) Is $H$. pylori infection a necessary condition for the occurrence of gastric cancer?

B) Which factors modulate the progression towards cancer in $H$. pylori-infected subjects?

In the last two decades, we witnessed to the gradual acceptance of $H$. pylori infection and smoking as the most important environmental factors contributing to the occurrence of gastric cancer. For other exposures, however, there is much less robust evidence on the magnitude of the associations or their role throughout carcinogenesis. The accumulated evidence suggests causal mechanisms for gastric cancer in which $H$. pylori infection plays the role of necessary component cause. The confirmation of this hypothesis would be a major achievement of cancer epidemiology, as it could translate into the possibility of preventing gastric cancer by acting over a single modifiable exposure. However, the understanding of the usefulness of the available tools for eradication of infection, as well as future vaccines or other primary prevention strategies, also depends on our knowledge on the role of infection in the different causal mechanisms at a finer level. The fact that infection may act predominantly as an initiator or the existence of points of no return in the gastric carcinogenesis pathway may restrict the time window for cancer prevention actions based on the control of infection. In fact, these strategies may need to be complemented with others addressing the component causes that interact with $H$. pylori. This requires the identification of the other factors acting in potentially step-specific causal mechanisms leading to gastric cancer.

Given the high gastric cancer risk in Portugal, and the also high prevalences of precancerous lesions and $H$. pylori infection, research conducted in this population may provide valuable information for understanding which factors contribute to the relation between infection and cancer to be underestimated in studies conducted in these settings rather than reflecting a weaker association between these factors. Also, studying cardia cancer taking into account the recent evidence of a similar association between $H$. pylori infection and cardia and noncardia cancers in high-risk settings may 
contribute to widen the range of action attributed to infection, and to clarify the aetiology of these two cancer types. Furthermore, the high prevalence of infection that is observed since young ages in Portugal is likely to shorten the induction time for the other factors in this population. Considering the initiator role given to $H$. pylori and the possibility of infection being present in all causal mechanisms leading to cancer, this setting may be useful for studying the interaction between $\mathrm{H}$. pylori and genetic and environmental factors, as the conjunction of these factors may be expected after shorter induction periods than in a population in which most subjects get infected later in life.

The African setting also presents a high prevalence of infection since childhood, but the gastric cancer risk is low. Under this scenario, the role that genetic and other environmental risk factors play in the causal mechanisms leading to cancer may be clarified by confirming the low exposure to these component causes in this setting. Since gastric cancer is particularly rare in most African countries, research conducted in these populations may be more feasible if the cancer precursor lesions, namely atrophy and intestinal metaplasia, or even earlier events such as CDX2 expression, are targeted instead of cancer. The quantification of these associations may contribute to understand which steps of carcinogenesis the different exposures may act upon.

This thesis includes reports from investigations with the following specific objectives:

1) To explain the underestimation of the association between $H$. pylori infection and noncardia gastric cancer, in a high-risk European population (paper I);

2) To provide evidence on the frequency of aetiologically distinct cases of cardia cancer, either resembling distal stomach cancer or oesophageal adenocarcinoma (paper II);

3) To quantify the association between dietary salt exposure, assessed by different methods, and gastric cancer, according to $H$. pylori infection, smoking, tumour site and histological type (paper III); 
4) To identify differences in the prevalence of gastric precancerous lesions and genetic susceptibility, H. pylori virulence, and lifestyles between dyspeptic subjects from Portugal and Mozambique (paper IV);

5) To quantify the association between IL1B-511, IL1RN VNTR, and TNFA-308 gene polymorphisms and intestinal metaplasia, using original data in two diverse populations from Portugal and Mozambique, and systematically reviewing the literature on the association between these polymorphisms and gastric precancerous lesions, placing our results into context (paper $\mathrm{V}$ );

6) To quantify the association between $H$. pylori infection and other environmental risk factors and the gastric expression of CDX2, according to the presence of gastric precancerous lesions, in Mozambique (paper VI). 

RESEARCH METHODS 

The objectives of this thesis were accomplished through the analysis of data obtained from two different studies conducted in Portugal and one in Mozambique. A general description of the participants and methods for each study is provided below. The selection of participants to be used in each analysis depended on the specific objectives of the investigations and is described in detail in the methods sections of the papers.

\section{Case-control study (Portugal)}

From 2001 to 2006, 709 incident cases of gastric adenocarcinoma with no previous cancer diagnosis (except for non-melanoma skin cancer) and not having undergone a subtotal gastrectomy for benign conditions were identified in the two major hospitals providing care to oncological patients in the Northern region of Portugal, both in Porto (Hospital de São João, EPE and Instituto Português de Oncologia do Porto Francisco Gentil, EPE). Cases were evaluated during their stay in the hospitals, as soon as possible after diagnosis, and most before treatment.

Cancer diagnosis was based on gastrectomy specimens, endoscopic biopsy material or the evaluation of metastases. Anatomic location was classified following image or pathology descriptions, as cardia (defined as cardioesophageal junction, oesophagogastric junction and gastroesophageal junction) (145), noncardia (all other specified sites) or non-accurately classifiable. The tumour's histological type was classified according to Laurén's criteria (38) as intestinal, diffuse, mixed or unclassifiable by a single pathologist who reviewed all pathology reports and reassessed the slides whenever routine information was considered insufficient or inconsistent.

Controls were part of a representative sample of the adult population of Porto, assembled from 1999 to 2003 (146). Participants were recruited by random digit dialling using households as the sampling frame, followed by simple random sampling to select in each household one eligible person among permanent residents that was invited to visit our department for interview. The overall sample comprised 2485 community controls, aged 18-92 years, corresponding to a participation proportion of $70 \%$ (147). Subjects were eligible for this analysis if there was no previous cancer diagnosis, except for non-melanoma skin cancer.

Trained interviewers inquired both cases and controls using a structured questionnaire covering demographic, social, behavioural and medical characteristics. To assess cognitive function, all individuals aged above 64 years underwent a Mini- 
Mental State Examination, which resulted in the exclusion of those scoring less than 18 (148). Dietary habits in the previous year, for controls, or the year before onset of symptoms, for cases, when applicable, were recorded using a previously validated $(149,150)$ semi-quantitative food frequency questionnaire (FFQ) comprising 82 food items/groups or beverage categories.

A blood sample was drawn from the participants, and serum samples were kept frozen at $-20^{\circ} \mathrm{C}$ until analysis. Anti-H. pylori serum immunoglobulin $\mathrm{G}(\mathrm{IgG})$ titers were quantified by enzyme-linked immunosorbent assay (ELISA) (Anti-Helicobacter pylori ELISA (IgG), Eurolmmun ${ }^{\circledR}$, Germany). Further testing of $H$. pylori infection status was performed by western blot (Helico Blot 2.1, Genelabs Diagnostics ${ }^{\circledR}$, Singapore).

The ethics committees of involved hospitals approved the study, and all participants provided written informed consent.

This study was used to address objectives 1 to 3 . For objective 1 , noncardia cancer cases and controls providing a blood sample were analyzed.

In objective 2, a case-control study and a case-case analysis were conducted, including cardia and noncardia cancer cases in which both the $H$. pylori infection status and the histological characteristics of the neoplastic and nonneoplastic mucosa were available. Controls were matched by age ( \pm 5 years) and sex (1:1).

For objective 3, all participants (cases and controls) who answered the FFQ and specific questions regarding salt intake (visual analogical scale, use of table salt and refrigerator ownership) were included.

\section{Cross-sectional study (Portugal)}

Workers of the Viana do Castelo shipyard, in Portugal, were invited for a gastric pathology survey in 1998. Four hundred and sixty (435 men and 25 women), nearly $40 \%$ of all the workers, volunteered to the study.

All participants completed a physician-administered questionnaire on digestive symptoms and had a blood sample drawn to assess anti- $H$. pylori serum lgG (COBAS ${ }^{\circledR}$ CORE, Roche Diagnostic Systems).

All participants classified as symptomatic or having a positive serologic test for $H$. pylori were eligible for an upper digestive endoscopy, and 412 agreed to be submitted to this procedure. Biopsy specimens (one from corpus, one from antrum, and two from incisura angularis) were taken from each subject. The histological evaluation was performed according to the updated Sydney system (151), and the diagnosis was based on the most severe lesion, following this descending order: intestinal metaplasia, chronic atrophic gastritis, and chronic non-atrophic gastritis. Modified Giemsa-stained 
sections were used to assess $H$. pylori infection. Additionally, $H$. pylori $\operatorname{cag} A$ and vacuolating cytotoxin $\mathrm{A}(\operatorname{vac} A) s$ and $m$ genotypes were directly determined in the gastric biopsy specimen from the greater curvature of the antrum by multiplex polymerase chain reaction (PCR) and reverse hybridization, as previously described (152).

Genomic DNA was retrieved from blood samples using standard phenol/chloroform extraction. The $I L 1 B-511$ and TNFA-308 SNPs were genotyped by PCR-single-strand conformation polymorphism analysis and the IL1RN penta-allelic VNTR by PCR-standard agarose gel electrophoresis, as previously described (153).

Written informed consent was obtained from all participants and the study protocol was approved by the ethics committee of Hospital de São João, EPE, Porto, Portugal.

Participants in this study for whom genotyping of cytokine gene polymorphisms was possible were used to address objective 5. To accomplish objective 4, the dyspeptic subjects of this sample were compared with the Mozambican population described below.

\section{Cross-sectional study (Mozambique)}

Patients submitted to an upper digestive endoscopy due to dyspeptic complaints at the Central Hospital of Maputo, Mozambique were consecutively invited to this study between August 2005 and April 2008.

A blood sample and four biopsy specimens (one from corpus, one from antrum, and two from incisura angularis) were collected, and the histological classification followed the updated Sydney system (151). Each participant was assigned an histological diagnosis based upon the most severe lesion found in any biopsy specimen, following this descending order: intestinal metaplasia, chronic atrophic gastritis, and chronic non-atrophic gastritis.

CDX2 expression was determined by immunohistochemistry in sections from gastric biopsy specimens from the incisura angularis or the antrum, as previously described (154).

$H$. pylori infection status was assessed by histology and infection status assigned to each subject was based upon the highest density of colonization observed in any biopsy. Additionally, $H$. pylori $\operatorname{cag} A$ and $\operatorname{vac} A$ ( $s$ and $m$ ) genotypes were determined by PCR as previously described (155), in the gastric biopsy specimen from the greater curvature of the antrum (156). 
Genomic DNA was retrieved from blood samples using standard phenol/chloroform extraction. The IL1B-511 SNP was genotyped by PCR-single-strand conformation polymorphism analysis and the IL1RN penta-allelic VNTR by PCRstandard agarose gel electrophoresis, as previously described (153).

Trained interviewers inquired the patients using a structured questionnaire to collect socio-demographic and behavioural data, such as smoking and drinking habits and preference for salted/salty foods. Also, dietary intake in the year preceding the symptoms was evaluated using a 43-item FFQ, from which data on the consumption of fruits, vegetables and meat was obtained.

The study protocol was approved by the National Mozambican Ethics Committee, and written informed consent was obtained from all participants.

The total sample comprised 310 subjects. Cytokine gene polymorphisms were evaluated only in the first 100 subjects enrolled in this study, and these participants were used to address objective 5 and then compared with the Portuguese population in objective 4. Regarding objective 6 , those presenting chronic atrophic gastritis or intestinal metaplasia were gender- and age-matched (1:2) with those having a normal mucosa or chronic non-atrophic gastritis. 
PAPERS 



\section{PAPER I}

Peleteiro B, Lunet N, Barros R, La Vecchia C, Barros H. Factors contributing to the underestimation of Helicobacter pylori-associated gastric cancer risk in a high-prevalence population. Cancer Causes Control. 2010;21(8):1257-64. 



\section{Factors contributing to the underestimation of Helicobacter pylori- associated gastric cancer risk in a high-prevalence population}

Bárbara Peleteiro · Nuno Lunet · Rita Barros ·

Carlo La Vecchia · Henrique Barros

Received: 11 August 2009/Accepted: 23 March 2010/Published online: 7 April 2010

(c) Springer Science+Business Media B.V. 2010

\begin{abstract}
Objective This study aimed to identify sources of underestimation of the association between Helicobacter pylori infection and non-cardia gastric cancer, in a highrisk European population.

Methods Non-cardia gastric cancer patients $(n=420)$ recruited in two major hospitals in North of Portugal and population controls $(n=1,389)$ were evaluated. Wholecell $\mathrm{IgG}$ antibodies against $H$. pylori were quantified by ELISA and Western Blot testing was conducted in a subsample (272 cases and 186 controls) allowing for the detection of current infection marker and CagA. Sex- and age-adjusted odds ratios (OR) and 95\% confidence intervals $(95 \% \mathrm{CI})$ were computed.
\end{abstract}

B. Peleteiro - N. Lunet $\cdot$ H. Barros

Department of Hygiene and Epidemiology, University of Porto Medical School, Porto, Portugal

B. Peleteiro $\cdot \mathrm{N}$. Lunet $\cdot \mathrm{H}$. Barros

Institute of Public Health, University of Porto (ISPUP), Porto, Portugal

\section{R. Barros}

Institute of Molecular Pathology and Immunology, University of Porto (IPATIMUP), Porto, Portugal

C. La Vecchia

Istituto di Ricerche Farmacologiche "Mario Negri", Milan, Italy

C. La Vecchia

Istituto di Statistica Medica e Biometria, Università di Milano, Milan, Italy

B. Peleteiro $(\square)$

Serviço de Higiene e Epidemiologia, Faculdade de Medicina

da Universidade do Porto, Al. Prof. Hernâni Monteiro,

4200-319 Porto, Portugal

e-mail: barbarap@med.up.pt
Results When assessing infection by ELISA, the OR for its association with gastric cancer decreases and reverts as IgG titers increased, from 1.96 (95\% CI: 1.09-3.54) for borderline positive results $(16.0-21.9 \mathrm{RU} / \mathrm{ml})$ to $0.52(95 \%$ CI: $0.36-0.74$ ) for the highest IgG levels ( $\geq 102.0 \mathrm{RU} / \mathrm{ml})$. The same pattern was observed across strata of age and blood collection timing with stronger associations among younger subjects and those providing blood samples earlier after diagnosis. The presence of CagA (Western Blot) was associated with an increased risk of gastric cancer $(\mathrm{OR}=11.32 ; 95 \%$ CI: 5.64-22.73).

Conclusion The use of methods with low sensitivity to detect past infection leads to a substantial underestimation of gastric cancer risk in high-prevalence settings.

Keywords Helicobacter pylori .

Non-cardia gastric cancer - ELISA - Western Blot

\section{Introduction}

Helicobacter pylori infection affects nearly $50 \%$ of the world adult population [1], and it has been classified as a human carcinogen [2], being responsible for two-thirds of all gastric cancers [1]. However, the association between $H$. pylori infection and gastric cancer is recognized only for non-cardia cancers [3-5], and its magnitude tends to be lower in high-prevalence settings [6-12]. Publication bias may have played an effect since only a few articles reporting negative findings have been published [13-15] after the earlier meta-analyses.

Among gastric cancer cases, the $H$. pylori seroprevalence decreases with age, and in more advanced stages, the proportion of infected subjects is lower [4, 16]. Methods allowing a valid assessment of infection are needed to 
avoid the underestimation of the association with advanced cancer in case-control designs [17, 18].

In the general population, the frequency of infection gradually increases with age in low-prevalence regions, but in high-risk populations the prevalence of infection reaches $80-90 \%$ at young adulthood [19]. Moreover, in the latter settings, the high proportion of subjects with chronic atrophic gastritis [20] contributes to a lower prevalence of infection, especially at older ages $[4,16]$. Therefore, in high-risk settings, the association between infection and gastric cancer would be underestimated, even among young adults, unless it is possible to stratify the infected subjects using finer markers of cancer risk.

This study aimed to identify sources of underestimation of the association between $H$. pylori infection and noncardia gastric cancer, in a high-risk European population.

\section{Materials and methods}

This is a case-control study of non-cardia gastric adenocarcinoma, conducted in the North of Portugal [21].

\section{Cases}

From June 2001 to December 2006, we evaluated 589 incident cases of non-cardia gastric adenocarcinoma. As previously described, patients were admitted to the surgery wards of the two largest public hospitals providing care to cancer patients in the North of the country, Hospital de S. João, and Instituto Português de Oncologia Francisco Gentil, both in Porto [22, 23]. Cancer diagnosis was based on gastrectomy specimens, endoscopic biopsy material, or the evaluation of metastasis. The anatomic site was classified following image or pathology descriptions. Subjects were eligible if there was no previous cancer diagnosis and no sub-total gastrectomy for benign conditions. The interview took place during in-hospital stay, shortly after admission, mostly before surgical treatment.

A blood sample was drawn from 420 cases and serum was kept frozen at $-20^{\circ} \mathrm{C}$. For $62(14.8 \%)$ participants blood was obtained only after surgery, during follow-up medical visits (median number of months elapsed between surgical treatment and blood collection: 7.95; percentile 25: 2.77; percentile 75: 13.70). However, no significant differences were found between these participants and those for whom blood sampling occurred during hospitalization, regarding gender (males: 61.3 vs. $56.6 \%$, $p=0.489$ ), age (median age: 62 vs. $64, p=0.506$ ) or education (median number of school years: 4 vs. 4 , $p=0.082$ ). Likewise, no significant differences were observed between cases who provided a blood sample and those who did not, regarding gender (57.4 vs. $60.7 \%$ males, $p=0.525$ ), age (median age: 64 vs. $66, p=0.172$ ), or education (median number of school years: 4 vs. 4 , $p=0.316$ ). Also, no significant differences were observed concerning tumor classification ( 41.0 vs. $44.7 \%$ classified as intestinal type, $p=0.819$ ), but patients for whom a blood sample was available were more likely to have undergone surgery ( 87.9 vs. $80.0 \%, p=0.029$ ).

\section{Controls}

Controls were part of a representative sample of the adult population of Porto [24, 25]. Participants were recruited by random digit dialing using households as the sampling frame, followed by simple random sampling to select one eligible person among permanent residents in each household that was invited to visit our department for interview and blood collection. Serum samples were kept frozen at $-20^{\circ} \mathrm{C}$ until analysis. The overall sample comprised 2,485 community controls, aged 18 to 92 , corresponding to a participation proportion of $70 \%$. For this analysis, we selected 1,389 controls with no previous diagnosis of cancer and a blood sample available when this study was conducted. Compared with controls for whom no blood sample was available, those included in the present analysis were more frequently males $(42.3$ vs. $32.5 \%, p<0.001)$ and younger (median age: 51 vs. $55, p<0.001$ ), but no differences were found regarding educational level (median number of school years: 8 vs. $8, p=0.184$ ).

Assessment of $H$. pylori infection status

Anti-H. pylori serum IgG titers (420 non-cardia gastric cancer cases and 1,389 controls) were quantified by ELISA (Anti-Helicobacter pylori ELISA (IgG), EuroImmun ${ }^{\circledR}$, Germany). Participants were classified as negative if they had less than $16 \mathrm{RU} / \mathrm{ml}$, as borderline if their antibody concentration was between 16 and $22 \mathrm{RU} / \mathrm{ml}$ and as positive if the antibody level was equal or greater than $22 \mathrm{RU} / \mathrm{ml}$, according to the manufacturer's instructions. Subjects testing positive were further grouped in three categories, using the percentile $25(38.0 \mathrm{RU} / \mathrm{ml})$ and median $(102.0$ $\mathrm{RU} / \mathrm{ml}$ ) values of the distribution of anti- $H$. pylori $\operatorname{IgG}$ antibodies concentration in the control group as cut-offs.

Further testing of $H$. pylori infection status was performed by Western Blot (Helico Blot 2.1, Genelabs Diagnostics ${ }^{\circledR}$, Singapore) in a subsample of 458 participants (272 noncardia gastric cancer cases and 186 controls). We randomly selected cases and controls according to the prevalence of $H$. pylori infection in each of these two groups as determined by ELISA in each of the age strata $(18-39,40-54,55-70$, and $>70$ years). The assay was conducted as proposed by the manufacturer, and the results were interpreted following the manufacturer's recommended criteria for $H$. pylori 
seropositivity: 1) presence of the $116 \mathrm{kD}$ band (CagA) with one or more of the following bands: $89 \mathrm{kD}$ (VacA), $37 \mathrm{kD}$, $35 \mathrm{kD}, 30 \mathrm{kD}$ (UreA) and $19.5 \mathrm{kD}$ together, or with current infection marker; 2) presence of any band at $89 \mathrm{kD}, 37 \mathrm{kD}$, or $35 \mathrm{kD}$, with or without current infection marker; and 3 ) presence of both $30 \mathrm{kD}$ and $19.5 \mathrm{kD}$ bands, with or without current infection marker. CagA status was defined according to the manufacturer's instructions as the presence of the CagA band at $116 \mathrm{kD}$ with one or more of the following bands: $89 \mathrm{kD}$ (VacA), $37 \mathrm{kD}, 35 \mathrm{kD}, 30 \mathrm{kD}$ (UreA) and $19.5 \mathrm{kD}$ together. The presence of the CagA band was also considered regardless of the remaining criteria to define infection.

\section{Statistical analysis}

The association of gastric cancer with $H$. pylori infection was quantified using age and sex-adjusted $O R$ and the corresponding $95 \%$ confidence intervals, computed by unconditional logistic regression. STATA ${ }^{\circledR}$ version 9.0 was used for all the analyses. Stratified analyses were performed according to the median age ( $<65$ vs. $\geq 65$ years) and the blood collection timing (in-hospital stay vs. followup visits) in cases.

\section{Ethics}

The ethics committees of involved hospitals approved the study, and all participants provided written informed consent.

\section{Results}

Association between anti- $H$. pylori IgG titers and gastric cancer

As IgG titers increased, the OR for the association with gastric cancer changed from 1.96 (95\% CI: 1.09-3.54) for borderline positive results (16.0-21.9 RU/ml) to $0.52(95 \%$ CI: $0.36-0.74)$ for the highest $\operatorname{IgG}$ levels $(\geq 102.0 \mathrm{RU} / \mathrm{ml})$ ( $p$ for trend: $<0.001$ ). The same trend was observed across strata of age and timing of blood collection with stronger associations among the younger subjects and those providing a blood sample earlier after diagnosis (Table 1).

Association between $H$. pylori infection

and gastric cancer

In the sub-sample of subjects evaluated by both ELISA and Western Blot, $165(88.7 \%)$ controls and $229(84.2 \%)$ cases were ELISA positive. The prevalence of infection was lower when considering the results from Western Blot analysis $(80.6 \%$ in controls and $75.7 \%$ in cases).

No substantial differences in the association between infection and cancer were observed when more specific (positive test by both ELISA and Western Blot) or more sensitive (positive test by ELISA or Western Blot) criteria were used to classify subjects as infected (Table 2).

No significant association was observed when the detection of the current infection marker or $\mathrm{CagA}$ status were considered (Table 2).

The presence of the CagA band, regardless of the remaining criteria to define infection, was significantly associated with an increased risk of gastric cancer, 261 (96\%) of cases versus $130(70 \%)$ of controls $(\mathrm{OR}=11.32$; 95\% CI: 5.64-22.73) (Table 2). A stronger association was observed in participants aged below 65 and cases having blood collected during in-hospital stay (OR $=13.72 ; 95 \%$ CI: $4.70-40.05$ ).

Defining the subjects testing negative by both methods (ELISA negative and CagA band negative) as the reference group, the OR of the association was 0.57 (95\% CI: 0.14 2.30) for subjects positive by ELISA and negative by Western Blot, and the individuals testing positive for the CagA band had an increased risk of gastric cancer $(\mathrm{OR}=7.60$; 95\% CI: 2.40-24.05) (Table 2). Further excluding individuals aged 65 or above and cases for whom blood sampling was only possible later after diagnosis, we found that all remaining cases $(n=132)$ had the CagA band compared with $89.3 \%(n=109)$ of the controls.

Age, current infection marker, and CagA according to anti-H. pylori $\operatorname{IgG}$ titters

Among controls, the proportion of individuals aged below 65 was higher in those testing negative by ELISA. The proportion of subjects with the current infection marker increased with the increased concentration of anti-H. pylori IgG antibodies. No substantial differences in the proportion of subjects with the CagA band were observed across groups of IgG titers within those testing positive by ELISA (Fig. 1).

Among cases, similar results were obtained regarding the marker of current infection, but no differences were observed as IgG titers increased in the proportion of individuals aged 64 or below or presenting the CagA band (Fig. 1).

\section{Discussion}

In Portugal, a European high-risk population, no positive association between $H$. pylori infection and gastric cancer was found when the assessment of infection was made by 
Table 1 Association between non-cardia gastric cancer and Helicobacter pylori infection defined by anti- $H$. pylori IgG titters detected by ELISA (420 cases and 1,389 controls)

\begin{tabular}{|c|c|c|c|c|}
\hline & \multirow{2}{*}{$\begin{array}{l}\text { Controls } \\
n(\%)\end{array}$} & \multicolumn{3}{|l|}{ Cases } \\
\hline & & $n(\%)$ & Crude OR $(95 \% \mathrm{CI})$ & Adjusted $\mathrm{OR}^{\mathrm{b}}(95 \% \mathrm{CI})$ \\
\hline \multicolumn{5}{|l|}{ All participants } \\
\hline \multicolumn{5}{|c|}{ Anti- $H$. pylori $\mathrm{IgG}$ antibodies ${ }^{\mathrm{a}}(\mathrm{RU} / \mathrm{ml})$} \\
\hline$<16.0$ (negative) & $173(12.5)$ & $63(15.0)$ & 1 & 1 \\
\hline 16.0-21.9 (borderline) & $35(2.5)$ & $36(8.6)$ & $2.82(1.63-4.88)$ & $1.96(1.09-3.54)$ \\
\hline$\geq 22.0$ (positive) & $1,181(85.0)$ & $321(76.4)$ & $0.75(0.54-1.02)$ & $0.57(0.41-0.80)$ \\
\hline $22.0-37.9$ & $132(9.5)$ & $65(15.5)$ & $1.35(0.89-2.04)$ & $0.84(0.54-1.31)$ \\
\hline $38.0-101.9$ & $353(25.4)$ & $105(25.0)$ & $0.82(0.57-1.17)$ & $0.56(0.38-0.83)$ \\
\hline$\geq 102.0$ & $696(50.1)$ & $151(36.0)$ & $0.60(0.42-0.84)$ & $0.52(0.36-0.74)$ \\
\hline \multicolumn{5}{|l|}{ Participants aged $<65$} \\
\hline \multicolumn{5}{|c|}{ Anti-H. pylori $\mathrm{IgG}$ antibodies ${ }^{\mathrm{a}}(\mathrm{RU} / \mathrm{ml})$} \\
\hline$<16.0$ & $144(13.9)$ & $28(13.2)$ & 1 & 1 \\
\hline $16.0-21.9$ & $24(2.3)$ & $20(9.4)$ & $4.28(2.09-8.79)$ & $2.87(1.34-6.16)$ \\
\hline $22.0-37.9$ & $84(8.1)$ & $25(11.7)$ & $1.53(0.84-2.80)$ & $0.87(0.46-1.64)$ \\
\hline $38.0-101.9$ & $245(23.7)$ & $58(27.2)$ & $1.22(0.74-2.00)$ & $0.76(0.45-1.28)$ \\
\hline$\geq 102.0$ & $537(51.9)$ & $82(38.5)$ & $0.78(0.49-1.25)$ & $0.66(0.40-1.08)$ \\
\hline \multicolumn{5}{|l|}{ Participants aged $\geq 65$} \\
\hline \multicolumn{5}{|c|}{ Anti- $H$. pylori $\mathrm{IgG}$ antibodies ${ }^{\mathrm{a}}(\mathrm{RU} / \mathrm{ml})$} \\
\hline$<16.0$ & $29(8.2)$ & $35(16.9)$ & 1 & 1 \\
\hline $16.0-21.9$ & $11(3.1)$ & $16(7.7)$ & $1.20(0.48-3.00)$ & $1.17(0.47-2.92)$ \\
\hline $22.0-37.9$ & $48(13.5)$ & $40(19.3)$ & $0.69(0.36-1.32)$ & $0.69(0.36-1.32)$ \\
\hline $38.0-101.9$ & $108(30.4)$ & $47(22.7)$ & $0.36(0.20-0.66)$ & $0.36(0.20-0.66)$ \\
\hline$\geq 102.0$ & $159(44.8)$ & $69(33.3)$ & $0.36(0.20-0.63)$ & $0.38(0.21-0.67)$ \\
\hline \multicolumn{5}{|c|}{ All controls and cases having blood collected during in-hospital stay } \\
\hline \multicolumn{5}{|c|}{ Anti-H. pylori $\operatorname{IgG}$ antibodies ${ }^{\mathrm{a}}(\mathrm{RU} / \mathrm{ml})$} \\
\hline$<16.0$ & $173(12.5)$ & $47(13.2)$ & 1 & 1 \\
\hline $16.0-21.9$ & $35(2.5)$ & $30(8.4)$ & $3.16(1.76-5.66)$ & $2.22(1.19-4.14)$ \\
\hline $22.0-37.9$ & $132(9.5)$ & $58(16.4)$ & $1.62(1.03-2.53)$ & $1.01(0.63-1.62)$ \\
\hline $38.0-101.9$ & $353(25.4)$ & $90(25.2)$ & $0.94(0.63-1.40)$ & $0.65(0.42-0.99)$ \\
\hline$\geq 102.0$ & $696(50.1)$ & $132(37.0)$ & $0.70(0.48-1.01)$ & $0.61(0.41-0.91)$ \\
\hline \multicolumn{5}{|c|}{ All controls and cases having blood collected during follow-up visits } \\
\hline \multicolumn{5}{|c|}{ Anti- $H$. pylori IgG antibodies ${ }^{\mathrm{a}}(\mathrm{RU} / \mathrm{ml})$} \\
\hline$<16.0$ & $173(12.5)$ & $16(26.2)$ & 1 & 1 \\
\hline $16.0-21.9$ & $35(2.5)$ & $6(9.8)$ & $1.85(0.68-5.07)$ & $1.20(0.42-3.43)$ \\
\hline $22.0-37.9$ & $132(9.5)$ & $7(11.5)$ & $0.57(0.23-1.43)$ & $0.31(0.12-0.80)$ \\
\hline $38.0-101.9$ & $353(25.4)$ & $14(23.0)$ & $0.43(0.20-0.90)$ & $0.26(0.12-0.57)$ \\
\hline$\geq 102.0$ & $696(50.1)$ & $18(29.5)$ & $0.28(0.14-0.56)$ & $0.24(0.12-0.50)$ \\
\hline
\end{tabular}

${ }^{\text {a }}<16.0 \mathrm{RU} / \mathrm{ml}$ are negative; $16.0-21.9 \mathrm{RU} / \mathrm{ml}$ are borderline; $38.0 \mathrm{RU} / \mathrm{ml}$ is the percentile 25 of the controls distribution; $102.0 \mathrm{RU} / \mathrm{ml}$ is the median value observed in the controls

b Age and sex-adjusted

ELISA, in accordance with the results from a previous Portuguese small case-control study [26], and with findings from other studies conducted in high-risk settings [6-12]. Still, subjects with CagA band at Western Blot had an over tenfold excess risk of gastric cancer. Further dividing the group of subjects testing positive in three categories we observed a decrease and reversion of the relation between infection and non-cardia adenocarcinoma as serum concentrations of anti- $H$. pylori $\mathrm{IgG}$ increased, also in accordance with previous observations [27].

We observed that the associations were stronger in participants aged below 65 than in those aged 65 or above.

Q Springer 
Table 2 Association between non-cardia gastric cancer and Helicobacter pylori infection assessed by ELISA and Western Blot analyses (272 cases and 186 controls)

\begin{tabular}{|c|c|c|c|c|}
\hline & \multirow{2}{*}{$\begin{array}{l}\text { Controls } \\
n(\%)\end{array}$} & \multicolumn{3}{|l|}{ Cases } \\
\hline & & $n(\%)$ & Crude OR (95\% CI) & Adjusted $\mathrm{OR}^{\mathrm{b}}(95 \% \mathrm{CI})$ \\
\hline \multicolumn{5}{|l|}{ ELISA analysis } \\
\hline \multicolumn{5}{|l|}{ H. pylori infection status } \\
\hline Negative & $21(11.3)$ & $43(15.8)$ & 1 & 1 \\
\hline Positive $^{\mathrm{a}}$ & $165(88.7)$ & $229(84.2)$ & $0.68(0.39-1.18)$ & $0.66(0.37-1.17)$ \\
\hline \multicolumn{5}{|l|}{ Western Blot analysis } \\
\hline \multicolumn{5}{|l|}{ H. pylori infection status } \\
\hline Negative & $36(19.4)$ & $66(24.3)$ & 1 & 1 \\
\hline Positive & $150(80.6)$ & $206(75.7)$ & $0.75(0.47-1.18)$ & $0.73(0.46-1.17)$ \\
\hline \multicolumn{5}{|l|}{ Presence of current infection marker ${ }^{c}$} \\
\hline Negative & $68(39.8)$ & $118(43.4)$ & 1 & 1 \\
\hline Positive & $117(63.2)$ & $154(56.6)$ & $0.76(0.52-1.11)$ & $0.76(0.52-1.13)$ \\
\hline \multicolumn{5}{|l|}{ CagA status } \\
\hline Negative & $70(37.6)$ & $91(33.5)$ & 1 & 1 \\
\hline Positive & $116(62.4)$ & $181(66.5)$ & $1.20(0.81-1.77)$ & $1.20(0.81-1.79)$ \\
\hline \multicolumn{5}{|l|}{ Presence of Cag A band } \\
\hline Negative & $56(30.1)$ & $11(4.0)$ & 1 & 1 \\
\hline Positive & $130(69.9)$ & $261(96.0)$ & $10.22(5.18-20.17)$ & $11.32(5.64-22.73)$ \\
\hline \multicolumn{5}{|l|}{ ELISA and Western Blot analysis } \\
\hline \multicolumn{5}{|l|}{ H. pylori infection status } \\
\hline Negative by at least one method & $40(21.5)$ & $84(30.9)$ & 1 & 1 \\
\hline Positive $^{\mathrm{a}}$ by both methods & $146(78.5)$ & $188(69.1)$ & $0.61(0.40-0.95)$ & $0.62(0.40-0.96)$ \\
\hline \multicolumn{5}{|l|}{ H. pylori infection status } \\
\hline Negative by both methods & $17(9.1)$ & $25(9.2)$ & 1 & 1 \\
\hline Positive $^{a}$ by at least one method & $169(90.9)$ & $247(90.8)$ & $0.99(0.52-1.90)$ & $0.90(0.46-1.75)$ \\
\hline \multicolumn{5}{|c|}{ CagA status by Western Blot and infection status by ELISA } \\
\hline Negative by both methods & $19(10.2)$ & $30(11.0)$ & 1 & 1 \\
\hline Positive $^{a}$ by ELISA and negative for CagA status & $51(27.4)$ & $61(22.4)$ & $0.76(0.38-1.50)$ & $0.67(0.33-1.35)$ \\
\hline Positive $^{a}$ for CagA status & $116(62.4)$ & $181(66.6)$ & $0.99(0.53-1.84)$ & $0.91(0.48-1.72)$ \\
\hline \multicolumn{5}{|c|}{ Presence of CagA band by Western Blot and infection status by ELISA } \\
\hline Negative by both methods & $15(8.1)$ & $4(1.5)$ & 1 & 1 \\
\hline Positive $^{\mathrm{a}}$ by ELISA and negative for CagA band & $41(22.0)$ & $7(2.5)$ & $0.64(0.16-2.50)$ & $0.57(0.14-2.30)$ \\
\hline Positive $^{\mathrm{a}}$ for CagA band & $130(69.9)$ & $261(96.0)$ & $7.53(2.45-23.14)$ & $7.60(2.40-24.05)$ \\
\hline
\end{tabular}

${ }^{a}$ Borderline results in the ELISA analysis were considered positive

b Age and sex-adjusted

${ }^{c}$ Current infection marker detection was not available for one subject

A previous meta-analysis had already shown that $H$. pylori seropositivity increases with age in subjects without but not in those with gastric cancer [16]. Among cases, the prevalence of infection decreases as subjects get older, resulting in a stronger association for gastric cancer in $H$. pyloriinfected younger patients than in older age groups [4, 28]. The lower seroprevalence of the infection observed in older patients may be attributed to the presence of precancerous lesions with advancing age, such as atrophic gastritis and intestinal metaplasia [20, 29], which are more common among subjects with gastric cancer than in controls [16, 30].
The measurement of pepsinogens I and II level and its ratio has been used as a marker of atrophy in order to stratify gastric cancer risk [31-33]. In this study, this quantitation was not performed but atrophy in the non-neoplastic mucosa of the cases was recorded. However, no differences were observed in the proportion of cases having atrophy in the non-neoplastic mucosa between CagA negative and CagA positive subjects. All cases with no evidence of atrophy in the non-neoplastic mucosa presented the CagA band, while $98.6 \%$ of those with atrophy presented the same band. 


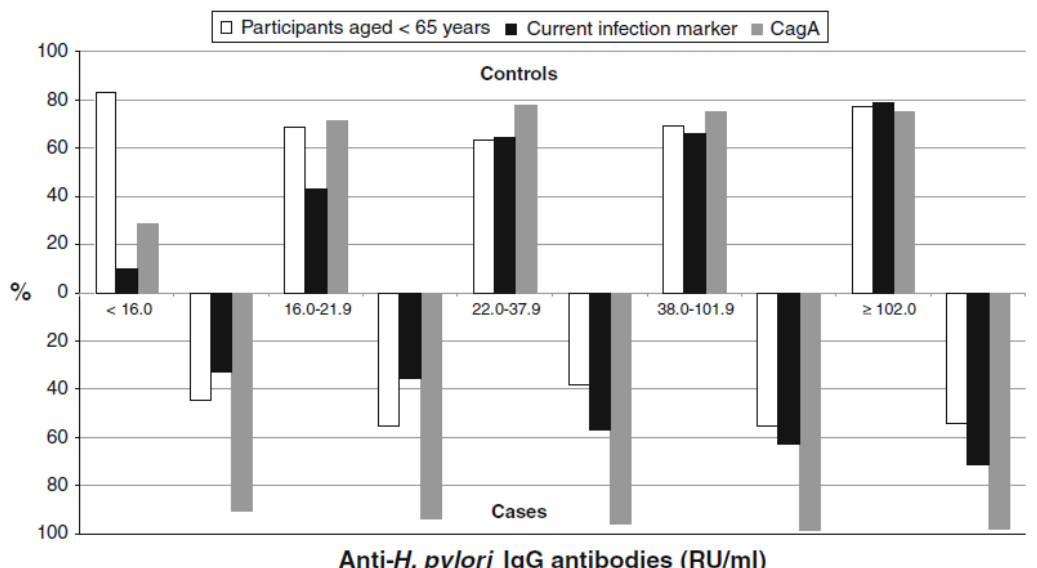

Fig. 1 Distribution of age, current infection marker, and CagA according to anti-Helicobacter pylori IgG titters detected by ELISA among controls and cases

A higher risk for gastric cancer associated with H. pylori infection was found for subjects who had their blood sample drawn during hospital stay. This can be explained by the fact that seroconversion might be expected in time after total or partial gastrectomy [34, 35]. Brenner et al. found that an increased proportion of gastric cancer cases were considered $H$. pylori-infected when subjects that had their blood sample collected more than 90 days after gastrectomy were excluded from the analysis [17].

This study is one of the first investigations using Western Blot in a high-risk setting [36] and showed a stronger association between $H$. pylori infection and gastric cancer when infection status was assessed by this method. In previous studies, a higher prevalence of infection was obtained in gastric cancer cases, reaching nearly $100 \%$ for the presence of CagA [17, 18, 36-38]. A possible explanation for this is that antibodies to CagA may persist longer after $H$. pylori clearance than the surface antibodies detected by conventional IgG ELISA [28, 39, 40].

In the subsample of subjects evaluated by both methods, ELISA and Western Blot, the prevalence of $H$. pylori was higher in both cases and controls, if seropositivity was defined as testing positive by at least one method. However, the distribution of the bands in the Western Blot analysis was different between groups. The presence of the CagA band was associated with a substantially increased risk of gastric cancer. These results are in accordance with previous studies reporting that immunoblot detecting $\mathrm{Cag} \mathrm{A}$ is a better method to detect prior infection [18, 41-43]. Additionally, in controls, the prevalence of infection is continuously raising with age [44-46]. This suggests that controls are more likely to have been infected later in life and to persist with infection during their adulthood, whereas the cases are more likely to have been infected earlier and tend to lose the infection as cancer progresses [47]. In high-prevalence settings, where a longer lag is expected between exposure and the outcome, this may have a greater impact on the underestimation of the association between infection and cancer. Having a finer marker of past infection ( $\mathrm{CagA}$ ) will help to overcome this methodological issue in case-control studies, particularly in high-prevalence settings. In addition, different bacterial strains may be involved in this process, and patients with gastric cancer are more frequently infected with toxic strains ( cagA) of $H$. pylori compared with controls. There is a strong association between infection with cagA positive bacteria and an increased risk for gastric precancerous lesions [48] and for intestinal-type gastric cancer [49].

The results obtained for controls testing negative by ELISA are in accordance to what we would expect in the general population: a higher proportion of subjects aged below 65 and a low proportion of subjects having the current infection marker or the CagA band. However, among cases, the proportion of younger subjects did not vary consistently across classes of $\mathrm{IgG}$ titers, and the proportion of subjects presenting the CagA band was similar in all categories, suggesting that a differential misclassification could be affecting the cases, or just reflecting different timings of exposure and susceptibility to cancer development.

Since we lack reliable information on previous $H$. pylori eradication therapy, we cannot rule out the possibility that the decline in antibody concentration found among cases could be due to treatment $[50,51]$, which cases are most likely to have undergone than controls, if symptomatic. However, the differences found between cases and controls are larger than it would be expected if this was the only explanation. 
Another possible explanation is that the immune response could change as cancer develops. During infection with $H$. pylori, Th1 cells appear to predominate. The IgG subclass response to infection is considered to be a biomarker of the Th cell response, with IgG2 subclass production being promoted and IgG1 production being suppressed. However, these results seem to be different according to the setting [52]. While in developed countries a Th1 response is predominant, a Th2 is mainly observed in developing countries. Both environmental and genetic factors influence Th1 or Th2 differentiation, and the immune response shifts across age groups [52]. Also, the immune response could be divergent among $H$. pyloriinfected individuals, as reported for developing countries [53, 54]. Gastric cancer cases could present a specific immune response enabling the distinction between those who will and will not develop cancer among the infected. So, in high-risk settings, a similar observation could be made despite the economical features of the country, but inability to discriminate $\mathrm{IgG}$ class in this study precludes such an inference.

In case-control designs, false-negative results in serological assessment of infection status (classified as ever in life) are more likely in older participants, in patients with advanced gastric cancer, and for lower virulence strains. The presence of the CagA band could be regarded as a strong indicator of gastric cancer risk, as it is a finer marker of prior $H$. pylori infection, especially among cases, and allows a more valid comparison between cases and controls. The use of methods with low sensitivity to detect past infection, including study design, selection of the participants and assessment of infection status, leads to a substantial underestimation of gastric cancer risk in highprevalence settings.

Acknowledgments Grants from Fundação para a Ciência e Tecnologia are gratefully acknowledged (PTDC/SAU-ESA/71517/2006, POCI/ SAL-ESP/56126/2004, POCI/SAL-ESP/61685/2004, POCTI/ESP/ 35769/99, PRAXIS/2/2.1/SAU/1332/1995, SFRH/BD/368 18/2007).

\section{References}

1. Parkin DM (2006) The global health burden of infection-associated cancers in the year 2002. Int J Cancer 118:3030-3044

2. IARC (1994) Schistosomes, liver flukes and Helicobacter pylori. IARC working group on the evaluation of carcinogenic risks to humans. Lyon, 7-14 June 1994. IARC Monogr Eval Carcinog Risks Hum 61:1-241

3. Eslick GD, Lim LL, Byles JE, Xia HH, Talley NJ (1999) Association of Helicobacter pylori infection with gastric carcinoma: a meta-analysis. Am J Gastroenterol 94:2373-2379

4. Helicobacter and Cancer Collaborative Group (2001) Gastric cancer and Helicobacter pylori: a combined analysis of 12 case control studies nested within prospective cohorts. Gut 49 : $347-353$
5. Xue FB, Xu YY, Wan Y, Pan BR, Ren J, Fan DM (2001) Association of $H$. pylori infection with gastric carcinoma: a meta analysis. World J Gastroenterol 7:801-804

6. Webb PM, Yu MC, Forman D, Henderson BE, Newell DG, Yuan JM, Gao YT, Ross RK (1996) An apparent lack of association between Helicobacter pylori infection and risk of gastric cancer in China. Int J Cancer 67:603-607

7. Kato S, Onda M, Matsukura N, Tokunaga A, Matsuda N, Yamashita K, Shields PG (1996) Genetic polymorphisms of the cancer related gene and Helicobacter pylori infection in Japanese gastric cancer patients. An age and gender matched case-control study. Cancer 77:1654-1661

8. Fukuda H, Saito D, Hayashi S, Hisai H, Ono H, Yoshida S, Oguro Y, Noda T, Sato T, Katoh M et al (1995) Helicobacter pylori infection, serum pepsinogen level and gastric cancer: a casecontrol study in Japan. Jpn J Cancer Res 86:64-71

9. Blaser MJ, Kobayashi K, Cover TL, Cao P, Feurer ID, PerezPerez GI (1993) Helicobacter pylori infection in Japanese patients with adenocarcinoma of the stomach. Int $\mathrm{J}$ Cancer 55:799-802

10. Tatsuta M, Iishi H, Okuda S, Taniguchi H, Yokota Y (1993) The association of Helicobacter pylori with differentiated-type early gastric cancer. Cancer 72:1841-1845

11. Azuma T, Ito S, Sato F, Yamazaki Y, Miyaji H, Ito Y, Suto H, Kuriyama M, Kato T, Kohli Y (1998) The role of the HLADQA1 gene in resistance to atrophic gastritis and gastric adenocarcinoma induced by Helicobacter pylori infection. Cancer 82:1013-1018

12. Shibata T, Imoto I, Ohuchi Y, Taguchi Y, Takaji S, Ikemura N, Nakao K, Shima T (1996) Helicobacter pylori infection in patients with gastric carcinoma in biopsy and surgical resection specimens. Cancer 77:1044-1049

13. Shen J, Wang RT, Wang LW, Xu YC, Wang XR (2004) A novel genetic polymorphism of inducible nitric oxide synthase is associated with an increased risk of gastric cancer. World J Gastroenterol 10:3278-3283

14. Shin A, Shin HR, Kang D, Park SK, Kim CS, Yoo KY (2005) A nested case-control study of the association of Helicobacter pylori infection with gastric adenocarcinoma in Korea. $\mathrm{Br} \mathbf{J}$ Cancer 92:1273-1275

15. Watabe H, Mitsushima T, Yamaji Y, Okamoto M, Wada R, Kokubo T, Doi H, Yoshida H, Kawabe T, Omata M (2005) Predicting the development of gastric cancer from combining Helicobacter pylori antibodies and serum pepsinogen status: a prospective endoscopic cohort study. Gut 54:764-768

16. Huang JQ, Sridhar S, Chen Y, Hunt RH (1998) Meta-analysis of the relationship between Helicobacter pylori seropositivity and gastric cancer. Gastroenterology 114:1169-1179

17. Brenner H, Arndt V, Stegmaier C, Ziegler H, Rothenbacher D (2004) Is Helicobacter pylori infection a necessary condition for noncardia gastric cancer? Am J Epidemiol 159:252-258

18. Ekstrom AM, Held M, Hansson LE, Engstrand L, Nyren O (2001) Helicobacter pylori in gastric cancer established by CagA immunoblot as a marker of past infection. Gastroenterology 121:784-791

19. Lunet N, Barros H (2006) Helicobacter pylori infection and gastric cancer in developing countries: revisiting the "enigmas". In: Ly A, Khayat D (eds) About cancer in Africa: from epidemiology to biomedical applications and perspectives. INCa, Paris, pp 257-272

20. Weck MN, Gao L, Brenner H (2009) Helicobacter pylori infection and chronic atrophic gastritis: associations according to severity of disease. Epidemiology 20:569-574

21. Lunet N, Pina F, Barros H (2004) Regional trends in Portuguese gastric cancer mortality (1984-1999). Eur J Cancer Prev 13: 271-275 
22. Lunet N, Valbuena C, Carneiro F, Lopes C, Barros H (2006) Antioxidant vitamins and risk of gastric cancer: a case-control study in Portugal. Nutr Cancer 55:71-77

23. Lunet N, Valbuena C, Vieira AL, Lopes C, David L, Carneiro F, Barros H (2007) Fruit and vegetable consumption and gastric cancer by location and histological type: case-control and metaanalysis. Eur J Cancer Prev 16:312-327

24. Ramos E, Lopes C, Barros H (2004) Investigating the effect of nonparticipation using a population-based case-control study on myocardial infarction. Ann Epidemiol 14:437-441

25. Gal DL, Santos AC, Barros H (2005) Leisure-time versus full-day energy expenditure: a cross-sectional study of sedentarism in a Portuguese urban population. BMC Public Health 5:16

26. Estevens J, Fidalgo P, Tendeiro T, Chagas C, Ferra A, Leitao CN, Mira FC (1993) Anti-Helicobacter pylori antibodies prevalence and gastric adenocarcinoma in Portugal: report of a case-control study. Eur J Cancer Prev 2:377-380

27. Hansen S, Melby KK, Aase S, Jellum E, Vollset SE (1999) Helicobacter pylori infection and risk of cardia cancer and noncardia gastric cancer. A nested case-control study. Scand J Gastroenterol 34:353-360

28. Klaamas K, Held M, Wadstrom T, Lipping A, Kurtenkov O (1996) IgG immune response to Helicobacter pylori antigens in patients with gastric cancer as defined by ELISA and immunoblotting. Int J Cancer 67:1-5

29. Kuipers EJ (1999) Review article: exploring the link between Helicobacter pylori and gastric cancer. Aliment Pharmacol Ther 13(Suppl 1):3-11

30. Correa P, Haenszel W, Cuello C, Tannenbaum S, Archer M (1975) A model for gastric cancer epidemiology. Lancet 2:58-60

31. Ohata H, Kitauchi S, Yoshimura N, Mugitani K, Iwane M, Nakamura H, Yoshikawa A, Yanaoka K, Arii K, Tamai H, Shimizu Y, Takeshita T, Mohara O, Ichinose M (2004) Progression of chronic atrophic gastritis associated with Helicobacter pylori infection increases risk of gastric cancer. Int J Cancer 109:138143

32. Weck MN, Stegmaier C, Rothenbacher D, Brenner H (2007) Epidemiology of chronic atrophic gastritis: population-based study among 9,444 older adults from Germany. Aliment Pharmacol Ther 26:879-887

33. Yanaoka K, Oka M, Mukoubayashi C, Yoshimura N, Enomoto S, Iguchi M, Magari H, Utsunomiya H, Tamai H, Arii K, Ohata H, Fujishiro M, Takeshita T, Mohara O, Ichinose M (2008) Cancer high-risk subjects identified by serum pepsinogen tests: outcomes after 10-year follow-up in asymptomatic middle-aged males. Cancer Epidemiol Biomarkers Prev 17:838-845

34. Katsube T, Ogawa K, Hamaguchi K, Murayama M, Konnno S, Shimakawa T, Naritaka Y, Yagawa H, Kajiwara T, Aiba M (2002) Prevalence of Helicobacter pylori in the residual stomach after gastrectomy for gastric cancer. Hepatogastroenterology 49:128-132

35. Kuipers EJ, Pena AS, van Kamp G, Uyterlinde AM, Pals G, Pels NF, Kurz-Pohlmann E, Meuwissen SG (1993) Seroconversion for Helicobacter pylori. Lancet 342:328-331

36. Sasazuki S, Inoue M, Iwasaki M, Otani T, Yamamoto S, Ikeda S, Hanaoka T, Tsugane S (2006) Effect of Helicobacter pylori infection combined with CagA and pepsinogen status on gastric cancer development among Japanese men and women: a nested case-control study. Cancer Epidemiol Biomarkers Prev 15:13411347

37. Siman JH, Engstrand L, Berglund G, Forsgren A, Floren $\mathrm{CH}$ (2007) Helicobacter pylori and CagA seropositivity and its association with gastric and oesophageal carcinoma. Scand J Gastroenterol 42:933-940
38. Mitchell H, English DR, Elliott F, Gengos M, Barrett JH, Giles GG, Forman D (2008) Immunoblotting using multiple antigens is essential to demonstrate the true risk of Helicobacter pylori infection for gastric cancer. Aliment Pharmacol Ther 28:903-910

39. Sorberg M, Engstrand L, Strom M, Jonsson KA, Jorbeck H, Granstrom M (1997) The diagnostic value of enzyme immunoassay and immunoblot in monitoring eradication of Helicobacter pylori. Scand J Infect Dis 29:147-151

40. Romero-Gallo J, Perez-Perez GI, Novick RP, Kamath P, Norbu T, Blaser MJ (2002) Responses of endoscopy patients in Ladakh, India, to Helicobacter pylori whole-cell and Cag A antigens. Clin Diagn Lab Immunol 9:1313-1317

41. Lu CY, Kuo CH, Lo YC, Chuang HY, Yang YC, Wu IC, Yu FJ, Lee YC, Jan CM, Wang WM, Wu DC (2005) The best method of detecting prior Helicobacter pylori infection. World J Gastroenterol 11:5672-5676

42. Rahman SH, Azam MG, Rahman MA, Arfin MS, Alam MM, Bhuiyan TM, Ahmed N, Rahman M, Nahar S, Hassan MS (2008) Non-invasive diagnosis of $H$. pylori infection: evaluation of serological tests with and without current infection marker CIM. World J Gastroenterol 14:1231-1236

43. Veijola L, Oksanen A, Sipponen P, Rautelin H (2008) Evaluation of a commercial immunoblot, Helicoblot 2.1, for diagnosis of Helicobacter pylori infection. Clin Vaccine Immunol 15:17051710

44. Xia HH, Talley NJ (1997) Natural acquisition and spontaneous elimination of Helicobacter pylori infection: clinical implications. Am J Gastroenterol 92:1780-1787

45. Lunet N, Barros H (2003) Helicobacter pylori infection and gastric cancer: facing the enigmas. Int J Cancer 106:953-960

46. Rothenbacher D, Brenner H (2003) Burden of Helicobacter pylori and $H$. pylori-related diseases in developed countries: recent developments and future implications. Microbes Infect 5:693-703

47. Hansson LR, Engstrand L, Nyren O, Lindgren A (1995) Prevalence of Helicobacter pylori infection in subtypes of gastric cancer. Gastroenterology 109:885-888

48. Plummer M, van Doorn LJ, Franceschi S, Kleter B, Canzian F, Vivas J, Lopez G, Colin D, Munoz N, Kato I (2007) Helicobacter pylori cytotoxin-associated genotype and gastric precancerous lesions. J Natl Cancer Inst 99:1328-1334

49. Huang JQ, Zheng GF, Sumanac K, Irvine EJ, Hunt RH (2003) Meta-analysis of the relationship between cagA seropositivity and gastric cancer. Gastroenterology 125:1636-1644

50. Gisbert JP, Blanco M, Benito LM, Pajares JM (2000) Value of quantitative serology for confirmation of Helicobacter pylori eradication: an 18-month follow-up study. Clin Infect Dis 30:976-980

51. Herbrink P, van Doorn LJ (2000) Serological methods for diagnosis of Helicobacter pylori infection and monitoring of eradication therapy. Eur J Clin Microbiol Infect Dis 19:164-173

52. Mitchell HM, Ally R, Wadee A, Wiseman M, Segal I (2002) Major differences in the IgG subclass response to Helicobacter pylori in the first and third worlds. Scand J Gastroenterol 37:517522

53. Campbell DI, Pearce MS, Parker L, Thomas JE, Sullivan PB, Dale A (2004) Immunoglobulin G subclass responses to Heli cobacter pylori vary with age in populations with different levels of risk of gastric carcinoma. Clin Diagn Lab Immunol 11:631633

54. Mbulaiteye SM, Gold BD, Pfeiffer RM, Brubaker GR, Shao J, Biggar RJ, Hisada M (2006) $H$. pylori-infection and antibody immune response in a rural Tanzanian population. Infect Agent Cancer 1:3 
PAPER II

Peleteiro B, Cavaleiro-Pinto M, Barros R, Barros H, Lunet N. Is cardia cancer aetiologically different from distal stomach cancer?

Eur J Cancer Prev. 2011;20(2):96-101. 



\section{Is cardia cancer aetiologically different from distal stomach cancer?

\author{
Bárbara Peleteiro ${ }^{\mathrm{a}, \mathrm{b}}$, Marlene Cavaleiro-Pinto ${ }^{\mathrm{a}}$, Rita Barros ${ }^{\mathrm{c}}$, \\ Henrique Barros ${ }^{a, b}$ and Nuno Lunet ${ }^{a, b}$
}

The coexistence of two aetiologically distinct types of cardia cancer, with distinctive histological characteristics of the neoplastic and nonneoplastic gastric mucosa, may explain the heterogeneous evidence of its association with Helicobacter pylori infection. We compared gastric cardia and noncardia cancers with regard to the frequency of $H$. pylori infection, the histological characteristics of the nonneoplastic gastric mucosa and the tumour histological type. We evaluated 41 cardia and 339 noncardia cancer cases undergoing gastrectomy, and 380 community controls. H. pylori infection and CagA infection status were assessed by enzyme-linked immunosorbent assay and western blot, respectively. Histological characteristics of the neoplastic and nonneoplastic mucosa were obtained from pathology reports. The association between infection and cancers with different location was quantified in a case-control analysis and cardia and noncardia cancers were further compared. No positive relation was found for $\mathrm{H}$. pylori infection, but CagA-positive strains were associated with an increased risk of noncardia cancer (odds ratio $=1.60$, $95 \%$ confidence interval $=1.17-2.18$ ). Twenty-seven $(65.8 \%)$ cardia cancer cases, predominantly of the intestinal type $(66.7 \%)$, had nonneoplastic atrophic

\section{Introduction}

The discovery of Helicobacter pylori (Warren and Marshall, 1983 ) and its recognition as a human carcinogen (IARC Working Group on the Evaluation of Carcinogenic Risks to Humans, 1994) proved to be a key point in the understanding of gastric cancer aetiology. Both cohort and case-control studies show an average three-fold increased risk of distal gastric cancer among the infected, but apparently no positive relation between $H$. pylori infection and cardia cancer. The evidence supporting this lack of association, however, is based on contradictory findings (Dawsey et al., 2002; Huang et al., 1998, 2003). Studies from Western countries support a negative association between $H$. pylori infection and cardia cancer (Enroth et al., 2002; Brenner $e t$ al., 2004; Kato et al., 2004; Nomura et al., 2005; Shin et al., 2005; Kamangar et al., 2006; Knekt et al., 2006), whereas there is a trend towards positive association in studies from Eastern Asia (Kato et al., 2004; Shin et al., 2005; Yang et al., 2006; Kamangar et al., 2007; Suzuki et al., 2007).

0959-8278 (c) 2011 Wolters Kluwer Health | Lippincott Williams \& Wilkins mucosa and $208(61.4 \%)$ noncardia cancers $(56.7 \%$ of the intestinal type). Among the cases occurring in nonatrophic patients, the proportion of cancers of the Laurén's intestinal type was $\mathbf{7 1 . 4 \%}$ for cardia and $54.2 \%$ for noncardia gastric cancers. Cardia and noncardia cancers were similar with regard to the relation with infection, histological type and condition of the nonneoplastic mucosa, supporting the predominance of cardia cancers determined by $\mathrm{H}$. pylori infection in this European high-risk setting. European Journal of Cancer Prevention 20:96-101 (c) 2011 Wolters Kluwer Health | Lippincott Williams \& Wilkins.

European Journal of Cancer Prevention 2011, 20:96-101

Keywords: atrophy, gastric cancer, gastric cardia cancer, Helicobacter pylor

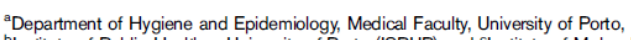
Pathology and Immunology - University of Porto (PATIMUP). Porto, Portug a

Correspondence to Bárbara Peleteiro, MSc (Epi), Serviço de Higiene e Epidemiologia, Faculdade de Medicina da Universidade do Porto, Alameda Professor Hernâni Monteiro, 4200-319 Porto, Portugal Tel: + 351 225513652; fax: + 351 225513653; e-mail: barbarap@med.up.pt

Received 7 June 2010 Accepted 12 November 2010

The cardia is the most proximal part of the stomach, adjacent to the oesophagus, involving the gastroesophageal junction. Tumours described as 'cardia cancers' include a mixture of neoplasms arising from the lower oesophagus and the gastric cardia, to a higher or lesser extent depending on the frequency of oesophageal and gastric adenocarcinomas on the populations under study (Dawsey et al., 2002; Marsman et al., 2005). Different classification systems can be used to make such distinction, accounting for some of the heterogeneity of the results reported earlier (Ekstrom et al., 1999; Dawsey et al., 2002; Corley and Kubo, 2004). Controversy also exists with regard to the type of mucosa present in this area, with the hypothesis that it is the result of a metaplastic lesion caused by reflux (Chandrasoma, 2005) having been challenged (Odze, 2005).

The observation of a positive association with gastric atrophy (Zhang et al., 1999; Ye et al., 2004; Palli et al., 2007), despite no overall relation with $H$. pylori infection, DOI: 10.1097/CE.0b013e3283429e77 
supports the coexistence of two aetiologically distinct types of cardia cancer (Hansen et al., 2007; Derakhshan et al., 2008; Bornschein et al., 2010), one associated with H. pylori-induced atrophic gastritis, aetiologically similar to noncardia cancer, more frequent in populations with higher overall gastric cancer incidence; and the other arising in nonatrophic gastric mucosa, associated with acid/ bile-induced damage to the distal oesophagus, resembling oesophageal adenocarcinoma, and likely to have a higher relative frequency in settings with low gastric cancer risk.

The potential for misclassification of gastric cancer topography brings important challenges to the study of the cardia cancer aetiology, as it is usually impossible to determine the origin of these cancers by examining them grossly or microscopically (Hansen $e t$ al., 2007). However, the hypothesis described above provides a basis for a surrogate definition of two subtypes of gastric cardia cancer, and may be useful for a proper assessment of its aetiology (Hansen et al., 2007).

This comprises a case-control study, in which cardia and noncardia cancers are compared with community controls with regard to the frequency of infection with $\mathrm{H}$. pylori, taking into account the virulence of the infecting strains, and a case-case analysis for the comparison of cardia and noncardia cancers with regard to the histological characteristics of the neoplastic and nonneoplastic mucosa. The latter comparison is stratified according to the infection status of the cases, aiming to provide evidence for the frequency of aetiologically distinct cases of cardia cancer, either resembling distal stomach cancer or oesophageal adenocarcinoma.

\section{Materials and methods}

Cases

From 2001 to 2006, we identified 709 incident cases of gastric adenocarcinoma with no earlier cancer diagnosis (except for skin nonmelanoma) and not having undergone a subtotal gastrectomy for benign conditions. As described earlier (Lunet et al., 2006, 2007), patients were admitted to the surgery wards of the two largest public hospitals, Hospital de São João and Instituto Português de Oncologia Francisco Gentil, both in Porto, providing care to cancer patients in the north of the country. Cancer diagnosis was based on gastrectomy specimens, endoscopic biopsy material or the evaluation of metastasis. A blood sample was collected from each patient and serum was kept frozen at $-20^{\circ} \mathrm{C}$ until analysis.

\section{Controls}

Controls were part of a representative sample of the adult population of Porto (Ramos et al., 2004; Gal et al., 2005). Participants were recruited by random digit dialling using household as the sampling frame, followed by simple random sampling to select one eligible person among permanent residents in each household who was invited to visit our department for interview and blood collection. Participants were eligible for this analysis only if there was no earlier cancer diagnosis (except for skin nonmelanoma). We selected one age-matched $( \pm 5$ years $)$ and sex-matched control per case eligible for the analysis.

\section{Assessment of Helicobacter pylori infection status}

$H$. pylori infection status was assessed using an anti-H. pylori IgG antibody enzyme-linked immunosorbent assay (ELISA anti-H. pylori ELISA, Eurolmmun, Lubeck, Germany) on serum samples. Participants were classified according to the manufacturer's instructions as negative if they had less than $16 \mathrm{RU} / \mathrm{ml}$ antibody concentration, as borderline if their antibody concentration was between 16 and $22 \mathrm{RU} / \mathrm{ml}$ and as positive if the antibody concentration was equal to or greater than $22 \mathrm{RU} / \mathrm{ml}$. For analysis, participants having borderline results were considered infected.

Further testing of $H$. pylori infection status was performed by western blot (Helico Blot 2.1, Genelabs Diagnostics, Singapore). The assay was conducted as proposed by the manufacturer, and the results were interpreted after the recommended criteria for CagA seropositivity: presence of the $116 \mathrm{kD}$ band (CagA) with one or more of the following bands: 89 (VacA); 37; 35; 30 (UreA) and $19.5 \mathrm{kD}$ together.

\section{Assessment of the tumour location}

For each case, tumour location was assessed using the information provided in the pathological report of the resected specimen for patients submitted for gastrectomy. Cardia cancer was defined as a tumour in the cardioesophageal junction, oesophagogastric junction or gastroesophageal junction, according to the criteria from the Union for International Cancer Control (UICC) (Sobin and Wittekind, 2002).

\section{Assessment of the histological characteristics of the} neoplastic and nonneoplastic mucosa of cases

For a more accurate classification of the tumour histological type (Palli et al., 1991; Flucke et al., 2002) and characterization of gastric lesions in the nonneoplastic mucosa, only those cases in which a surgical specimen was available were evaluated. The tumour's histological type was classified according to the Lauren's criteria as intestinal, diffuse or mixed (Lauren, 1965) by a single pathologist who reviewed all pathology reports and reassessed the slides whenever routine information was considered insufficient or inconsistent.

Cases were classified with regard to the characteristics of the nonneoplastic mucosa based on the information available in the surgical specimen pathology reports. In this study, we considered that atrophy was present in individuals having histological evidence of chronic atrophic gastritis regardless of the presence of other gastric lesions. 


\section{Statistical analysis}

This analysis included only those cases in which both the $H$. pylori infection status and the histological characteristics of the neoplastic and nonneoplastic mucosa could be assessed by serology and evaluation of pathology reports, respectively.

A blood sample and a gastrectomy specimen were available for 444 cases, from which 64 had to be excluded because of nonaccurately classifiable tumour location $(n=33)$, unclassifiable histological type $(n=14)$ and no reliable information on histological evidence of chronic atrophic gastritis $(n=17)$. The remaining 380 cases were not significantly different from those excluded, regarding sex ( 60.5 vs. $57.8 \%$ men; $P=0.661$ ), age (median: 64 vs. 66 years; $P=0.584$ ) or education (median number of school years: 4 vs. 4 years; $P=0.988$ ).

Odds ratios (OR) and the corresponding $95 \%$ confidence intervals (95\% CI) were computed by multinomial logistic regression to quantify the association between $H$. pylori infection and gastric cardia and noncardia cancers and by unconditional logistic regression to compare cardia and noncarzdia cancer cases. All analyses were conducted using STATA, version 9.2 (StataCorp LP, College Station, Texas, USA).

\section{Ethics}

The ethics committees of the involved hospitals approved the study, and all participants provided written informed consent.

\section{Results}

\section{Case-control study}

No positive association was observed between $H$. pylori infection and gastric cancer, either for cardia $(\mathrm{OR}=2.06$, $95 \% \mathrm{CI}=0.61-6.96)$ or for noncardia cancers $(\mathrm{OR}=0.94$, 95\% CI $=0.62-1.42)$. Infection with CagA-positive strains was associated with increased risk of noncardia cancer $(\mathrm{OR}=1.60,95 \% \mathrm{CI}=1.17-2.18)$ but not significantly with cardia cancer $(\mathrm{OR}=1.59,95 \% \mathrm{CI}=0.80$ 3.19; Table 1).

\section{Case-case analysis}

The frequency of infection with CagA-positive strain was similar in cardia and noncardia cancers (age-adjusted and sex-adjusted $\mathrm{OR}=0.97,95 \% \mathrm{CI}=0.48-1.97$ )

Approximately two-thirds of the cases classified as H. pylori-infected had nonneoplastic atrophic mucosa. Nearly $60 \%$ of the cardia and noncardia cancers were of the intestinal histological type, regardless of the characteristics of the nonneoplastic mucosa (Table 2). Similar results were observed among participants infected with CagA-positive strains (Table 3).

Among cases classified as $H$. pylori-negative, a similar proportion of both cardia and noncardia cancers had nonneoplastic atrophic mucosa. All cardia and nearly half of noncardia cancers were of the Laurén's intestinal type

Table 2 Comparison between gastric cardia and noncardia cancers with regard to the histological characteristics of the nonneoplastic gastric mucosa and the tumour histological type, according to Helicobacter pylori infection status assessed by enzyme-linked immunosorbent assay (case-case analysis)

\begin{tabular}{|c|c|c|c|}
\hline & $\begin{array}{l}\text { Cardia } \\
n(\%)\end{array}$ & $\begin{array}{c}\text { Noncardia } \\
n(\%)\end{array}$ & $\begin{array}{c}\text { Cardia vs. } \\
\text { noncardia } \\
\text { Adjusted }^{\mathrm{a}} \mathrm{OR} \\
(95 \% \mathrm{Cl})\end{array}$ \\
\hline \multicolumn{4}{|c|}{$\begin{array}{l}\text { Helicobacter pylori-infected subjects } \\
\text { Nonneoplastic gastric mucosa }\end{array}$} \\
\hline Nonatrophic & $13(34.2)$ & $106(36.9)$ & 1 \\
\hline Atrophic & $25(65.8)$ & $181(63.1)$ & $1.06(0.51-2.19)$ \\
\hline \multicolumn{4}{|c|}{ Tumour histological type } \\
\hline \multicolumn{4}{|c|}{ Cases with nonatrophic nonneoplastic mucosa } \\
\hline Intestinal & $9(69.2)$ & $60(56.6)$ & 1 \\
\hline Diffuse/mixed & $4(30.8)$ & $46(43.4)$ & $0.67(0.18-2.50)$ \\
\hline \multicolumn{4}{|c|}{ Cases with atrophic nonneoplastic mucosa } \\
\hline Intestinal & $16(64.0)$ & $103(56.9)$ & 1 \\
\hline Diffuse/mixed & $9(36.0)$ & $78(43.1)$ & $0.79(0.33-1.89)$ \\
\hline \multicolumn{4}{|c|}{ Helicobacter pylori-uninfected subjects } \\
\hline \multicolumn{4}{|c|}{ Nonneoplastic gastric mucosa } \\
\hline Nonatrophic & 1 (зз.3) & $25(48.1)$ & 1 \\
\hline Atrophic & $2(66.7)$ & $27(51.9)$ & $1.41(0.10-20.07)$ \\
\hline \multicolumn{4}{|c|}{ Tumour histological type } \\
\hline \multicolumn{4}{|c|}{ Cases with nonatrophic nonneoplastic mucosa } \\
\hline Intestinal & $1(100.0)$ & $11(44.0)$ & 1 \\
\hline Diffuse/mixed & $0(0.0)$ & $14(56.0)$ & - \\
\hline \multicolumn{4}{|c|}{ Cases with atrophic nonneoplastic mucosa } \\
\hline Intestinal & $2(100.0)$ & $15(55.6)$ & 1 \\
\hline Diffuse/mixed & $0(0.0)$ & $12(44.4)$ & - \\
\hline
\end{tabular}

$\mathrm{Cl}$, confidence interval; OR, odds ratio.

Age-adjusted (categorical: $18-39,40-54,55-69, \geq 70$ years) and sex-adjusted.

Table 1 Association between Helicobacter pylori infection and CagA strains, and cardia and noncardia cancers (case-control study)

\begin{tabular}{|c|c|c|c|c|c|}
\hline & \multirow{2}{*}{$\frac{\text { Controls }}{n(\%)}$} & \multicolumn{2}{|c|}{ Cardia } & \multicolumn{2}{|c|}{ Noncardia } \\
\hline & & $n(\%)$ & Adjusted $^{\mathrm{a}}$ OR $(95 \% \mathrm{Cl})$ & $n(\%)$ & Adjusted $^{a}$ OR (95\% Cl) \\
\hline \multicolumn{6}{|c|}{ Helicobacter pylori infection status } \\
\hline Negative & $55(14.5)$ & $3(7.3)$ & 1 & $52(15.3)$ & 1 \\
\hline Positive & $325(85.5)$ & $38(92.7)$ & $2.06(0.61-6.96)$ & $287(84.7)$ & $0.94(0.62-1.42)$ \\
\hline \multicolumn{6}{|c|}{ CagA infection status } \\
\hline Negative & $160(42.1)$ & $13(31.7)$ & 1 & 107 (31.6) & 1 \\
\hline Positive & $220(57.9)$ & $28(68.3)$ & $1.59(0.80-3.19)$ & $232(68.4)$ & $1.60(1.17-2.18)$ \\
\hline
\end{tabular}

$\mathrm{Cl}$, confidence interval: $\mathrm{OR}$, odds ratio.

${ }^{a}$ Age-adjusted (categorical: $18-39,40-54,55-69, \geq 70$ years) and sex-adjusted. 
Table 3 Comparison between gastric cardia and noncardia cancers with regard to the histological characteristics of the nonneoplastic gastric mucosa and the tumour histological type.

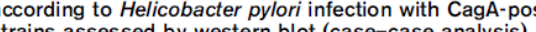
Cardia Noncardia Cardia vs. noncardia

Subjects infected with CagA positive strains Nonneoplastic gastric mucos

$\begin{array}{lll}\text { Nonatrophic } & 8(28.6) & 90(38.8)\end{array}$

Atrophic $20(28.6)$

Tumour histological type

Cases with nonatrophic nonneoplastic mucos

Intestinal $\quad 4(50.0) \quad 47(52.2)$

Diffuse/mixed $4(50.0) \quad 43(47.8)$

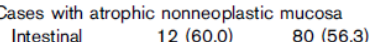

$\begin{array}{lrr}\text { Intestinal } & 12(60.0) & 80(56.3) \\ \text { Diffuse/mixed } & 8(40.0) & 62(43.7)\end{array}$

$\begin{array}{ccc}\text { Diffuse/mixed } & 8(40.0) & 62(43.7) \\ & \end{array}$

Nonneoplastic gastric mucosa

$\begin{array}{lll}\text { Nonatrophic } & 6(46.2) & 41(38.3)\end{array}$

$\begin{array}{lll}\text { Atrophic } & 7(53.8) & 66(61.7)\end{array}$

Tumour histological type

Cases with nonatrophic nonneoplastic mucosa

$\begin{array}{lll}\text { Intestinal } & 6(100.0) & 24(58.5)\end{array}$

Diffuse/mixed $\quad 0(0.0) \quad 17(4.5)$

Cases with atrophic nonneoplastic mucosa

Intestinal $\quad 6(85.7) \quad 38(57.6)$

$\begin{array}{llll}\text { Diffuse/mixed } & 1(14.3) & 28(42.4) & 1 \\ & & 0.18(0.02-1.8\end{array}$

$\mathrm{Cl}$, confidence interval; OR, odds ratio.

a Age-adjusted (categorical: 18-39, 40-54, 55-69, $\geq 70$ years) and sex-adjusted.

for cases occurring in nonatrophic patients. The same trend was found for cases presenting nonneoplastic atrophic mucosa (Table 2). Similar results were observed among participants not infected with $H$. pylori or infected with CagA-negative strains (Table 3 ).

\section{Discussion}

The infection with $H$. pylori CagA-positive strains was associated with an increased risk of both cardia and noncardia cancers. Two-thirds of the gastric cardia cancer cases observed in this high-gastric cancer risk setting had nonneoplastic atrophic mucosa, and most of them were of the intestinal histological type, similar to what was observed for noncardia cancers. Among the cases occurring in noninfected patients, cardia cancers were predominantly of the intestinal type whereas only half of noncardia cancers presented with Lauren's intestinal type, regardless of the characteristics of the nonneoplastic mucosa.

The interpretation of these results, although limited by the small sample size, is driven by a sound and welldocumented hypothesis. As in other high-risk settings, we found no association between $H$. pylori infection and gastric cancer. The high prevalence of infection observed in the general Portuguese population contributes to weak associations between infection and gastric cancer, namely at distal locations (Huang et al., 1998; Peleteiro et al., 2010). In the general population the prevalence of infection increases with age (Lunet and Barros, 2003) and the infection tends to persist during adulthood, while cancer patients are more likely to have been infected early in life and to lack evidence of infection as cancer progresses (Hansson $e t$ al., 1995). In high-prevalence settings, the difference between cancer cases and controls with regard to the proportion of participants infected later in life tends to be clearer and the potential for underestimation of the association between infection and cancer in case-control designs is even higher (Peleteiro et al., 2010). In our study, however, infection with CagA-positive strains was associated with an increased risk of gastric cancer, in accordance with earlier studies reporting that CagA antibodies reflect past infection more accurately than surface antibodies detected by conventional IgG ELISA (Ekstrom et al., 2001).

The positive association between infection and gastric cardia cancer observed in our study, although divergent from the mainstream opinion that there is no such relation (Huang et al., 1998, 2003; Helicobacter and Cancer Collaborative Group, 2001), is consistent with the results obtained in samples from populations with high risk for gastric cancer and prevalence of infection (Pinto et al., 2009), and probably reflects the predominance of the gastric cardia cancer subtype arising from $H$. pylori-induced atrophic gastritis. These tumours are expected to be similar to the noncardia cancers with regard to the relation with infection and histological type, which is also supported by our results. Among $H$. pylori-infected cases, a $1: 1$ ratio of intestinal and diffuse/mixed histological subtypes was observed for both cardia and noncardia cancers. However, unlike noncardia cancers, the cardia cases occurring in noninfected patients had a much higher proportion of intestinal versus diffuse/mixed histological subtype. This predominant intestinal histological subtype is similar to that reported in oesophageal adenocarcinoma (Reid $e t$ al., 2010) and supports an aetiological resemblance with the latter. Taking into account that this is the first study from a European high-risk setting exploring the similarities between cardia and distal stomach cancers using the characteristics of the nonneoplastic mucosa to distinguish subtypes of cardia cancer that are aetiologically different, our results are consistent with the three earlier reports on this subject (Hansen et al., 2007; Derakhshan et al., 2008; Bornschein et al., 2010).

The use of different definitions of gastric cardia cance across studies may account for heterogeneous results on the relation between $H$. pylori infection and cancer (Ekstrom et al., 1999; Dawsey et al., 2002; Corley and Kubo, 2004). Our study and those by Hansen et al. (2007) and Derakhshan $e t$ al. (2008) relied on similar criteria to define tumour location (Percy et al., 1990), while Bornschein et al. (2010) applied a different set of criteria (Siewert and Stein, 1998) to define 'proximal' tumours. The latter, however, excluded the tumours with a more proximal origin and included those located in the fundus or in the proximal third of the corpus, which may have contributed to a higher homogeneity between the proximal and distal tumours with regard to $H$. pylori infection, presence of atrophy in the nonneoplastic mucosa and tumour histological type. 
The exclusion of cases not submitted for gastrectomy, as all histological characteristics were assessed in surgical specimens, precludes the generalization of our results to all gastric cancer cases. As diffuse cancers have a worse prognosis than those of the Lauren's intestinal type (Adachi et al., 2000; Tahara, 2004), this selection bias may have contributed to an oversampling of the latter, among which the presence of an atrophic nonneoplastic mucosa is more likely (Correa et al., 1975).

Tumours located at the cardia were shown to have a poorer 5-year relative survival than those with more distal locations $(7.5 \%$ in cardia vs. $8.5 \%$ in fundus vs. $12.3 \%$ in corpus vs. $18.6 \%$ in antrum vs. $21.1 \%$ in pylorus; Verdecchia et al., 2004). The aetiological heterogeneity of gastric cardia cancer supported by our results may find a parallel in prognosis and have consequences in the management of gastric cardia cancer patients, but these specific issues need to be addressed in future research.

In conclusion, our findings support the existence of two aetiologically different types of gastric cardia cancer, one of which is positively associated with $H$. pylori infection and therefore more frequent in high-risk settings. These results contribute to explaining the heterogeneous results across high and low gastric cancer risk settings with regard to the association with $H$. pylori infection, and should be taken into account when assessing the impact of preventive measures to tackle the consequences of $H$. pylori infection.

\section{Acknowledgement}

The authors gratefully acknowledge the Grants received from Fundação para a Ciência e Tecnologia (PTDC/SAUESA/71517/2006, POCI/SAU-ESP/56126/2004, POCI/SAUESP/61685/2004, POCTI/ESP/35769/99, PRAXIS/2/2.1/SAU/ 1332/1995, SFRH/BD/36818/2007)

\section{References}

Adachi Y, Yasuda K, Inomata M, Sato K, Shiraishi N, Kitano S (2000). Pathology and prognosis of gastric carcinoma: well versus poorly differentiated type. Cancer 89:1418-1424.

Bornschein J, Selgrad M, Warnecke M, Kuester D, Wex T, Malfertheiner P (2010). H. pylori infection is a key risk factor for proximal gastric cancer. Dig Dis So 55:3124-3131.

Brenner H, Arndt V, Stegmaier C, Ziegler H, Rothenbacher D (2004). Is Helicobacter pylori infection a necessary condition for noncardia gastric cancer? Am J Epidemiol 159:252-258.

Chandrasoma $\mathrm{P}$ (2005). Controversies of the cardiac mucosa and Barrett's oesophagus. Histopathology 46:361-373.

Corley DA, Kubo A (2004). Influence of site classification on cancer incidence rates: an analysis of gastric cardia carcinomas. I Natl Cancer Inst 96 : 1383-1387.

Correa P, Haenszel W, Cuello C, Tannenbaum S, Archer M (1975). A model for gastric cancer epidemiology. Lancet 2:58-60.

Dawsey SM, Mark SD, Taylor PR, Limburg PJ (2002). Gastric cancer and H pylori. Gut 51:457-458.

Derakhshan MH, Malekzadeh R, Watabe H, Yazdanbod A, Fyfe V, Kazemi A, et al. (2008). Combination of gastric atrophy, reflux symptoms and histological subtype indicates two distinct aetiologies of gastric cardia cancer. Gu 57:298-305.

Ekstrom AM, Held M, Hansson LE, Engstrand L, Nyren O (2001). Helicobacter pylori in gastric cancer established by CagA immunoblot as a marker of pas infection. Gastroenterology 121:784-791.
Ekstrom AM, Signorello LB, Hansson LE, Bergstrom R, Lindgren A, Nyren O (1999). Evaluating gastric cancer misclassification: a potential explanatio for the rise in cardia cancer incidence. I Nat/ Cancer Inst 91:786-790.

Enroth H, Kraaz W, Rohan T, Nyren O, Engstrand L (2002). Does the method of Helicobacter pylori detection influence the association with gastric cancer
(a) risk? Scand J Gastroenterol 37:884-890.

Flucke U, Monig SP, Baldus SE, Zirbes TK, Bollschweiler E, Thiele J, et al. (2002). Differences between biopsy- or specimen-related Lauren and World Health Organization classification in gastric cancer. World J Surg 26:137-140.

Gal DL, Santos AC, Barros H (2005). Leisure-time versus full-day energy expenditure: a cross-sectional study of sedentarism in a Portuguese urban population. BMC Public Health 5:16.

Hansen S, Vollset SE, Derakhshan MH, Fyfe V, Melby KK, Aase S, et al. (2007). Two distinct aetiologies of cardia cancer; evidence from premorbid serological markers of gastric atrophy and Helicobacter pylori status. Gu 56:918-925.

Hansson LR, Engstrand L, Nyren O, Lindgren A (1995). Prevalence of Helicobacter pylori infection in subtypes of gastric cancer. Gastroenterology 109:885-888.

Helicobacter and Cancer Collaborative Group (2001). Gastric cancer and Helicobacter pylori: a combined analysis of 12 case control studies nested within prospective cohorts. Gut 49:347-353.

Huang JQ, Sridhar S, Chen Y, Hunt RH (1998). Meta-analysis of the relationship between Helicobacter pylori seropositivity and gastric cancer. Gastroenterology 114:1169-1179.

Huang JQ, Zheng GF, Sumanac K, Irvine El, Hunt RH (2003). Meta-analysis of the relationship between $\mathrm{cag}^{\mathrm{A}}$ seropositivity and gastric cancer. Gastroenterology 125:1636-1644.

IARC Working Group on the Evaluation of Carcinogenic Risks to Humans (1994). Schistosomes liver flukes and Helicobacter pylori. Vol 61. Lyon: IARC Monogr Eval Carcinog Risks Hum .

Kamangar F Dawsey SM, Blaser MJ, Perez-Pez GI, Pietinen P, Newschaffer OJ,

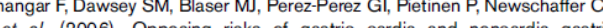
et al. (2006). Opposing risks of gastric cardia and noncardia gastric Cancer Inst 98:1445-1452.

Kamangar F, Qiao YL, Blaser MJ, Sun XD, Katki H, Fan JH, et al. (2007). Helicobacter pylori and oesophageal and gastric cancers in a prospective study in China. Br J Cancer 96:172-176.

Kato M, Asaka M, Shimizu Y, Nobuta A, Takeda H, Sugiyama T (2004) Relationship between Helicobacter pylori infection and the prevalence, site and histological type of gastric cancer. Aliment Pharmacol Ther 20 (Suppl 1) 85-89.

Knekt P, Teppo L, Aromaa A, Rissanen H, Kosunen TU (2006). Helicobacter pylori IgA and IgG antibodies, serum pepsinogen I and the risk of gastric cancer: changes in the risk with extended follow-up period. Int $J$ Cancer 119:702-705

Lauren $P$ (1965). The two histological main types of gastric carcinoma: diffuse and so-called intestinal-type carcinoma an attempt at a histo-clinical classification. Acta Pathol Microbiol Scand 64:31-49.

Lunet N, Barros $\mathrm{H}$ (2003). Helicobacter pylori infection and gastric cancer: facing the enigmas. Int J Cancer 106:953-960.

unet N, Valbuena C, Carneiro F, Lopes C, Barros H (2006). Antioxidant vitamin and risk of gastric cancer: a case-control study in Portugal. Nutr Cancer 55:71-77.

Lunet N, Valbuena C, Vieira AL, Lopes C, David L, Carneiro F, et al. (2007). Fruit and vegetable consumption and gastric cancer by location and histological type: case-control and meta-analysis. Eur J Cancer Prev 16:312-327.

Marsman WA, Tytgat GN, Ten Kate FJ, Van Lanschot JJ (2005). Differences and similarities of adenocarcinomas of the esophagus and esophagogastric junction. J Surg Onco/ 92:160-168.

Nomura AM, Kolonel LN, Miki K, Stemmemann GN, Wilkens LR, Goodman MT, et al (2005). Heli, Mkeri, pepsinogen, and gatric adenocarcin in Hawaii. I Infect Dis 191:2075-2081.

Odze RD (2005). Unraveling the mystery of the gastroesophageal junction: a pathologist's perspective. Am J Gastroenterol 100:1853-1867.

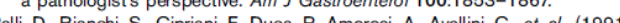
R, Blanchi S, Cipriani F, Duca P, Amorosi A, Avellini C, et al. (1991). Reproducibility of histologic classification of gastric cancer. $\mathrm{Br} J$ Cancer
$63: 765-768$.

Palli D, Masala G, Del Giudice G, Plebani M, Basso D, Berti D, et al. (2007). CagA + Helicobacter pylori infection and gastric cancer risk in the EPIC

Peleteiro B, Lunet N, Barros R, La Vecchia C, Barros H (2010). Factors contributing to the underestimation of Helicobacter pylori-associated gastric cancer risk in a high-prevalence population. Cancer Causes Control 21:1257-1264. 
Percy C, Van Holten V, Mair C, editors. (1990). International classification of disease. 2nd ed. Geneva: World Health Organization.

Pinto MC, Peleteiro B, Lunet N (2009). Helicobacter pylori infection and gastric cardia cancer: systematic review and meta-analysis. Eur J Epidemio/ 24:42. Ramos E, Lopes C, Barros H (2004). Investigating the effect of nonparticipation using a population-based case-control study on myocardial infarction. Ann Epidemiol 14:437-441.

Reid BJ, Li X, Galipeau PC, Vaughan TL (2010). Barrett's oesophagus and oesophageal adenocarcinoma: time for a new synthesis. Nat Rev Cancer 10:87-101.

Shin A, Shin HR, Kang D, Park SK, Kim CS, Yoo KY (2005). A nested case control study of the association of Helicobacter pylori infection with gastric adenocarcinoma in Korea. Br J Cancer 92:1273-1275.

Siewert JR, Stein HJ (1998). Classification of adenocarcinoma of the oesophagogastric junction. $B r J$ Surg 85:1457-1459.

Sobin LH, Wittekind C, editors. (2002). UICC, TNM classification of malignan tumors. New York: Wiley-Liss.

, Cullings H, Fujwara S, Hattori N, Matsuura S, Hakoda M, et al. (2007).

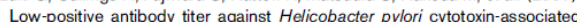
gene A (CagA) may predict future gastric cancer better than simple seropositivity against $H$. pylori CagA or against $H$. pylori. Cancer Epidemiol Biomarkers Prev 16:1224-1228.

Tahara $E$ (2004). Genetic pathways of two types of gastric cancer. IARC Sci Publ $327-349$

erdecchia A, Corazziari I, Gatta G, Lisi D, Faivre J, Forman D (2004). Explaining gastric cancer
109:737-741.

Warren JR, Marshall BJ (1983). Unidentified curved bacilli on gastric epithelium in

active chronic gastritis. Lancet 1:1273-1275.
Yang KC, Chu A, Liao CS, Lin YM, Wang GM (2006). Evaluation of the role of H. pylori infection in pathogenesis of gastric cancer by immunoblot assay. World I Gastroenterol 12:7029-7032

Ye W, Held M, Lagergren J, Engstrand L, Blot WJ, McLaughlin JK, et al. (2004). Helicobacter pylori infection and gastric atrophy: risk of adenocarcinoma and squamous-cell carcinoma of the esophagus and adenocarcinoma of the

Zhang ZF, Kurtz RC, Klimstra DS, Yu GP, Sun M, Harlap S, et al. (1999) Helicobacter pylori infection on the risk of stomach cancer and chronic 
Peleteiro B, Lopes C, Figueiredo C, Lunet N. Salt intake and gastric cancer risk according to Helicobacter pylori infection, smoking, tumour site and histological type. Br J Cancer. 2011;104(1):198-207. 



\section{Salt intake and gastric cancer risk according to Helicobacter pylori infection, smoking, tumour site and histological type}

B Peleteiro*, ${ }^{*, 2}$, C Lopes ${ }^{1,2}$, C Figueiredo ${ }^{3,4}$ and $\mathbf{N}$ Lunet $^{1,2}$

'Department of Hygiene and Epidemiology, Faculty of Medicine, University of Porto, Porto, Portugal; ${ }^{2}$ Institute of Public Health, University of Porto (ISPUP), Porto, Portugal; Institute of Molecular Pathology and Immunology, University of Porto (IPATIMUP), Porto, Portugal; ${ }^{4}$ Department of Pathology, Faculty of Medicine, University of Porto, Porto, Portugal

BACKGROUND: Although salt intake is considered a probable risk factor for gastric cancer, relevant studies have provided heterogeneous results, and the magnitude of the association has not been accurately quantified.

METHODS: To quantify gastric cancer risk in relation to dietary salt exposure according to Helicobacter pylori infection status and virulence, smoking, tumour site, and histological type, we evaluated 422 gastric cancer cases and 649 community controls. Salt exposure was estimated in the year before the onset of symptoms through: sodium intake (estimated by a food frequency questionnaire (FFQ)); main food items/groups contributing to dietary sodium intake; visual analogical scale for salt intake preference; use of table salt; and duration of refrigerator ownership.

RESULTS: Comparing subjects with the highest with those with the lowest salt exposure (3rd vs I st third), sodium intake (OR=2.0I, $95 \% \mathrm{Cl}: 1.16-3.46)$, consumption of food items with high contribution to sodium intake $(\mathrm{OR}=2.54,95 \% \mathrm{Cl}: 1.56-4.14)$ and salt intake evaluated by visual analogical scale $(\mathrm{OR}=1.83,95 \% \mathrm{Cl}$ : 1.28-2.63) were associated with an increased gastric cancer risk. Subjects owning a refrigerator for $>50$ years had a lower risk for gastric cancer $(O R=0.28,95 \% \mathrm{Cl}: 0.14-0.57)$. These associations were observed regardless of $\mathrm{H}$. pylori infection status and virulence, smoking, tumour site or histological type. CONCLUSION: Our results support the view that salt intake is an important dietary risk factor for gastric cancer, and confirms the evidence of no differences in risk according to $\mathrm{H}$. pylor infection and virulence, smoking, tumour site and histological type. British Joumal of Cancer (201 I) I 04, I98-207. doi:I0.1038/s.bjc.6605993 www.bjcancer.com

Published online 16 November 2010

(c) 2011 Cancer Research UK

Keywords: stomach neoplasms; salt intake; smoking; Helicobacter pylor; tumour site; histological type

The decline in gastric cancer mortality (Coleman et al, 1993) has primarily been attributed to a more frequent consumption of fresh products, together with a decrease of salt in food preservation (Howson et al, 1986). In 2007, salt and salted/salty foods were classified as probable risk factors for gastric cancer (World Cancer However, the available evidence is mixed, largely because of the complexity of evaluating salt intake (Dias-Neto et al, 2010), but it may also reflect aetiological differences between gastric cancer subtypes, or potential effect modification not accounted for in the analyses. Few studies presented subgroup analyses according to histological type, although a greater influence of environmental factors on the intestinal than the diffuse type has been suggested (Lunet et al, 2007; Ladeiras-Lopes et differential association between salt intake and gastric cancers with different topographies may occur, as observed for Helicobacter pylor infection (Huang et al, 1998; Helicobacter and Cancer Collaborative Group, 2001). Also, a potential synergistic effect of salt and $H$. pylori has been described (Shikata et al, 2006), as high dietary salt intake may enhance the deleterious effects of infection (Fox et al, 1999; Loh et al, 2007). Smokers may have a higher

*Correspondence: Dr B Peleteiro; E-mail: barbarap@med.up.pt Received 4 August 2010; revised 8 October 2010; accepted 19 October 2010; published online 16 November 2010 average salt consumption (Chen et al, 2002; van den Brandt et al, 2003; Shikata et al, 2006), possibly potentiating both the above detrimental effects (Tatematsu et al, 1975; Charnley and Tannenbaum, 1985).

Therefore, we aimed to quantify the association between dietary salt exposure, assessed by different methods, and gastric cancer, according to $H$. pylori infection, smoking, tumour site and histological type.

\section{MATERIALS AND METHODS}

We conducted a case-control study of incident cases of gastric adenocarcinoma admitted to the surgery wards of the two major public hospitals for cancer patients in the North of Portugal (Hospital de S. João and Instituto Português de Oncologia Francisco Gentil, both in Porto), with appropriate community controls selected among Porto dwellers. From June 2001 to December 2006, we evaluated 709 incident cases of gastric adenocarcinoma. As previously described (Lunet et al, 2006), patients were admitted to the surgery wards and the interview took place during in-hospital stay, shortly after admission, mostly before surgical treatment. Subjects were eligible if there was no previous cancer diagnosis and no sub-total gastrectomy for benign conditions. Cancer was diagnosed according to the routine 

single experienced pathologist reviewed all pathology reports, and slides were reassessed by three pathologists whenever routine information was considered insufficient or inconsistent, allowing reclassification according to the Laurén criteria. Anatomic location was classified following image or pathology descriptions, as cardia (defined as cardioesophageal junction, oesophagogastric junction and gastroesophageal junction) (Sobin and Wittekind, 2002) or non-cardia (all other specified sites)

Controls were part of a representative sample of the adult population of Porto. As previously described in detail (Ramos et al, 2004; Gal et al, 2005), participants were recruited by random digit dialling using households as the sampling frame, followed by simple random sampling to select one eligible person among permanent residents in each household who was invited to visit permanent residents in each household who was invited to visit
our department for interview. The overall sample comprised 2485 community controls, aged $18-92$ years, corresponding to a participation proportion of $70 \%$. Subjects were eligible for this analysis if there was no previous cancer diagnosis.

Trained interviewers inquired both cases and controls using a structured questionnaire covering demographic, social, behavioural and medical characteristics. To assess cognitive function, all individuals aged $>64$ years had a Mini Mental State Examination, which resulted in the exclusion of 40 cases and 20 controls scoring $<18$ (Murden et al, 1991). Dietary habits were recorded using a semiquantitative food frequency questionnaire $(\mathrm{FFQ})$ comprising 82 food items/groups or beverage categories, previously validated (Lopes, 2000; Lopes et al, 2007), for the previous year, or the year (Lopes, 2000; Lopes et al, 2007), for the previous year, or the year
before onset of symptoms for cases. A total of 31 cases declared to have changed their food intake $\geqslant 12$ months before interview because of gastrointestinal symptoms, and were excluded from this analysis. Cases and controls who had modified their habits during the previous year because of any other previous condition were not excluded, but were asked to recall dietary intake in the year before the change.

A blood sample was drawn and serum was kept frozen at $-20^{\circ} \mathrm{C}$, as previously described (Peleteiro et al, 2010). AntiH. pylori serum IgG titres were quantified by ELISA (Pyloriset EIAG III (IgG); Orion Diagnostica, Espoo, Finland). Participants were classified as negative if they had $<16 \mathrm{RU} \mathrm{ml}^{-1}$, as borderline if their antibody concentration was between 16 and $22 \mathrm{RU} \mathrm{ml}^{-1}$ and as positive if this was $\geqslant 22 \mathrm{RU} \mathrm{ml}^{-1}$, according to the manufacturer's instructions. For analysis, subjects with borderline IgG titres were classified as infected. Further testing of $H$. pylori infection status was performed by western blot (Helico Blot 2.1; Genelabs Diagnostics, Singapore) in a randomly selected subsample of cases $(n=406)$ and controls $(n=255)$, according to the prevalence of $H$. pylori infection in each of these groups and by age strata $(18-39,40-54,55-70$ and $>70$ years), as determined by strata $(18-39,40-54,55-70$ and $>70$ years), as determined by
ELISA. The assay followed the manufacturer's instructions, and the results the recommended criteria for $H$. pylori seropositivity: (1) presence of the $116 \mathrm{kD}$ band (CagA) with one or more of the following bands: $89 \mathrm{kD}$ (VacA), 37,35 or $30 \mathrm{kD}$ (UreA) and $19.5 \mathrm{kD}$ together, or with current infection marker; (2) presence of any band at 89,37 or $35 \mathrm{kD}$, with or without current infection marker; and (3) presence of both 30 and $19.5 \mathrm{kD}$ bands, with or without and (3) presence of both 30 and $19.5 \mathrm{kD}$ bands, with or without
current infection marker. The presence of the CagA band was also current infection marker. The presence of the CagA band was also
considered to define infection, regardless of the remaining criteria. For analysis, $H$. pylori infection status was defined according to the results of the ELISA test performed in all participants, and subjects were classified as $H$. pylori negative or $H$. pylori positive. To define $H$. pylori virulence status, the results $H$. pylori positive. To define $H$. pylori virulence status, the results
from ELISA and western blot analyses were used. A subject was classified as $H$. pylori negative if tested negative by both tests, or $H$. pylori positive if tested positive by any of the methods. CagA

infection status was determined by the presence of the CagA band in the western blot evaluation, and $H$. pylori-positive subjects were divided into CagA negative and CagA positive. Information was recorded on smoking habits, and participants were classified as never smokers (those who never smoked) or ever smokers (of any amount of cigarettes).

We used different approaches to evaluate salt intake. First, we considered the sodium intake estimated using the FFQ, considering the food's intrinsic sodium content plus an estimate of added salt during cooking, taking into account the specific contribution of the different food items/groups. The database used was the Food Processor Plus software (1997; ESHA Research, Salem, OR, USA), which has been adapted to traditional Portuguese food and dishes presented in the Portuguese table of food composition (Ferreira and Graça, 1985). Second, we used information on the main food items or food groups contributing to the dietary sodium intake, according to a previous survey also conducted in the North of Portugal (Lopes et al, 2006), namely grains, cereals and potatoes $(31.2 \%)$, particularly 'rice, pasta and potatoes' $(14.7 \%)$ and bread (14.0\%); also, 'meat, meat products and offals' (16.6\%), 'vegetable soup' $(15.8 \%)$, fish $(12.8 \%)$ and cheese $(6.7 \%)$. The consumption of these salty foods was estimated by adding up the amounts of each single item or group consumed per day. For analysis, the tertiles of sodium or salty foods intake observed in the controls were used as cutoffs to define groups of exposure. Dietary salt intake was also estimated through a $10-\mathrm{cm}$ (3.94 inches) visual analogical scale limited by the expressions 'without salt' and 'salty', on the left and right sides of the rule, respectively. The tertiles observed in the controls were used as cutoffs to classify each subject regarding salt intake using this method.

Use of table salt was assessed by the question 'Do you add salt to already seasoned food, at the table?' The answer options were 'never', 'sometimes', 'most times' and 'always', and the latter three were further grouped for analysis. Subjects were asked if they had refrigerator at home, and for how many years. Duration of refrigerator ownership was categorised into $<25$ (including subjects who never owned a refrigerator), $25-50$ and $>50$ years (including life-long ownership, regardless of their age).

Although all participants were asked to fill the FFQ, more specific questions regarding salt intake, namely the visual analogical scale, use of table salt and refrigerator ownership, were only performed to all cases and a subsample of controls. Data were available for 422 cases and 649 controls. No significant differences were found between subjects included and excluded from these analyses regarding gender (proportion of men: cases, $60.7 \mathrm{vs}$ analyses regarding gender (proportion of men: cases, 60.7 vs
$59.1 \%, P=0.687$; controls, 38.1 vs $38.0 \%, P=0.973$ ). Compared with subjects with incomplete information, those included were younger (median age: cases, 62 vs 69 years, $P<0.001$; controls, 51 vs 54 years, $P<0.001$ ) and more educated among controls (proportion of subjects with $>9$ schooling years: cases, $5.7 \mathrm{vs}$ $5.1 \%, P=0.726$; controls: 45.0 vs $36.9 \%, P<0.001)$ than the $5.1 \%, P=0.7$
excluded.

Statistical analysis

The association between salt consumption and gastric cancer was quantified using crude and gender-, age-, education-, smoking-, $H$ pylori infection- and total energy intake-adjusted odds ratios (ORs) and the corresponding $95 \%$ confidence intervals (95\% CIs), computed by unconditional logistic regression. Stratified analyses were performed according to $H$. pylori infection and virulence of the infecting strains, smoking status, tumour site and histological type. A potential effect modification by $H$. pylori or smoking was assessed by including interaction terms in the regression models, for infection status (negative or positive), virulence of the infecting strains ( $H$. pylori negative, CagA negative or CagA positive) and smoking status (never or ever). In addition to the comparisons with the control group, ORs and $95 \%$ CIs were computed by 
unconditional logistic regression to compare gastric cancer cases according to tumour site (non-cardia $v s$ cardia) and histologica type (intestinal $v s$ diffuse). STATA, version 9.2 (StatCorp LP, College Station, TX, USA), was used for all the analyses.

The ethics committees of involved hospitals approved the study, and all participants provided written informed consent.

\section{RESULTS}

Most cancers were located in the non-cardia region (86.5\%) with histological type classified as intestinal $(64.3 \%)$. The prevalence of H. pylori infection was $85.8 \%$ in cases and $85.0 \%$ in controls, as determined by ELISA, raised to $91.4 \%$ in cases and controls when western blot results are also taken into account. Among the infected, infection with CagA-positive strains was more frequent in cases $(95.1 \%)$ than in controls $(71.2 \%)$. The proportion of ever smokers was $43.1 \%$ among cases and $46.2 \%$ among controls.

The median sodium intake from FFQ was higher for cases than controls (3531.1 vs $3474.1 \mathrm{mg} \mathrm{day}^{-1}$ ), as well as the median number of daily servings of food items with the highest contribution to sodium intake ( $7.8 v s 7.2$ servings per day), and the median salt consumption by visual scale ( 50 vs $45 \mathrm{~mm}$ ). Among cases, $13.0 \%$ declared never using table salt, in comparison with $10.6 \%$ of controls. In comparison with $60.1 \%$ of controls, $34.8 \%$ of case reported living in a house with a refrigerator for $>50$ years.

Risk was higher in participants with the highest salt exposures (3rd $v s$ 1st third), estimated through sodium intake $(\mathrm{OR}=2.01$; $95 \%$ CI: $1.16-3.46$ ), consumption of food items with the highest contribution to sodium intake ( $\mathrm{OR}=2.54 ; 95 \% \mathrm{CI}: 1.56-4.14)$ and dietary salt intake evaluated by a visual scale $(O R=1.83 ; 95 \%$ CI: $1.28-2.63)$. No significant association was found with frequen use of table salt $(\mathrm{OR}=1.35,95 \% \mathrm{CI}: 0.85-2.15)$. Subjects owning a refrigerator for a longer time had a lower gastric cancer risk ( $>50$ $v s<25$ years, $\mathrm{OR}=0.28,95 \%$ CI: $0.14-0.57$; Table 1 ).
Despite the suggestion of a stronger association with salt exposure among the $H$. pylori infected (Table 2), significant differences between strata were observed only when FFQ information was used (e.g., highest $v s$ lowest third of sodium intake: $\mathrm{OR}=0.67,95 \%$ CI: $0.13-3.48$ among the $H$. pylori negative and $\mathrm{OR}=2.36,95 \%$ CI: $1.32-4.22$ in the $H$. pylori positive; $P$ for interaction $=0.045$ ), but no consistent differences were observed for other measures of salt exposure. When further dividing the H. pylori infected by virulence (Table 3), no significant differences in gastric cancer risk were observed (e.g., highest $v s$ lowest third of sodium intake from FFQ: $\mathrm{OR}=4.50,95 \% \mathrm{CI}: 0.18-112.64$ among the $H$. pylori-negative group, and $\mathrm{OR}=3.93,95 \% \mathrm{CI}: 0.30-52.27$ in the $H$. pylori-positive/CagA-negative group, $P$ for interaction $=0.612$; and $\mathrm{OR}=1.52,95 \% \mathrm{CI}: 0.71-3.28$ in the $H$. pylori-positive/CagA-positive group, $P$ for interaction $=0.407$ ). No effect modification by smoking was observed across the different measures of dietary salt intake, the risk in never and ever smokers being similar (e.g., highest vs lowest third of sodium intake from FFQ: $\mathrm{OR}=1.84,95 \% \mathrm{CI}: 0.85-4.02$ among never smokers and $\mathrm{OR}=2.14,95 \% \mathrm{CI}$ : $0.98-4.65$ among ever smokers; $P$ for interaction $=0.960$; Table 4 )

No consistent or meaningful variations in gastric cancer risk associated with dietary salt intake were observed by tumour site (e.g., highest $v s$ lowest third of sodium intake from $\mathrm{FFQ}: \mathrm{OR}=1.46$, $95 \%$ CI: $0.50-4.33$ for non-cardia $v s$ cardia cancers; Table 5) or histological type corresponding $(\mathrm{OR}=0.68,95 \% \mathrm{CI}$ : $0.23-2.02$ for intestinal $v s$ diffuse tumours; Table 6).

\section{DISCUSSION}

Dietary salt intake, as assessed by different methods, independently increased the risk of gastric cancer, regardless of tumour site and histological type and with no evidence of effect modification by $\mathrm{H}$. pylori infection or smoking. Most observational studies have used questionnaires to assess dietary salt intake, with

Table I Association between gastric cancer and dietary salt intake using different approaches to evaluate salt intake

\begin{tabular}{|c|c|c|c|c|}
\hline & \multirow{2}{*}{$\begin{array}{c}\text { Controls }(n=649) \\
n(\%)\end{array}$} & \multirow{2}{*}{$\begin{array}{c}\text { Cases }(n=422) \\
n(\%)\end{array}$} & \multicolumn{2}{|c|}{ OR $(95 \% \mathrm{Cl})$} \\
\hline & & & Crude & Adjusted $^{\mathrm{a}}$ \\
\hline \multicolumn{5}{|c|}{ Sodium intake from food frequency questionnaire $\left(m g d a y^{-1}\right)^{b}$} \\
\hline$<3067.5$ & $214(33.0)$ & $132(31.3)$ & 1 & 1 \\
\hline $3067.5-3960.1$ & $215(33.1)$ & $146(34.6)$ & $1.10(0.81-1.48)$ & $1.39(0.94-2.06)^{c}$ \\
\hline$>3960.1$ & $220(33.9)$ & $144(34.1)$ & $1.06(0.78-1.44)$ & $2.01(1.16-3.46)^{\circ}$ \\
\hline \multicolumn{5}{|c|}{ Food items with the highest contribution to sodium intake (servings per day) ${ }^{b}$} \\
\hline$<6.3$ & $214(33.0)$ & $92(21.8)$ & 1 & 1 \\
\hline $6.3-8.1$ & $215(33.1)$ & $137(32.5)$ & $1.48(1.07-2.05)$ & $1.28(0.85-1.92)^{6}$ \\
\hline$>8.1$ & $220(33.9)$ & $193(45.7)$ & $2.04(1.49-2.79)$ & $2.54(1.56-4.14)^{c}$ \\
\hline \multicolumn{5}{|c|}{ Salt consumption by visual analogical scale $(\mathrm{mm})^{b}$} \\
\hline$<35$ & $216(33.2)$ & $108(25.6)$ & 1 & 1 \\
\hline $35-49$ & $210(32.4)$ & $81(19.2)$ & $0.77(0.55-1.09)$ & $0.79(0.53-1.20)$ \\
\hline$>49$ & $223(34.4)$ & $233(55.2)$ & $2.09(1.56-2.81)$ & $1.83(1.28-2.63)$ \\
\hline \multicolumn{5}{|l|}{ Use of table salt } \\
\hline Never & $580(89.4)$ & $367(87.0)$ & 1 & 1 \\
\hline Sometimes/most times/always & $69(10.6)$ & $55(13.0)$ & $1.26(0.86-1.84)$ & $1.35(0.85-2.15)$ \\
\hline \multicolumn{5}{|c|}{ Duration of refrigerator ownership (years) } \\
\hline$<25^{\mathrm{d}}$ & $15(2.3)$ & $72(17.1)$ & 1 & 1 \\
\hline $25-50$ & $244(37.6)$ & $203(48.1)$ & $0.17(0.10-0.31)$ & $0.18(0.09-0.35)$ \\
\hline$>50$ (including all their lives) & $390(60.1)$ & $147(34.8)$ & $0.08(0.04-0.14)$ & $0.28(0.14-0.57)$ \\
\hline
\end{tabular}

'Additionally adjusted for total energy intake. IIncluding four cases who do not currently have refrigerator. 


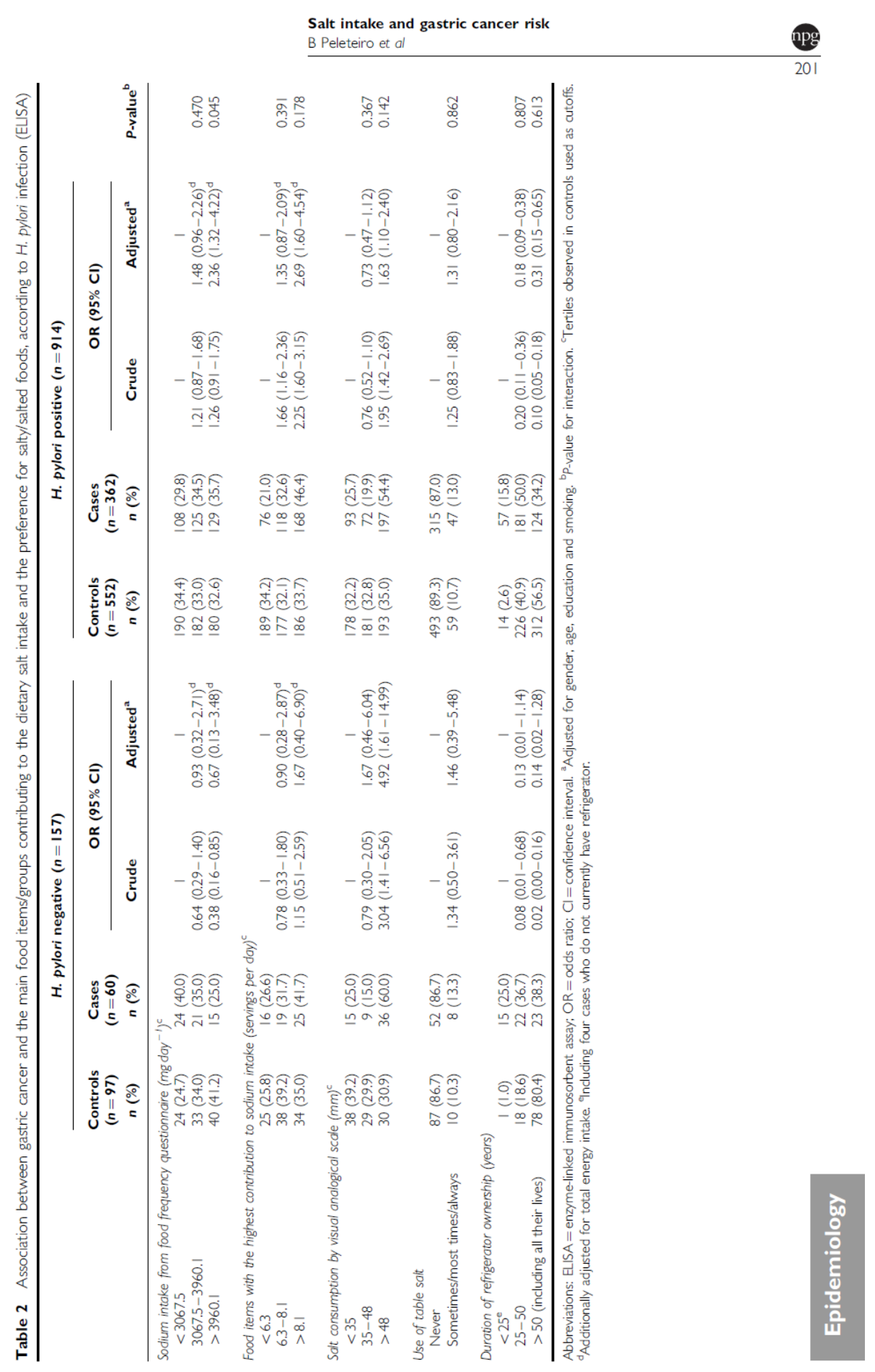




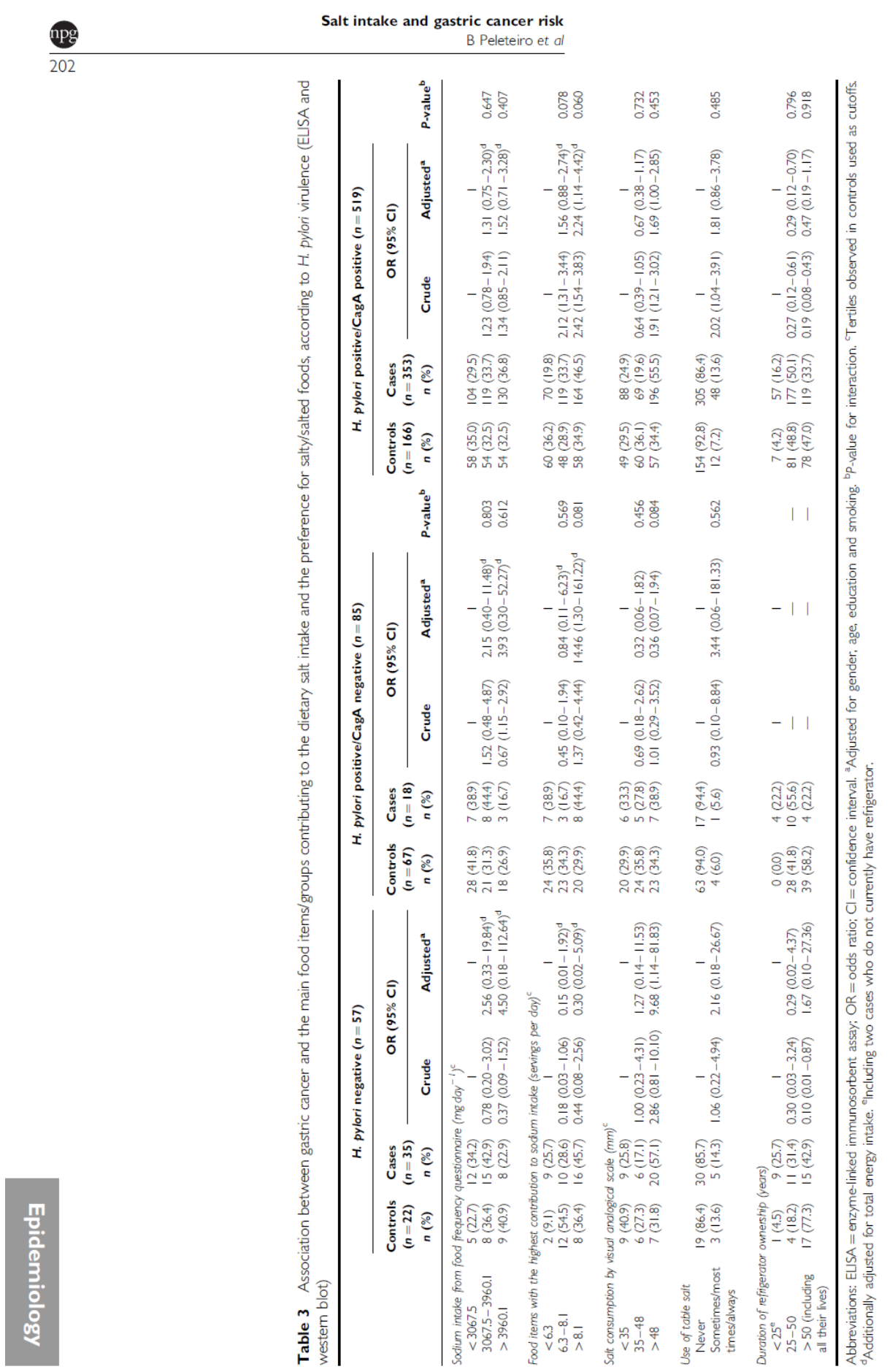

British Journal of Cancer (2011) 104(I), 198-207 


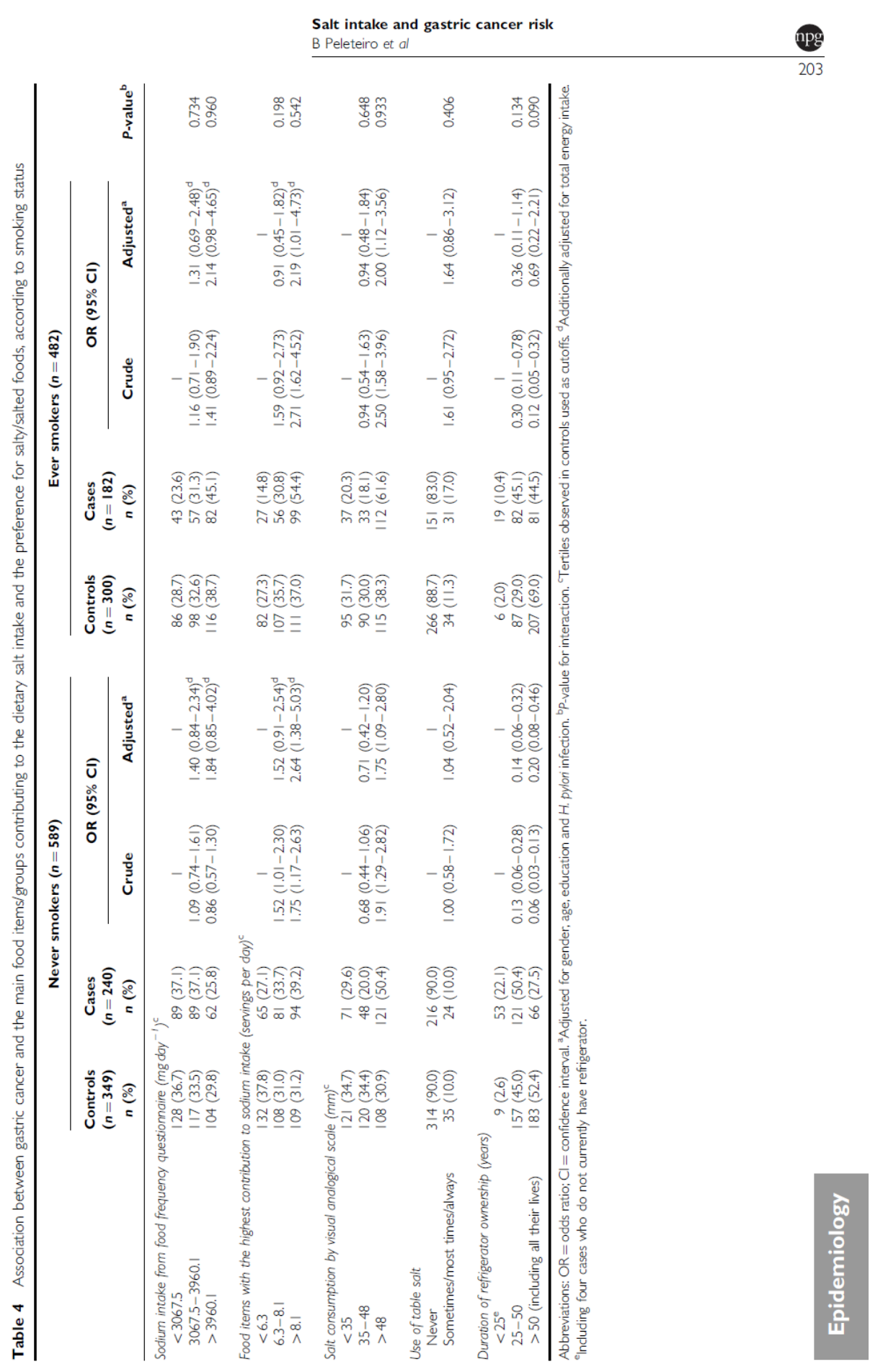




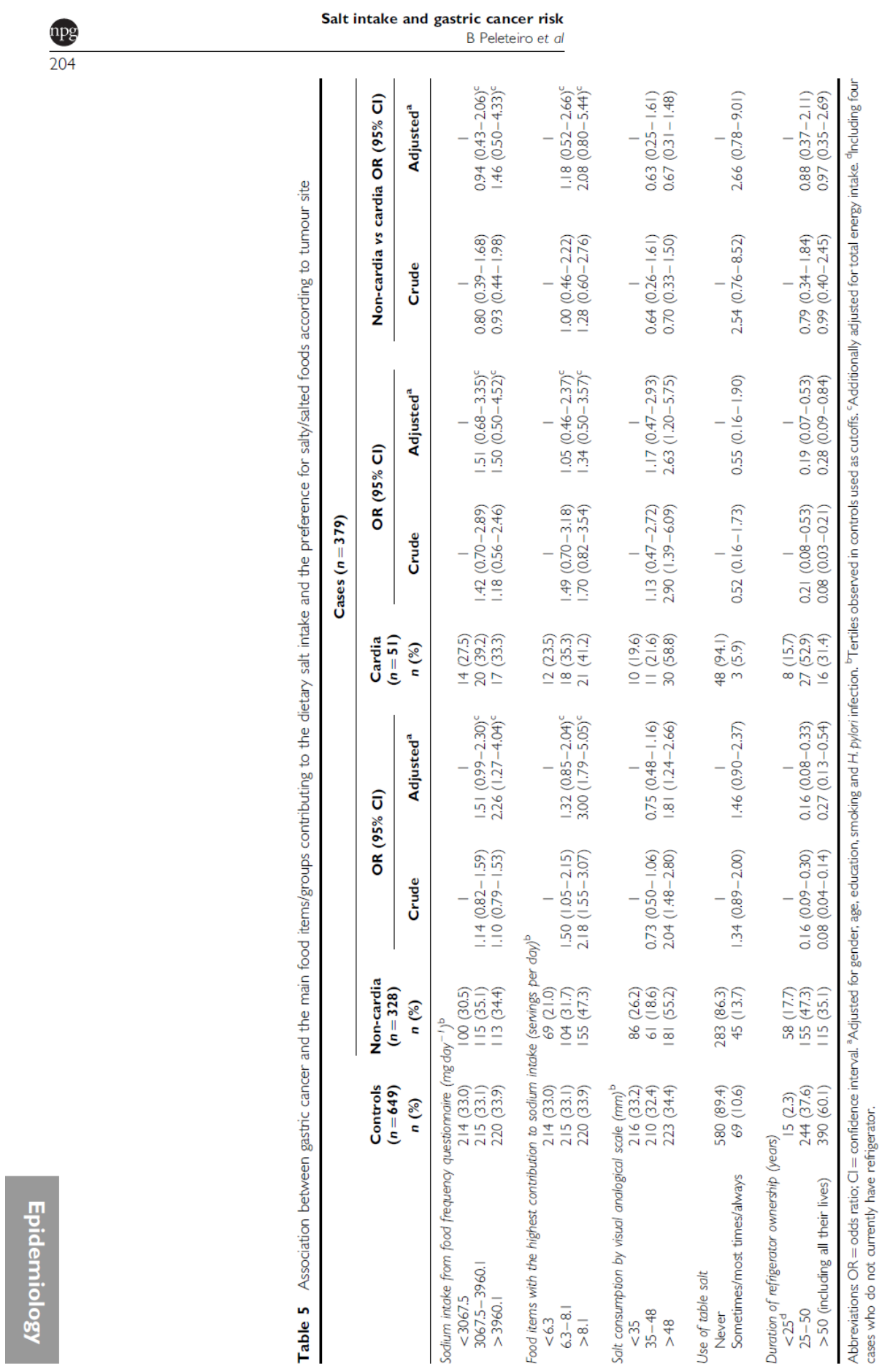

British Journal of Cancer (2011) 104(I), 198-207 


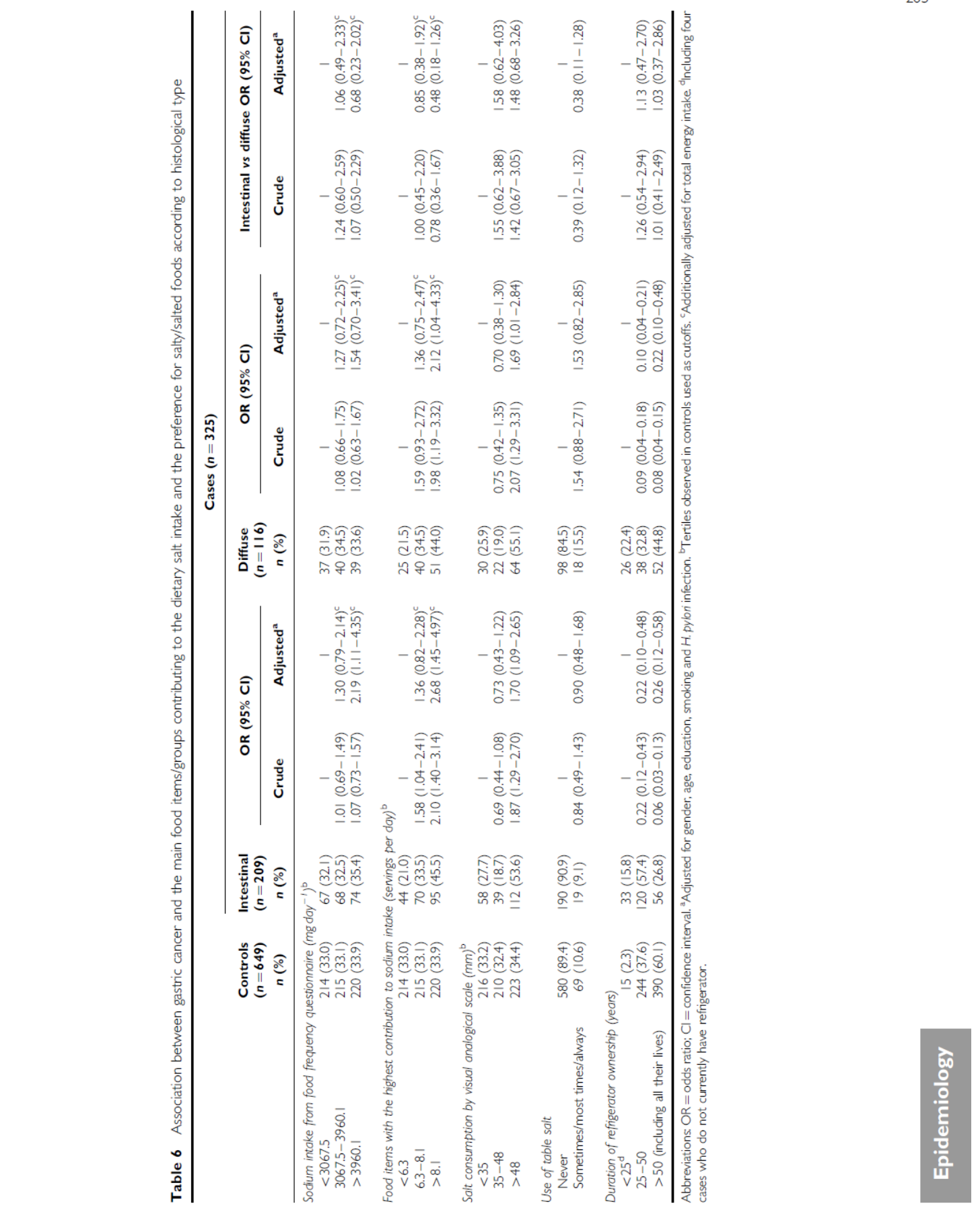


relative risk estimates ranging from 0.53 to 24.92 (Tsugane, 2005 Tsugane and Sasazuki, 2007; Wang et al, 2009). In our study, the odds of gastric cancer were approximately twice as high for subjects in the highest than the lowest categories of salt exposure as estimated through sodium intake, consumption of food items with the highest contribution to sodium intake and dietary salt intake evaluated by a visual scale. Reasons for these discrepancies include: first, dietary habits in a specific setting can influence not only sodium consumption but also the perceived salt intake, and levels reported as 'high' in one study might be considered 'low' in other studies in settings with higher average exposures. Second, the public perception of deleterious effects of salt may produce Hawthorne effect. Third, co-morbidities associated with a recommended reduction in dietary salt may not be taken into account. Fourth, recall bias may occur in case-control studies. Cases may provide a less accurate report of their past dietary habits, because unnoticed changes in intake may occur as cancer develops and becomes symptomatic (Botterweck et al, 1998); cancer patients may also over-report exposures perceived as causal.

A major concern in assessing salt intake are the facts that it is natural component of most foods, and that it can also be added during cooking or at the table in amounts that people usually ignore or are unable to report accurately (Chen et al, 1990) Excretion of sodium in urine over a 24 -h period reflects accurately the sodium ingested from different sources (World Cancer Research Fund/American Institute for Cancer Research, 2007) but it cannot be used retrospectively in case-control studies. We therefore used different approaches and in our analysis, both intrinsic sodium content and salt added during food preparation were taken into account.

Methods of measuring the salt that is added during food preparation depend not only on subjects' perception but also on their cognitive ability for understanding and properly assigning their preference for salt use (Gagliese et al, 2005; Pesonen et al, 2009). This may explain the inconsistency in our results for $2009)$. This may explain the inconsistency in our results for
the visual scale, despite the exclusion of subjects classified the visual scale, despite the exclusion of subjects classified as cognitively impaired. Nevertheless, we found a similar positive association when assessing salt intake by the visual scale, suggesting a suitable assessment. We excluded all subjects who reported to have changed their dietary habits because of any previous condition, as co-morbidities for which reduction in dietary salt is recommended may be a source of reduction in

The subjects analysed were younger and more educated than The subjects analysed were younger and more educated than
those excluded because of missing items (e.g., visual analogical those excluded because of missing items (e.g., visual analogica may have resulted in selection of refrigerator own as, among the controls, the younger and more educated participants reported higher salt consumption, and the positive association with salt may be underestimated in our study.

Refrigeration enables consumption of fresh foods including seasonal vegetables and fruits all year round as well as fresh meat, and reduces the need for salting, smoking, curing and pickling to preserve food. As in Portugal the widespread availability of domestic refrigeration occurred mostly at the end of the twentieth century, duration of refrigerator ownership may best reflect the length of time exposed to salt-preserved foods due more to lack of alternatives than a natural preference for these foods. Although alternatives than a natural preference for these foods. Although
refrigerators were initially restricted to higher social classes, leading to a potential confounding by socioeconomic status, in the present study the strong protective effect of refrigerator ownership was independent of the most probable confounders.

The increased risk in gastric cancer might be because of compounds other than salt that are produced during the preservation process. Foods such as processed meat, cured meat or dried fish, whose consumption is used as a surrogate for salt exposure, also have a high content of nitrosated compounds, which may be involved in gastric carcinogenesis (World Cancer Research Fund/American Institute for Cancer Research, 2007). In our study, using measurements less subject to the confounding effect of nitrosated compounds, such as the visual scale of salt intake, an increased risk was still observed, supporting the independent deleterious effect of salt consumption.

In our study, confounding is unlikely to be a major concern, as the main potential confounders were taken into account. Further adjustment for fruit and vegetables intake, and total or red/ processed meat consumption did not change the conclusions (data not shown), and therefore we opted to show models adjusted only for gender, age, education, smoking, $H$. pylori infection and total energy intake. No information on physical activity or body mass index was collected, and although associations with these exposures show less consistent results than for the main potential confounders (Friedenreich et al, 2010; Gonzalez and Riboli, 2010), it is unlikely that their inclusion would yield substantially different OR estimates and different conclusions.

Proposed mechanisms by which salt can cause gastric cancer are either direct damage to the gastric mucosa leading to hyperplasia of the gastric pit epithelium with increased potential for mutations or the result of interaction with $\mathrm{H}$. pylori, as the damage caused by salt may also increase gastric $H$. pylori colonisation (Fox et al, 1999; Nozaki et al, 2002). This would imply a stronger association among $H$. pylori-infected subjects, especially those infected with CagA-positive strains, but this was not confirmed in our study. The high prevalence of infection in Portugal compared with other Western countries (Quina, 1994) may further obscure an effect modification, as there is a high potential for misclassification of infection status, especially among the cases (Peleteiro et al, 2010). The possible interaction may be more important in relation to strain virulence, as infection with CagA-positive strains is a better marker of gastric cancer risk (Peleteiro et al, 2010). Nevertheless, it is also possible that the joint effect of salt and infection is less pronounced in our population, as infection with more virulent strains would be expected to be more important in gastric cancer risk than salt exposure. A synergistic effect might occur if any gastric mucosa damage by salt was enhanced by tobacco carcinogens (Iwata et al, 1995), but no effect modification was observed across the different measures of salt intake.

The World Health Organization recommendation for maximum intake of salt of $5 \mathrm{~g} \mathrm{day}^{-1}$ (World Health Organization, 2003 lies well below the estimated dietary intake of $9.2 \mathrm{gday}^{-1}$ of the Portugese population (Lopes et al, 2006). One of the major sources of this dietary salt intake, taking into account only the intrinsic sodium content, is bread, which represents $24.5 \%$ of the overall sodium intake (Lopes et al, 2006). In August 2010, a new law was implemented in Portugal regulating the maximum quantity of salt allowed to $1.4 \mathrm{~g}$ per $100 \mathrm{~g}$ of bread (Lei no. 75/2009, 2009). This may contribute to reducing (Lunet et al, 2004) the risk of gastric cancer in a country with gastric cancer mortality ranking among the highest in Europe.

Taking into account site, histological type, smoking and $H$. pylori infection status and virulence, our study confirms the association between dietary salt intake and gastric cancer.

\section{ACKNOWLEDGEMENTS}

This work was performed using grants from Fundação para a Ciência e a Tecnologia (POCTI/SAU-ESP/56126/2004, POCTI/ SAU-ESP/61685/2004, PTDC/SAU-ESA/71517/2006) and Agência Portuguesa de Segurança Alimentar. This work, presented at the GRELL Meeting 2010 in Toledo, was awarded the 'Enrico Anglesio' Prize, offered by the 'Anglesio Moroni Foundation', Turin, Italy. 


\section{REFERENCES}

Botterweck AA, van den Brandt PA, Goldbohm RA (1998) A prospective cohort study on vegetable and fruit consumption and stomach cancer risk in The Netherlands. Am J Epidemiol 148(9): 842-853

Charnley G, Tannenbaum SR (1985) Flow cytometric analysis of the effect of sodium chloride on gastric cancer risk in the rat Cancer Res 45 (11 Part 2): $5608-5616$

Chen H, Ward MH, Graubard BI, Heineman EF, Markin RM, Potischman NA, Russell RM, Weisenburger DD, Tucker KL (2002) Potischman NA, Russell RM, Weisenburger DD, Tucker KL (2002)
Dietary patterns and adenocarcinoma of the esophagus and distal Dietary patterns and adenocarcinoma
stomach. Am J Clin Nutr 75(1): 137-144

Chen VW, Abu-Elyazeed RR, Zavala DE, Ktsanes VK, Haenszel W, Cuello C, Montes G, Correa P (1990) Risk factors of gastric precancerous Cuello C, Montes G, Correa P (1990) Risk factors of gastric precancerous
lesions in a high-risk Colombian population. I. Salt. Nutr Cancer 13 lesions in a high

Coleman MP, Esteve J, Damiecki P, Arslan A, Renard H (1993) Trends in Coleman MP, Esteve J, Damiecki P, Arslan A, Renard H (1993)
cancer incidence and mortality. IARC Sci Publ (121): $1-806$

Dias-Neto M, Pintalhao M, Ferreira M, Lunet N (2010) Salt intake and risk of gastric intestinal metaplasia: systematic review and meta-analysis. Nutr Cancer 62(2): 133-147

Ferreira F, Graça M (1985) Portuguese Table of Food Composition [in Portuguese]. National Health Institute Dr Ricardo Jorge: Lisbon Fox JG, Dangler CA, Taylor NS, King A, Koh TJ, Wang TC (1999) High-sal diet induces gastric epithelial hyperplasia and parietal cell loss, and enhances Helicobacter pylori colonization in C57BL/6 mice. Cancer Res 59(19): 4823-4828

Friedenreich CM, Neilson HK, Lynch BM (2010) State of the epidemiological evidence on physical activity and cancer prevention. Eur J Cancer 46(14): $2593-2604$

Gagliese L, Weizblit N, Ellis W, Chan VW (2005) The measurement of postoperative pain: a comparison of intensity scales in younger and older surgical patients. Pain 117(3): $412-420$

Gal DL, Santos AC, Barros H (2005) Leisure-time versus full-day energy expenditure: a cross-sectional study of sedentarism in a Portuguese urban population. BMC Public Health 5: 16

Gonzalez CA, Riboli E (2010) Diet and cancer prevention: contributions from the European Prospective Investigation into Cancer and Nutrition (EPIC) study. Eur J Cancer 46(14): 2555-2562

Helicobacter and Cancer Collaborative Group (2001) Gastric cancer and Helicobacter pylori: a combined analysis of 12 case
nested within prospective cohorts. Gut $49(3): 347-353$

nested within prospective cohorts. Gut 49) (3): epidemiology of an unplanned triumph. Epidemiol Rev 8: 1-27

epidemiology of an unplanned Huang JQ, Sridhar S, Chen Y, Hunt RH (1998) Meta-analysis of the relationship between Helicobacter pylori seropositivity and gastric

Iwata F, Zhang XY, Leung FW (1995) Aggravation of gastric mucosal lesions in rat stomach by tobacco cigarette smoke. Dig Dis Sci $40(5)$ : $1118-112$

Ladeiras-Lopes R, Pereira AK, Nogueira A, Pinheiro-Torres T, Pinto I Santos-Pereira R, Lunet N (2008) Smoking and gastric cancer: systematic review and meta-analysis of cohort studies. Cancer Causes Control 19(7): $689-701$

Laurén P (1965) The two histological main types of gastric carcinoma: diffuse and so-called intestinal-type carcinoma. An attempt at a histo-clinical classification. Acta Pathol Microbiol Scand 64: 31-49

Lei no. 75/2009 (2009) Diário da República, 1. ${ }^{\text {a }}$ série - N. ${ }^{\circ} 155-12$ de Agosto de 2009 [in Portuguese]

Loh JT, Torres VJ, Cover TL (2007) Regulation of Helicobacter pylori cagA expression in response to salt. Cancer Res 67(10): 4709-4715

Lopes C (2000) Reproducibility and validation of a semi-quantitative food-frequency questionnaire. Diet and Acute Myocardial Infarction: A Population-Based Case-Control Study. PhD Thesis [in Portuguese]. University of Porto, Porto

Lopes C, Aro A, Azevedo A, Ramos E, Barros H (2007) Intake and adipose tissue composition of fatty acids and risk of myocardial infarction in a male Portuguese community sample. J Am Diet Assoc 107(2): $276-286$

Lopes C, Oliveira A, Santos AC, Ramos E, Gaio AR, Severo M, Barros H (2006) Food Consumption in Porto [in Portuguese]. Faculty of Medicin of the University of Porto

Lunet N, Pina F, Barros H (2004) Regional trends in Portuguese gastric cancer mortality (1984-1999). Eur J Cancer Prev 13(4): 271-275

Lunet N, Valbuena C, Carneiro F, Lopes C, Barros H (2006) Antioxidant vitamins and risk of gastric cancer: a case-control study in Portugal.
and Nutr Cancer 55(1): $71-77$

Lunet N, Valbuena C, Vieira AL, Lopes C, David L, Carneiro F, Barros H (2007) Fruit and vegetable consumption and gastric cancer by location and histological type: case-control and meta-analysis. Eur J Cancer Prev 16(4): $312-327$

Murden RA, McRae TD, Kaner S, Bucknam ME (1991) Mini-Mental State exam scores vary with education in blacks and whites. J Am Geriatr So 39(2): $149-155$

Nozaki K, Shimizu N, Inada $K$, Tsukamoto $T$, Inoue $M$, Kumagai $T$, Sugiyama A, Mizoshita T, Kaminishi M, Tatematsu M (2002) Synergistic promoting effects of Helicobacter pylori infection and high-salt diet on gastric carcinogenesis in Mongolian gerbils. Jpn J Cancer Res 93(10): $1083-108$

Peleteiro B, Lunet N, Barros R, La Vecchia C, Barros H (2010) Factor contributing to the underestimation of Helicobacter pylori-associate gastric cancer risk in a high-prevalence population. Cancer Causes Control 21(8): 1257-1264

Pesonen A, Kauppila T, Tarkkila P, Sutela A, Niinisto L, Rosenberg PH (2009) Evaluation of easily applicable pain measurement tools fo the assessment of pain in demented patients. Acta Anaesthesiol Scand 53(5): $657-664$

Quina MG (1994) Helicobacter pylori: the Portuguese scene. Grupo de Estudo Portugues do Helicobacter pylori (GEPHP). Eur J Cancer Prev 3(Suppl 2): $65-67$

Ramos E, Lopes C, Barros H (2004) Investigating the effect of nonparticipation using a population-based case-control study on myocardial infarction. Ann Epidemiol 14(6): 437-441

Shikata K, Kiyohara Y, Kubo M, Yonemoto K, Ninomiya T, Shirota T, Tanizaki Y, Doi Y, Tanaka K, Oishi Y, Matsumoto T, Iida M (2006) A prospective study of dietary salt intake and gastric cancer incidence in a defined Japanese population: the Hisayama study. Int J Cancer 119(1): 196-201

Sobin LH, Wittekind C (2002) UICC, TNM Classification of Malignant Tumors 6th edn. Wiley-Lis:

Tatematsu M, Takahashi M, Fukushima S, Hananouchi M, Shirai T (1975)

Effects in rats of sodium chloride on experimental gastric cancers induced by N-methyl-N-nitro-N-nitrosoguanidine or 4-nitroquinoline-1 oxide. J Natl Cancer Inst 55(1): $101-106$

Tsugane S (2005) Salt, salted food intake, and risk of gastric cancer: epidemiologic evidence. Cancer Sci 96(1): 1-6

Tsugane S, Sasazuki S (2007) Diet and the risk of gastric cancer: review of epidemiological evidence. Gastric Cancer 10(2): $75-83$

van den Brandt PA, Botterweck AA, Goldbohm RA (2003) Salt intake, cured meat consumption, refrigerator use and stomach cancer incidence: a prospective cohort study (Netherlands). Cancer Causes Control 14(5): $427-438$

Wang XQ, Terry PD, Yan H (2009) Review of salt consumption and stomach cancer risk: epidemiological and biological evidence. World Gastroenterol 15(18): 2204-2213

World Cancer Research Fund/American Institute for Cancer Research (2007) Food, Nutrition, Physical Activity, and the Prevention of Cancer: A Global Perspective. World Cancer Research Fund/American Institute for Cancer Research: Washington DC

World Health Organization (2003) Diet, Nutrition and the Prevention of Chronic Diseases. Report of a Joint WHO/FAO Expert Consultation. WHO Technical Report Series, No. 916: Geneva 


\section{PAPER IV}

Peleteiro B, Carrilho C, Modcoicar P, Cunha L, Ismail M, Guisseve A, Lorenzoni C, Fernandes F, Almeida R, Figueiredo C, David L, Lunet N.

Chronic atrophic gastritis, intestinal metaplasia, Helicobacter pylori virulence, IL1RN polymorphisms and smoking in dyspeptic patients from Mozambique and Portugal. Helicobacter. 2009;14(4):306-8. 



\section{Chronic Atrophic Gastritis, Intestinal Metaplasia, Helicobacter pylori Virulence, IL 1RN Polymorphisms, and Smoking in Dyspeptic Patients from Mozambique and Portugal}

Dear Editor,

We thank Maaroos and Vorobjova [1] for their comments on our paper recently published in Virchows Archiv [2], giving us the opportunity to further clarify how our results can be placed in the context of previous research on this topic.

The extent to which the so-called African enigma can be interpreted as an artifact or the reflection of true variation across populations is naturally conditioned by the amount and quality of available information. The frequency of cancer in case-series of patients undergoing upper endoscopy can hardly be interpreted or compared across studies without having setting-specific information on healthcareseeking behavior and referral patterns. Access to healthcare and quality of information is hampered by the shortage of diagnostic facilities and trained personnel in Africa, and its heterogeneity between and within countries. The limitations of cancer statistics in the African continent and the different age structure of populations from developed and developing regions may partially explain the "enigma." However, the frequency of gastric cancer in Africa, estimated from cancer registries and population-based surveys, is lower than expected for settings with high prevalence of Helicobacter pylori infection even when comparing agestandardized rates, or the proportion of stomach cancers among all tumors. Moreover, in developing countries, most subjects are expected to get infected early in their lives and the clinical outcomes may be observed at younger ages than in developed countries with low prevalence of infection.

The study of chronic atrophic gastritis and intestinal metaplasia, key lesions in the natural history of most stomach cancers, may provide important information to understand which factors operate to produce gastric cancer in infected subjects. However, this type of individualbased research is relatively rare in Africa, and follow-up studies are almost inexistent. Cross-sectional analyses may obviously produce important pieces of evidence, especially if these analyses are providing information from regions for which there were no previous reports, and especially when these are relying on prospective data collection and accurate diagnosis of gastric lesions, allowing sound comparisons with results from other studies. In recent studies, the prevalence of chronic atrophic gastritis and intestinal metaplasia was, respectively, $2.4 \%$ and $4.8 \%$ in Gambia [3], 16.7\% and $9.4 \%$ in Nigeria [4], and $15 \%$ and $2 \%$ in Kenya [5]. Our study provided the first estimates on the frequency of gastric precancerous lesions in dyspeptic patients from Mozambique. We believe our conclusions do not exceed the generated evidence and are according to previous reports, showing very low prevalence of gastric atrophy and intestinal metaplasia in Africa.

The concerns expressed by Maaroos and Vorobjova [1] regarding the relatively young age of the participants in our investigation seem unjustified, since, in our study, older participants also presented a low prevalence of chronic atrophic gastritis and intestinal metaplasia (Table 1). The validity of our findings is reinforced by the comparison with data from Portugal, a country with high prevalence of H. pylori infection and high gastric cancer rates. Portuguese participants $(n=116)$ reporting dyspeptic symptoms underwent upper digestive endoscopy and gastric biopsy samples were collected following the same standardized protocol [6]. The same experienced pathologists evaluated the Mozambican and Portuguese biopsy specimens.

The prevalence of chronic atrophic gastritis and intestinal metaplasia was lower in Mozambican subjects when compared to the Portuguese, across age and education strata (Table 1). Also, divergent distribution of ILIRN polymorphisms and smoking in men could contribute to explain the observed differences (Table 1). Further research in the African setting is warranted to explore these potential explanations to the "enigmas."

\section{Acknowledgements and Disclosures}

Grants from the Fundação Calouste Gulbenkian (projects FC54918 and FC-68697) and Fundação para a Ciência e a Tecnologia (JNICT UIGD 51/94 and SFRH/BD/36818/2007) are gratefully acknowledged.

The authors have no conflict of interest to declare. 
Table 1 Distribution of socio-demographic, Helicobacter pylori infection, genetic, and behavioral characteristics in dyspeptic subjects from Mozambique and Portugal

\begin{tabular}{|c|c|c|c|}
\hline & Mozambique $(n=109)$ & Portugal $(n=116)$ & $p$ \\
\hline \multicolumn{4}{|c|}{ Prevalence of precancerous lesions according to age and education } \\
\hline $\begin{array}{l}\text { Chronic atrophic gastritis } \\
\text { Age (years) }\end{array}$ & $9(8.3)$ & $42(36.3)$ & $<.001$ \\
\hline$<40$ & $4(6.4)$ & $7(21.9)$ & .040 \\
\hline $40-50$ & $3(10.3)$ & $27(40.3)$ & .004 \\
\hline$>50$ & $2(12.5)$ & $8(47.1)$ & .057 \\
\hline \multicolumn{4}{|l|}{ Education (years) ${ }^{a}$} \\
\hline $0-4$ & $3(13.6)$ & $10(38.5)$ & .101 \\
\hline $5-9$ & $4(9.3)$ & $18(31.0)$ & .014 \\
\hline$>9$ & $2(4.8)$ & $7(35.0)$ & .004 \\
\hline Intestinal metaplasia & $9(8.3)$ & $43(37.1)$ & $<.001$ \\
\hline \multicolumn{4}{|l|}{ Age (years) } \\
\hline$<40$ & $6(9.5)$ & $6(18.8)$ & .211 \\
\hline $40-50$ & $2(6.7)$ & $30(44.8)$ & $<.001$ \\
\hline$>50$ & $1(6.2)$ & $7(41.2)$ & .039 \\
\hline \multicolumn{4}{|l|}{ Education (years) ${ }^{\mathrm{a}}$} \\
\hline $0-4$ & $0(0.0)$ & $10(38.5)$ & .001 \\
\hline $5-9$ & $3(7.0)$ & $21(36.2)$ & .001 \\
\hline$>9$ & $6(14.0)$ & $5(25.0)$ & .304 \\
\hline \multicolumn{4}{|c|}{ H. pylori infection and its characteristics } \\
\hline \multicolumn{4}{|c|}{ H. pylori infection status } \\
\hline Negative & $6(5.5)$ & $2(1.7)$ & \\
\hline Positive & $103(94.5)$ & $114(98.3)$ & .161 \\
\hline \multicolumn{4}{|l|}{ cagA genotype ${ }^{b}$} \\
\hline cagA negative & $44(44.0)$ & $42(40.0)$ & \\
\hline cagA positive & $56(56.0)$ & $63(60.0)$ & .574 \\
\hline \multicolumn{4}{|l|}{ vacA s genotype ${ }^{c}$} \\
\hline $\operatorname{vacAs} S_{2}$ & $21(21.2)$ & $33(31.7)$ & \\
\hline $\operatorname{vacA} s_{1} / s_{2}$ & $21(21.2)$ & $23(22.1)$ & \\
\hline $\operatorname{vacAs} s_{1}$ & $57(57.6)$ & $48(46.2)$ & 0.190 \\
\hline \multicolumn{4}{|l|}{ vacA m genotype ${ }^{d}$} \\
\hline $\operatorname{vacA} m_{2}$ & $39(45.4)$ & $41(39.8)$ & \\
\hline $\operatorname{vacA} m_{1} / m_{2}$ & $11(12.8)$ & $24(23.3)$ & \\
\hline $\operatorname{vacA} m_{1}$ & $36(41.9)$ & $38(36.9)$ & 0.194 \\
\hline \multicolumn{4}{|c|}{ IL1RN polymorphisms and smoking habits } \\
\hline \multicolumn{4}{|c|}{ IL1RN VNTR genotype } \\
\hline $\mathrm{L}-\mathrm{L}$ & $95(92.2)$ & $40(58.8)$ & \\
\hline 2 carriers & $8(7.8)$ & $28(41.2)$ & $<.001$ \\
\hline \multicolumn{4}{|l|}{ Smoking status in males ${ }^{f}$} \\
\hline Never smokers & $24(70.6)$ & $25(32.5)$ & \\
\hline Ever smokers & $10(29.4)$ & $52(67.5)$ & $<.001$ \\
\hline
\end{tabular}

Information available for 108 participants in the Mozambican sample and 104 in the Portuguese sample.

IInformation available for 100 participants in the Mozambican sample and 105 in the Portuguese sample.

Information available for 99 participants in the Mozambican sample and 104 in the Portuguese sample.

dInformation available for 86 participants in the Mozambican sample and 103 in the Portuguese sample.

eInformation available for 103 participants in the Mozambican sample and 68 in the Portuguese sample.

IInformation available for 34 participants in the Mozambican sample and 77 in the Portuguese sample (females were not considered due to an insufficient number of smokers among women). 
Bárbara Peleteiro, ${ }^{*}+$ Carla Carrilho, $\ddagger \S$ Prassad Modcoicar, II Lina Cunha, ,I Mamudo Ismail, $\neq \S$ Acucena Guisseve, $\ddagger$ Cesaltina Lorenzoni, $\neq \S$ Fabiola Fernandes, $\neq \S$ Raquel Almeida, ${ }^{* *}+\dagger$ Céu Figueiredo, ${ }^{* *}+\dagger$ Leonor David ${ }^{* *}+\dagger$ and Nuno Lunet* + *Department of Hygiene and Epidemiology, Medical Faculty, University of Porto, Porto, Portugal, +Institute of Public Health (ISPUP), University of Porto, Porto, Portugal, $\ddagger$ Department of Pathology, Medical Faculty, Eduardo Mondlane University, Maputo, Mozambique, §Department of Anatomical Pathology, Maputo Central Hospital, Maputo, Mozambique, IIDepartment of Gastroenterology, Maputo Central Hospital, Maputo, Mozambique, **Institute of Molecular Pathology and Immunology (IPATIMUP), University of Porto, Porto, Portugal, †DDepartment of Pathology, Medical Faculty, University of Porto, Porto, Portugal

Reprints request to: Bárbara Peleteiro, Serviço de Higiene e Epidemiologia, Faculdade de Medicina da Universidade do Porto, Al. Prof. Hernâni Monteiro, 4200-319 Porto, Portugal. E-mail: barbarap@med.up.pt

\section{References}

1 Maaroos HI, Vorobjova T. Chronic gastritis develops and progresses over the years under permanent exposure of Helicobacter pylori: is the case different in Mozambican dyspeptic patients? Helicobacter 2009; (in press).

2 Carrilho C, Modcoicar P, Cunha L et al. Prevalence of Helicobacter pylori infection, chronic gastritis, and intestinal metaplasia in Mozambican dyspeptic patients. Virchows Arch 2009;454:153-60.

3 Campbell DI, Warren BF, Thomas JE, Figura N, Telford JL, Sullivan PB. The African enigma: low prevalence of gastric atrophy, high prevalence of chronic inflammation in West African adults and children. Helicobacter 2001;6:263-7.

4 Oluwasola AO, Ogunbiyi JO. Chronic gastritis and Helicobacter pylori infection in University College Hospital Ibadan, Nigeria - a study of 85 fibre optic gastric biopsies. Niger J Med 2004;13:372-8.

5 Kalebi A, Rana F, Mwanda W, Lule G, Hale M. Histopathological profile of gastritis in adult patients seen at a referral hospital in Kenya. World J Gastroenterol 2007;13:4117-21.

6 Peleteiro B, Lunet N, Figueiredo C, Carneiro F, David L, Barros H Smoking, Helicobacter pylori virulence, and type of intestinal metaplasia in Portuguese males. Cancer Epidemiol Biomarkers Prev 2007;16:322-6. 



\section{PAPer V}

Peleteiro B, Lunet N, Carrilho C, Durães C, Machado JC, La Vecchia C, Barros H. Association between cytokine gene polymorphisms and gastric precancerous lesions: systematic review and meta-analysis. Cancer Epidemiol Biomarkers Prev. 2010;19(3):762-76. 



\section{Association Between Cytokine Gene Polymorphisms and Gastric Precancerous Lesions: Systematic Review and Meta-analysis}

Bárbara Peleteiro ${ }^{1,3}$, Nuno Lunet ${ }^{1,3}$, Carla Carrilho ${ }^{5,6}$, Cecilia Durães ${ }^{4}$, José Carlos Machado ${ }^{2,4}$, Carlo La Vecchia ${ }^{7,8}$, and Henrique Barros ${ }^{1,3}$

Abstract

Polymorphisms within interleukin-1 (IL1) and tumor necrosis factor $\alpha$ (TNFA) gene clusters are associated with an increased risk of gastric cancer. However, their role in gastric precancerous lesions remains poorly understood. Our objective was to perform a meta-analysis of studies addressing the association between IL1B-511, IL1RN variable number of tandem repeat, and TNFA-308 gene polymorphisms and gastric precancerous lesions, including original data from Portugal and Mozambique. Published studies on the association between these cytokine gene polymorphisms and gastric precancerous lesions were identified by systematic review, and estimates of the association were combined using random-effects meta-analysis taking into account new data obtained from Portuguese volunteer shipyard workers $(n=215)$ and Mozambican dyspeptic patients $(n=96)$ who underwent endoscopic and pathologic evaluation following the same protocol. Odds ratio (OR) estimates for intestinal metaplasia were 2.83 [95\% confidence interval ( $95 \% \mathrm{CI}), 1.15-6.96$ ] for the IL1RN*22 genotype, 1.86 (95\% CI, 1.03-3.36) for IL1B-511 T carriers, and 0.59 ( $95 \%$ CI, $0.12-3.04)$ for the TNFA$308^{*}$ AA genotype in the Portuguese sample. All Mozambican subjects with intestinal metaplasia were T carriers for $I L 1 B-511$ and none had the 2 allele for $I L 1 R N$. In meta-analysis, IL1RN*22 genotype was associated with an increased risk of gastric precancerous lesions (22 versus LL: OR, $2.27 ; 95 \%$ CI, $1.40-3.70 ; I^{2}=26.4 \% ; 12$ studies). No such association was found for the IL1B-511 (TT versus CC: OR, $1.34 ; 95 \%$ CI, $0.87-2.07 ; I^{2}=$ $65.7 \%$; 13 studies) or TNFA-308 genotypes (AA versus GG: OR, $0.93 ; 95 \%$ CI, $0.35-2.43 ; I^{2}=0.0 \% ; 7$ studies). The IL1RN*22 genotype seems to consistently increase the risk of gastric precancerous lesions, supporting a role for this polymorphism in the early stages of gastric carcinogenesis. Cancer Epidemiol Biomarkers Prev; 19(3); 762-76. (C2010 AACR.

\section{Introduction}

Helicobacter pylori is a human carcinogen (1) accounting for up to two thirds of gastric cancer cases (2). It infects the gastric mucosa leading to an acute followed by chronic inflammatory response, accompanied by the production of several proinflammatory cytokines. These cytokines enhance the immune response and inhibit gastric acid secretion. This results in hypochlorhydria, allowing further colonization by the bacteria. Consequently, an ex-

Authors' Affiliations: ${ }^{1}$ Department of Hygiene and Epidemiology, and ${ }^{2}$ Department of Pathology, Medical Faculty, and Institute of Public Health and 4Institute of Molecular Pathology and Immunology, University of Porto, Porto, Portugal; 5Department of Pathology, Medical Faculty, Eduardo Mondlane University and ${ }^{\circ}$ Department of Anatomical Pathology, Maputo Central Hospital, Maputo, Mozambique; and 7 Istituto di Ricerche Farmacologiche "Mario Negri" and 8Istituto di Statistica Medica e Biometria, Universita di Milano, Milano, Italy

Corresponding Author: Bárbara Peleteiro, Serviço de Higiene e Epidemiologia, Faculdade de Medicina da Universidade do Porto, Al. Prof. Tax. $351-22-5513653$. E-mat:

doi: 10.1158/1055-9965.EPI-09-0917

(C2010 American Association for Cancer Research. cessive production of gastrin and free radicals ultimately lead to neoplastic transformation of the gastric mucosa (3). Individual differences in the intensity of the inflammatory response may contribute to gastric mucosa transformation (4)

Certain cytokine gene polymorphisms have been associated with the occurrence of gastric cancer, with the most consistent results referring to the increased gastric cancer risk associated to IL1B-511, IL1RN variable number tandem repeat (VNTR), and TNFA-308, despite the heterogeneous findings across previous meta-analyses (5-11). Different risk estimates have been described according to the histologic type of the tumor, with stronger associations for the intestinal type $(5-7,10)$. These tumors are the most frequent (12) and are preceded by a set of sequential precancerous lesions (13), from which intestinal metaplasia is much more frequent than dysplasia (14) and more strongly associated with gastric cancer than gastric atrophy. Addressing the potential associations between the cytokine gene polymorphisms and gastric precancerous lesions may contribute to the understanding of some of the previous heterogeneous findings from studies having gastric cancer as the outcome. 
We analyzed original data in two diverse populations from Portugal and Mozambique, aiming to quantify the association between IL1B-511, IL1RN VNTR, and TNFA308 gene polymorphisms and intestinal metaplasia, and systematically reviewed the literature on the association between these polymorphisms and gastric precancerous lesions, placing our results into context.

\section{Materials and Methods}

\section{Original Data From Portugal and Mozambique}

Workers from the Viana do Castelo shipyard, North of Portugal, were invited for a gastric pathology survey in 1998 , as previously described (15). Nearly $40 \%$ of all the workers volunteered to the study. Four hundred and sixty participants completed a physician-administered questionnaire on digestive symptoms and had a blood sample drawn. An upper digestive endoscopy was done in 354 individuals who presented with dyspeptic symptoms or were classified as $\mathrm{H}$. pylori-infected by an immunoenzymatic assay (COBAS ${ }^{\circledast}$ CORE, Roche Diagnostic Systems).

Between August 2005 and May 2006, as previously described (16), patients with dyspeptic complaints who had an upper digestive endoscopy done at the Gastroenterology Department, Maputo Central Hospital, Mozambique, were consecutively invited for further questionnaire evaluation.

Both studies were approved by local ethics committees, and all participants provided written informed consent.

Gastric biopsy samples were collected following the same standardized protocol both in the Portuguese and in the Mozambican participants. Four specimens (one from corpus, one from antrum, and two from incisura angularis) were taken from each subject. Histologic evaluation was done according to the Modified Sydney system (17), using semiquantitative scoring for chronic inflammation, glandular atrophy, and density of $\mathrm{H}$. pylori colonization. Intestinal metaplasia, dysplasia, and gastric cancer were reported as either present or absent. Each participant was assigned a global histopathologic diagnosis of normal mucosa, chronic nonatrophic gastritis, atrophic gastritis, intestinal metaplasia, dysplasia, or gastric cancer, corresponding to the most severe condition observed.

Modified Giemsa-stained sections were used to assess H. pylori infection. Additionally, $H$. pylori cag $A$ and vacA $(s$ and $m$ ) genotypes were directly determined in a gastric biopsy specimen from the greater curvature of the antrum, by multiplex PCR and reverse hybridization, as previously described $(16,18)$. Participants were considered to be $H$. pylori-infected if they tested positive by at least one method (histology, PCR, or serology).

Genomic DNA was retrieved from blood samples using standard phenol/chloroform extraction. The IL1B 511 and TNFA-308 single nucleotide polymorphisms were genotyped by PCR-single-strand conformation polymorphism analysis and the IL1RN penta-allelic VNTR by PCR-standard agarose gel electrophoresis, as previously described (19). The participants' IL1B-511 genotype was classified as CC, CT, or TT and the TNFA-308 genotype was classified as GG, GA, or AA. The IL1RN alleles were coded according to the number of repeats observed. The short (2) allele, which has been associated with an increased gastric cancer risk, corresponds to two repeats and the long allele (L) corresponds to three repeats or more.

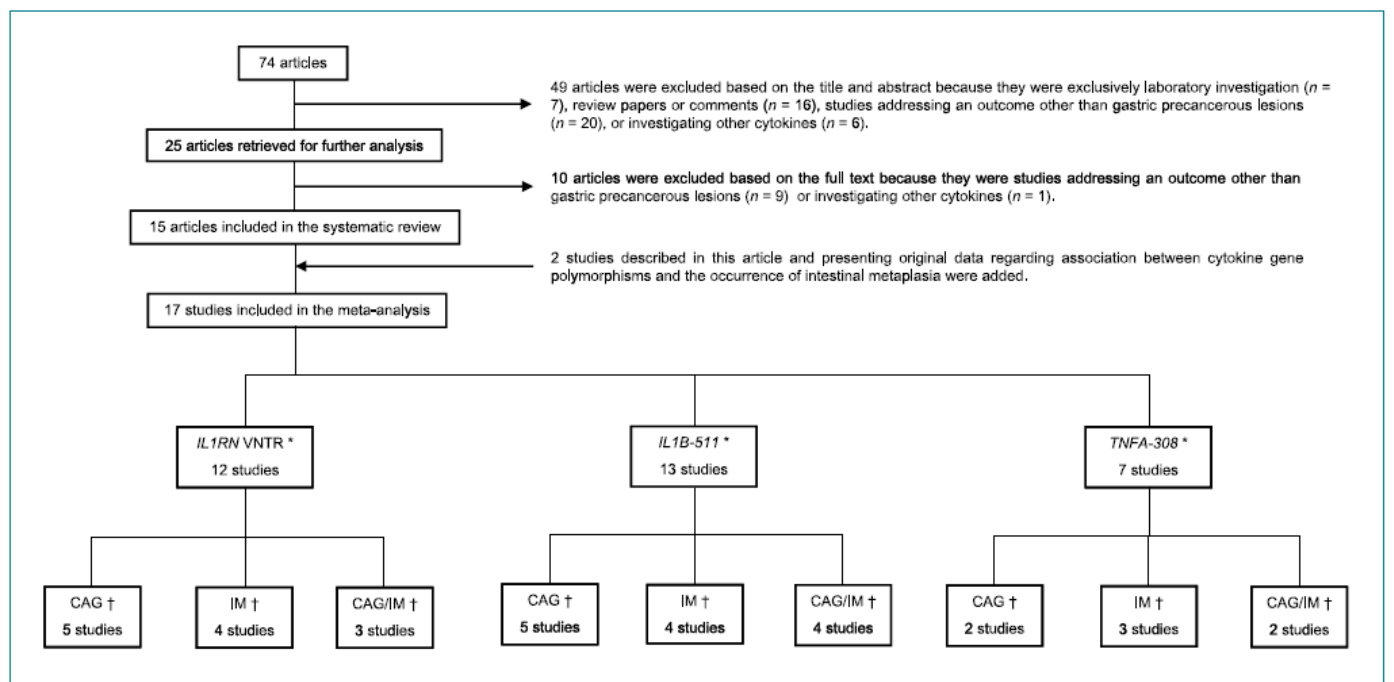

Figure 1. Systematic review flowchart. CAG, chronic atrophic gastritis; IM, intestinal metaplasia; ", exposure; $\dagger$, outcome studied 
Table 1. Association between cytokine gene polymorphisms and intestinal metaplasia in Portugal and Mozambique

\begin{tabular}{|c|c|c|c|c|c|c|}
\hline & \multicolumn{3}{|c|}{ Portugal } & \multicolumn{3}{|c|}{ Mozambique } \\
\hline & \multirow{2}{*}{$\begin{array}{c}\begin{array}{c}\text { Normal mucosa/ } \\
\text { chronic nonatrophic } \\
\text { gastritis }\end{array} \\
n(\%)\end{array}$} & \multicolumn{2}{|c|}{ Intestinal metaplasia } & \multirow{2}{*}{$\begin{array}{c}\begin{array}{c}\text { Normal mucosa/ } \\
\text { chronic nonatrophic } \\
\text { gastritis }\end{array} \\
n(\%)\end{array}$} & \multicolumn{2}{|c|}{ Intestinal metaplasia } \\
\hline & & $n(\%)$ & OR $(95 \% \mathrm{Cl})$ & & $n(\%)$ & OR $(95 \% \mathrm{Cl})^{*}$ \\
\hline \multicolumn{7}{|l|}{ IL1RN VNTR } \\
\hline LL & $79(56.8)$ & $33(43.4)$ & 1 & $81(92.0)$ & $8(100.0)$ & 1 \\
\hline L2 & 49 (35.3) & $30(39.5)$ & $1.46(0.80-2.70)$ & $6(6.8)$ & $0(0.0)$ & $0.74(0.04-14.26)$ \\
\hline 22 & $11(7.9)$ & $13(17.1)$ & $2.83(1.15-6.96)$ & $1(1.2)$ & $0(0.0)$ & $3.20(0.12-84.74)$ \\
\hline 2 carriers & $60(43.2)$ & $43(56.6)$ & $1.72(0.98-3.02)$ & $7(8.0)$ & $0(0.0)$ & $0.64(0.03-12.20)$ \\
\hline \multicolumn{7}{|l|}{ IL1B-511 } \\
\hline $\mathrm{CC}$ & $62(44.6)$ & $23(30.3)$ & 1 & $11(12.5)$ & $0(0.0)$ & 1 \\
\hline $\mathrm{CT}$ & $61(43.9)$ & $42(55.3)$ & $1.86(1.00-3.45)$ & $44(50.0)$ & $5(62.5)$ & $2.84(0.15-55.23)$ \\
\hline$\pi$ & $16(11.5)$ & $11(14.4)$ & $1.85(0.75-4.58)$ & $33(37.5)$ & $3(37.5)$ & $2.40(0.12-50.13)$ \\
\hline T carriers & 77 (55.4) & $53(69.7)$ & $1.86(1.03-3.36)$ & 77 (87.5) & $8(100.0)$ & $2.52(0.14-46.71)$ \\
\hline \multicolumn{7}{|l|}{$T_{N F A}-308^{\dagger}$} \\
\hline GG & $98(70.5)$ & $55(72.4)$ & 1 & - & - & - \\
\hline GA & $35(25.2)$ & $19(25.0)$ & $0.97(0.51-1.85)$ & - & - & - \\
\hline AA & $6(4.3)$ & $2(2.6)$ & $0.59(0.12-3.04)$ & - & - & - \\
\hline A carriers & $41(29.5)$ & $21(27.6)$ & $0.91(0.49-1.70)$ & - & - & - \\
\hline
\end{tabular}

*To each cell of the $2 \times 2$ table was added 0.5 to allow the computation of OR as a measure of association (Harris et al., 2008).

${ }^{\dagger}$ TNFA-308 polymorphisms genotyping was only available for the Portuguese sample.

One Mozambican patient with a gastric carcinoma diagnosis and individuals from both samples presenting chronic atrophic gastritis as the most severe lesion were excluded from data analysis (10 from Portugal and 5 from Mozambique), as the small number of subjects with these conditions did not allow the assessment of its specific risk factors. For analysis, the remaining participants were classified as having normal mucosa/chronic nonatrophic gastritis or intestinal metaplasia.

Two-hundred and fifteen Portuguese subjects (median age, $49 \mathrm{y}$; interquartile range, $45-54 \mathrm{y}$; all Caucasian; $94 \%$ males) and 96 Mozambican patients (median age, $36 \mathrm{y}$; interquartile range, $28-44 \mathrm{y}$; all Black; $31 \%$ males) were evaluated. We tested for the Hardy-Weinberg equilibrium among individuals with a normal mucosa/chronic nonatrophic gastritis by using a $\chi^{2}$ test or a Fisher exact test, as appropriate (20). The distributions of IL1RN VNTR (Portugal, $P=0.388$; Mozambique, $P=0.153$ ), IL1B-511 (Portugal, $P=0.866$; Mozambique, $P=0.532$ ), and TNFA-308 (Portugal, $P=0.221$ ) genotypes investigated were in Hardy-Weinberg equilibrium.

\section{Systematic Review and Meta-analysis}

PubMed was searched from inception until June 2009 for cohort, case-control, and cross-sectional studies addressing the association between IL1B, IL1RN, and TNFA polymorphisms and gastric precancerous lesions (chronic atrophic gastritis, intestinal metaplasia, or dysplasia).
Seventy-four references were retrieved using the following expression: (precancerous conditions OR "precancerous lesions" OR "atrophic gastritis" OR atrophy OR "intestinal metaplasia" OR dysplasia) AND (stomach OR gastric) AND (interleukin-1 OR IL-1 OR interleukin 1 receptor antagonist OR IL-1Ra OR IL-1RN OR tumor necrosis factor OR TNF-alpha) AND (gene OR polymorphism OR SNPs OR VNTR).

One reviewer (BP) screened all the references. Articles were excluded if they were as follows: exclusively laboratory investigation (e.g., in vitro studies, animal research), review articles or comments, studies addressing an outcome other than gastric precancerous lesions (e.g., gastric cancer, esophageal diseases), or investigating other cytokines. Reference lists of all eligible articles were hand searched to identify original reports on this topic using the same criteria, but no additional studies were retrieved. The systematic review flowchart is presented in Fig. 1.

After excluding 59 articles, we were left with a total of fifteen studies (21-35). From each study, we extracted information on publication year, country, race/ethnicity, description of sampling procedures including selection criteria, sample size, prevalence of $H$. pylori infection, outcome studied, reference group, criteria for histologic classification, polymorphisms studied, genotyping method, and respective quality control. In addition, we recorded the distribution of gene polymorphisms in the 


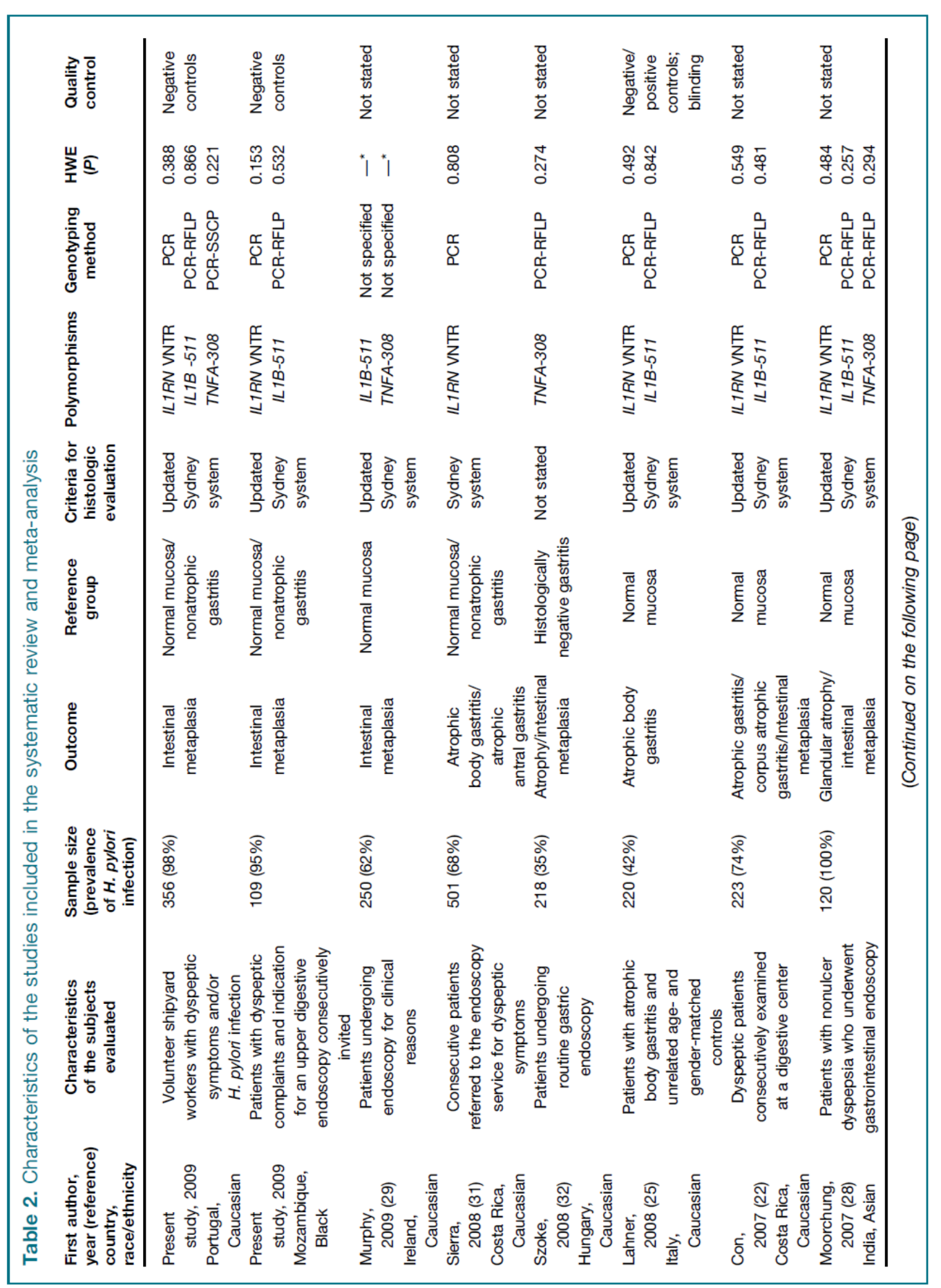




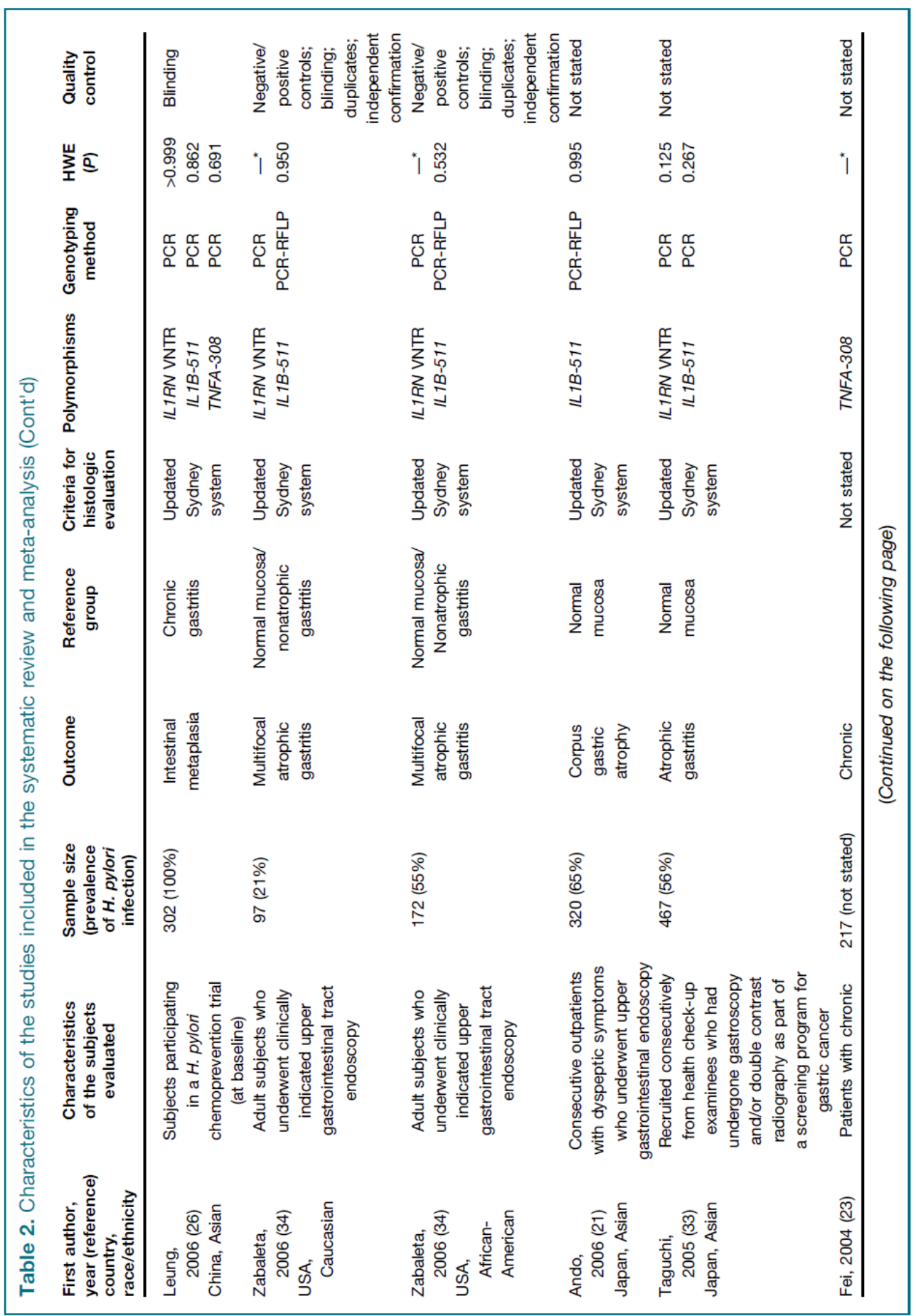




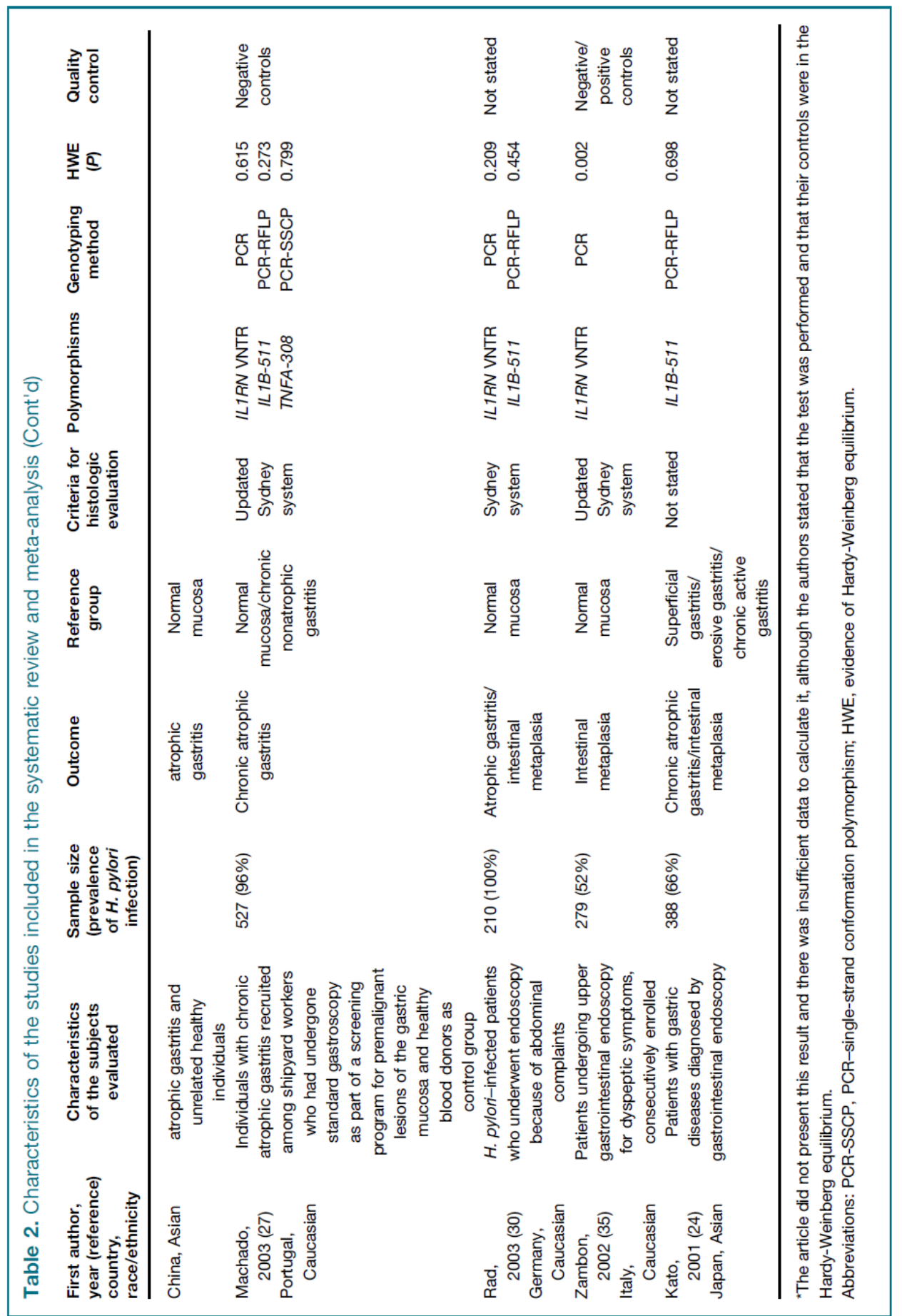


reference and precancerous lesions groups, or the odds ratio (OR) of the association between gene polymorphisms and precancerous lesions if studies did not present the counts. A total of 17 studies $(15$ studies retrieved from the systematic review plus original data from our 2 studies) were used to quantify the association between each polymorphism (IL1RN VNTR, IL1B-511, and TNFA-308) and each outcome studied (chronic atrophic gastritis, intestinal metaplasia, or both lesions).

Participants' race/ethnicity was assumed to be Caucasian for three studies $(22,31,35)$. One article provided race/ethnicity-specific risk estimates in the same report (34), and these were extracted and analyzed separately.

Part of the Portuguese sample had already been evaluated in a previous report retrieved by systematic review (27). In that report, chronic atrophic gastritis was defined as the outcome of interest, whereas in the present study, we addressed intestinal metaplasia. In the meta-analyses, we opted for the latter results, and both studies were only considered when stratifying the data by outcome studied.

\section{Statistical Analysis}

For each study, we tested for the Hardy-Weinberg equilibrium among the reference group by using a $x^{2}$ test or a Fisher exact test, as appropriate (20).

We used unconditional logistic regression to obtain OR and their $95 \%$ confidence intervals (CI) to quantify the association between the cytokine gene polymorphisms and the occurrence of intestinal metaplasia.

We added 0.5 to each cell of the $2 \times 2$ table to be able to compute the OR as a measure of association (36) for studies showing no counts in the unexposed/exposed category of the reference group or precancerous lesions group. We computed the combined OR and the corresponding 95\% CI using a random-effects model (DerSimonianLaird method; ref. 37). Between-study heterogeneity was quantified through the $I^{2}$ statistics (38)

We analyzed the data for each cytokine gene polymorphisms considering the following groups: IL1RN VNTR-L2 versus LL genotype, 22 versus LL genotype and 2 carriers versus LL genotype; IL1B-511-CT versus CC genotype, TT versus CC genotype, and T carriers versus CC genotype; TNFA-308-GA versus GG genotype, AA versus GG genotype, and A carriers versus GG genotype.

We performed sensitivity analyses for the IL1RN VNTR and IL1B-511 gene polymorphisms, excluding studies without evidence of Hardy-Weinberg equilibrium and studies not stating quality control for genotyping. We also conducted stratified analyses according to race/ethnicity, participants' characteristics, $H$. pylori prevalence, and outcome studied. No such analyses were done for the TNFA-308 gene polymorphisms due to insufficient data.

All analyses were conducted with STATA ${ }^{\circledR}$, version 9.0 (StataCorp LP).

\section{Results}

\section{Portugal and Mozambique Samples}

The prevalence of $H$. pylori infection was $99.5 \%$ in the Portuguese sample $\left(53.7 \%\right.$ cag $A$ positive, $43.2 \%$ vac $A s_{1}$, and $33.6 \% v a c A m_{1}$ ) and $95.9 \%$ among Mozambican participants (53.3\% cagA positive, $53.8 \%$ vac $A s_{1}$, and $38.0 \%$ $\left.\operatorname{vac} A m_{1}\right)$.

In the Portuguese sample, the OR for the association between intestinal metaplasia and the IL1RN*22 genotype was 2.83 (95\% CI, 1.15-6.96). It was $1.86(95 \%$ CI, 1.03-3.36) for IL1B-511 T carriers and 0.59 (95\% CI, 0.12-3.04) for TNFA-308*AA genotype. All Mozambican subjects presenting intestinal metaplasia were $\mathrm{T}$ carriers for IL1B-511 and none had the 2 allele for IL1RN (Table 1).

\section{Systematic Review and Meta-analysis}

Data on the association between cytokine gene polymorphisms and the occurrence of gastric precancerous lesions were obtained for seventeen studies, whose characteristics are given in Table 2. Six were from Asian countries (China, 2; India, 1; Japan, 3), seven were from Europe (Germany, 1; Hungary, 1; Ireland, 1; Italy, 2; Portugal, 2), two were from Central America (Costa Rica), one was from North America (United States), and one was from Africa (Mozambique). Thirteen studies were carried out in a hospital setting assessing dyspeptic patients, and four studies included volunteer subjects from screening programs. The median number of subjects evaluated was 269 , with a prevalence of H. pylori infection ranging from $35 \%$ to $100 \%$. The histologic diagnosis was based on the Sydney system for 14 studies and 7 investigated atrophy as their main outcome, whereas 5 focused on intestinal metaplasia. The remaining 5 articles studied both types of lesions, although this outcome is probably equivalent to that analyzed in the studies estimating the risk of atrophy without specifying that only subjects with chronic atrophic gastritis as the most severe lesion were considered.

Hardy-Weinberg equilibrium among the reference group was violated in one study (35). Three articles did not present this result, and there was insufficient data to calculate it, although the authors stated that the test was performed and that their controls were in the Hardy-Weinberg equilibrium $(23,29,34)$. Ten of 17 studies did not provide information on the quality control of genotypes (21-24, 28-32). In one study, the laboratory personnel performing the genotyping were blinded to the histologic diagnoses of the patients. In another study, besides blinding, at least $10 \%$ of the samples were run twice in separate assays and an independent confirmation of the results was carried out. Five studies only stated to have performed negative and/or positive controls.

For the ILIRN VNTR, we obtained data from ten studies and from our Portuguese and Mozambican 
samples (Fig. 2). Table 3 gives the corresponding pooled ORs overall and in selected strata. We observed an increased risk of gastric precancerous lesions for individuals having the 22 genotype (OR, 2.27; $95 \% \mathrm{CI}$, $1.40-3.70 ; I^{2}=26.4 \%$ ) compared with the LL genotype. Carriers of the allele 2 had an increased risk of developing gastric precancerous lesions (OR, 1.35; $95 \%$ CI, $1.12-1.63 ; I^{2}=1.4 \%$ ). When stratifying our analysis according to different study characteristics for the IL1RN VNTR gene polymorphisms, consistent positive associations were restricted to Caucasian populations, stronger associations were observed in settings with higher $H$. pylori prevalence, and all genotypes conferred an increased risk of intestinal metaplasia. No further substantial differences were observed across strata.

Concerning IL1B-511, data were available from eleven studies obtained through the systematic review and from

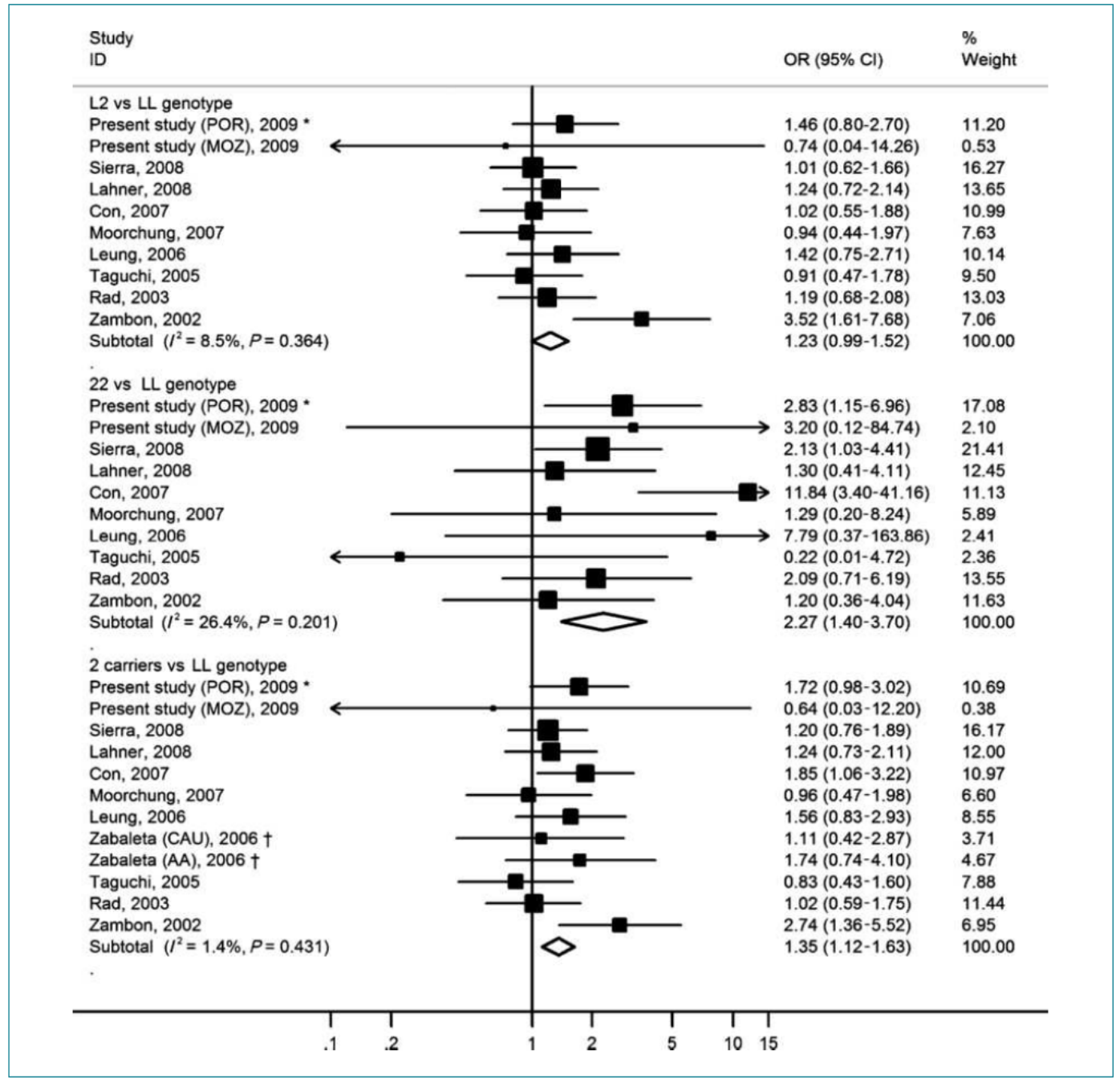

Figure 2. Association between IL1RN VNTR and gastric precancerous lesions (L2 versus LL genotype; 22 versus LL genotype; 2 carriers versus LL genotype; random-effects meta-analysis). POR, Portuguese sample; MOZ, Mozambican sample; CAU, Caucasian; AA, African-American; ", considering the Portuguese sample evaluated in the present study instead of the previous report (19) evaluating chronic atrophic gastritis in a same sample that included participants common to the present study; t, only presented data for two carriers. 
Table 3. Association between IL1RN VNTR gene polymorphisms and gastric precancerous lesions according to different inclusion criteria (random-effects meta-analysis)

\begin{tabular}{|c|c|c|c|c|c|c|c|c|c|}
\hline & \multicolumn{9}{|c|}{ IL1RN VNTR } \\
\hline & \multicolumn{3}{|c|}{ L2 vs LL } & \multicolumn{3}{|c|}{22 vs LL } & \multicolumn{3}{|c|}{2 carriers vs LL } \\
\hline & $n$ & OR $(95 \% \mathrm{Cl})$ & $I^{2}(\%)$ & $n$ & OR $(95 \% \mathrm{Cl})$ & $I^{2}(\%)$ & $n$ & OR $(95 \% \mathrm{Cl})$ & $I^{2}(\%)$ \\
\hline All studies* & 10 & $1.23(0.99-1.52)$ & 8.5 & 10 & $2.27(1.40-3.70)$ & 26.4 & 12 & $1.35(1.12-1.63)$ & 1.4 \\
\hline $\begin{array}{l}\text { Excluding the study without evidence } \\
\text { of the Hardy-Weinberg equilibrium }\end{array}$ & 9 & $1.14(0.92-1.40)$ & 0.0 & 9 & $2.47(1.46-4.18)$ & 27.3 & 11 & $1.28(1.06-1.55)$ & 0.0 \\
\hline $\begin{array}{l}\text { Excluding studies that do not state } \\
\text { quality control for genotyping }\end{array}$ & 5 & $1.60(1.10-2.32)$ & 23.4 & 5 & $1.96(1.09-3.54)$ & 0.0 & 7 & $1.60(1.22-2.09)$ & 0.0 \\
\hline \multicolumn{10}{|l|}{ Race/ethnicity ${ }^{*}$} \\
\hline Caucasian & 6 & $1.32(0.97-1.80)$ & 38.4 & 6 & $2.42(1.38-4.23)$ & 44.1 & 7 & $1.44(1.13-1.83)$ & 16.1 \\
\hline Asian & 3 & $1.08(0.73-1.61)$ & 0.0 & 3 & $1.31(0.24-7.01)$ & 23.3 & 3 & $1.09(0.74-1.61)$ & 1.1 \\
\hline African & 1 & $0.74(0.04-14.26)$ & - & 1 & $3.20(0.12-84.74)$ & - & 2 & $1.61(0.71-3.68)$ & 0.0 \\
\hline \multicolumn{10}{|l|}{ Participants characteristics ${ }^{*}$} \\
\hline Dyspeptic subjects & 7 & $1.24(0.91-1.67)$ & 29.8 & 7 & $2.24(1.25-4.01)$ & 34.4 & 9 & $1.35(1.09-1.68)$ & 1.6 \\
\hline Volunteer individuals & 3 & $1.25(0.87-1.81)$ & 0.0 & 3 & $2.15(0.49-9.44)$ & 33.4 & 3 & $1.34(0.86-2.06)$ & 33.8 \\
\hline \multicolumn{10}{|l|}{ H. pylori prevalence ${ }^{\star \dagger}$} \\
\hline$\leq 70 \%$ & 4 & $1.34(0.81-2.23)$ & 64.0 & 4 & $1.59(0.93-2.73)$ & 0.0 & 6 & $1.33(0.98-1.82)$ & 26.9 \\
\hline$>70 \%$ & 6 & $1.20(0.91-1.58)$ & 0.0 & 6 & $3.41(1.77-6.57)$ & 18.2 & 6 & $1.39(1.07-1.82)$ & 0.0 \\
\hline \multicolumn{10}{|l|}{ Outcome studied ${ }^{\star}$} \\
\hline Chronic atrophic gastritis & 4 & $1.19(0.91-1.55)$ & 0.0 & 4 & $1.65(1.02-2.66)$ & 0.0 & 6 & $1.26(1.00-1.60)$ & 0.0 \\
\hline Intestinal metaplasia & 4 & $1.79(1.11-2.89)$ & 27.7 & 4 & $2.27(1.14-4.51)$ & 0.0 & 4 & $1.86(1.30-2.65)$ & 0.0 \\
\hline Both lesions & 3 & $1.07(0.74-1.53)$ & 0.0 & 3 & $3.43(0.92-12.80)$ & 64.6 & 3 & $1.25(0.82-1.90)$ & 32.6 \\
\hline
\end{tabular}

${ }^{*}$ Considering the Portuguese sample evaluated in the present study instead of the previous report (Machado et al., 2001) evaluating chronic atrophic gastritis in a same sample that included participants common to the present study.

${ }^{\dagger}$ According to the median value of the $H$. pylori prevalence among studies.

the Portuguese and Mozambican studies reported here (Fig. 3). Table 4 gives the corresponding pooled ORs. No significant association was found between any of the genotypes and the presence of gastric precancerous lesions (e.g., TT versus CC genotype: OR, $1.34 ; 95 \%$ CI, $\left.0.87-2.07 ; I^{2}=65.7 \%\right)$. In the stratified analysis, the association between IL1B-511 polymorphisms and gastric precancerous lesions was more pronounced, showing lower between-study heterogeneity in studies conducted in high $H$. pylori prevalence settings and with intestinal metaplasia as the outcome.

When restricting our analyses to studies in populations with high $H$. pylori prevalence, associations between gene polymorphisms and gastric precancerous lesions were strengthened for IL1RN VNTR (Fig. 4) and became apparent for IL1B-511 (Fig. 5).

Regarding TNFA-308, information on the association between the gene polymorphisms and gastric precancerous lesions were available from six articles and from the Portuguese sample evaluated on this study (Fig. 6). No overall association was found between any of the genotypes and the presence of gastric precancerous lesions (e.g., AA versus GG genotype: OR, 0.93; 95\% CI, $\left.0.35-2.43 ; I^{2}=0.0 \%\right)$.

\section{Discussion}

This meta-analysis showed a positive association between IL1RN VNTR gene polymorphisms and gastric precancerous lesions. No such association was found for the IL1B-511 or the TNFA-308 gene polymorphisms.

The role of cytokine gene polymorphisms is currently a hot topic in gastric cancer research. However, even when using a sensitive and nonspecific search expression, we could only identify a relatively low number of articles from our systematic review. Despite this type of research is much more frequent using cancer as outcome, previous systematic reviews addressing the association between cytokine polymorphisms and gastric cancer had a similar yielding regarding the number of studies identified, regardless of the number of databases searched. Kamangar et al. (7) identified 35 studies after screening 131 references retrieved from PubMed, whereas Wang et al. (10) identified 39 relevant studies from 633 references retrieved from several databases (PubMed, Springer, Elsevier, Ovid, Ebsco, CNKI, and Wanfang).

Although previous meta-analyses have shown that these cytokine polymorphisms conferred an increased 
risk for gastric cancer, the overall association was moderate (5-11). In addition, results differed when stratifying the data by race/ethnicity. Associations were generally stronger in Caucasian than Asian subjects (5, 6, 8, 10, $11)$, reflecting the high prevalence of the susceptibility allele among the latter populations. Our meta-analysis yielded similar findings for gastric precancerous lesions.
We observed low to moderate heterogeneity for al genotypes, except for the IL1B-511 gene polymorphisms (moderate to high). The genetic variants addressed in this meta-analysis may influence the inflammatory response to a trigger such as $\mathrm{H}$. pylori and thereby influence the development of gastric precancerous lesions $(39,40)$. As a consequence, one would expect to see an association

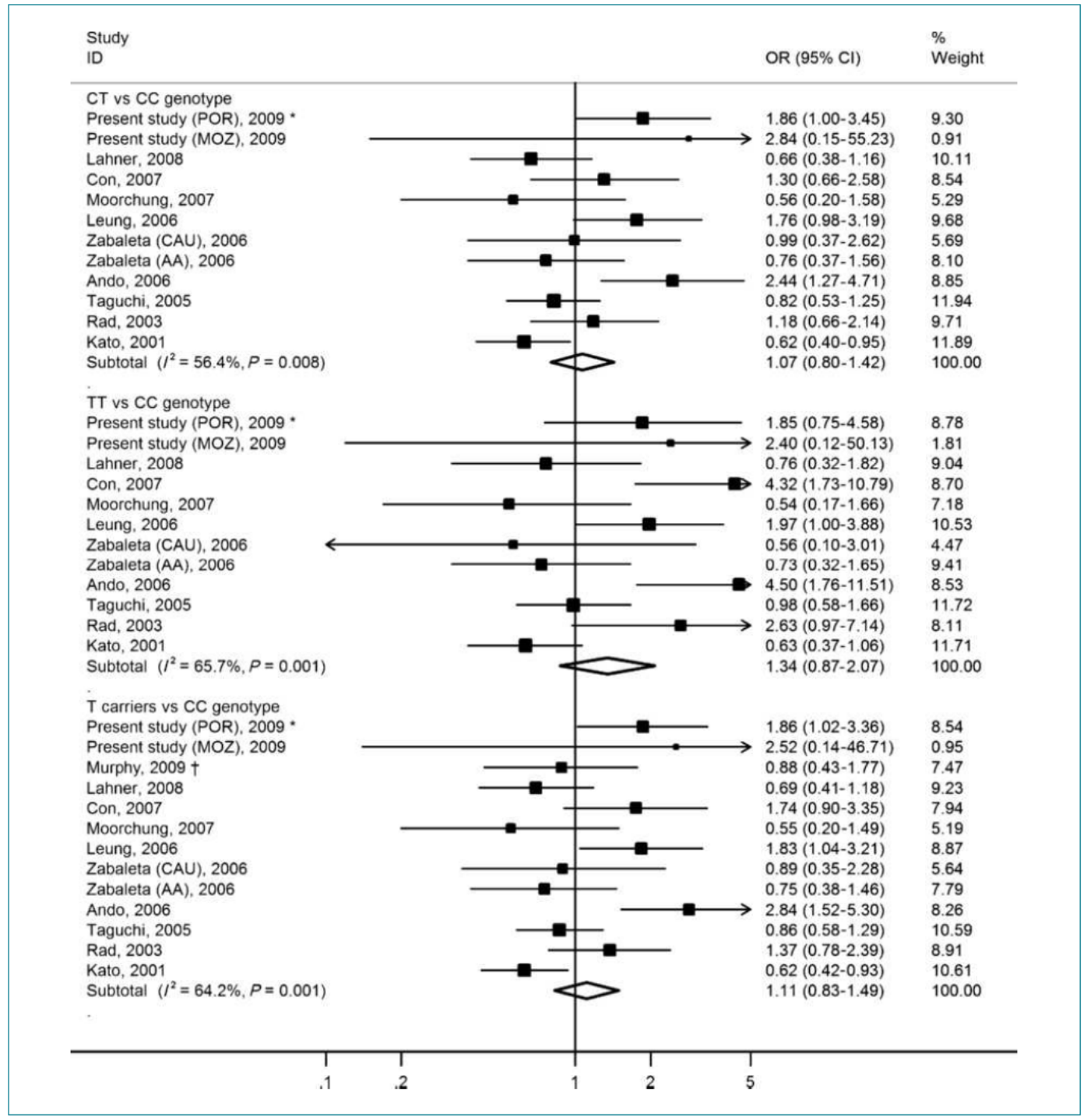

Figure 3. Association between IL1B-511 and gastric precancerous lesions (CT versus CC genotype; TT versus CC genotype; T carriers versus CC genotype; random-effects meta-analysis). POR, Portuguese sample; MOZ, Mozambican sample; CAU, Caucasian; AA, African-American; ", considering the Portuguese sample evaluated in the present study instead of the previous report (19) evaluating chronic atrophic gastritis in a same sample that included participants common to the present study; $t$, only presented data for $\mathrm{T}$ carriers. 
Table 4. Association between $I L 1 B-511$ gene polymorphisms and gastric precancerous lesions according to different inclusion criteria (random-effects meta-analysis)

\begin{tabular}{|c|c|c|c|c|c|c|c|c|c|}
\hline & \multicolumn{9}{|c|}{ IL1B-511 } \\
\hline & \multicolumn{3}{|c|}{ CT vs $\mathrm{CC}$} & \multicolumn{3}{|c|}{ TT vs CC } & \multicolumn{3}{|c|}{$\mathbf{T}$ carriers vs $\mathbf{C C}$} \\
\hline & $n$ & OR $(95 \% \mathrm{Cl})$ & $I^{2}(\%)$ & $n$ & OR $(95 \% \mathrm{Cl})$ & $I^{2}(\%)$ & $n$ & OR $(95 \% \mathrm{Cl})$ & $I^{2}(\%)$ \\
\hline All studies* ${ }^{*}$ & 12 & $1.06(0.80-1.42)$ & 56.4 & 12 & $1.34(0.87-2.07)$ & 65.7 & 13 & $1.11(0.83-1.49)$ & 64.2 \\
\hline $\begin{array}{l}\text { Excluding studies that do not state } \\
\text { quality control for genotyping }\end{array}$ & 6 & $1.14(0.74-1.77)$ & 49.1 & 6 & $1.18(0.75-1.87)$ & 21.6 & 6 & $1.14(0.73-1.76)$ & 53.7 \\
\hline \multicolumn{10}{|l|}{ Race/ethnicity* } \\
\hline Caucasian & 5 & $1.13(0.78-1.63)$ & 36.5 & 5 & $1.70(0.84-3.46)$ & 58.6 & 6 & $1.17(0.83-1.66)$ & 43.3 \\
\hline Asian & 5 & $1.06(0.62-1.80)$ & 76.9 & 5 & $1.22(0.63-2.37)$ & 77.1 & 5 & $1.10(0.62-1.97)$ & 82.3 \\
\hline African & 2 & $0.82(0.41-1.65)$ & 0.0 & 2 & $0.79(0.36-1.75)$ & 0.0 & 2 & $0.80(0.41-1.54)$ & 0.0 \\
\hline \multicolumn{10}{|l|}{ Participants characteristics ${ }^{\star}$} \\
\hline Dyspeptic subjects & 9 & $0.96(0.68-1.36)$ & 51.5 & 9 & $1.29(0.69-2.41)$ & 71.9 & 9 & $1.04(0.69-1.55)$ & 67.4 \\
\hline Volunteer individuals & 3 & $1.34(0.76-2.36)$ & 69.5 & 3 & $1.42(0.87-2.31)$ & 35.2 & 4 & $1.25(0.80-1.95)$ & 60.7 \\
\hline \multicolumn{10}{|l|}{ H. pylori prevalence ${ }^{\star \dagger}$} \\
\hline$\leq 70 \%$ & 6 & $0.89(0.60-1.31)$ & 61.5 & 6 & $0.98(0.58-1.67)$ & 63.9 & 7 & $0.91(0.63-1.32)$ & 65.7 \\
\hline$>70 \%$ & 6 & $1.40(1.04-1.87)$ & 0.0 & 6 & $1.98(1.16-3.37)$ & 38.4 & 6 & $1.54(1.15-2.06)$ & 3.8 \\
\hline \multicolumn{10}{|l|}{ Outcome studied ${ }^{*}$} \\
\hline Chronic atrophic gastritis & 6 & $1.10(0.71-1.68)$ & 66.1 & 6 & $1.20(0.70-2.05)$ & 58.6 & 6 & $1.12(0.72-1.76)$ & 72.0 \\
\hline Intestinal metaplasia & 3 & $1.82(1.20-2.78)$ & 0.0 & 3 & $1.94(1.14-3.31)$ & 0.0 & 4 & $1.54(1.06-2.23)$ & 8.0 \\
\hline Both lesions & 4 & $0.87(0.57-1.32)$ & 43.8 & 4 & $1.38(0.49-3.90)$ & 82.7 & 4 & $0.97(0.55-1.71)$ & 71.0 \\
\hline
\end{tabular}

*Considering the Portuguese sample evaluated in the present study instead of the previous report (Machado et al., 2001) evaluating chronic atrophic gastritis in a same sample that included participants common to the present study.

${ }^{\dagger}$ According to the median value of the $H$. pylori prevalence among studies.

between the genetic variants and gastric precancerous lesions only among subjects who have been exposed to an inflammatory trigger. When conducting a subgroup analysis, the associations were markedly strengthened among studies with high $H$. pylori prevalence compared with studies with low H. pylori prevalence. Furthermore, in IL1B-511, associations between gene polymorphisms and gastric precancerous lesions only became apparent in this subgroup analysis. However, H. pylori infection is not the only inflammatory trigger, and other infectious agents, salt intake, ethanol, tobacco, and nonsteroidal antiinflammatory drugs can also act as stimulants of interlukin-1 $\beta$ (IL-1 $\beta)(41,42)$, which may also justify a trend toward a positive association between IL1RN VNTR gene polymorphisms and intestinal metaplasia.

Further explanations for the between-study heterogeneity are the diversity of the outcomes studied. Although biopsy by endoscopy is often considered the gold standard for diagnosis, intraobserver and interobserver variation about the presence and the severity of the precancerous lesions has been reported to be large, especially for chronic atrophic gastritis (43-45), even when standard criteria such as those in the Sydney system are used. The misclassification of the outcome is more likely for chronic atrophic gastritis and may have accounted for the differences in summary estimates according to the outcome. On the other hand, after chronic inflammation is induced by H. pylori infection, the longstanding inhibition of gastric acid secretion by proinflammatory cytokines (46) may play a more important role in the progression to more severe lesions, namely intestinal metaplasia and cancer, than to the earlier chronic atrophic gastritis, which would also explain the stronger associations observed for intestinal metaplasia. Similarly to gastric cancer, intestinal metaplasia develops in a small proportion of subjects infected with $H$. pylori (14), and is likely to result from distinct adaptative responses to selection pressures from environmental and genetic factors.

The visual inspection of the forest plots and the relative weights of the different studies to the summary estimates do not suggest that our conclusions are driven by only a few highly influential studies. However, associations between gene polymorphisms and any outcome may be misleading if the distribution of genotypes in the control group (normally, healthy individuals) in case-control studies deviates from the Hardy-Weinberg equilibrium. These deviations may reflect selection bias (47), but the summary risk estimates remained virtually unchanged when excluding the study by Zambon et al. (35), the only one that violated the Hardy-Weinberg equilibrium and the one yielding the stronger association between IL1RN VNTR and gastric precancerous lesions. The summary risk estimates were also similar when the studies that did not state having done any quality control for genotyping were 
excluded. Heterogeneity, however, tended to decrease when these reports were not considered in the analyses.

In most geographic regions, a high prevalence of $\mathrm{H}$. pylori infection is correlated with a high incidence of gastric cancer, but some African countries report low gastric cancer rates despite the high prevalence of infection. This phenomenon has been called the African "enigma" (48), and one of the explanations for this is that different host genetic profiles may lead to a divergent immunologic response to the infection (49). The data from Mozambique are not robust, and due to its small weight in the meta-analysis, the combined estimates did not vary meaningfully after its exclusion in the sensitivity analysis. However, this is the first study to address the association between proinflammatory gene polymorphisms and gastric precancerous lesions in an African setting and these results should be regarded as a first approach to the potential role of population differences in the distribution of these susceptibility markers as an explanation for the "African enigma". All subjects with intestinal metaplasia presented the IL1B-511 susceptibility alleles, in accordance with previous reports, and there were no African intestinal metaplasia patients with the higher risk IL1RN polymorphisms, unlike what has been observed in the other settings. These results, despite the small sample size, suggest that differences in the distribution of IL1RN polymorphisms, but not in the IL1B-511 polymorphisms, are likely to contribute to the "African enigma".

Within the Portuguese sample, subjects carrying the $I L 1 R N^{*} 22$ genotype or the IL1B-511 T allele had an increased risk of developing intestinal metaplasia. The estimates from the Portuguese sample are in accordance with those from studies in other Caucasian populations, with either a high prevalence of H. pylori infection or having intestinal metaplasia as the outcome.

The present meta-analysis showed an association between IL1RN*22 and IL1B-511 TT genotypes and gastric precancerous lesions, mainly among studies conducted in high $H$. pylori prevalence samples, in accordance to what is known about the function of the ILIRN and $I L 1 B$ genes, and their potential interaction with infection. $H$. pylori infection induces both IL- $1 \beta$ and tumor necrosis factor- $\alpha(\mathrm{TNF}-\alpha)$ production, and these cytokines inhibit

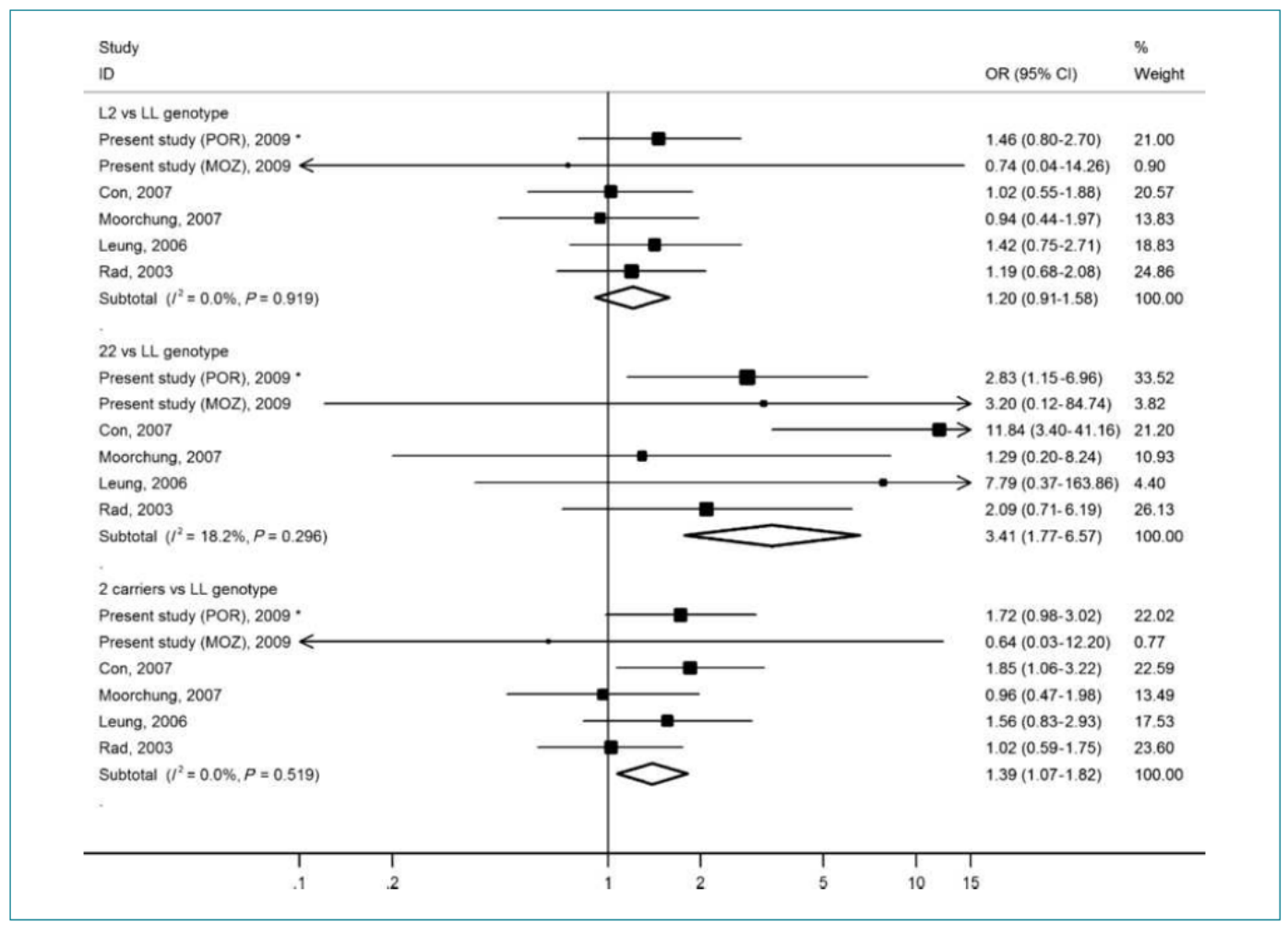

Figure 4. Association between IL1RN VNTR and gastric precancerous lesions in studies with high H. pylori prevalence (L2 versus LL genotype; 22 versus LL genotype; 2 carriers versus LL genotype; random-effects meta-analysis). POR, Portuguese sample; MOZ, Mozambican sample; ", considering the Portuguese sample evaluated in the present study instead of the previous report (19) evaluating chronic atrophic gastritis in a same sample that included participants common to the present study. 
gastric acid secretion, leading to the development of gastric precancerous lesions and cancer $(50,51)$. The IL1B gene codes for the IL-1 $\beta$ and the IL1RN gene codes for an antiinflammatory cytokine, IL-1 receptor antagonist (IL-1ra). Polymorphisms within the IL1B gene increase IL-1 $\beta$ expression and IL-1ra binds to the IL-1 receptors, modulating the proinflammatory effects of IL- $1 \beta$. Regarding the ILIRN gene, a VNTR polymorphism has been detected within intron 2 , and five allelic variants have been identified in the number of repeats varying from 2 to $6(4$, 42). The TNFA gene codes for the TNF- $\alpha$ but no association between TNFA-308 genotypes and gastric precancerous lesions were shown in our meta-analysis.

Although these cytokine polymorphisms have been the most commonly associated to gastric-related diseases, other proinflammatory cytokines have also been investigated, namely IL-8 and IL-10. Two meta-analyses suggest associations between IL10-1082 promoter and IL8-251 gene polymorphisms and gastric cancer $(52,53)$, but research on their effect in gastric precancerous lesions is scarce.
In summary, this is the first systematic review and meta-analysis addressing the association between cytokine gene polymorphisms and gastric precancerous lesions. In addition to the reports retrieved by literature search, it includes original results from two unpublished studies, one of which is the first study on this topic conducted in an African setting. We were able to identify sources of heterogeneous results across individual studies, namely race/ethnicity of the populations, $H$. pylor prevalence, and outcome studied. The small number of studies published thus far on this topic precludes the calculation of more robust summary estimates for subgroups of homogeneous studies.

Cytokine gene polymorphisms have been associated with an increased risk of gastric cancer, and a moderate association with gastric precancerous lesions was now confirmed for IL1RN VNTR with no such relation for IL1B-511 and TNFA-308. This strengthens the evidence on the role of ILIRN polymorphism at the earlier stages of gastric carcinogenesis.

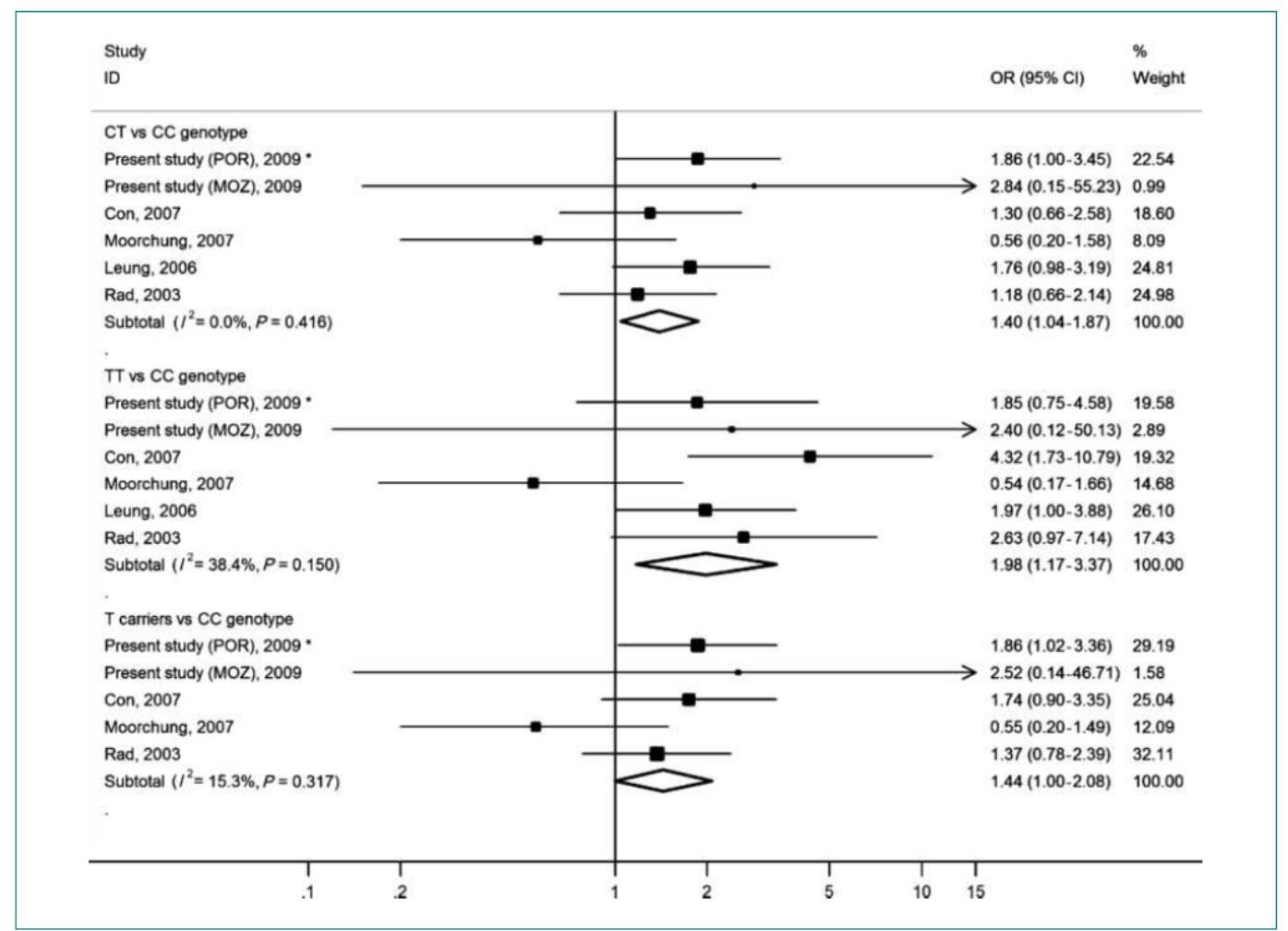

Figure 5. Association between IL1B-511 and gastric precancerous lesions in studies with high $H$. pylori prevalence (CT versus CC genotype; TT versus CC genotype; T carriers versus CC genotype; random-effects meta-analysis). POR, Portuguese sample; MOZ, Mozambican sample; ", considering the Portuguese sample evaluated in the present study instead of the previous report (19) evaluating chronic atrophic gastritis in a same sample that included participants common to the present study. 


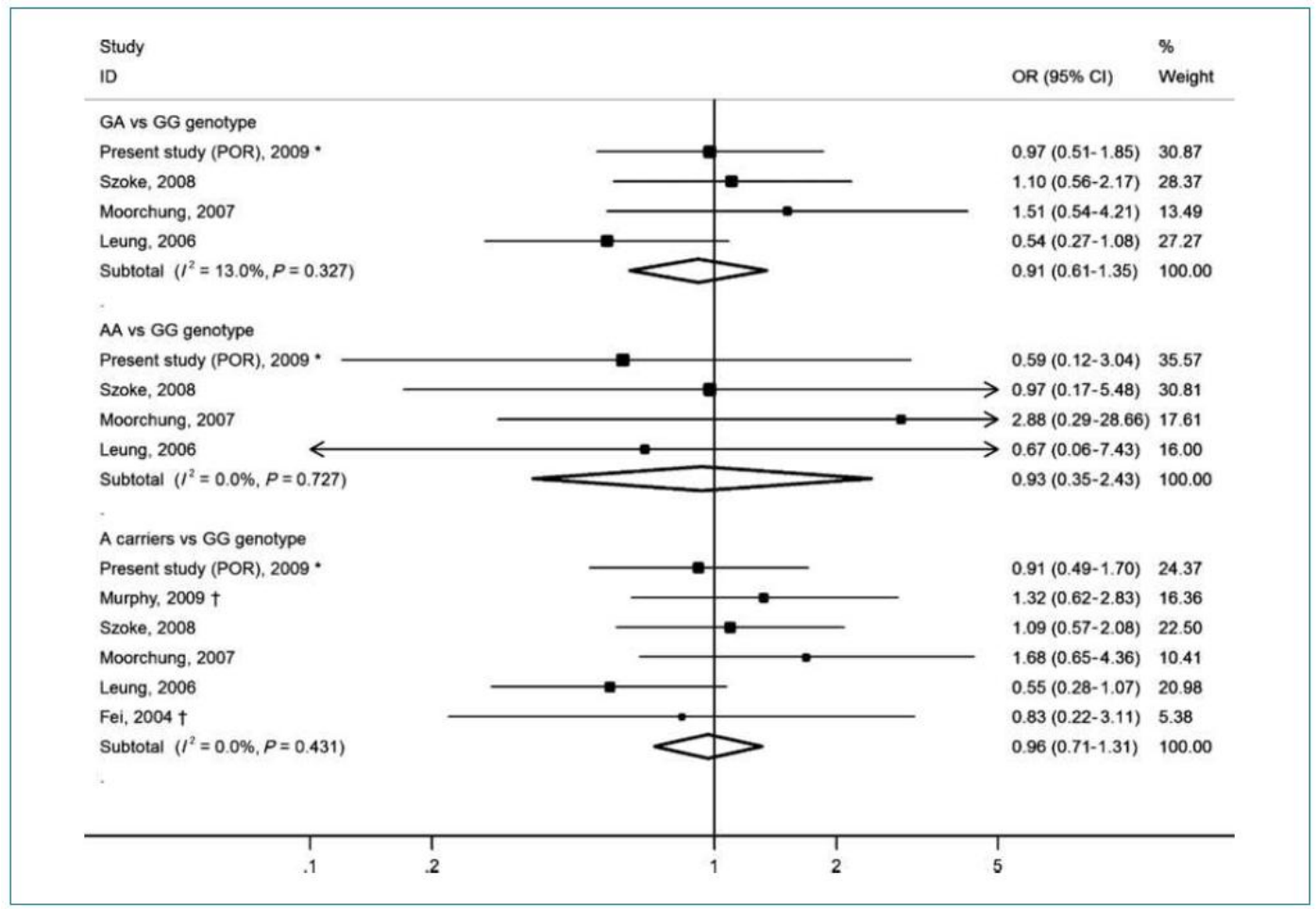

Figure 6. Association between TNFA-308 and gastric precancerous lesions (GA versus GG genotype; AA versus GG genotype; A carriers versus GG genotype; random-effects meta-analysis). POR, Portuguese sample; ", considering the Portuguese sample evaluated in the present study instead of the previous report (19) evaluating chronic atrophic gastritis in a same sample that included participants common to the present study; $t$, only presented data for A carriers.

\section{Disclosure of Potential Conflicts of Interest}

No potential conflicts of interest were disclosed.

\section{Acknowledgments}

We thank Leonor David, leader of the projects funded by Fundação Calouste Gulbenkian, for setting up the studies carried in Portugal and Mozambique.

\section{References}

1. IARC Working Group on the Evaluation of Carcinogenic Risks to Humans. Schistosomes, liver flukes and Helicobacter pylori. Lyon, 7-14 June 1994. IARC Monogr Eval Carcinog Risks Hum 1994;61:1-241.

2. Parkin DM. The global health burden of infection-associated cancers in the year 2002. Int J Cancer 2006;118:3030-44.

3. Matthews GM, Butler RN. Cellular mucosal defense during Helicobacter pylori infection: a review of the role of glutathione and the oxidative pentose pathway. Helicobacter 2005;10:298-306.

4. Gonzalez CA, Sala N, Capella G. Genetic susceptibility and gastric cancer risk. Int J Cancer 2002;100:249-60.

5. Camargo MC, Mera R, Correa P, et al. Interleukin-1 $\beta$ and interleukin-1

\section{Grant Support}

This work was supported by the Fundação Calouste Gulbenkian (project nos. FC-54918 and FC-68697) and the Fundação para a Ciência a Tecnologia (SFRH/BD/36818/2007)

The costs of publication of this article were defrayed in part by the payment of page charges. This article must therefore be hereby marked advertisement in accordance with 18 U.S.C. Section 1734 solely to indicate this fact.

Received 09/08/2009; revised 11/28/2009; accepted 12/17/2009; published OnlineFirst 03/02/2010.

receptor antagonist gene polymorphisms and gastric cancer: a metaanalysis. Cancer Epidemiol Biomarkers Prev 2006;15:1674-87.

6. Gorouhi F, Islami F, Bahrami H, Kamangar F. Tumour-necrosis factor-A polymorphisms and gastric cancer risk: a meta-analysis. $\mathrm{Br} J$ Cancer 2008;98:1443-51.

7. Kamangar F, Cheng C, Abnet CC, Rabkin CS. Interleukin-1B polymorphisms and gastric cancer risk-a meta-analysis. Cancer Epidemorphisms and gastric cancer risk-a
miol Biomarkers Prev 2006;15:1920-8.

8. Loh M, Koh KX, Yeo BH, et al. Meta-analysis of genetic polymorphisms and gastric cancer risk: variability in associations according to race. Eur J Cancer 2009;45:2562-8. 
9. Vincenzi B, Patti G, Galluzzo S, et al. Interleukin 1-511T gene (IL1 $\beta$ ) polymorphism is correlated with gastric cancer in the Caucasian population: results from a meta-analysis. Oncol Rep 2008:20:1213-20.

10. Wang $P$, Xia HH, Zhang JY, Dai LP, Xu XQ, Wang KJ. Association of interleukin-1 gene polymorphisms with gastric cancer: a metaanalysis. Int J Cancer 2007;120:552-62.

11. Zhang J, Dou C, Song $Y$, et al. Polymorphisms of tumor necrosis factor- $\alpha$ are associated with increased susceptibility to gastric cancer: a meta-analysis. J Hum Genet 2008;53:479-89.

12. Lauren PA, Nevalainen TJ. Epidemiology of intestinal and diffuse types of gastric carcinoma. A time-trend study in Finland with types of gastic carcinoma. A time-trend study in Finland 1993; $71: 2926-33$

13. Correa P, Haenszel W, Cuello C, Tannenbaum S, Archer M. A model for gastric cancer epidemiology. Lancet 1975;2:58-60.

14. Uemura N, Okamoto S, Yamamoto S, et al. Helicobacter pylori infection and the development of gastric cancer. N Engl J Med 2001;345:784-9.

15. Peleteiro B, Lunet N, Figueiredo C, Carneiro F, David L, Barros $\mathrm{H}$ Smoking, Helicobacter pylori virulence, and type of intestinal metaplasia in Portuguese males. Cancer Epidemiol Biomarkers Prev 2007;16:322-6.

16. Carrilho C, Modcoicar P, Cunha L, et al. Prevalence of Helicobacter pylori infection, chronic gastritis, and intestinal metaplasia in Mozambican dyspeptic patients. Virchows Arch 2009;454:153-60.

17. Dixon MF, Genta RM, Yardley JH, Correa P. Classification and grading of gastritis. The updated Sydney System. International Workshop on the Histopathology of Gastritis, Houston 1994. Am J Surg Pathol 1996;20:1161-81.

18. van Doorn LJ, Figueiredo C, Rossau R, et al. Typing of Helicobacter pylori vacA gene and detection of cagA gene by PCR and reverse hybridization. J Clin Microbiol 1998;36:1271-6.

19. Machado JC, Pharoah $P$, Sousa $S$, et al. Interleukin $1 B$ and interleukin 1RN polymorphisms are associated with increased risk of gastric carcinoma. Gastroenterology 2001;121:823-9.

20. Ledwina T, Gnot S. Testing for Hardy-Weinberg equilibrium. Biometrics 1980;36:161-5.

21. Ando $\mathrm{T}, \mathrm{El}-\mathrm{Omar} \mathrm{EM}$, Goto $\mathrm{Y}$, et al. Interleukin $1 \mathrm{~B}$ proinflammatory genotypes protect against gastro-oesophageal reflux disease through induction of corpus atrophy. Gut 2006;55:158-64.

22. Con SA, Con-Wong R, Con-Chin GR, et al. Serum pepsinogen levels, Helicobacter pylori CagA Status, and cytokine gene polymorphisms associated with gastric premalignant lesions in Costa Rica. Cancer Epidemiol Biomarkers Prev 2007;16:2631-6.

23. Fei BY, Xia B, Deng CS, et al. Association of tumor necrosis facto genetic polymorphism with chronic atrophic gastritis and gastric adenocarcinoma in Chinese Han population. World J Gastroenterol 2004;10:1256-61

24. Kato S, Onda M, Yamada S, Matsuda N, Tokunaga A, Matsukura N. Association of the interleukin-1 $\beta$ genetic polymorphism and gastric cancer risk in Japanese. J Gastroenterol 2001:36:696-9.

25. Lahner E, Corleto VD, D'Ambra G, Di Giulio E, Delle Fave G, Annibale $B$. Is interleukin-1 genotyping useful for the clinical management of patients with atrophic body gastritis? Aliment Pharmacol Ther 2008 27:355-65.

26. Leung WK, Chan MC, To KF, et al. H. pylori genotypes and cytokin gene polymorphisms influence the development of gastric intestinal metaplasia in a Chinese population. Am J Gastroenterol 2006;101: 714-20.

27. Machado JC, Figueiredo C, Canedo P, et al. A proinflammatory genetic profile increases the risk for chronic atrophic gastritis and gastric carcinoma. Gastroenterology 2003;125:364-71.

28. Moorchung N, Srivastava AN, Gupta NK, Ghoshal UC, Achyut BR, Mittal B. Cytokine gene polymorphisms and the pathology of chronic gastritis. Singapore Med J 2007:48:447-54.

29. Murphy G, Thornton J, McManus R, et al. Association of gastric disease with polymorphisms in the inflammatory-related genes IL-1B, IL-1RN, IL-10, TNF and TLR4. Eur J Gastroenterol Hepatol 2009;21:630-5.

30. Rad R, Prinz C, Neu B, et al. Synergistic effect of Helicobacter pylon vinulence factors and interleukin-1 polymorphisms for the develop- ment of severe histological changes in the gastric mucosa. J Infect Dis 2003;188:272-81.

31. Sierra R, Une C, Ramirez V, et al. Relation of atrophic gastritis with Helicobacter pylori-CagA $(+)$ and interleukin-1 gene polymorphisms. World J Gastroenterol 2008;14:6481-7.

32. Szoke D, Molnar B, Solymosi N, et al. T-251A polymorphism of IL-8 relating to the development of histological gastritis and G-308A polymorphism of TNF-a relating to the development of macroscopic erosion. Eur J Gastroenterol Hepatol 2008;20:191-5.

33. Taguchi A, Ohmiya N, Shirai K, et al. Interleukin-8 promoter polymorphism increases the risk of atrophic gastritis and gastric cancer in Japan. Cancer Epidemiol Biomarkers Prev 2005;14:2487-93.

34. ZabaletaJ, Camargo MC, Piazuelo MB, et al. Association of interleukin$1 \beta$ gene polymorphisms with precancerous gastric lesions in African Americans and Caucasians. Am J Gastroenterol 2006;101:163-71.

35. Zambon CF, Basso D, Navaglia F, et al. Helicobacter pylori virulence genes and host IL-1RN and IL-1 $\beta$ genes interplay in favouring the development of peptic ulcer and intestinal metaplasia. Cytokine 2002;18:242-51.

36. Sweeting MJ, Sutton AJ, Lambert PC. What to add to nothing? Use and avoidance of continuity corrections in meta-analysis of sparse data. Stat Med 2004;23:1351-75

37. Harris RJ, Bradburn MJ, Deeks JJ, Harbord RM, Altman DG, Steme JAC. Metan: fixed- and random-effects meta-analysis. Stata J 2008; 8:3-28.

38. Higgins JP, Thompson SG. Quantifying heterogeneity in a metaanalysis. Stat Med 2002;21:1539-58.

39. McNamara D, El-Omar E. Helicobacter pylori infection and the pathogenesis of gastric cancer. a paradigm for host-bacterial interactions. Dig Liver Dis 2008;40:504-9.

40. Schneider BG, Camargo MC, Ryckman KK, et al. Cytokine polymorphisms and gastric cancer risk: an evolving view. Cancer Biol Ther 2008;7:157-62.

41. Dinarello CA. Biologic basis for interleukin-1 in disease. Blood 1996; 87:2095-147.

42. El-Omar EM. The importance of interleukin $1 \beta$ in Helicobacter pylori associated disease. Gut 2001;48:743-7.

43. Aydin O, Egilmez R, Karabacak T, Kanik A. Interobserver variation in histopathological assessment of Helicobacter pylori gastritis. World J Gastroenterol 2003;9:2232-5.

44. Chen XY, van der Hulst RW, Bruno MJ, et al. Interobserver variation in the histopathological scoring of Helicobacter pylori related gastritis. J Clin Pathol 1999:52:612-5.

45. Plummer M, Buiatti E, Lopez G, et al. Histological diagnosis of precancerous lesions of the stomach: a reliability study. Int $\mathrm{J}$ Epidemiol 1997;26:716-20.

46. Macarthur M, Hold GL, El-Omar EM. Inflammation and Cancer II. Role of chronic inflammation and cytokine gene polymorphisms in the pathogenesis of gastrointestinal malignancy. Am J Physiol Gastrointest Liver Physiol 2004:286:G515-20.

47. Trikalinos TA, Salanti G, Khoury MJ, loannidis JP. Impact of violations and deviations in Hardy-Weinberg equilibrium on postulated gene-disease associations. Am J Epidemiol 2006;163:300-9.

48. Holcombe C. Helicobacter pylori: the African enigma. Gut 1992;33: 429-31.

49. Mitchell HM, Ally R, Wadee A, Wiseman M, Segal I. Major differences in the IgG subclass response to Helicobacter pylori in the first and third worlds. Scand J Gastroenterol 2002:37:517-22.

50. El-Omar EM, Carrington M, Chow WH, et al. Interleukin-1 polymorphisms associated with increased risk of gastric cancer. Nature 2000;404:398-402.

51. Hwang IR, Kodama T, Kikuchi S, et al. Effect of interleukin 1 polymorphisms on gastric mucosal interleukin $1 \beta$ production in Helicobacter pylori infection. Gastroenterology 2002;123:1793-803.

52. L $Y$ Y, Wang $Z D$, Shen $J, X U, Y C$. Meta-analysis on the relationship between IL8-251 gene polymorphism and gastric cancer. Zhonghua Yu Fang Yi Xue Za Zhi 2007;41 Suppl:39-42.

53. Zhou Y, Li N, Zhuang W, et al. Interleukin-10-1082 promoter polymorphism associated with gastric cancer among Asians. Eur J Cancer 2008;44:2648-54. 



\section{Paper VI}

Peleteiro B, Barros R, Carrilho C, Artiaga J, Cunha L, Modcoicar P, Ferreira R, Figueiredo C, Almeida R, La Vecchia C, David L, Barros H, Lunet N. Determinants of gastric CDX2 expression: a study in Mozambique.

[submitted] 



\section{Determinants of gastric CDX2 expression: a study in Mozambique}

Bárbara Peleteiro ${ }^{1,2}$, Rita Barros ${ }^{3}$, Carla Carrilho ${ }^{4,5}$, Jeronimo Artiaga ${ }^{4}$, Lina Cunha ${ }^{6}$, Prassad Modcoicar ${ }^{6}$, Rui Ferreira ${ }^{3,7}$, Céu Figueiredo ${ }^{3,7}$, Raquel Almeida ${ }^{3,7}$, Carlo La Vecchia $^{8,9}$, Leonor David ${ }^{3,7}$, Henrique Barros ${ }^{1,2}$, Nuno Lunet ${ }^{1,2}$

${ }^{1}$ Department of Hygiene and Epidemiology, Medical Faculty, University of Porto, Porto, Portugal

${ }^{2}$ Institute of Public Health - University of Porto (ISPUP), Porto, Portugal

${ }^{3}$ Institute of Molecular Pathology and Immunology - University of Porto (IPATIMUP), Porto, Portugal

${ }^{4}$ Department of Pathology, Medical Faculty, Eduardo Mondlane University, Maputo, Mozambique

${ }^{5}$ Department of Anatomical Pathology, Maputo Central Hospital, Maputo, Mozambique ${ }^{6}$ Department of Gastroenterology, Maputo Central Hospital, Maputo, Mozambique

${ }^{7}$ Department of Pathology, Medical Faculty, University of Porto, Porto, Portugal

${ }^{8}$ Istituto di Ricerche Farmacologiche "Mario Negri", Milano, Italy

${ }^{9}$ Istituto di Statistica Medica e Biometria, Università di Milano, Milano, Italy 


\section{Abstract}

Background: CDX2 expression precedes the occurrence of gastric pre-neoplastic lesions in the intestinal differentiation pathway. Studying these steps of gastric carcinogenesis may contribute to understand the early effects of the gastric cancer determinants. Our aim was to quantify the association between $H$. pylori infection and other environmental exposures and gastric expression of CDX2.

Methods: Dyspeptic subjects undergoing upper digestive endoscopy (Gastroenterology Department, Maputo Central Hospital) were invited consecutively and classified as having normal stomach/chronic non-atrophic gastritis (NS/CNAG), chronic atrophic gastritis (CAG) or intestinal metaplasia (IM). All subjects with CAG or IM and a subsample of NS/CNAG patients (gender- and age-matched, 1:2) had $H$. pylori infection assessed by histology and PCR, and were assessed for CDX2 gene expression by immunohistochemistry. Age-, gender-, education- and $H$. pylori infection-adjusted odds ratios $(\mathrm{OR})$ and $95 \%$ confidence intervals $(95 \% \mathrm{Cl})$ were computed.

Results: CDX2 expression was observed in 56 NS/CNAG (49.1\%), 39 CAG (86.7\%) and all IM patients $(n=12)$. It was more frequent among the $H$. pylori-infected $(\mathrm{OR}=2.26,95 \% \mathrm{Cl}: 1.00-5.15)$. Infection with high-virulent strains was associated with CDX2 expression in subjects with CAG (cagA $\left.A^{+}, \mathrm{OR}=3.20,95 \% \mathrm{Cl}: 1.35-7.52\right)$ and IM ( $\left.\operatorname{vac} A m_{1}, \mathrm{OR}=5.86,95 \% \mathrm{Cl}: 1.08-31.62\right)$. Subjects having a lower frequency of vegetables consumption had a higher risk of marked CDX2 expression (OR=3.64, 95\%Cl: 1.02-12.95).

Conclusion: CDX2 expression was similar to the observed in other $H$. pylori highprevalence settings. The virulence of the infecting strains and vegetables consumption were associated with CDX2 expression and may play a role in the progression to more advanced lesions. 


\section{Introduction}

Stomach cancer is among the most frequent oncologic diseases, both in developed and in developing countries, with a wide variation in incidence and mortality rates across geographical areas [1]. Approximately two thirds of all incident cases are attributed to Helicobacter pylori infection, which is the most important environmental risk factor [2] and affects more than 50\% of the world adult population [3].

Although $H$. pylori infection tends to be more frequent in regions with high gastric cancer frequency, in many African countries the high $H$. pylori prevalences coexist with low gastric cancer rates [4], which has been labelled as the African "enigma" [5]. The "intestinal" type gastric carcinomas, expectedly the most frequent in developing countries [6], are preceded by chronic atrophic gastritis, intestinal metaplasia, and dysplasia, following a set of sequential steps [7]. In Africa, however, the frequency of intestinal metaplasia is also surprisingly low [8, 9], extending the concept of the African "enigma" to precancerous lesions.

The African setting may therefore provide valuable clues to understand how the virulence of the bacterial strains [10], the host genetic susceptibility [11, 12] or other environmental exposures $[13,14]$ modulate the progression towards cancer among $H$. pylori-infected subjects. So far few investigations on this topic have been performed in this region, namely addressing the determinants of precancerous lesions. Intestinal differentiation depends on the expression of the homeobox gene CDX2 [15]. CDX2 expression occurs in pre-neoplastic lesions and can be considered a putative early step of intestinal differentiation in the cancer pathway [16]. The study of such an early outcome may allow the understanding of the role of gastric cancer determinants in the first steps of carcinogenesis.

Therefore, we aimed to quantify the association between $H$. pylori infection and other environmental risk factors and the gastric expression of CDX2.

\section{Materials and Methods}

Patients with dyspeptic complaints and indication for an upper digestive endoscopy at the Central Hospital of Maputo, Mozambique were consecutively invited for this study between August 2005 and April 2008, as previously described [9].

Four biopsy specimens (one from corpus, one from antrum, and two from incisura angularis) were taken from each subject. $H$. pylori density, chronic inflammation, polymorphonuclear activity, epithelial damage, glandular atrophy and intestinal metaplasia were scored according to the updated Sydney system [17]. The 
histological diagnosis was based upon the most severe lesion found in any biopsy specimen, from intestinal metaplasia (the most severe), chronic atrophic gastritis to chronic non-atrophic gastritis (the least severe). Subjects that did not present any lesion according to the histological evaluation were grouped with the least severe diagnosis.

\section{Assessment of environmental exposures}

Trained interviewers inquired the patients using a structured questionnaire to collect socio-demographic and behavioural data. Each subject was classified as never, former (for six or more months) or current smoker (of any amount of cigarettes) at the time of the endoscopy. For analysis, smoking habits were dichotomized in never and ever, the latter including current and former smokers. For alcohol drinking (beer, hard liquor, traditional drinks, wine), the participants were categorized according to the frequency of consumption at the time of the endoscopy in drinkers up to one drink (including never and former drinkers) or more than one drink per week. The frequency of regularly available and seasonal fruits, raw and cooked vegetables and red, white and processed meat consumption was recorded, and the total number of servings per day was computed for each of these food groups. The use of table salt was assessed by asking the participants "Do you add salt to already seasoned food, at the table?". The answer options were "never", "sometimes", "most times" and "always", and the latter three were further grouped for analysis.

\section{Assessment of $H$. pylori infection status and virulence}

H. pylori infection status was assessed by histology and by polymerase chain reaction (PCR).

The density of $H$. pylori colonization was evaluated in all biopsy specimens, and classified as absent, mild, moderate or marked. The infection status assigned to each subject was based upon the highest density of colonization observed in any biopsy.

After isolating DNA from the paraffin-embedded gastric biopsy specimen from the greater curvature of the antrum [18], H. pylori cagA and vacA ( $s$ and $m$ ) genotypes were determined by PCR followed by $2 \%$ agarose gel electrophoresis, as previously described [19]. Each subject was classified as H. pylori-infected, if testing positive for any of the genotypes, or uninfected, if negative for all genotypes. $\mathrm{H}$. pylori-infected individuals were further categorized as infected with $\operatorname{cag} A$ positive or $\operatorname{cag} A$ negative strains, and $\operatorname{vac} A s_{1}, \operatorname{vac} A s_{2}$ or $\operatorname{vac} A s_{1} / s_{2}$ strains, and $\operatorname{vac} A m_{1}, \operatorname{vac} A m_{2}$ or $\operatorname{vac} A$ $m_{1} / m_{2}$ strains. 


\section{Assessment of CDX2 expression status}

CDX2 gene expression was determined by immunohistochemistry. Sections from gastric biopsy specimens from the incisura angularis or the antrum were used. This assay was carried out using a monoclonal antibody against CDX2 (Biogenex ${ }^{\circledR}$ ), diluted 1:50, as previously described [20].

Participants were classified as negative or positive for CDX2 expression, irrespective of the extent of the staining. The extent of the staining was evaluated as the percentage of cells showing immunoreactivity, and CDX2 expression was classified as absent $(0 \%)$, mild $(1-5 \%)$, moderate $(5-25 \%)$ or marked $(>25 \%)$. We also considered the pattern of expression, and classified it as absent, isolated (staining of $\leq 3$ consecutive epithelial cells), focal (staining of $>3$ consecutive epithelial cells) or glandular (whole positive units) (Figure 1).

Figure 1 - CDX2 immunostaining in histologically non-mestaplastic cells, according to the pattern of expression: (A) isolated, staining of $\leq 3$ consecutive epithelial cells; (B) focal, staining of $>3$ consecutive epithelial cells; (C) glandular, whole positive units.

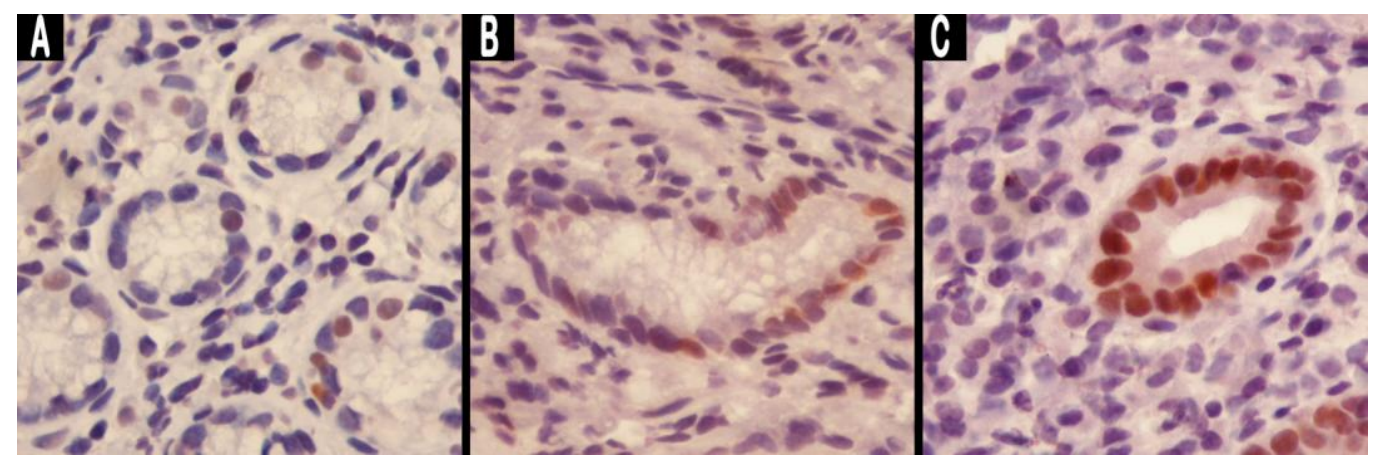

\section{Statistical analysis}

The present analysis included all subjects with cancer precursor lesions (45 participants presenting chronic atrophic gastritis [CAG] and 12 with intestinal metaplasia $[\mathrm{IM}]$ ) and gender- and age ( \pm 3 years)-matched (1:2) normal stomach/chronic non-atrophic gastritis [NS/CNAG] participants.

The association between consumption of tobacco, alcohol, fruits, vegetables, meat, salt and $H$. pylori infection status, and gastric CDX2 expression was quantified through age-, gender-, education- and H. pylori infection-adjusted odds ratios (OR) and corresponding $95 \%$ confidence intervals $(95 \% \mathrm{Cl})$, computed using multinomial logistic regression (subjects with no CDX2 expression were the reference category in all analyses) using STATA ${ }^{\circledR}$, version 9.2. 
Ethics

The study protocol was approved by the National Mozambican Ethics Committee, and written informed consent was obtained from all participants.

Results

CDX2 expression was observed in $86.7 \%$ of the individuals with CAG, most of them with mild extent $(60.0 \%)$ or isolated pattern (55.6\%) of expression, and in all IM patients, with marked glandular expression (Figure 2). Among subjects with CAG, CDX2 was expressed in $77.8 \%$ and $92.6 \%$ of men and women, respectively $(p=0.152)$. The median age of the participants was 30 years in the CAG group (30 years in those expressing CDX2 and 32 years in those not expressing CDX2) and 34 years in the IM group $(p=0.338)$.

Figure 2 - CDX2 expression among subjects with normal stomach/chronic non-atrophic gastritis, chronic atrophic gastritis and intestinal metaplasia: a) according to the extent of the staining and b) according to the pattern of expression.
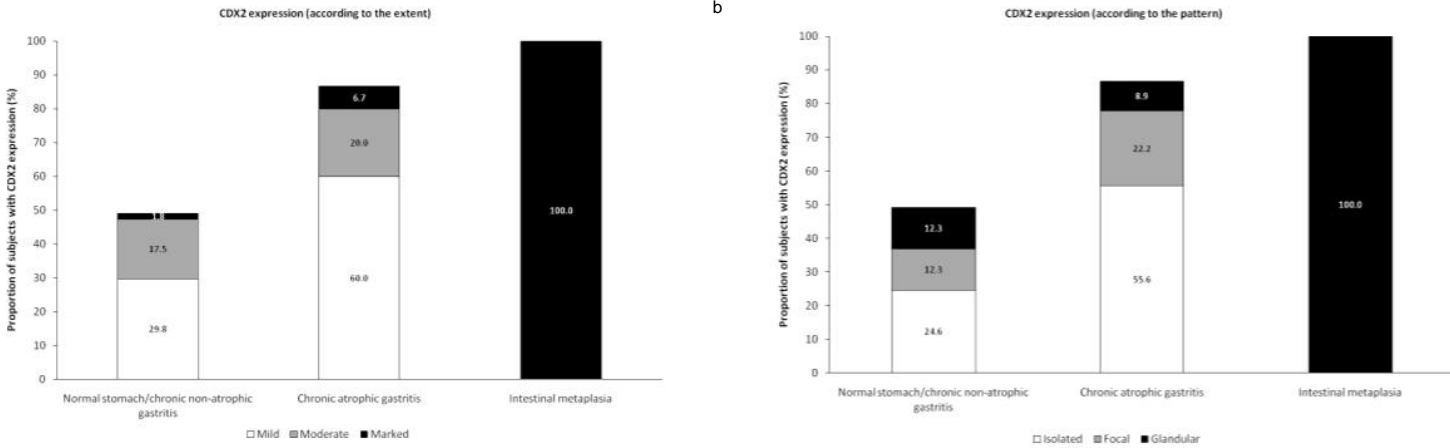

a) Extent of the staining (percentage of cells showing immunoreactivity) - mild: $1-5 \%$; moderate: 5-25\%; marked: > $25 \%$; b) Pattern of expression - isolated: staining of $\leq 3$ consecutive epithelial cells; focal: staining of $>3$ consecutive epithelial cells; glandular: whole positive units.

In the NS/CNAG group, most individuals presented a mild (29.8\%) and isolated (24.6\%) CDX2 expression (Figure 2). Among subjects with no gastric precancerous lesions, CDX2 expression was more frequent among women (56.9\% vs. $35.7 \%$, $\mathrm{p}=0.029$ ) but did not differ significantly across age groups (<30 vs. 30-40 vs. $>40$ years: $44.2 \%$ vs. $47.6 \%$ vs. $58.6 \%, p=0.471)$.

The frequency of CDX2 expression was higher among the $H$. pylori-infected, when infection status was evaluated either by histology $(\mathrm{OR}=4.70,95 \% \mathrm{Cl}$ : 2.03-10.88 for moderate/marked $H$. pylori colonization) or PCR (OR=2.26, $95 \% \mathrm{Cl}: 1.00-5.15)$ (Table 1). The association was stronger in subjects that presented with NS/CNAG or $\mathrm{CAG}$, when histology was used to assess infection, and higher OR estimates were 
observed for those with CAG or IM, when infection status was assessed by PCR (Table 1). The results were essentially the same when CDX2 expression status was defined by the extent of the staining (Table 2) or the pattern of expression (Table 3).

Infection with high-virulent strains was associated with higher frequency of CDX2 expression only in subjects with more advanced gastric lesions (cag $A^{+}$, $\mathrm{OR}=3.20,95 \% \mathrm{Cl}: 1.35-7.52$ for $\mathrm{CAG}$; vacA $m_{1}$, OR=5.86, 95\% $\mathrm{Cl}: 1.08-31.62$ for IM) (Table 1 ), or in those with higher percentage of cells expressing CDX2 (marked expression: vacA $s_{1}, \mathrm{OR}=6.49,95 \% \mathrm{Cl}$ : 1.24-33.94 and $\operatorname{vac} A m_{1}, \mathrm{OR}=5.46,95 \% \mathrm{Cl}$ : 1.26-23.62) (Table 2), or with a glandular pattern of CDX2 expression (cag $A^{+}$, OR=2.67, 95\% Cl: 1.06-6.77) (Table 3).

Marked CDX2 expression was significantly more frequent among subjects with lower frequency of vegetables consumption (OR=3.64, 95\%Cl: 1.02-12.95) (Table 2), and similar point estimates were observed for subjects with IM (OR=3.39) (Table 1) and those presenting glandular CDX2 expression (OR=2.25) (Table 3).

The odds of smoking were nearly twice higher among subjects expressing CDX2 (Table 1), and the OR ranged from 2.52 to 4.79 when only more severe lesions (Table 1) or pronounced CDX2 expression (Tables 2 and 3) were considered, but none of these results reached statistical significance.

No significant or consistent associations were observed with alcohol drinking, fruits intake, meat consumption or use of table salt (Tables 1 to 3 ). 
Table 1 - Association between Helicobacter pylori infection, lifestyles, and CDX2 expression, according to gastric histology

\begin{tabular}{|c|c|c|c|c|c|c|c|c|c|}
\hline & \multirow{3}{*}{$\begin{array}{c}\text { CDX2 negative * } \\
\mathrm{n}(\%)\end{array}$} & \multicolumn{8}{|c|}{ CDX2 positive } \\
\hline & & \multicolumn{2}{|c|}{ All subjects } & \multicolumn{2}{|c|}{$\begin{array}{l}\text { Normal stomach/Chronic } \\
\text { non-atrophic gastritis }\end{array}$} & \multicolumn{2}{|c|}{ Chronic atrophic gastritis } & \multicolumn{2}{|c|}{ Intestinal metaplasia } \\
\hline & & $\mathrm{n}(\%)$ & $\begin{array}{l}\text { Adjusted } † \text { OR } \\
(95 \% \mathrm{Cl})\end{array}$ & $\mathrm{n}(\%)$ & $\begin{array}{l}\text { Adjusted † OR } \\
(95 \% \mathrm{Cl})\end{array}$ & $\mathrm{n}(\%)$ & $\begin{array}{l}\text { Adjusted }+ \text { OR } \\
(95 \% \mathrm{Cl})\end{array}$ & $\mathrm{n}(\%)$ & $\begin{array}{l}\text { Adjusted † OR } \\
(95 \% \mathrm{Cl})\end{array}$ \\
\hline \multicolumn{10}{|l|}{ H. pylori infection status by histology } \\
\hline Negative & $24(37.5)$ & $21(19.6)$ & 1 & $10(17.9)$ & 1 & $6(15.4)$ & 1 & $5(41.7)$ & 1 \\
\hline Mild & $20(31.2)$ & $23(21.5)$ & $1.28(0.53-3.12) \ddagger$ & $14(25.0)$ & $1.65(0.57-4.78) \ddagger$ & $8(20.5)$ & $1.58(0.45-5.50) \ddagger$ & $1(8.3)$ & $0.22(0.02-2.14) \neq$ \\
\hline Moderate/Marked & $20(31.2)$ & $63(58.9)$ & $4.70(2.03-10.88) \ddagger$ & $32(57.1)$ & $5.17(1.90-14.02) \ddagger$ & $25(64.1)$ & $6.23(2.03-19.16) \ddagger$ & $6(50.0)$ & $1.89(0.47-7.54) \ddagger$ \\
\hline \multicolumn{10}{|l|}{ H. pylori infection status by PCR } \\
\hline Negative & $16(25.0)$ & $15(14.0)$ & 1 & $10(17.9)$ & 1 & $4(10.3)$ & 1 & $1(8.3)$ & 1 \\
\hline Positive & $48(75.0)$ & $92(86.0)$ & $2.26(1.00-5.15) \ddagger$ & $46(82.1)$ & $1.72(0.68-4.37) \ddagger$ & $35(89.7)$ & $3.08(0.92-10.25) \ddagger$ & $11(91.7)$ & $4.16(0.48-36.03) \ddagger$ \\
\hline \multicolumn{10}{|l|}{ cagA genotype } \\
\hline Negative (including $H$. pylori uninfected) & $38(59.4)$ & $50(46.7)$ & 1 & $32(57.1)$ & 1 & $12(30.8)$ & 1 & $6(50.0)$ & 1 \\
\hline Positive & $26(40.6)$ & $57(53.3)$ & $1.69(0.88-3.25) \ddagger$ & $24(42.9)$ & $1.11(0.52-2.37) \ddagger$ & $27(69.2)$ & $3.20(1.35-7.52) \ddagger$ & $6(50.0)$ & $1.47(0.42-5.23) \ddagger$ \\
\hline \multicolumn{10}{|l|}{ vacA s genotype § } \\
\hline$s_{2}$ (including $H$. pylori uninfected) & $25(41.7)$ & $41(38.7)$ & 1 & $24(42.9)$ & 1 & $15(39.5)$ & 1 & $2(16.7)$ & 1 \\
\hline$s_{1} / s_{2}$ & $9(15.0)$ & $14(13.2)$ & $0.76(0.27-2.13) \ddagger$ & $8(14.3)$ & $0.74(0.23-2.40) \ddagger$ & $5(13.2)$ & $0.77(0.21-2.87) \ddagger$ & $1(8.3)$ & $1.04(0.08-13.81) \ddagger$ \\
\hline$s_{1}$ & $26(43.3)$ & $51(48.1)$ & $1.10(0.54-2.25) \ddagger$ & $24(42.9)$ & $0.89(0.39-2.04) \ddagger$ & $18(47.4)$ & $1.03(0.42-2.55) \ddagger$ & $9(75.0)$ & $4.30(0.80-23.02) \ddagger$ \\
\hline \multicolumn{10}{|l|}{ vacA $\boldsymbol{m}$ genotype § } \\
\hline$m_{2}$ (including $H$. pylori uninfected) & $35(57.4)$ & $58(55.8)$ & 1 & $33(62.3)$ & 1 & $23(59.0)$ & 1 & $2(16.7)$ & 1 \\
\hline$m_{1} / m_{2}$ & $0(0.0)$ & $8(7.7)$ & - & $5(9.4)$ & & $1(2.5)$ & & $2(16.7)$ & - \\
\hline$m_{1}$ & $26(42.6)$ & $38(36.5)$ & $0.88(0.44-1.74) \ddagger$ & $15(28.3)$ & $0.64(0.28-1.46) \ddagger$ & $15(38.5)$ & $0.82(0.35-1.93) \ddagger$ & $8(66.6)$ & $5.86(1.08-31.62) \ddagger$ \\
\hline \multicolumn{10}{|l|}{ Smoking status } \\
\hline Never smoker & $59(92.2)$ & $94(87.8)$ & 1 & $49(87.5)$ & 1 & $35(89.7)$ & 1 & $10(83.3)$ & 1 \\
\hline Ever smoker & $5(7.8)$ & $13(12.2)$ & $1.91(0.58-6.34)$ & $7(12.5)$ & $1.89(0.49-7.26)$ & $4(10.3)$ & $1.56(0.35-6.91)$ & $2(16.7)$ & $4.79(0.60-37.86)$ \\
\hline \multicolumn{10}{|l|}{ Alcohol consumption (drinks/week) § } \\
\hline$\leq 1$ (including never and former drinkers) & $23(62.2)$ & $46(64.8)$ & 1 & $24(60.0)$ & 1 & $18(78.3)$ & 1 & $4(50.0)$ & 1 \\
\hline$>1$ & $14(37.8)$ & $25(35.2)$ & $0.96(0.39-2.36)$ & $16(40.0)$ & $1.21(0.45-3.30)$ & $5(21.7)$ & $0.46(0.13-1.65)$ & $4(50.0)$ & $1.69(0.31-9.25)$ \\
\hline \multicolumn{10}{|l|}{ Fruits intake (servings/day) } \\
\hline$\geq 1$ & $40(62.5)$ & $71(66.4)$ & 1 & $38(67.9)$ & 1 & $24(61.5)$ & 1 & $9(75.0)$ & 1 \\
\hline \multirow{2}{*}{\multicolumn{10}{|c|}{ Vegetables intake (servings/day) }} \\
\hline & & & & & & & & & \\
\hline$\geq 0.5$ & $35(54.7)$ & $53(49.5)$ & 1 & $34(60.7)$ & 1 & $16(41.0)$ & 1 & $3(25.0)$ & 1 \\
\hline$<0.5$ & $29(45.3)$ & $54(50.5)$ & $1.16(0.58-2.30)$ & $22(39.3)$ & $0.67(0.30-1.51)$ & $23(59.0)$ & $1.72(0.72-4.12)$ & $9(75.0)$ & $3.39(0.80-14.35)$ \\
\hline \multicolumn{10}{|l|}{ Meat intake (servings/day) } \\
\hline$\leq 0.5$ & $28(43.8)$ & $50(46.7)$ & 1 & $28(50.0)$ & 1 & $19(48.7)$ & 1 & $3(25.0)$ & 1 \\
\hline$>0.5$ & $36(56.2)$ & 57 (53.3) & $1.03(0.50-2.12)$ & $28(50.0)$ & $0.93(0.41-2.10)$ & $20(51.3)$ & $0.93(0.38-2.28)$ & $9(75.0)$ & $2.58(0.58-11.53)$ \\
\hline \multicolumn{10}{|l|}{ Use of table salt § } \\
\hline Never & $52(82.5)$ & $85(82.5)$ & 1 & $44(83.0)$ & 1 & $31(81.6)$ & 1 & $10(83.3)$ & 1 \\
\hline Sometimes/Most times/Always & $11(17.5)$ & $18(17.5)$ & $1.09(0.43-2.76)$ & $9(17.0)$ & $1.11(0.38-3.26)$ & $7(18.4)$ & $1.02(0.32-3.20)$ & $2(16.7)$ & $1.29(0.21-7.76)$ \\
\hline
\end{tabular}


Table 2 - Association between Helicobacter pylori infection, lifestyles, and CDX2 expression, according to the extent of the staining

CDX2 expression

\begin{tabular}{|c|c|c|c|c|c|c|c|}
\hline & \multicolumn{7}{|c|}{ CDX2 expression } \\
\hline & \multirow{2}{*}{$\begin{array}{c}\text { Absent } \\
\text { n (\%) }\end{array}$} & \multicolumn{2}{|r|}{ Mild } & \multicolumn{2}{|c|}{ Moderate } & \multicolumn{2}{|r|}{ Marked } \\
\hline & & $\mathrm{n}(\%)$ & $\begin{array}{c}\text { Adjusted * OR } \\
(95 \% \mathrm{Cl})\end{array}$ & $\mathrm{n}(\%)$ & $\begin{array}{c}\text { Adjusted * OR } \\
(95 \% \mathrm{Cl}) \\
\end{array}$ & $n(\%)$ & $\begin{array}{c}\text { Adjusted * OR } \\
(95 \% \mathrm{Cl})\end{array}$ \\
\hline \multicolumn{8}{|l|}{ H. pylori infection status by histology } \\
\hline Negative & $24(37.5)$ & $14(23.0)$ & 1 & $2(6.9)$ & 1 & $5(29.4)$ & 1 \\
\hline Moderate/Marked & $20(31.2)$ & $37(60.6)$ & $4.05(1.62-10.13) \dagger$ & $17(58.6)$ & $16.64(3.15-87.79) \dagger$ & $9(52.9)$ & $2.73(0.74-10.06) \dagger$ \\
\hline \multicolumn{8}{|l|}{ H. pylori infection status by PCR } \\
\hline Negative & $16(25.0)$ & $10(16.4)$ & 1 & $4(13.8)$ & 1 & $1(5.9)$ & 1 \\
\hline Positive & $48(75.0)$ & $51(83.6)$ & $1.81(0.72-4.52) \dagger$ & 25 (86.2) & $2.51(0.72-8.72) \dagger$ & $16(94.1)$ & $6.25(0.74-53.08) \dagger$ \\
\hline \multicolumn{8}{|l|}{ cagA genotype } \\
\hline Positive & $26(40.6)$ & $33(54.1)$ & $1.70(0.82-3.54) \dagger$ & $13(44.8)$ & $1.22(0.48-3.05) \dagger$ & $11(64.7)$ & $3.05(0.96-9.70) \dagger$ \\
\hline \multicolumn{8}{|l|}{$\operatorname{vacA} s$ genotype $\ddagger$} \\
\hline$s_{2}$ (including $H$. pylori uninfected) & $25(41.7)$ & $21(35.0)$ & 1 & $18(62.1)$ & 1 & $2(11.8)$ & 1 \\
\hline$s_{1} / s_{2}$ & $9(15.0)$ & $10(16.7)$ & $1.03(0.34-3.16) \dagger$ & $1(3.4)$ & $0.12(0.01-1.07) \dagger$ & $3(17.6)$ & $3.58(0.47-27.27) \dagger$ \\
\hline$s_{1}$ & $26(43.3)$ & 29 (48.3) & $1.18(0.52-2.68) \dagger$ & $10(34.5)$ & $0.46(0.17-1.26) \dagger$ & $12(70.6)$ & $6.49(1.24-33.94) \dagger$ \\
\hline \multicolumn{8}{|l|}{ vacA $\boldsymbol{m}$ genotype $\ddagger$} \\
\hline$m_{2}$ (including $H$. pylori uninfected) & $35(57.4)$ & $34(57.6)$ & 1 & $21(72.4)$ & 1 & $3(18.8)$ & 1 \\
\hline$m_{1} / m_{2}$ & $0(0.0)$ & $4(6.8)$ & - & $1(3.5)$ & - & $3(18.8)$ & - \\
\hline$m_{1}$ & $26(42.6)$ & $21(35.6)$ & $0.80(0.37-1.73) \dagger$ & $7(24.1)$ & $0.44(0.15-1.26) \dagger$ & $10(62.4)$ & $5.46(1.26-23.62) \dagger$ \\
\hline \multicolumn{8}{|l|}{ Smoking status } \\
\hline Never smoker & $59(92.2)$ & $54(88.5)$ & 1 & $26(89.7)$ & 1 & $14(82.4)$ & 1 \\
\hline \multicolumn{8}{|l|}{ Alcohol consumption (drinks/week) $\ddagger$} \\
\hline$\leq 1$ (including never and former drinkers) & $23(62.2)$ & $29(67.4)$ & 1 & $12(63.2)$ & 1 & $5(55.6)$ & 1 \\
\hline$>1$ & $14(37.8)$ & $14(32.6)$ & $0.79(0.29-2.14)$ & $7(36.8)$ & $1.22(0.34-4.31)$ & $4(44.4)$ & $1.28(0.25-6.50)$ \\
\hline \multicolumn{8}{|l|}{ Fruits intake (servings/day) } \\
\hline$\geq 1$ & $40(62.5)$ & $42(68.8)$ & 1 & $16(55.2)$ & 1 & $13(76.5)$ & 1 \\
\hline$<1$ & $24(37.5)$ & $19(31.2)$ & $0.90(0.40-2.03)$ & $13(44.8)$ & $1.92(0.70-5.27)$ & $4(23.5)$ & $0.58(0.16-2.11)$ \\
\hline \multicolumn{8}{|l|}{ Vegetables intake (servings/day) } \\
\hline$\geq 0.5$ & $35(54.7)$ & $32(52.5)$ & 1 & $17(58.6)$ & 1 & $4(23.5)$ & 1 \\
\hline$<0.5$ & $29(45.3)$ & $29(47.5)$ & $1.01(0.47-2.17)$ & $12(41.4)$ & $0.83(0.30-2.24)$ & $13(76.5)$ & $3.64(1.02-12.95)$ \\
\hline \multicolumn{8}{|l|}{ Meat intake (servings/day) } \\
\hline$\leq 0.5$ & $28(43.8)$ & $29(47.5)$ & 1 & $16(55.2)$ & 1 & $5(29.4)$ & 1 \\
\hline$>0.5$ & $36(56.2)$ & $32(52.5)$ & $0.96(0.43-2.12)$ & $13(44.8)$ & $0.85(0.31-2.32)$ & $12(70.6)$ & $2.02(0.58-7.10)$ \\
\hline \multicolumn{8}{|l|}{ Use of table salt $\ddagger$} \\
\hline Never & $52(82.5)$ & $51(86.4)$ & 1 & $20(74.1)$ & 1 & $14(82.4)$ & 1 \\
\hline Sometimes/Most times/Always & $11(17.5)$ & $8(13.6)$ & $0.74(0.25-2.21)$ & $7(25.9)$ & $2.05(0.59-7.09)$ & $3(17.6)$ & $1.24(0.26-5.74)$ \\
\hline
\end{tabular}


Table 3 - Association between Helicobacter pylori infection, lifestyles, and CDX2 expression, according to the pattern of expression.

CDX2 expression

\begin{tabular}{|c|c|c|c|c|c|c|c|}
\hline & \\
\hline & \multirow{2}{*}{$\begin{array}{c}\text { Absent } \\
\mathrm{n}(\%)\end{array}$} & \multicolumn{2}{|r|}{ Isolated } & \multicolumn{2}{|c|}{$\begin{array}{r}\text { CDXzexpression } \\
\text { Focal }\end{array}$} & \multicolumn{2}{|r|}{ Glandular } \\
\hline & & $\mathrm{n}(\%)$ & $\begin{array}{c}\text { Adjusted * OR } \\
(95 \% \mathrm{Cl})\end{array}$ & n (\%) & $\begin{array}{c}\text { Adjusted * OR } \\
(95 \% \mathrm{Cl}) \\
\end{array}$ & $\mathrm{n}(\%)$ & $\begin{array}{c}\text { Adjusted * OR } \\
(95 \% \mathrm{Cl}) \\
\end{array}$ \\
\hline \multicolumn{8}{|l|}{ H. pylori infection status by histology } \\
\hline Negative & $24(37.5)$ & $12(22.6)$ & 1 & $2(8.3)$ & 1 & $7(23.3)$ & 1 \\
\hline Mild & $20(31.2)$ & $8(15.1)$ & $0.79(0.26-2.41) \dagger$ & $10(41.7)$ & $6.79(1.24-37.15) \dagger$ & $5(16.7)$ & $0.78(0.20-3.00) \dagger$ \\
\hline Moderate/Marked & $20(31.2)$ & $33(62.3)$ & $4.23(1.65-10.86) \dagger$ & $12(50.0)$ & $11.00(2.03-59.58) \dagger$ & $18(60.0)$ & $4.06(1.33-12.42) \dagger$ \\
\hline \multicolumn{8}{|l|}{ H. pylori infection status by PCR } \\
\hline Negative & $16(25.0)$ & $8(15.1)$ & 1 & $4(16.7)$ & 1 & $3(10.0)$ & 1 \\
\hline Positive & $48(75.0)$ & $45(84.9)$ & $2.13(0.81-5.64) \dagger$ & $20(83.3)$ & $1.74(0.49-6.16) \dagger$ & $27(90.0)$ & $3.39(0.87-13.17) \dagger$ \\
\hline \multicolumn{8}{|l|}{ cagA genotype } \\
\hline Negative (including $H$. pylori uninfected) & $38(59.4)$ & $25(47.2)$ & 1 & $14(58.3)$ & 1 & $11(36.7)$ & 1 \\
\hline Positive & $26(40.6)$ & $28(52.8)$ & $1.68(0.79-3.58) \dagger$ & $10(41.7)$ & $0.98(0.36-2.66) \dagger$ & 19 (63.3) & $2.67(1.06-6.77) \dagger$ \\
\hline \multicolumn{8}{|l|}{ vacA s genotype $\ddagger$} \\
\hline$s_{2}$ (including $H$. pylori uninfected) & $25(41.7)$ & $19(36.6)$ & 1 & $13(54.2)$ & 1 & $9(30.0)$ & 1 \\
\hline$s_{1} / s_{2}$ & $9(15.0)$ & $10(19.2)$ & $1.25(0.40-3.87) \dagger$ & $1(4.2)$ & $0.15(0.02-1.45) \dagger$ & $3(10.0)$ & $0.67(0.14-3.28) \dagger$ \\
\hline$s_{1}$ & $26(43.3)$ & $23(44.2)$ & $1.12(0.48-2.61) \dagger$ & $10(41.6)$ & $0.60(0.21-1.72) \dagger$ & $18(60.0)$ & $1.80(0.66-4.96) \dagger$ \\
\hline \multicolumn{8}{|l|}{ vacA $m$ genotype $\ddagger$} \\
\hline$m_{2}$ (including $H$. pylori uninfected) & $35(57.4)$ & $30(58.8)$ & 1 & $17(70.8)$ & 1 & $11(37.9)$ & 1 \\
\hline$m_{1} / m_{2}$ & $0(0.0)$ & $4(7.8)$ & - & $0(0.0)$ & & $4(13.8)$ & - \\
\hline$m_{1}$ & $26(42.6)$ & $17(33.3)$ & $0.78(0.35-1.74) \dagger$ & $7(29.2)$ & $0.47(0.16-1.40) \dagger$ & $14(48.3)$ & $1.84(0.69-4.95) \dagger$ \\
\hline \multicolumn{8}{|l|}{ Smoking status } \\
\hline Never smoker & $59(92.2)$ & $47(88.7)$ & 1 & $21(87.5)$ & 1 & $26(86.7)$ & 1 \\
\hline Ever smoker & $5(7.8)$ & $6(11.3)$ & $1.75(0.44-6.92)$ & $3(12.5)$ & $2.01(0.38-10.77)$ & $4(13.3)$ & $2.52(0.53-12.02)$ \\
\hline \multicolumn{8}{|l|}{ Alcohol consumption (drinks/week) † } \\
\hline$\leq 1$ (including never and former drinkers) & $23(62.2)$ & $26(70.3)$ & 1 & $12(80.0)$ & 1 & $8(42.1)$ & 1 \\
\hline$>1$ & $14(37.8)$ & $11(29.7)$ & $0.73(0.26-2.05)$ & $3(20.0)$ & $0.43(0.09-2.00)$ & $11(57.9)$ & $2.72(0.80-9.31)$ \\
\hline \multicolumn{8}{|l|}{ Fruits intake (servings/day) } \\
\hline$\geq 1$ & $40(62.5)$ & $32(60.4)$ & 1 & $17(70.8)$ & 1 & $22(73.3)$ & 1 \\
\hline$<1$ & $24(37.5)$ & $21(39.6)$ & $1.26(0.56-2.86)$ & $7(29.2)$ & $0.92(0.30-2.80)$ & $8(26.7)$ & $0.72(0.26-1.99)$ \\
\hline \multicolumn{8}{|l|}{ Veqetables intake (servinqs/day) } \\
\hline$\geq 0.5$ & $35(54.7)$ & $28(52.8)$ & 1 & $15(62.5)$ & 1 & $10(33.3)$ & 1 \\
\hline$<0.5$ & $29(45.3)$ & $25(47.2)$ & $0.99(0.45-2.19)$ & $9(37.5)$ & $0.84(0.29-2.42)$ & $20(66.7)$ & $2.25(0.86-5.89)$ \\
\hline \multicolumn{8}{|l|}{ Meat intake (servings/day) } \\
\hline$\leq 0.5$ & $28(43.8)$ & $27(50.9)$ & 1 & $14(58.3)$ & 1 & $9(30.0)$ & 1 \\
\hline$>0.5$ & $36(56.2)$ & $26(49.1)$ & $0.82(0.36-1.86)$ & $10(41.7)$ & $0.76(0.26-2.21)$ & $21(70.0)$ & $2.22(0.79-6.23)$ \\
\hline \multicolumn{8}{|l|}{ Use of table salt $\ddagger$} \\
\hline Never & $52(82.5)$ & $43(86.0)$ & 1 & $20(87.0)$ & 1 & $22(73.3)$ & 1 \\
\hline Sometimes/Most times/Always & $11(17.5)$ & $7(14.0)$ & $0.80(0.26-2.48)$ & $3(13.0)$ & $0.83(0.18-3.73)$ & $8(26.7)$ & $2.18(0.67-7.11)$ \\
\hline
\end{tabular}

Pattern of CDX2 expression - isolated: staining of isolated or $\leq 3$ consecutive epithelial cells, focal: staining of $>3$ consecutive epithelial cells, glandular: whole positive units; ${ }^{*}$ adjusted for gender, age (continuous), education $(\leq 4,5-9,10-12,>12$ years) and $H$. pylori infection status, except if otherwise specified; $\dagger$ adjusted for gender, age (continuous) and education ( $\leq 4,5-9$, $10-12,>12$ years); $\ddagger$ the number of participants does not correspond to 171 due to missing data. 


\section{Discussion}

In this African population, with high prevalence of infection and low gastric cancer risk, CDX2 expression was observed in a large proportion of subjects with no precancerous lesions and in most of those with CAG or IM. H. pylori infection was associated with an increased CDX2 expression frequency, which was in general more pronounced in subjects infected with high-virulent strains $\left(\operatorname{cag} A^{+}, \operatorname{vac} A s_{1}\right.$ or $\left.\operatorname{vac} A m_{1}\right)$ and in those with low vegetables consumption.

Our results confirm that $H$. pylori infection induces CDX2 expression, a marker of intestinal differentiation that has been described as an early event in the pathway to gastric cancer, also in this African setting where CAG and IM are relatively rare. This supports the hypothesis that the low frequency of gastric cancer and precancerous lesions in Africa depends on factors that modulate the progression to more advanced lesions among the infected [4, 8]. CDX2 expression was observed in approximately two-thirds of the patients, and in half of those presenting no gastric precancerous lesions, in accordance with previous reports from $H$. pylori high-prevalence settings [21-24]. In the present study, CDX2 expression among subjects with normal or atrophic mucosa was predominantly mild and isolated, in keeping with the low gastric cancer rates registered in the country [25] and the low density of $H$. pylori colonization in these subjects [26].

Among the possible explanations for the African "enigma", the differences in the exposure to environmental factors are plausible and have been supported empirically $[4,8,27,28]$. The known relation between infection with high-virulent strains and the occurrence of precancerous lesions and their progression to cancer [29-32] is in accordance with our observation of $\operatorname{cag} A^{+}$, vacA $s_{1}$ and $\operatorname{vac} A m_{1}$ genotypes being associated with CDX2 expression only among subjects with more advanced lesions. However, the frequency of infection with high-virulent strains in Africa is similar to that observed in high-risk countries [33,34] and the differences in gastric cancer rates across countries can hardly be directly ascribed to a heterogeneous distribution of the infection with more virulent strains.

Associations between smoking and CDX2 expression were not statistically significant in our study, although point estimates suggest a strong association between this factor and CDX2 expression, especially in the more advanced steps of carcinogenesis. This is in accordance with previous ecological data and individualbased observational studies conducted among $H$. pylori-infected subjects supporting an important role of smoking as a modulator of the progression to cancer [8, 29, 35]. The relatively low exposure to tobacco smoking observed in the Mozambican 
population [36] complies with the low frequency of CAG, IM and gastric cancer in this setting.

We found a consistent association between the low frequency of vegetables consumption and a more pronounced CDX2 expression, in line with previous studies showing a protective effect towards the development of intestinal metaplasia $[35,37$, 38]. Nevertheless, this does not provide a potential explanation for the low frequency of gastric lesions in this $H$. pylori high-prevalence setting, as less than half of the Mozambicans report a daily consumption of vegetables [36, 39].

Despite that high salt and meat intake and low fruits consumption are probable risk factors for gastric cancer [40-43], we found no significant associations between these exposures and CDX2 expression in our study. Although this could point to a role of these dietary factors in the steps of carcinogenesis closer to stomach cancer [35], not detectable by our study, a very low consumption of these food items in the African setting hampers the detection of subtle changes in risk. In fact, about $60 \%$ of the Mozambicans report a less than daily fruit consumption [36, 39], as well as low estimates of meat intake are observed, with a food supply of $8.3 \mathrm{Kg} / \mathrm{capita} / \mathrm{year}$ compared with $86.2 \mathrm{Kg} / \mathrm{capita} / \mathrm{year}$ in the European Union [44], and in Africa salt excretion is generally much lower than in Western countries [45]. Under these circumstances, the effect of other environmental factors may easily overcome the subtle impact of dietary exposures. In settings with a high prevalence of infection in the general population, the effect of salt exposure may be more difficult to detect among subjects with an already higher risk due to infection, namely with the more virulent strains [46, 47]. Furthermore, the inconsistency of our results may be explained by the fact that salt is a natural component of most foods and that it can also be added during cooking which was not accounted for in this study.

Our conclusions are limited by the small sample size and the lack of validated methods to evaluate dietary exposures, but our study is the first to assess the determinants of very early steps of intestinal differentiation in an African population. This provides relevant data to understand the low frequency of gastric lesions under such high prevalences of infection, although other factors could also contribute to explain the "enigma". In Africa, H. pylori is acquired early in life [48] and in many subjects it coexists with other bacterial or parasitic infections [49]. These factors may modulate the immune response to infection, and while in developed countries a $\mathrm{T}$ helper (Th) 1 response is predominant, a Th2 response is more frequent in developing countries, which could contribute to a lower gastric cancer risk in the latter settings [50]. Also, the host genetic profile could influence the response to $H$. pylori infection $[12,51$ 53], and, in Mozambique, a divergent distribution of IL1RN polymorphisms could 
contribute to explain the observed differences, as a significant lower proportion of carriers of the risk allele (ILRN*2) are observed [12, 33].

Further studies in larger samples and in other African countries are needed to confirm our results, aiming to properly identify the determinants of gastric carcinogenesis, such as genetic host factors or environmental exposures, which could contribute to the interruption of progression or even lead to regression of gastric lesions in African settings.

\section{References}

1. Curado MP, Edwards B, Shin HR, et al., editors. Cancer Incidence in Five Continents, Vol. IX. Lyon: IARC Scientific Publications No. 160; 2007.

2. Eslick GD. Helicobacter pylori infection causes gastric cancer? A review of the epidemiological, meta-analytic, and experimental evidence. World $J$ Gastroenterol 2006;12:2991-9.

3. Parkin DM. The global health burden of infection-associated cancers in the year 2002. Int J Cancer 2006;118:3030-44.

4. Lunet $\mathrm{N}$, Barros $\mathrm{H}$. Helicobacter pylori infection and gastric cancer: facing the enigmas. Int J Cancer 2003;106:953-60.

5. Holcombe C. Helicobacter pylori: the African enigma. Gut 1992;33:429-31.

6. Lauren PA, Nevalainen TJ. Epidemiology of intestinal and diffuse types of gastric carcinoma. A time-trend study in Finland with comparison between studies from high- and low-risk areas. Cancer 1993;71:2926-33.

7. Correa P, Haenszel W, Cuello C, et al. A model for gastric cancer epidemiology. Lancet 1975;2:58-60.

8. Peleteiro B, Bastos J, Barros $\mathrm{H}$, et al. Systematic review of the prevalence of gastric intestinal metaplasia and its area-level association with smoking. Gac Sanit 2008;22:236-47; discussion 46-7.

9. Carrilho C, Modcoicar P, Cunha L, et al. Prevalence of Helicobacter pylori infection, chronic gastritis, and intestinal metaplasia in Mozambican dyspeptic patients. Virchows Arch 2009;454:153-60.

10. Huang JQ, Zheng GF, Sumanac K, et al. Meta-analysis of the relationship between cagA seropositivity and gastric cancer. Gastroenterology 2003;125:1636-44.

11. Kamangar F, Cheng C, Abnet CC, et al. Interleukin-1B polymorphisms and gastric cancer risk--a meta-analysis. Cancer Epidemiol Biomarkers Prev 2006;15:19208. 
12. Peleteiro B, Lunet N, Carrilho C, et al. Association between cytokine gene polymorphisms and gastric precancerous lesions: systematic review and metaanalysis. Cancer Epidemiol Biomarkers Prev 2010;19:762-76.

13. Ladeiras-Lopes R, Pereira AK, Nogueira A, et al. Smoking and gastric cancer: systematic review and meta-analysis of cohort studies. Cancer Causes Control 2008;19:689-701.

14. Tsugane S, Sasazuki S. Diet and the risk of gastric cancer: review of epidemiological evidence. Gastric Cancer 2007;10:75-83.

15. Guo RJ, Suh ER, Lynch JP. The role of Cdx proteins in intestinal development and cancer. Cancer Biol Ther 2004;3:593-601.

16. Almeida R, Silva E, Santos-Silva F, et al. Expression of intestine-specific transcription factors, CDX1 and CDX2, in intestinal metaplasia and gastric carcinomas. J Pathol 2003;199:36-40.

17. Dixon MF, Genta RM, Yardley JH, et al. Classification and grading of gastritis. The updated Sydney System. International Workshop on the Histopathology of Gastritis, Houston 1994. Am J Surg Pathol 1996;20:1161-81.

18. Gonzalez CA, Figueiredo C, Lic CB, et al. Helicobacter pylori cagA and vacA Genotypes as Predictors of Progression of Gastric Preneoplastic Lesions: A LongTerm Follow-Up in a High-Risk Area in Spain. Am J Gastroenterol 2011.

19. van Doorn LJ, Figueiredo C, Sanna R, et al. Clinical relevance of the cagA, vacA, and iceA status of Helicobacter pylori. Gastroenterology 1998;115:58-66.

20. Barros R, Pereira B, Duluc I, et al. Key elements of the BMP/SMAD pathway co-localize with CDX2 in intestinal metaplasia and regulate CDX2 expression in human gastric cell lines. J Pathol 2008;215:411-20.

21. Satoh $\mathrm{K}$, Mutoh $\mathrm{H}$, Eda A, et al. Aberrant expression of CDX2 in the gastric mucosa with and without intestinal metaplasia: effect of eradication of Helicobacter pylori. Helicobacter 2002;7:192-8.

22. Eda A, Osawa $\mathrm{H}$, Yanaka $\mathrm{I}$, et al. Expression of homeobox gene CDX2 precedes that of CDX1 during the progression of intestinal metaplasia. $J$ Gastroenterol 2002;37:94-100.

23. Shiotani $\mathrm{A}$, lishi $\mathrm{H}$, Uedo $\mathrm{N}$, et al. Helicobacter pylori-induced atrophic gastritis progressing to gastric cancer exhibits sonic hedgehog loss and aberrant CDX2 expression. Aliment Pharmacol Ther 2006;24 Suppl 4:71-80.

24. Barros R, Peleteiro $B$, Almeida $R$, et al. Relevance of high virulence Helicobacter pylori strains and futility of CDX2 expression for predicting intestinal metaplasia after eradication of infection. Scand J Gastroenterol 2010;45:828-34. 
25. Prates MD, Torres FO. A cancer survey in Lourenco Marques, Portuguese East Africa. J Natl Cancer Inst 1965;35:729-57.

26. Lunet N, Peleteiro B, Carrilho C, et al. Sensitivity is not an intrinsic property of a diagnostic test: empirical evidence from histological diagnosis of Helicobacter pylori infection. BMC Gastroenterol 2009;9:98.

27. Correa P, Piazuelo MB. Natural history of Helicobacter pylori infection. Dig Liver Dis 2008;40:490-6.

28. Nneli RO, Nwafia WC, Orji JO. Diets/Dietary habits and certain gastrointestinal disorders in the tropics: a review. Niger J Physiol Sci 2007;22:1-13.

29. Peleteiro B, Lunet N, Figueiredo C, et al. Smoking, Helicobacter pylori virulence, and type of intestinal metaplasia in Portuguese males. Cancer Epidemiol Biomarkers Prev 2007;16:322-6.

30. Warburton VJ, Everett S, Mapstone NP, et al. Clinical and histological associations of cagA and vacA genotypes in Helicobacter pylori gastritis. J Clin Pathol 1998;51:55-61.

31. Nogueira C, Figueiredo C, Carneiro F, et al. Helicobacter pylori genotypes may determine gastric histopathology. Am J Pathol 2001;158:647-54.

32. Zambon CF, Navaglia F, Basso D, et al. Helicobacter pylori babA2, cagA, and s1 vacA genes work synergistically in causing intestinal metaplasia. J Clin Pathol 2003;56:287-91.

33. Peleteiro B, Carrilho C, Modcoicar $\mathrm{P}$, et al. Chronic atrophic gastritis, intestinal metaplasia, Helicobacter pylori virulence, IL1RN polymorphisms, and smoking in dyspeptic patients from Mozambique and Portugal. Helicobacter 2009;14:306-8.

34. Sugimoto M, Yamaoka Y. The association of vacA genotype and Helicobacter pylori-related disease in Latin American and African populations. Clin Microbiol Infect 2009;15:835-42.

35. Kato I, Vivas J, Plummer M, et al. Environmental factors in Helicobacter pylorirelated gastric precancerous lesions in Venezuela. Cancer Epidemiol Biomarkers Prev 2004;13:468-76.

36. Padrao P, Silva-Matos C, Damasceno A, et al. Association between tobacco consumption and alcohol, vegetable and fruit intake across urban and rural areas in Mozambique. J Epidemiol Community Health 2010.

37. Jedrychowski W, Popiela T, Drews M, et al. Effect of Helicobacter pylori infection, smoking and dietary habits on the occurrence of antrum intestinal metaplasia. Clinico-epidemiological study in Poland. Pol J Pathol 1999;50:289-95. 
38. Russo A, Maconi G, Spinelli $P$, et al. Effect of lifestyle, smoking, and diet on development of intestinal metaplasia in $\mathrm{H}$. pylori-positive subjects. Am J Gastroenterol 2001;96:1402-8.

39. Padrao P, Damasceno A, Silva-Matos C, et al. Alcohol consumption in Mozambique: Regular consumption, weekly pattern and binge drinking. Drug Alcohol Depend 2010.

40. World Cancer Research Fund, American Institute for Cancer Research. Food, Nutrition, Physical Activity, and the Prevention of Cancer: a Global Perspective. Washington DC: AICR, 2007.

41. Larsson SC, Orsini N, Wolk A. Processed meat consumption and stomach cancer risk: a meta-analysis. J Natl Cancer Inst 2006;98:1078-87.

42. Lunet N, Lacerda-Vieira A, Barros H. Fruit and vegetables consumption and gastric cancer: a systematic review and meta-analysis of cohort studies. Nutr Cancer 2005;53:1-10.

43. Wang $X Q$, Terry PD, Yan $H$. Review of salt consumption and stomach cancer risk: epidemiological and biological evidence. World J Gastroenterol 2009;15:2204-13.

44. Food and Agriculture Organization of the United Nations. FAO food balance sheets in 2007. Available from: URL: http://www.fao.org. Accessed March 11, 2011.

45. Lunet $\mathrm{N}$, Barros $\mathrm{H}$. Helicobacter pylori infection and gastric cancer: facing the enigmas (Part II). Reply to Tokudome et al. Int J Cancer 2004;112:168-9.

46. Pintalhao M, Dias-Neto M, Peleteiro B, et al. Salt intake and type of intestinal metaplasia in Helicobacter pylori-infected Portuguese men. Nutr Cancer 2010;62:115360.

47. Peleteiro B, Lopes C, Figueiredo C, et al. Salt intake and gastric cancer risk according to Helicobacter pylori infection, smoking, tumour site and histological type. $\mathrm{Br}$ J Cancer 2011;104:198-207.

48. Lunet $\mathrm{N}$, Barros $\mathrm{H}$. Helicobacter pylori infection and gastric cancer in developing countries: revisiting the "enigmas". In: Ly A, Khayat D, editors. About cancer in Africa: from epidemiology to biomedical applications and perspectives. Paris: INCa; 2006. p. 257-72.

49. Mbulaiteye SM, Gold BD, Pfeiffer RM, et al. H. pylori-infection and antibody immune response in a rural Tanzanian population. Infect Agent Cancer 2006;1:3.

50. Mitchell HM, Ally R, Wadee A, et al. Major differences in the IgG subclass response to Helicobacter pylori in the first and third worlds. Scand $J$ Gastroenterol 2002;37:517-22.

51. Chetty R, Naidoo R, Tarin M, et al. Chromosome $2 p, 3 p, 5 q$ and $18 q$ status in sporadic gastric cancer. Pathology 2002;34:275-81. 
52. Thye $T$, Burchard GD, Nilius $M$, et al. Genomewide linkage analysis identifies polymorphism in the human interferon-gamma receptor affecting Helicobacter pylori infection. Am J Hum Genet 2003;72:448-53.

53. Nyerere K, Sayed S, Revathi G, et al. Prevalence of gastric mucosal interleukin1 polymorphisms in Kenyan patients with advanced gastric cancer. $S$ Afr Med $J$ 2009;99:95-7. 

General Discussion 

This thesis aimed to contribute to clarify the role of Helicobacter pylori infection in the web of gastric cancer causation, by addressing two main research questions:

A) Is $H$. pylori infection a necessary condition for the occurrence of gastric cancer?

B) Which factors modulate the progression towards cancer in $H$. pylori-infected subjects?

The framework to address the characteristics of the causal relation between $H$. pylori and gastric cancer may be illustrated by figure 7, below.

Figure 7. Causal mechanisms leading to gastric cancer.

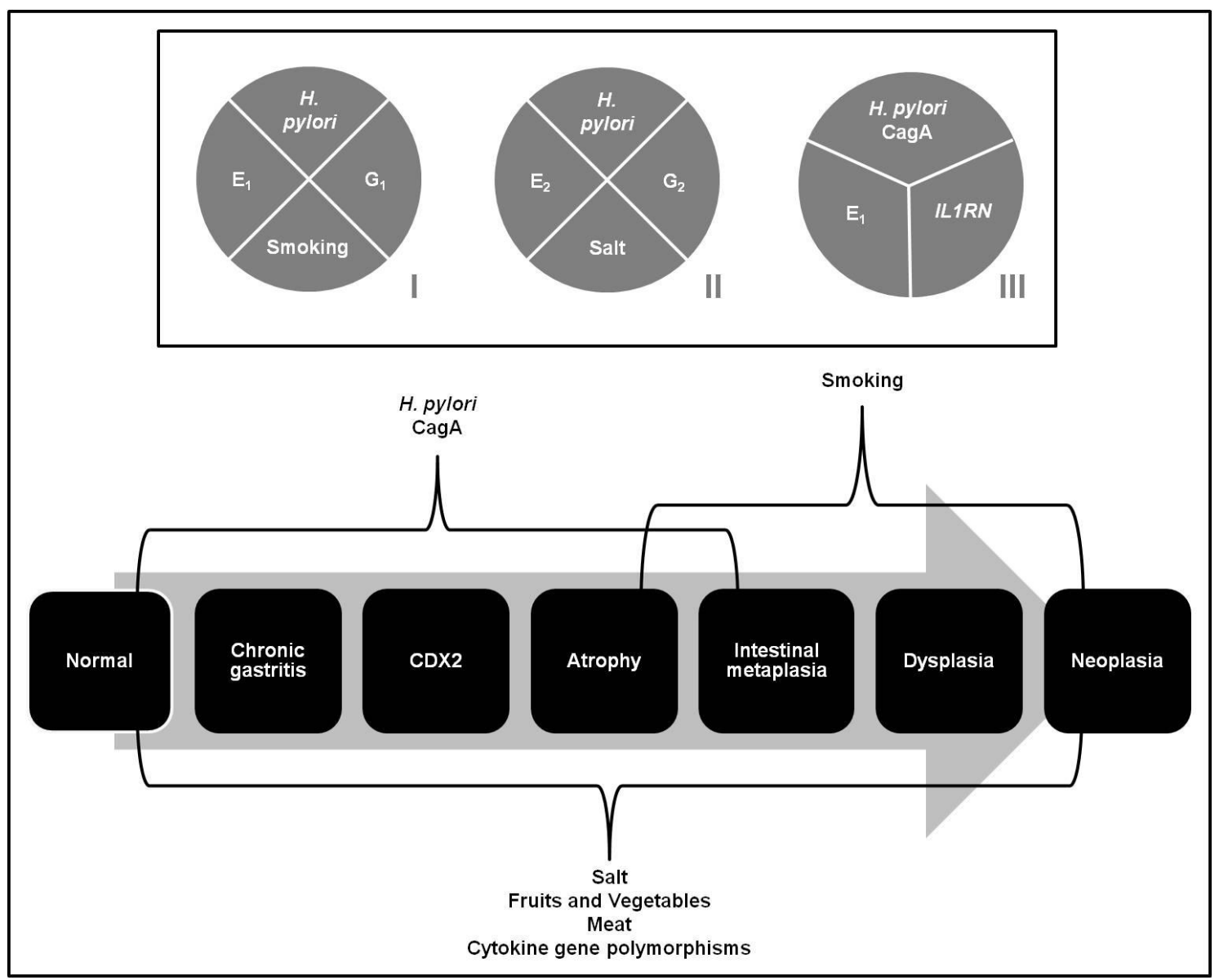

The pie-chart diagrams illustrate the model proposed by Rothman (53) and the arrow describing the sequence from normal gastric mucosa to cancer is based on Correa's model for gastric carcinogenesis $(44,55)$. The latter takes into account our 
current understanding of gastric cancer aetiology, both regarding the establishment of additional intermediate stages in carcinogenesis, such as CDX2 expression, and the recognition of 'new' (e.g., IL1RN gene polymorphisms) or the confirmation of 'old' (e.g., salt) risk factors and the identification of the steps in which they act.

Our studies support the role of $H$. pylori as a necessary component cause in gastric cancer through different lines of evidence.

Claiming an exposure as a necessary cause implies its presence in all cases of the disease. Under such hypothesis, the strength of association is expectedly high, much higher than the 2-fold increase shown in previous meta-analyses addressing the association between $H$. pylori infection and gastric cancer $(50,56,67-72)$. Our results from paper I show that methodological limitations in study design and selection of the participants lead to an underestimation of the magnitude of the association occurring in case-control studies conducted in high-prevalence settings $(157,158)$. Furthermore, almost $100 \%$ of our noncardia cancer cases were found to be infected with CagApositive strains (as detected by the presence of the CagA band in the western blot evaluation), possibly reflecting a higher sensitivity of this method to detect prior $H$. pylori infection $(82,159)$. On the other hand, it is possible that infection with CagApositive strains represents a necessary component cause in the different mechanisms leading to gastric cancer, requiring a smaller number of other component causes than mechanisms including infection with $H$. pylori strains with lower virulence, as depicted in figure 7.

The results from paper II provide further support to the hypothesis of $H$. pylori being a necessary cause by confirming recent evidence regarding its association also with gastric cardia cancer. This finding is consistent with the results obtained in samples from populations with high prevalence of infection and high risk of gastric cancer (72), and probably reflects the predominance of the cardia cancer subtype arising from $H$. pylori-induced atrophic gastritis in these settings.

Regarding the second major research question, our studies allow the identification of factors that modulate the progression towards cancer in $\mathrm{H}$. pyloriinfected subjects and provide evidence regarding which steps they may act on, namely by comparing the results obtained in Portugal and Mozambique. Divergent patterns of exposure to these factors may explain the differences in gastric precancerous lesions and cancer frequency across these populations (paper IV). 
A very early effect of $H$. pylori infection in the cascade of gastric lesions leading to cancer is confirmed by the observation of an association between $\mathrm{H}$. pylori and CDX2 expression in Mozambique where chronic atrophic gastritis and intestinal metaplasia are relatively rare (paper VI). A higher frequency of CDX2 expression among those infected with high-virulence strains is also observed in Mozambique, but only in subjects with more advanced gastric lesions (paper VI).

The relatively low exposure to tobacco observed in the Mozambican compared with the Portuguese dyspeptic subjects (paper V) complies with the low frequency of gastric precancerous lesions in this setting $(109,160,161)$. The results from paper VI suggest an association between smoking and CDX2 expression, especially in the more advanced steps of carcinogenesis, which is in accordance with the available evidence supporting that smoking acts in the stages closer to cancer.

Our findings from paper III support the view of salt intake as an important dietary risk factor for gastric cancer $(114,162)$, adding to previous research the consistency of the findings across subgroups defined according to the exposure to other environmental factors or tumour characteristics. This is compatible with the lack of association between high salt consumption and CDX2 expression in the Mozambican setting (paper $\mathrm{VI}$ ), given the low frequency of salt intake observed in Africa (163), and because these results do not rule out the hypothesis of this dietary factor acting in the steps closer to cancer. Similarly, high meat intake and low fruits consumption, which are considered to be probable risk factors for gastric cancer (114, $119,122)$, were not associated with CDX2 expression among Mozambicans (paper VI), and a very low consumption of these food items is also observed in the African setting $(164,165)$. The consistent association between the low frequency of vegetables consumption and a more pronounced CDX2 expression found in paper VI suggests that the protective action that vegetables may have occurs later in the gastric carcinogenesis pathway. However, this observation does not provide a potential explanation for the low frequency of gastric lesions in this $H$. pylori high-prevalence setting, as less than half of the Mozambicans report a daily consumption of vegetables (166).

From paper $\mathrm{V}$, we observed that the $I L 1 R N^{\star} 22$ genotype consistently increases the risk of gastric precancerous lesions, supportive of a role for this polymorphism in the early stages of gastric carcinogenesis. This conclusion is reinforced by the 
divergent distribution of ILIRN polymorphisms found when comparing Portugal and Mozambique (papers IV and V). The lack of the risk allele among the Mozambican subjects may be responsible for differences in the immunologic response to the infection (102), with potential impact on the progression towards cancer in this population.

The results from this thesis contribute to clarify the role, on the one hand, of $H$. pylori in the web of gastric cancer causation, by supporting the hypothesis that infection is a necessary causal component for the occurrence of gastric cancer, and, on the other hand, of genetic and other environmental factors in the different steps of the causal mechanisms.

Five main conclusions could be drawn from this thesis:

- $\quad$ The use of methods with low sensitivity to detect past infection, including study design, selection of the participants and assessment of infection status, leads to a substantial underestimation of gastric cancer risk in high-prevalence settings. Stronger associations were observed when these methodological limitations are overcome, which is more compatible with the hypothesis of $H$. pylori being a necessary cause for gastric cancer.

- In this Portuguese setting, the cardia cancer cases were similar to noncardia cancers with regard to the relation with infection, histological type and condition of the nonneoplastic mucosa, supporting the predominance of this cardia cancer subtype in high-risk settings. This suggests that only specific types of gastric cancer, more frequent in lowrisk settings, are not related to infection, reinforcing the evidence supporting the role of $H$. pylori as a necessary cause for gastric cancer.

- $\quad$ Salt intake was confirmed as an important dietary risk factor for gastric cancer, with no differences in risk according to the characteristics of the H. pylori infection, smoking and tumour location and histological type. 
- $\quad$ The divergent distribution of IL1RN polymorphisms and smoking between dyspeptic subjects from Portugal and Mozambique may contribute to explain the observed differences in the frequency of gastric precancerous lesions between these settings with similar prevalence of H. pylori infection.

- $\quad$ The virulence of the infecting strains and vegetables consumption were associated with CDX2 expression and may play a role in the progression to more advanced lesions as co-factors interacting with $H$. pylori infection to produce gastric cancer. 

References 

1. Levi F, Lucchini F, Gonzalez JR, Fernandez E, Negri E, La Vecchia C. Monitoring falls in gastric cancer mortality in Europe. Ann Oncol 2004;15(2):338-45.

2. Bertuccio P, Chatenoud L, Levi F, Praud D, Ferlay J, Negri E, et al. Recent patterns in gastric cancer: a global overview. Int J Cancer 2009;125(3):666-73.

3. Kaneko S, Yoshimura T. Time trend analysis of gastric cancer incidence in Japan by histological types, 1975-1989. Br J Cancer 2001;84(3):400-5.

4. Wu H, Rusiecki JA, Zhu K, Potter J, Devesa SS. Stomach carcinoma incidence patterns in the United States by histologic type and anatomic site. Cancer Epidemiol Biomarkers Prev 2009;18(7):1945-52.

5. Bashash M, Shah A, Hislop G, Brooks-Wilson A, Le N, Bajdik C. Incidence and survival for gastric and esophageal cancer diagnosed in British Columbia, 1990 to 1999. Can J Gastroenterol 2008;22(2):143-8.

6. Botterweck AA, Schouten LJ, Volovics A, Dorant E, van Den Brandt PA. Trends in incidence of adenocarcinoma of the oesophagus and gastric cardia in ten European countries. Int J Epidemiol 2000;29(4):645-54.

7. Liu Y, Kaneko S, Sobue T. Trends in reported incidences of gastric cancer by tumour location, from 1975 to 1989 in Japan. Int J Epidemiol 2004;33(4):808-15.

8. Ferlay J, Shin HR, Bray F, Forman D, Mathers C, Parkin DM. GLOBOCAN 2008, Cancer Incidence and Mortality Worldwide: IARC CancerBase No. 10 [Internet]. Lyon, France: International Agency for Research on Cancer; 2010. Available from: http://globocan.iarc.fr.

9. Howson CP, Hiyama T, Wynder EL. The decline in gastric cancer: epidemiology of an unplanned triumph. Epidemiol Rev 1986;8:1-27.

10. Marshall BJ, Warren JR. Unidentified curved bacilli in the stomach of patients with gastritis and peptic ulceration. Lancet 1984;1(8390):1311-5.

11. IARC Working Group on the Evaluation of Carcinogenic Risks to Humans. Schistosomes, liver flukes and Helicobacter pylori. IARC Monogr Eval Carcinog Risks Hum 1994;61:1-241.

12. Parkin DM. The global health burden of infection-associated cancers in the year 2002. Int J Cancer 2006;118(12):3030-44.

13. Marshall B. Helicobacter pylori: 20 years on. Clin Med 2002;2(2):147-52.

14. Bizzozero G. Ueber die schlauchformigen drusen des magendarmkanals und die bezienhungen ihres epithels zu dem oberflachenepithel der schleimhaut. Arch $f$ mikr Anat 1893;42:82. cited by [Kidd M, Modlin IM. A century of Helicobacter pylori: paradigms lost-paradigms regained. Digestion. 1998;59(1):1-15.].

15. Salomon H. Ueber das spirillum saugetiermagens und sien verhalten zu den belegzellen. Zentralbl Bakteriol 1896;19:433-42. cited by [Kidd M, Modlin IM. A century 
of Helicobacter pylori: paradigms lost-paradigms regained. Digestion. 1998;59(1):115.].

16. Chen M, Lee A, Hazell S. Immunisation against gastric helicobacter infection in a mouse/Helicobacter felis model. Lancet 1992;339(8801):1120-1.

17. Konturek JW. Discovery by Jaworski of Helicobacter pylori and its pathogenetic role in peptic ulcer, gastritis and gastric cancer. J Physiol Pharmacol 2003;54 Suppl 3:23-41.

18. Freedberg AS, Barron LE. The presence of spirochetes in human gastric mucosa. Am J Dig Dis 1940;7:443-5.

19. Palmer ED. Investigation of the gastric mucosa spirochetes of the human. Gastroenterology 1954;27(2):218-20.

20. Ito S. Anatomic structure of the gastric mucosa. In: Code CF, editor. Alimentary Canal. Washington: American Physiological Society; 1967. p. 705-41.

21. Lockard VG, Boler RK. Ultrastructure of a spiraled microorganism in the gastric mucosa of dogs. Am J Vet Res 1970;31(8):1453-62.

22. Steer HW, Colin-Jones DG. Mucosal changes in gastric ulceration and their response to carbenoxolone sodium. Gut 1975;16(8):590-7.

23. Marshall B. Helicobacter connections. ChemMedChem 2006;1(8):783-802.

24. Campylobacter pylori becomes Helicobacter pylori. Lancet 1989;2(8670):101920.

25. Suerbaum S, Michetti P. Helicobacter pylori infection. $N$ Engl J Med 2002;347(15):1175-86.

26. Zullo A, Hassan C, Andriani A, Cristofari F, De Francesco V, lerardi E, et al. Eradication therapy for Helicobacter pylori in patients with gastric MALT lymphoma: a pooled data analysis. Am J Gastroenterol 2009;104(8):1932-7.

27. Zullo A, Hassan C, Cristofari F, Andriani A, De Francesco V, lerardi E, et al. Effects of Helicobacter pylori eradication on early stage gastric mucosa-associated lymphoid tissue lymphoma. Clin Gastroenterol Hepatol 2010;8(2):105-10.

28. Raghunath AS, Hungin AP, Wooff D, Childs S. Systematic review: the effect of Helicobacter pylori and its eradication on gastro-oesophageal reflux disease in patients with duodenal ulcers or reflux oesophagitis. Aliment Pharmacol Ther 2004;20(7):73344.

29. Ford AC, Delaney BC, Forman D, Moayyedi P. Eradication therapy in Helicobacter pylori positive peptic ulcer disease: systematic review and economic analysis. Am J Gastroenterol 2004;99(9):1833-55.

30. Leodolter A, Kulig M, Brasch H, Meyer-Sabellek W, Willich SN, Malfertheiner P. A meta-analysis comparing eradication, healing and relapse rates in patients with 
Helicobacter pylori-associated gastric or duodenal ulcer. Aliment Pharmacol Ther 2001;15(12):1949-58.

31. Ford AC, Delaney BC, Forman D, Moayyedi P. Eradication therapy for peptic ulcer disease in Helicobacter pylori positive patients. Cochrane Database Syst Rev 2006;(2):CD003840.

32. Verdecchia A, Guzzinati S, Francisci S, De Angelis R, Bray F, Allemani C, et al. Survival trends in European cancer patients diagnosed from 1988 to 1999 . Eur J Cancer 2009;45(6):1042-66.

33. Dawsey SM, Mark SD, Taylor PR, Limburg PJ. Gastric cancer and H pylori. Gut 2002;51(3):457-8.

34. Marsman WA, Tytgat GN, ten Kate FJ, van Lanschot JJ. Differences and similarities of adenocarcinomas of the esophagus and esophagogastric junction. J Surg Oncol 2005;92(3):160-8.

35. Ekstrom AM, Signorello LB, Hansson LE, Bergstrom R, Lindgren A, Nyren O. Evaluating gastric cancer misclassification: a potential explanation for the rise in cardia cancer incidence. J Natl Cancer Inst 1999;91(9):786-90.

36. Corley DA, Kubo A. Influence of site classification on cancer incidence rates: an analysis of gastric cardia carcinomas. J Natl Cancer Inst 2004;96(18):1383-7.

37. Crew KD, Neugut Al. Epidemiology of gastric cancer. World J Gastroenterol 2006;12(3):354-62.

38. Lauren P. The two histological main types of gastric carcinoma: diffuse and socalled intestinal-type carcinoma. An attempt at a histo-clinical classification. Acta Pathol Microbiol Scand 1965;64:31-49.

39. Bosman F, Carneiro F, Hruban R, Theise N, editors. WHO Classification of Tumours of the Digestive System. Lyon: IARC Press; 2010.

40. Carneiro F. Classification of gastric carcinomas. Current Diagnostic Pathology 1997;4(1):51-9.

41. Correa P, Sasano N, Stemmermann GN, Haenszel W. Pathology of gastric carcinoma in Japanese populations: comparisons between Miyagi prefecture, Japan, and Hawaii. J Natl Cancer Inst 1973;51(5):1449-59.

42. Laurén PA, Nevalainen TJ. Epidemiology of intestinal and diffuse types of gastric carcinoma. A time-trend study in Finland with comparison between studies from high- and low-risk areas. Cancer 1993;71(10):2926-33.

43. Tahara E. Genetic pathways of two types of gastric cancer. IARC Sci Publ 2004;(157):327-49.

44. Correa P, Haenszel W, Cuello C, Tannenbaum S, Archer M. A model for gastric cancer epidemiology. Lancet 1975;2(7924):58-60. 
45. Correa P, Fox J, Fontham E, Ruiz B, Lin YP, Zavala D, et al. Helicobacter pylori and gastric carcinoma. Serum antibody prevalence in populations with contrasting cancer risks. Cancer 1990;66(12):2569-74.

46. Forman D, Sitas F, Newell DG, Stacey AR, Boreham J, Peto R, et al. Geographic association of Helicobacter pylori antibody prevalence and gastric cancer mortality in rural China. Int J Cancer 1990;46(4):608-11.

47. Kneller RW, Guo WD, Hsing AW, Chen JS, Blot WJ, Li JY, et al. Risk factors for stomach cancer in sixty-five Chinese counties. Cancer Epidemiol Biomarkers Prev 1992;1(2):113-8.

48. The EUROGAST Study Group. An international association between Helicobacter pylori infection and gastric cancer. Lancet 1993;341(8857):1359-62.

49. Palli D, Decarli A, Cipriani F, Sitas F, Forman D, Amadori D, et al. Helicobacter pylori antibodies in areas of Italy at varying gastric cancer risk. Cancer Epidemiol Biomarkers Prev 1993;2(1):37-40.

50. Forman D, Webb P, Parsonnet J. H pylori and gastric cancer. Lancet 1994;343(8891):243-4.

51. Crespi M, Citarda F. Helicobacter pylori and gastric cancer: an overrated risk? Scand J Gastroenterol 1996;31(11):1041-6.

52. Nyren O. Is Helicobacter pylori really the cause of gastric cancer? Semin Cancer Biol 1998;8(4):275-83.

53. Rothman KJ. Causes. 1976. Am J Epidemiol 1995;141(2):90-5.

54. Bosch FX, Lorincz A, Munoz N, Meijer CJ, Shah KV. The causal relation between human papillomavirus and cervical cancer. J Clin Pathol 2002;55(4):244-65.

55. Correa P. Human gastric carcinogenesis: a multistep and multifactorial process-First American Cancer Society Award Lecture on Cancer Epidemiology and Prevention. Cancer Res 1992;52(24):6735-40.

56. Huang JQ, Sridhar S, Chen Y, Hunt RH. Meta-analysis of the relationship between Helicobacter pylori seropositivity and gastric cancer. Gastroenterology 1998;114(6):1169-79.

57. Lunet N, Valbuena C, Vieira AL, Lopes C, David L, Carneiro F, et al. Fruit and vegetable consumption and gastric cancer by location and histological type: casecontrol and meta-analysis. Eur J Cancer Prev 2007;16(4):312-27.

58. Almeida R, Silva E, Santos-Silva F, Silberg DG, Wang J, De Bolos C, et al. Expression of intestine-specific transcription factors, CDX1 and CDX2, in intestinal metaplasia and gastric carcinomas. J Pathol 2003;199(1):36-40.

59. Guo RJ, Suh ER, Lynch JP. The role of Cdx proteins in intestinal development and cancer. Cancer Biol Ther 2004;3(7):593-601. 
60. Barros R, Marcos N, Reis CA, De Luca A, David L, Almeida R. CDX2 expression is induced by Helicobacter pylori in AGS cells. Scand J Gastroenterol 2009;44(1):124-5.

61. Satoh K, Mutoh H, Eda A, Yanaka I, Osawa H, Honda S, et al. Aberrant expression of CDX2 in the gastric mucosa with and without intestinal metaplasia: effect of eradication of Helicobacter pylori. Helicobacter 2002;7(3):192-8.

62. Eda A, Osawa H, Yanaka I, Satoh K, Mutoh H, Kihira K, et al. Expression of homeobox gene CDX2 precedes that of CDX1 during the progression of intestinal metaplasia. J Gastroenterol 2002;37(2):94-100.

63. $\mathrm{Xu} \mathrm{F}, \mathrm{Li} \mathrm{H}$, Jin T. Cell type-specific autoregulation of the Caudal-related homeobox gene Cdx-2/3. J Biol Chem 1999;274(48):34310-6.

64. Barros R, da Costa LT, Pinto-de-Sousa J, Duluc I, Freund JN, David L, et al. CDX2 autoregulation in human intestinal metaplasia of the stomach: impact on the stability of the phenotype. Gut 2011;60(3):290-8.

65. Yuasa $Y$, Nagasaki H, Akiyama Y, Hashimoto $Y$, Takizawa T, Kojima K, et al. DNA methylation status is inversely correlated with green tea intake and physical activity in gastric cancer patients. Int J Cancer 2009;124(11):2677-82.

66. Yuasa Y, Nagasaki H, Akiyama Y, Sakai H, Nakajima T, Ohkura Y, et al. Relationship between CDX2 gene methylation and dietary factors in gastric cancer patients. Carcinogenesis 2005;26(1):193-200.

67. Danesh J. Helicobacter pylori infection and gastric cancer: systematic review of the epidemiological studies. Aliment Pharmacol Ther 1999;13(7):851-6.

68. Eslick GD, Lim LL, Byles JE, Xia HH, Talley NJ. Association of Helicobacter pylori infection with gastric carcinoma: a meta-analysis. Am J Gastroenterol 1999;94(9):2373-9.

69. Helicobacter and Cancer Collaborative Group. Gastric cancer and Helicobacter pylori: a combined analysis of 12 case control studies nested within prospective cohorts. Gut 2001;49(3):347-53.

70. Xue FB, Xu YY, Wan Y, Pan BR, Ren J, Fan DM. Association of H. pylori infection with gastric carcinoma: a Meta analysis. World J Gastroenterol 2001;7(6):8014.

71. Wang $\mathrm{C}$, Yuan $\mathrm{Y}$, Hunt $\mathrm{RH}$. The association between Helicobacter pylori infection and early gastric cancer: a meta-analysis. Am J Gastroenterol 2007;102(8):1789-98.

72. Cavaleiro-Pinto M, Peleteiro B, Lunet N, Barros $\mathrm{H}$. Helicobacter pylori infection and gastric cardia cancer: systematic review and meta-analysis. Cancer Causes Control 2011;22(3):375-87. 
73. Huang JQ, Zheng GF, Sumanac K, Irvine EJ, Hunt RH. Meta-analysis of the relationship between cagA seropositivity and gastric cancer. Gastroenterology 2003;125(6):1636-44.

74. Gao L, Weck MN, Nieters A, Brenner H. Inverse association between a proinflammatory genetic profile and Helicobacter pylori seropositivity among patients with chronic atrophic gastritis: enhanced elimination of the infection during disease progression? Eur J Cancer 2009;45(16):2860-6.

75. Kokkola A, Kosunen TU, Puolakkainen P, Sipponen P, Harkonen M, Laxen F, et al. Spontaneous disappearance of Helicobacter pylori antibodies in patients with advanced atrophic corpus gastritis. APMIS 2003;111(6):619-24.

76. Weck MN, Brenner H. Association of Helicobacter pylori infection with chronic atrophic gastritis: Meta-analyses according to type of disease definition. Int $\mathrm{J}$ Cancer 2008;123(4):874-81.

77. Adamu MA, Weck MN, Gao L, Brenner H. Incidence of chronic atrophic gastritis: systematic review and meta-analysis of follow-up studies. Eur J Epidemiol 2010;25(7):439-48.

78. Hansen S, Vollset SE, Derakhshan MH, Fyfe V, Melby KK, Aase S, et al. Two distinct aetiologies of cardia cancer; evidence from premorbid serological markers of gastric atrophy and Helicobacter pylori status. Gut 2007;56(7):918-25.

79. Derakhshan MH, Malekzadeh R, Watabe H, Yazdanbod A, Fyfe V, Kazemi A, et al. Combination of gastric atrophy, reflux symptoms and histological subtype indicates two distinct aetiologies of gastric cardia cancer. Gut 2008;57(3):298-305.

80. Bornschein J, Selgrad M, Warnecke M, Kuester D, Wex T, Malfertheiner P. H. pylori infection is a key risk factor for proximal gastric cancer. Dig Dis Sci 2010;55(11):3124-31.

81. Brenner H, Arndt V, Stegmaier C, Ziegler H, Rothenbacher D. Is Helicobacter pylori infection a necessary condition for noncardia gastric cancer? Am J Epidemiol 2004;159(3):252-8.

82. Ekstrom AM, Held M, Hansson LE, Engstrand L, Nyren O. Helicobacter pylori in gastric cancer established by CagA immunoblot as a marker of past infection. Gastroenterology 2001;121(4):784-91.

83. Fuccio L, Zagari RM, Eusebi LH, Laterza L, Cennamo V, Ceroni L, et al. Metaanalysis: can Helicobacter pylori eradication treatment reduce the risk for gastric cancer? Ann Intern Med 2009;151(2):121-8.

84. Ito $\mathrm{M}$, Takata $\mathrm{S}$, Tatsugami $\mathrm{M}$, Wada $\mathrm{Y}$, Imagawa $\mathrm{S}$, Matsumoto $\mathrm{Y}$, et al. Clinical prevention of gastric cancer by Helicobacter pylori eradication therapy: a systematic review. J Gastroenterol 2009;44(5):365-71. 
85. Fuccio L, Zagari RM, Minardi ME, Bazzoli F. Systematic review: Helicobacter pylori eradication for the prevention of gastric cancer. Aliment Pharmacol Ther 2007;25(2):133-41.

86. Wong BC, Lam SK, Wong WM, Chen JS, Zheng TT, Feng RE, et al. Helicobacter pylori eradication to prevent gastric cancer in a high-risk region of China: a randomized controlled trial. JAMA 2004;291(2):187-94.

87. Correa P, Fontham ET, Bravo JC, Bravo LE, Ruiz B, Zarama G, et al. Chemoprevention of gastric dysplasia: randomized trial of antioxidant supplements and anti-helicobacter pylori therapy. J Natl Cancer Inst 2000;92(23):1881-8.

88. Mera R, Fontham ET, Bravo LE, Bravo JC, Piazuelo MB, Camargo MC, et al. Long term follow up of patients treated for Helicobacter pylori infection. Gut 2005;54(11):1536-40.

89. Rokkas T, Pistiolas D, Sechopoulos P, Robotis I, Margantinis G. The long-term impact of Helicobacter pylori eradication on gastric histology: a systematic review and meta-analysis. Helicobacter 2007;12 Suppl 2:32-8.

90. Wang J, Xu L, Shi R, Huang X, Li SW, Huang Z, et al. Gastric Atrophy and Intestinal Metaplasia before and after Helicobacter pylori Eradication: A Meta-Analysis. Digestion 2011;83(4):253-60.

91. Barros R, Peleteiro B, Almeida R, Figueiredo C, Barros H, David L, et al. Relevance of high virulence Helicobacter pylori strains and futility of CDX2 expression for predicting intestinal metaplasia after eradication of infection. Scand J Gastroenterol 2010;45(7-8):828-34.

92. Machado AM, Figueiredo C, Touati E, Maximo V, Sousa S, Michel V, et al. Helicobacter pylori infection induces genetic instability of nuclear and mitochondrial DNA in gastric cells. Clin Cancer Res 2009;15(9):2995-3002.

93. Busuttil RA, Boussioutas A. Intestinal metaplasia: a premalignant lesion involved in gastric carcinogenesis. J Gastroenterol Hepatol 2009;24(2):193-201.

94. Holcombe C. Helicobacter pylori: the African enigma. Gut 1992;33(4):429-31.

95. Miwa H, Go MF, Sato N. H. pylori and gastric cancer: the Asian enigma. Am J Gastroenterol 2002;97(5):1106-12.

96. Kidd M, Louw JA, Marks IN. Helicobacter pylori in Africa: observations on an 'enigma within an enigma'. J Gastroenterol Hepatol 1999;14(9):851-8.

97. Carrilho C, Modcoicar P, Cunha L, Ismail M, Guisseve A, Lorenzoni C, et al. Prevalence of Helicobacter pylori infection, chronic gastritis, and intestinal metaplasia in Mozambican dyspeptic patients. Virchows Arch 2009;454(2):153-60. 
98. Campbell DI, Warren BF, Thomas JE, Figura N, Telford JL, Sullivan PB. The African enigma: low prevalence of gastric atrophy, high prevalence of chronic inflammation in West African adults and children. Helicobacter 2001;6(4):263-7.

99. Kalebi A, Rana F, Mwanda W, Lule G, Hale M. Histopathological profile of gastritis in adult patients seen at a referral hospital in Kenya. World $\mathrm{J}$ Gastroenterol 2007;13(30):4117-21.

100. Oluwasola AO, Ogunbiyi JO. Chronic gastritis and Helicobacter pylori infection in University College Hospital Ibadan, Nigeria--a study of 85 fibre optic gastric biopsies. Niger J Med 2004;13(4):372-8.

101. Fernando N, Holton J, Zulu I, Vaira D, Mwaba P, Kelly P. Helicobacter pylori infection in an urban African population. J Clin Microbiol 2001;39(4):1323-7.

102. Mitchell HM, Ally R, Wadee A, Wiseman M, Segal I. Major differences in the IgG subclass response to Helicobacter pylori in the first and third worlds. Scand $\mathrm{J}$ Gastroenterol 2002;37(5):517-22.

103. Mbulaiteye SM, Gold BD, Pfeiffer RM, Brubaker GR, Shao J, Biggar RJ, et al. $\mathrm{H}$. pylori-infection and antibody immune response in a rural Tanzanian population. Infect Agent Cancer 2006;1:3.

104. Lunet N, Peleteiro B, Carrilho C, Figueiredo C, Azevedo A. Sensitivity is not an intrinsic property of a diagnostic test: empirical evidence from histological diagnosis of Helicobacter pylori infection. BMC Gastroenterol 2009;9:98.

105. Chetty R, Naidoo R, Tarin M, Sitti C. Chromosome $2 p, 3 p, 5 q$ and $18 q$ status in sporadic gastric cancer. Pathology 2002;34(3):275-81.

106. Thye T, Burchard GD, Nilius M, Muller-Myhsok B, Horstmann RD. Genomewide linkage analysis identifies polymorphism in the human interferon-gamma receptor affecting Helicobacter pylori infection. Am J Hum Genet 2003;72(2):448-53.

107. Nyerere K, Sayed S, Revathi G, Ojwang P, Matiru V, Devani S, et al. Prevalence of gastric mucosal interleukin-1 polymorphisms in Kenyan patients with advanced gastric cancer. S Afr Med J 2009;99(2):95-7.

108. Lunet $\mathrm{N}$, Barros $\mathrm{H}$. Helicobacter pylori infection and gastric cancer: facing the enigmas. Int J Cancer 2003;106(6):953-60.

109. Peleteiro B, Bastos J, Barros H, Lunet N. Systematic review of the prevalence of gastric intestinal metaplasia and its area-level association with smoking. Gac Sanit 2008;22(3):236-47.

110. Louw JA, Kidd MS, Kummer AF, Taylor K, Kotze U, Hanslo D. The relationship between Helicobacter pylori infection, the virulence genotypes of the infecting strain and gastric cancer in the African setting. Helicobacter $2001 ; 6(4): 268-73$. 
111. Uemura N, Okamoto S, Yamamoto S, Matsumura N, Yamaguchi S, Yamakido $\mathrm{M}$, et al. Helicobacter pylori infection and the development of gastric cancer. $\mathrm{N}$ Engl $\mathrm{J}$ Med $2001 ; 345(11): 784-9$.

112. Hsu PI, Lai KH, Hsu PN, Lo GH, Yu HC, Chen WC, et al. Helicobacter pylori infection and the risk of gastric malignancy. Am J Gastroenterol 2007;102(4):725-30.

113. World Cancer Research Fund, American Institute for Cancer Research. Food, nutrition and the prevention of cancer: a global perspective. Washington DC: AICR, 1997.

114. World Cancer Research Fund, American Institute for Cancer Research. Food, Nutrition, Physical Activity, and the Prevention of Cancer: a Global Perspective. Washington DC: AICR, 2007.

115. IARC Working Group on the Evaluation of Carcinogenic Risks to Humans. Tobacco smoke and involuntary smoking. IARC Monogr Eval Carcinog Risks Hum 2004;83:1-1438.

116. Gonzalez CA, Sala N, Capella G. Genetic susceptibility and gastric cancer risk. Int J Cancer 2002;100(3):249-60.

117. Tredaniel J, Boffetta P, Buiatti E, Saracci R, Hirsch A. Tobacco smoking and gastric cancer: review and meta-analysis. Int J Cancer 1997;72(4):565-73.

118. Riboli E, Norat T. Epidemiologic evidence of the protective effect of fruit and vegetables on cancer risk. Am J Clin Nutr 2003;78(3 Suppl):559S-69S.

119. Lunet N, Lacerda-Vieira A, Barros $\mathrm{H}$. Fruit and vegetables consumption and gastric cancer: a systematic review and meta-analysis of cohort studies. Nutr Cancer 2005;53(1):1-10.

120. Camargo MC, Mera R, Correa P, Peek RM, Jr., Fontham ET, Goodman KJ, et al. Interleukin-1beta and interleukin-1 receptor antagonist gene polymorphisms and gastric cancer: a meta-analysis. Cancer Epidemiol Biomarkers Prev 2006;15(9):167487.

121. Kamangar F, Cheng C, Abnet CC, Rabkin CS. Interleukin-1B polymorphisms and gastric cancer risk--a meta-analysis. Cancer Epidemiol Biomarkers Prev 2006;15(10):1920-8.

122. Larsson SC, Orsini N, Wolk A. Processed meat consumption and stomach cancer risk: a meta-analysis. J Natl Cancer Inst 2006;98(15):1078-87.

123. Wang $\mathrm{P}, \mathrm{Xia} \mathrm{HH}$, Zhang JY, Dai LP, Xu XQ, Wang KJ. Association of interleukin-1 gene polymorphisms with gastric cancer: a meta-analysis. Int $\mathrm{J}$ Cancer 2007;120(3):552-62. 
124. Gorouhi F, Islami F, Bahrami H, Kamangar F. Tumour-necrosis factor-A polymorphisms and gastric cancer risk: a meta-analysis. Br J Cancer 2008;98(8):144351.

125. Ladeiras-Lopes R, Pereira AK, Nogueira A, Pinheiro-Torres T, Pinto I, SantosPereira R, et al. Smoking and gastric cancer: systematic review and meta-analysis of cohort studies. Cancer Causes Control 2008;19(7):689-701.

126. Vincenzi B, Patti G, Galluzzo S, Pantano F, Venditti O, Santini D, et al. Interleukin 1beta-511T gene (IL1beta) polymorphism is correlated with gastric cancer in the Caucasian population: results from a meta-analysis. Oncol Rep 2008;20(5):121320.

127. Loh M, Koh KX, Yeo BH, Song CM, Chia KS, Zhu F, et al. Meta-analysis of genetic polymorphisms and gastric cancer risk: variability in associations according to race. Eur J Cancer 2009;45(14):2562-8.

128. Mesquita P, Raquel A, Nuno L, Reis CA, Silva LF, Serpa J, et al. Metaplasia--a transdifferentiation process that facilitates cancer development: the model of gastric intestinal metaplasia. Crit Rev Oncog 2006;12(1-2):3-26.

129. Kim N, Park YS, Cho SI, Lee HS, Choe G, Kim IW, et al. Prevalence and risk factors of atrophic gastritis and intestinal metaplasia in a Korean population without significant gastroduodenal disease. Helicobacter 2008;13(4):245-55.

130. Gonzalez CA, Lopez-Carrillo L. Helicobacter pylori, nutrition and smoking interactions: their impact in gastric carcinogenesis. Scand J Gastroenterol 2010;45(1):6-14.

131. Brenner H, Arndt V, Bode G, Stegmaier C, Ziegler H, Stumer T. Risk of gastric cancer among smokers infected with Helicobacter pylori. Int J Cancer 2002;98(3):4469.

132. Siman $\mathrm{JH}$, Forsgren A, Berglund $\mathrm{G}$, Floren $\mathrm{CH}$. Tobacco smoking increases the risk for gastric adenocarcinoma among Helicobacter pylori-infected individuals. Scand J Gastroenterol 2001;36(2):208-13.

133. Fox JG, Dangler CA, Taylor NS, King A, Koh TJ, Wang TC. High-salt diet induces gastric epithelial hyperplasia and parietal cell loss, and enhances Helicobacter pylori colonization in C57BL/6 mice. Cancer Res 1999;59(19):4823-8.

134. Nozaki K, Shimizu N, Inada K, Tsukamoto T, Inoue M, Kumagai T, et al. Synergistic promoting effects of Helicobacter pylori infection and high-salt diet on gastric carcinogenesis in Mongolian gerbils. Jpn J Cancer Res 2002;93(10):1083-9.

135. Dias-Neto $M$, Pintalhao $M$, Ferreira $M$, Lunet $N$. Salt intake and risk of gastric intestinal metaplasia: systematic review and meta-analysis. Nutr Cancer 2010;62(2):133-47. 
136. Chen VW, Abu-Elyazeed RR, Zavala DE, Ktsanes VK, Haenszel W, Cuello C, et al. Risk factors of gastric precancerous lesions in a high-risk Colombian population. I. Salt. Nutr Cancer 1990;13(1-2):59-65.

137. ECP-EURONUT. ECP-EURONUT-Intestinal Metaplasia Study: urinary and gastric juice analyses. Eur J Cancer Prev 1994;3(5):413-8.

138. Druesne-Pecollo N, Latino-Martel P, Norat T, Barrandon E, Bertrais S, Galan P, et al. Beta-carotene supplementation and cancer risk: a systematic review and metaanalysis of randomized controlled trials. Int J Cancer 2010;127(1):172-84.

139. Bjelakovic G, Nikolova D, Simonetti RG, Gluud C. Antioxidant supplements for prevention of gastrointestinal cancers: a systematic review and meta-analysis. Lancet 2004;364(9441):1219-28.

140. Sobala GM, Pignatelli B, Schorah CJ, Bartsch H, Sanderson M, Dixon MF, et al. Levels of nitrite, nitrate, $\mathrm{N}$-nitroso compounds, ascorbic acid and total bile acids in gastric juice of patients with and without precancerous conditions of the stomach. Carcinogenesis 1991;12(2):193-8.

141. You WC, Zhang L, Yang CS, Chang YS, Issaq H, Fox SD, et al. Nitrite, Nnitroso compounds, and other analytes in physiological fluids in relation to precancerous gastric lesions. Cancer Epidemiol Biomarkers Prev 1996;5(1):47-52.

142. El-Omar EM, Carrington M, Chow WH, McColl KE, Bream JH, Young HA, et al. Interleukin-1 polymorphisms associated with increased risk of gastric cancer. Nature 2000;404(6776):398-402.

143. Hwang IR, Kodama T, Kikuchi S, Sakai K, Peterson LE, Graham DY, et al. Effect of interleukin 1 polymorphisms on gastric mucosal interleukin 1beta production in Helicobacter pylori infection. Gastroenterology 2002;123(6):1793-803.

144. El-Omar EM. The importance of interleukin 1beta in Helicobacter pylori associated disease. Gut 2001;48(6):743-7.

145. Sobin LH, Wittekind C, editors. UICC, TNM classification of malignant tumors. 6th ed. New York: Wiley-Liss; 2002.

146. Gal DL, Santos AC, Barros H. Leisure-time versus full-day energy expenditure: a cross-sectional study of sedentarism in a Portuguese urban population. BMC Public Health 2005;5:16.

147. Ramos E, Lopes C, Barros $\mathrm{H}$. Investigating the effect of nonparticipation using a population-based case-control study on myocardial infarction. Ann Epidemiol 2004;14(6):437-41.

148. Murden RA, McRae TD, Kaner S, Bucknam ME. Mini-Mental State exam scores vary with education in blacks and whites. J Am Geriatr Soc 1991;39(2):149-55. 
149. Lopes C. Reproducibility and validation of a semi-quantitative food-frequency questionnaire. In: Diet and acute myocardial infarction: a population-based case-control study [PhD thesis in Portuguese]. Porto: University of Porto; 2000.

150. Lopes C, Aro A, Azevedo A, Ramos E, Barros H. Intake and adipose tissue composition of fatty acids and risk of myocardial infarction in a male Portuguese community sample. J Am Diet Assoc 2007;107(2):276-86.

151. Dixon MF, Genta RM, Yardley JH, Correa P. Classification and grading of gastritis. The updated Sydney System. International Workshop on the Histopathology of Gastritis, Houston 1994. Am J Surg Pathol 1996;20(10):1161-81.

152. van Doorn LJ, Figueiredo C, Rossau R, Jannes G, van Asbroek M, Sousa JC, et al. Typing of Helicobacter pylori vacA gene and detection of cagA gene by PCR and reverse hybridization. J Clin Microbiol 1998;36(5):1271-6.

153. Machado JC, Pharoah P, Sousa S, Carvalho R, Oliveira C, Figueiredo C, et al. Interleukin 1B and interleukin 1RN polymorphisms are associated with increased risk of gastric carcinoma. Gastroenterology 2001;121(4):823-9.

154. Barros R, Pereira B, Duluc I, Azevedo M, Mendes N, Camilo V, et al. Key elements of the BMP/SMAD pathway co-localize with CDX2 in intestinal metaplasia and regulate CDX2 expression in human gastric cell lines. J Pathol 2008;215(4):41120.

155. van Doorn LJ, Figueiredo C, Sanna R, Plaisier A, Schneeberger P, de Boer W, et al. Clinical relevance of the $\operatorname{cag} A$, vacA, and iceA status of Helicobacter pylori. Gastroenterology 1998;115(1):58-66.

156. Gonzalez CA, Figueiredo C, Lic CB, Ferreira RM, Pardo ML, Ruiz Liso JM, et al. Helicobacter pylori cagA and vacA Genotypes as Predictors of Progression of Gastric Preneoplastic Lesions: A Long-Term Follow-Up in a High-Risk Area in Spain. Am J Gastroenterol 2011;106(5):867-74.

157. Lin JT, Wang JT, Wang TH, Wu MS, Lee TK, Chen CJ. Helicobacter pylori infection in a randomly selected population, healthy volunteers, and patients with gastric ulcer and gastric adenocarcinoma. A seroprevalence study in Taiwan. Scand $\mathrm{J}$ Gastroenterol 1993;28(12):1067-72.

158. Kim HY, Cho BD, Chang WK, Kim DJ, Kim YB, Park CK, et al. Helicobacter pylori infection and the risk of gastric cancer among the Korean population. $J$ Gastroenterol Hepatol 1997;12(2):100-3.

159. Lu CY, Kuo CH, Lo YC, Chuang HY, Yang YC, Wu IC, et al. The best method of detecting prior Helicobacter pylori infection. World J Gastroenterol 2005;11(36):5672-6. 
160. Peleteiro B, Lunet N, Figueiredo C, Carneiro F, David L, Barros H. Smoking, Helicobacter pylori virulence, and type of intestinal metaplasia in Portuguese males. Cancer Epidemiol Biomarkers Prev 2007;16(2):322-6.

161. Kato I, Vivas J, Plummer M, Lopez G, Peraza S, Castro D, et al. Environmental factors in Helicobacter pylori-related gastric precancerous lesions in Venezuela. Cancer Epidemiol Biomarkers Prev 2004;13(3):468-76.

162. Wang $X Q$, Terry PD, Yan H. Review of salt consumption and stomach cancer risk: epidemiological and biological evidence. World J Gastroenterol 2009;15(18):220413.

163. Lunet $\mathrm{N}$, Barros $\mathrm{H}$. Helicobacter pylori infection and gastric cancer: facing the enigmas (part II). Reply to Tokudome et al. Int J Cancer 2004;112(1):168-9.

164. Padrao P, Silva-Matos C, Damasceno A, Lunet N. Association between tobacco consumption and alcohol, vegetable and fruit intake across urban and rural areas in Mozambique. J Epidemiol Community Health 2011;65(5):445-53.

165. Food and Agriculture Organization of the United Nations. FAO food balance sheets in 2007. Available from: URL: http://www.fao.org. Accessed March 11, 2011.

166. Padrão $P$, Laszczyńska $O$, Silva-Matos $C$, Damasceno $A$, Lunet $N$. Low fruit and vegetable consumption in a Sub-Saharan African population: results from a national STEPS survey. Br J Nutr 2011 [in press]. 